Clemson University

TigerPrints

$5-2020$

\title{
Test Frame Design for Characterization of Additive Manufacturing Compliant Materials
}

Sean Fry

Clemson University, frymaestro@gmail.com

Follow this and additional works at: https://tigerprints.clemson.edu/all_theses

\section{Recommended Citation}

Fry, Sean, "Test Frame Design for Characterization of Additive Manufacturing Compliant Materials" (2020). All Theses. 3358.

https://tigerprints.clemson.edu/all_theses/3358

This Thesis is brought to you for free and open access by the Theses at TigerPrints. It has been accepted for inclusion in All Theses by an authorized administrator of TigerPrints. For more information, please contact kokeefe@clemson.edu. 


\section{TEST FRAME DESIGN FOR CHARACTERIZATION OF ADDITIVE MANUFACTURING COMPLIANT MATERIALS}

\begin{tabular}{c} 
A Thesis \\
Presented to \\
the Graduate School of \\
Clemson University \\
In Partial Fulfillment \\
of the Requirements for the Degree \\
Master of Science \\
Mechanical Engineering \\
\hline bean Taylor Fry \\
May 2020 \\
Accepted by: \\
Dr. Cameron Turner, Committee Chair \\
Dr. Joshua Summers \\
Dr. Garrett Pataky
\end{tabular}




\begin{abstract}
With the application of using surrogate models with General Purpose Graphics Processing (GPGPU) computing to meet the need for "real-time" characterization of nonlinear anisotropic material systems and the growing work of using multiaxial robotic test frames for material characterization, there has been a solution for a specific application towards additive manufacturing materials, specifically polymers. Traditional testing using uniaxial and biaxial test machines has proven insufficient in characterizing the material properties of additive manufacturing materials, therefore developing a need for a multiaxial testing machine for characterization that can dynamically excite strain states for a more indepth look at the material properties. This design report presents the design of a multiaxial robotic test frame that incorporates a Stewart-Gough (SG) platform design to allow 6 degrees-of-freedom for multiple and combined loading applications. This solution is the next generation multiaxial machine focusing on additive manufacturing materials, specifically polymers. The problem statement is the following:

Design and fabricate a multiaxial robotic test frame that can test additive manufacturing materials, focusing on polymers and some metals, in 6 degrees-of-freedom while improving on performance and cost over the CSM design.
\end{abstract}




\section{DEDICATION}

I dedicate my thesis work to my family and friends, for they have helped and supported me throughout. 


\section{ACKNOWLEDGEMENTS}

I would like to thank my family first. I would also like to thank my advisor, Dr. Turner, for allowing me to work on this project, my committee members, Dr. Summers and Dr. Pataky, for the feedback during this work. Lastly, I would like to thank my fellow CEDARians for giving me feedback and helping through the years. 


\section{TABLE OF CONTENTS}

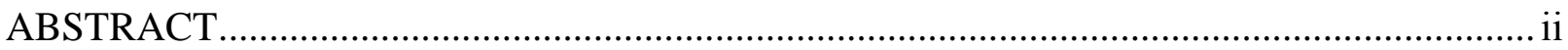

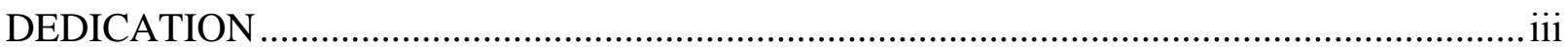

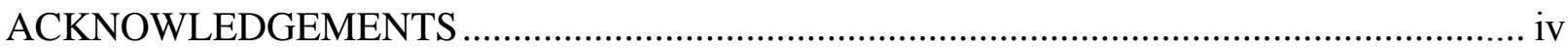

TABLE OF CONTENTS ................................................................................................

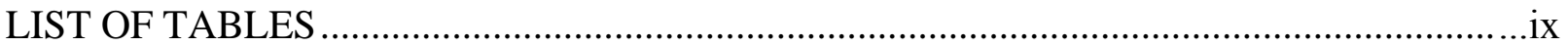

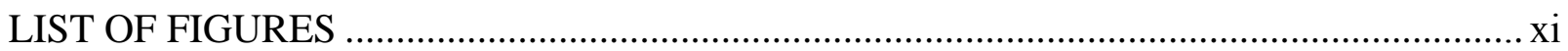

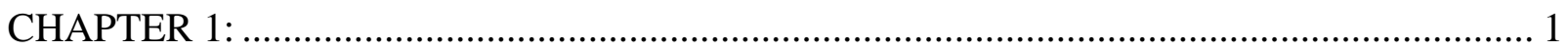

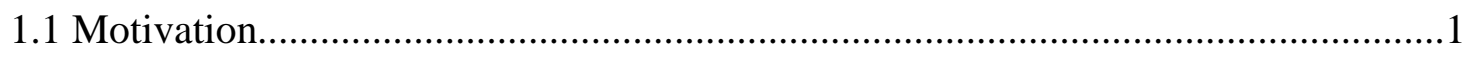

1.2 Test Frame Design Problem .............................................................................

1.3 Thesis Outline

CHAPTER 2: CHARACTERIZATION THROUGH HEXAPOD DESIGN ……....................... 3

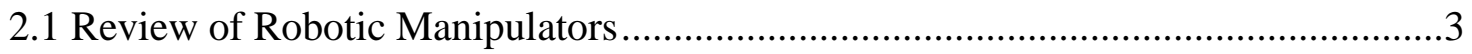

2.2 Stewart-Gough Platform ..............................................................................

2.2.1 Kinematics of a General Stewart-Gough Platform …………............................ 5

2.3 Jacobian Analysis of Stewart-Gough Platform.....................................................

2.4 Review of Material Characterization Using Multiaxial Testing...............................10

2.4.1 CSM Design Solution ……………………………................................... 10

2.4.2 Naval Research Laboratory Design ............................................................... 15

CHAPTER 3: DESIGN SOLUTION................................................................................ 17

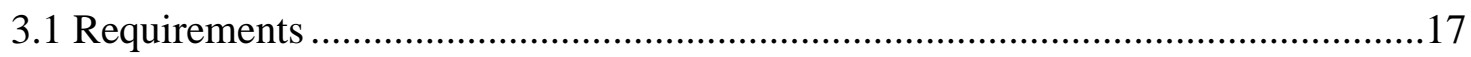

3.1.1 Constraints ................................................................................................. 17 


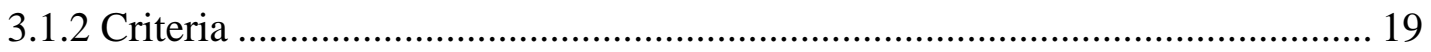

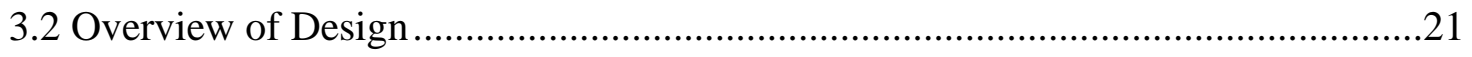

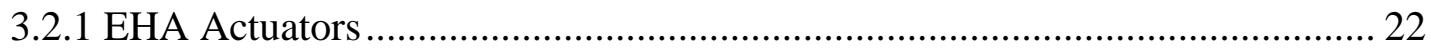

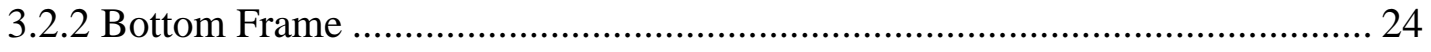

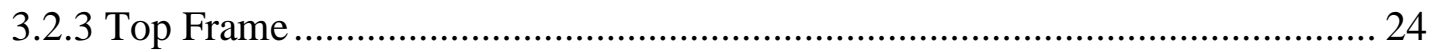

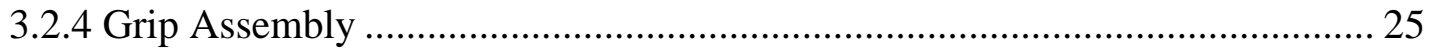

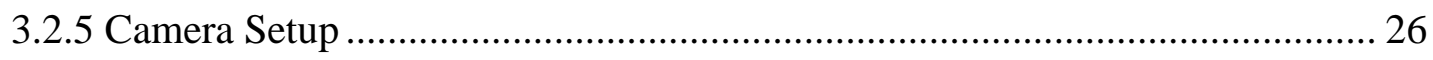

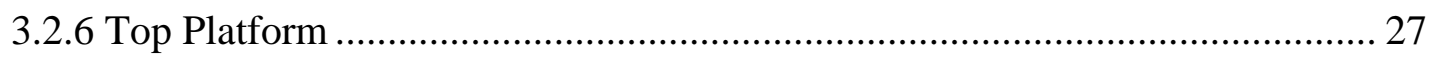

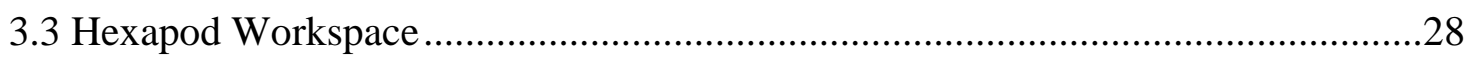

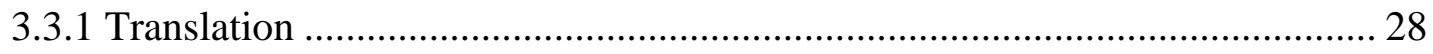

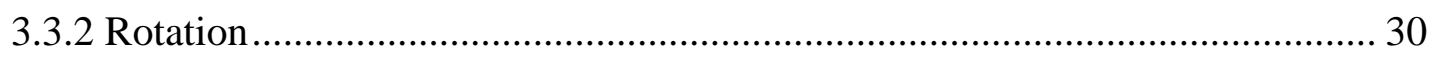

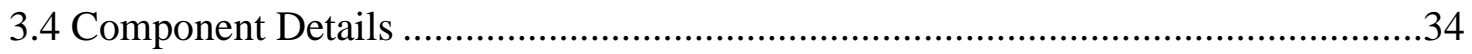

3.4.1 Camera Assembly ………………………………................................. 34

3.4.2 Grip Assembly ....................................................................................... 34

3.4.3 Actuator Assembly ..................................................................................... 35

3.4.4 Data Acquisition ...................................................................................... 36

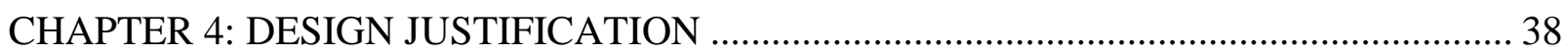

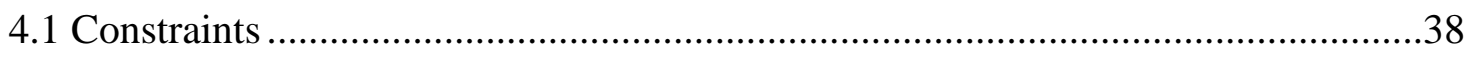

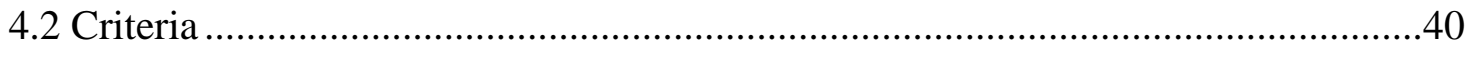

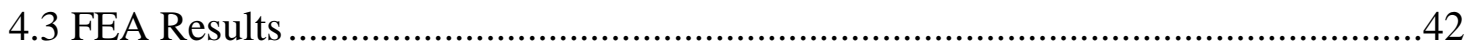

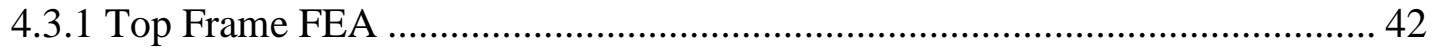

4.3.2 Bottom Frame FEA ..................................................................................... 44

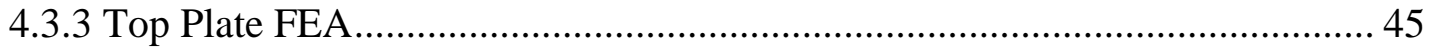

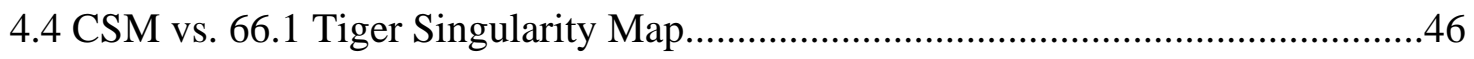




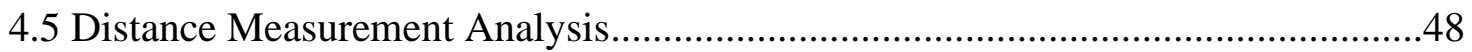

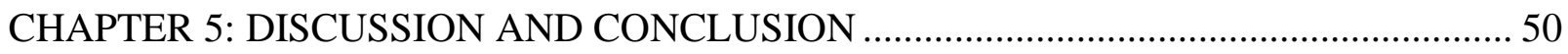

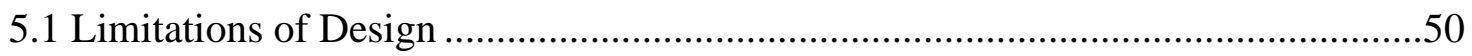

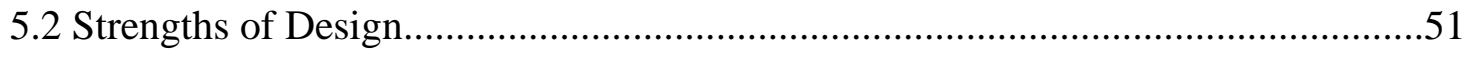

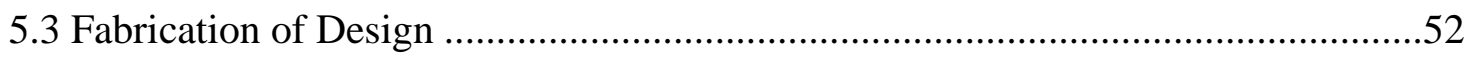

5.4 Functionality of Design ......................................................................................53

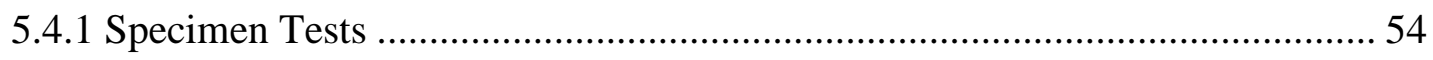

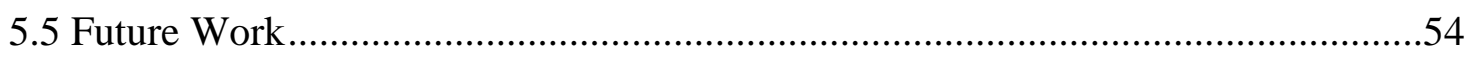

5.5.1 Possible Research Questions........................................................................ 56

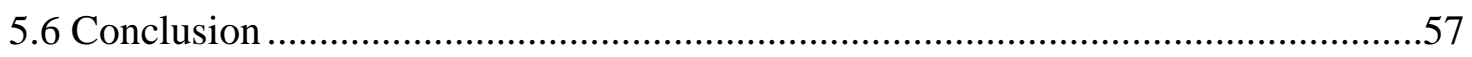

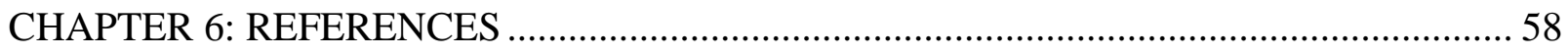

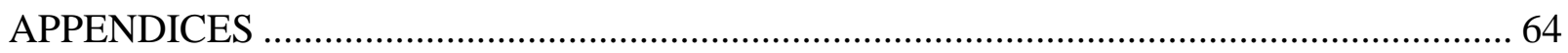

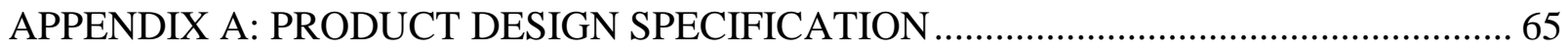

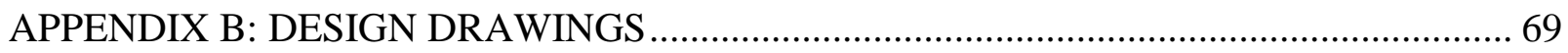

APPENDIX C: MATLAB CODE FOR SINGULARITY ANALYSIS ..................................... 89

APPENDIX D: DISTANCE MEASUREMENT PACKAGE.................................................. 97

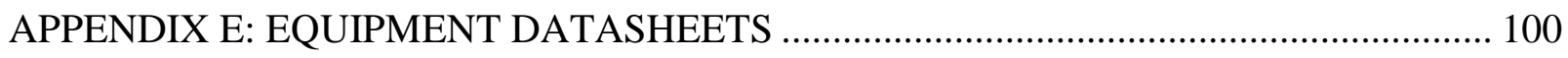

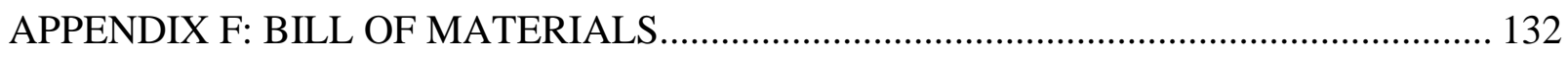

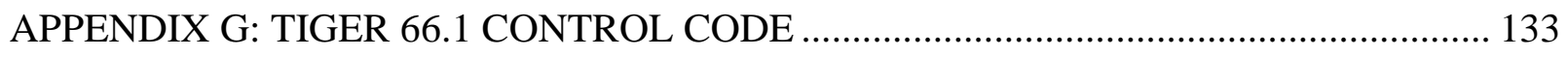

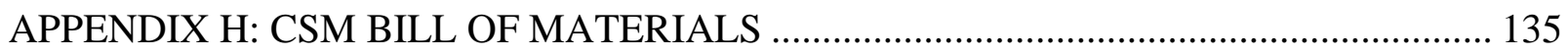

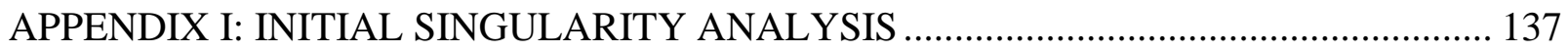

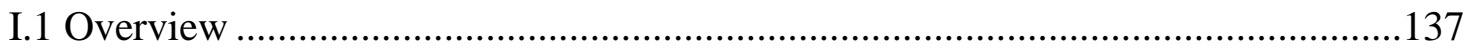

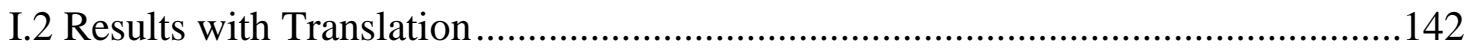

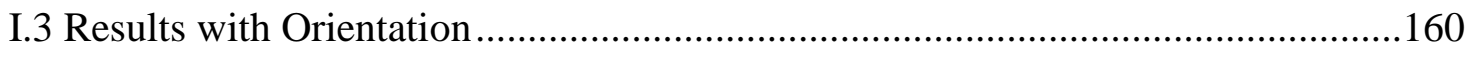




\section{LIST OF TABLES}

Table 2.1: Deflection predictions for bulk materials. Material properties are from SolidWorks.

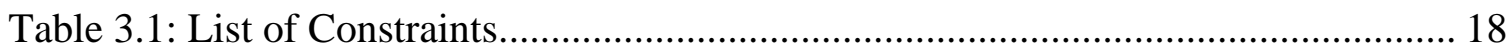

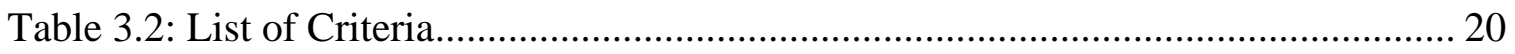

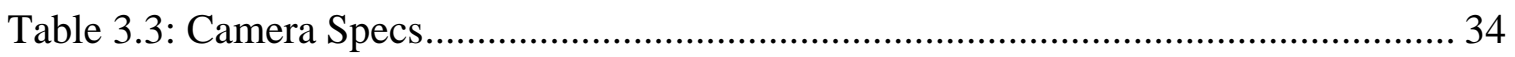

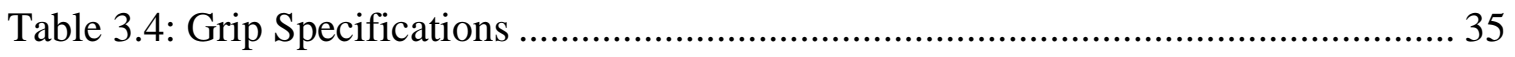

Table 3.5: Force/Torque Sensor Specifications ...................................................... 35

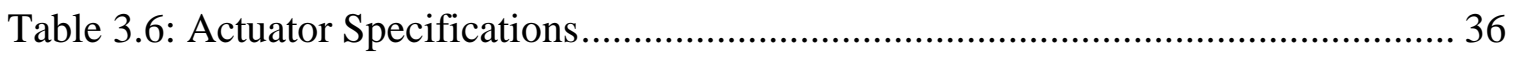

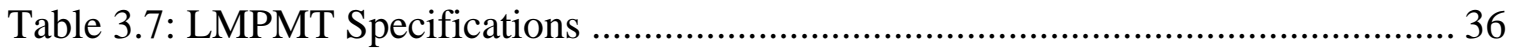

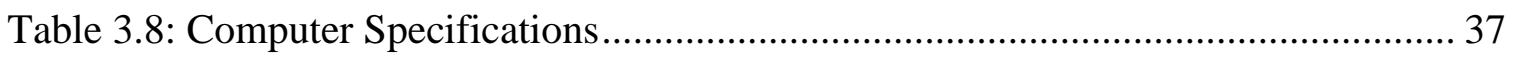

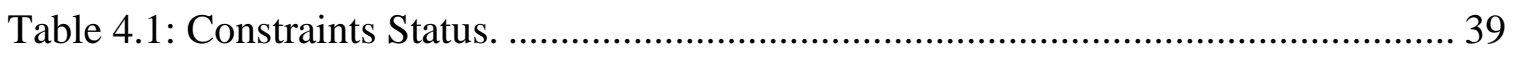

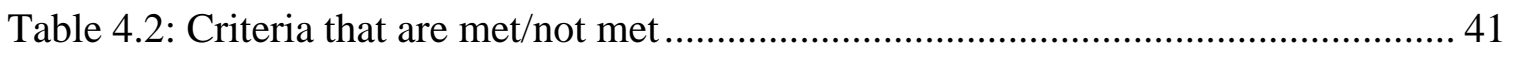

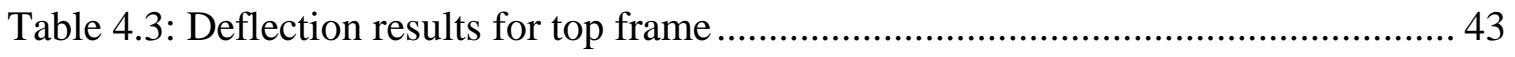

Table 4.4: Deflection results for bottom frame ...................................................... 44

Table 4.5: Deflection results for top plate …....................................................... 45

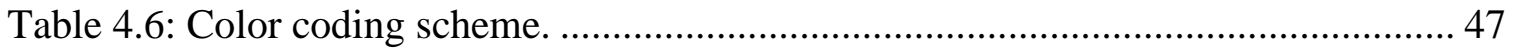

Table 4.7: Positive speed PID control values for Parker EHA................................... 49

Table 4.8: Negative speed PID control values for Parker EHA. ................................... 49

Table I.1: Material properties of ABS-ESD7 [6] ................................................... 139 
Table I.2: Results of deflection calculations of ABS-ESD7 ..................................... 143

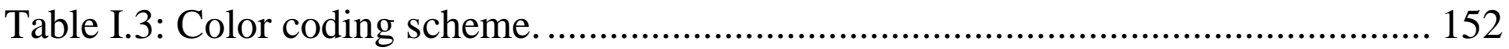




\section{LIST OF FIGURES}

Figure 2.1: Serial manipulator (left) and parallel manipulator (right) examples............... 4

Figure 2.2: Stewart-Gough platform with SPS configuration. [14] ............................... 6

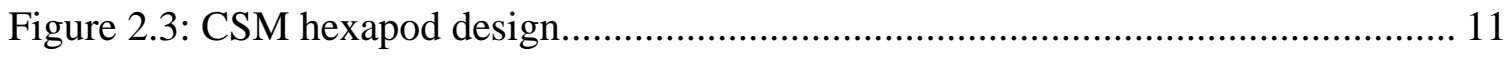

Figure 2.4: Close up of camera (red) and actuator (grey \& blue) ................................ 15

Figure 2.5: NRL 66.3 Multiaxial robotic test frame ................................................. 16

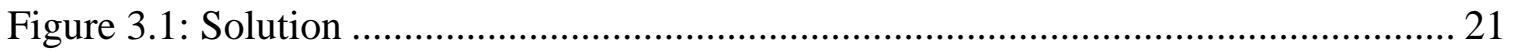

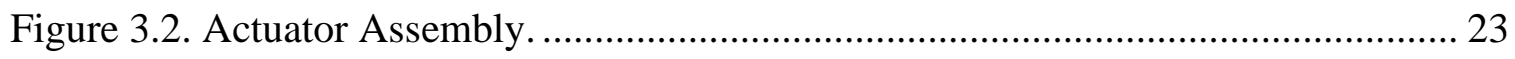

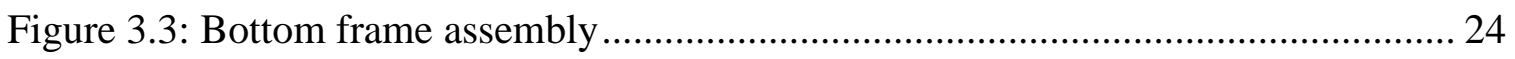

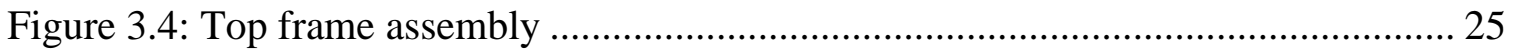

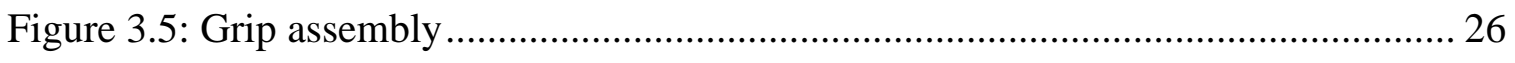

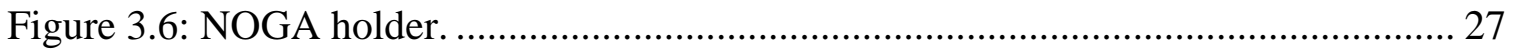

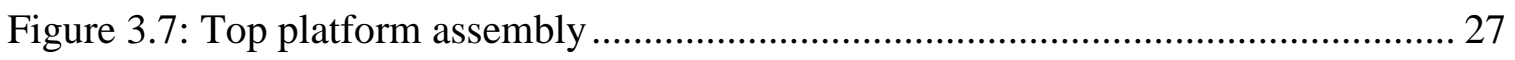

Figure 3.8: Workspace comparison, CSM (bottom) and 66.1 Tiger (top) ..................... 29

Figure 3.9: Rotation only comparison, 66.1 Tiger (left) and CSM (right). .................... 31

Figure 3.10: Pure bending comparison, 66.1 Tiger (top) and CSM (bottom). ................ 32

Figure 3.11: Difference between the traditional hexapod setup and the inverted

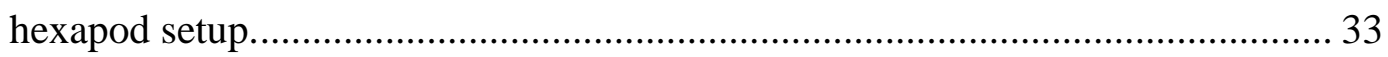

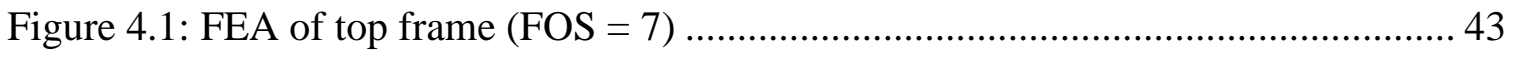

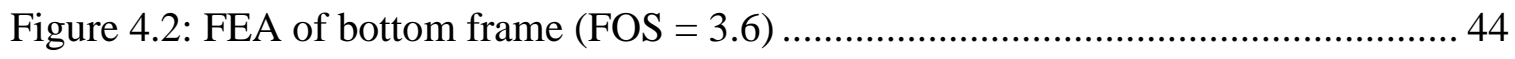

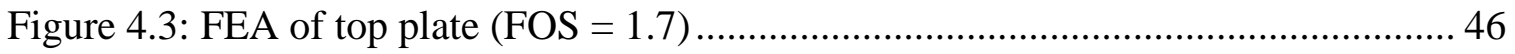


Figure 4.4: Singularity map of pure translation of the CSM (top) and 66.1 Tiger (bottom) designs.

Figure 4.5: Pure rotation scenarios for the singularity map of the 66.1 Tiger (right) and the CSM (left) designs. 48

Figure 5.1: SolidWorks Image of solution (left), solution pictured in the lab (right).

Figure I.1: Results of increasing the bottom plate radius while keeping the top radius of $250 \mathrm{~mm}$.

Figure I.2: Results of increasing the radius of the bottom plate. The top plate was kept at the initial $250 \mathrm{~mm}$ of the design.

Figure I.3: Results of increasing the top plate radius while keeping the bottom radius at a default of $250 \mathrm{~mm}$.

Figure I.4: Results of the condition number and determinant for a pure bending test. The top plate radius is kept at default while the bottom plate radius is increased.

Figure I.5: Results of the condition number and determinant for pure bending with increasing top plate radius and a constant default bottom plate radius

Figure I.6: Results of the condition number and determinant over the pathway of a pure torsion test with increasing bottom plate radius with a constant default top plate radius. Note that the last three legend values are close together on both charts 150

Figure I.7: Data for "slice" of workspace at the "home" location. 151 
Figure I.8: Color coding of position points based on condition number.

Figure I.9: Color coding scheme by changing yellow to range between 250 and 50,000 and red to range above 50,000.

Figure I.10 Condition number analysis at a height of $37.5 \mathrm{~mm}$ above the "home" position using the color scheme in table 2 .

Figure I.11: Condition number analysis at $37.5 \mathrm{~mm}$ below the "home" position. Same color scheme as table 2 .

Figure I.12: Condition number analysis at $75 \mathrm{~mm}$ above (top) and below (bottom) the "home" position.

Figure I.13: Condition number results using the color scheme in table 2, $19 \mathrm{~mm}$ above (top) and below (bottom)

Figure I.14: Condition analysis with increasing $\mathrm{z}$ value up to the "home" position from below

Figure I.15: Specimen designs used for analysis and testing. 161

Figure I.16: Results from moments about the specimen. 162

Figure I.17: Results for orientation of rotation about "home" position (top) and the results with greater distance between data points (bottom). 


\section{CHAPTER 1: TOWARDS CHARACTERIZATION WITH STEWART-GOUGH PLATFORMS}

The purpose of this research is to develop a 6 degree-of-freedom (6-DOF) multiaxial robotic test frame to actively characterize the constitutive material properties of additive manufacturing materials, specifically in dealing with polymers. 6-DOF supports motion in three translational directions, $\mathrm{X}, \mathrm{Y}$, and $\mathrm{Z}$, and the respective rotational directions. This allows 6-axis loading to be applied to a specimen to generate the complex nonlinear responses characteristic of additively manufactured (AM) materials. In this thesis previous design is reviewed to support the application of a new design that meets the need for multiaxial testing of nonlinear, anisotropic, polymer materials.

\subsection{Motivation}

The motivation for a move towards multiaxial testing comes from several disadvantages of using traditional uniaxial testing for nonlinear materials. Specifically, for the case of AM materials, nonlinear and anisotropic material behavior is of concern. Work done at the Naval Research Laboratory addresses the lack of knowledge from the nonlinear domain and provides particular solutions for characterizing composite materials using a multiaxial robotic test machines [1-4]. More recent work has followed through with showing the advantages and reasoning for multiaxial testing towards nonlinear domains of material behavior [5-12]. This work contains further development of the mentioned work towards AM material characterization, while improving in some aspects of the Colorado School of Mines (CSM) design, shown in Figure 2.3 and discussed in Section 2.4.1. 


\subsection{Test Frame Design Problem}

At the start of this research, a design solution was provided that was completed by a 2semester senior design team named "5DOF (Designers of the Future)" at the Colorado School of Mines [13]. This is referenced to show the reasoning for a redesign of a 6-degreeof-freedom test frame for material characterization. The team provided a process and background into designing the solution. The start of the research was to determine if 5DOF's design was suitable to go forward and fabricate. Ultimately, a decision was made to design a completely new solution as the given was not adequate due to issues outlined in section 2.1. Considering this, a problem statement is shown below:

Design and fabricate a multiaxial robotic test frame that can test additive manufacturing materials, focusing on polymers and some metals, in 6 degrees-of-freedom while improving on performance and cost over the CSM design.

\subsection{Thesis Outline}

Chapter 1 provides the introduction into the project with the motivation and problem statement. Chapter 2 introduces the background and previous work related to the problem. Chapter 3 includes the design solutions with its relation to the requirements. Chapter 4 summarizes the constraints and criteria and goes over the FEA, the singularity 'map' and work completed to see if inaccurate actuators can be made accurate with the use of PID and cheap electronics. Chapter 5 includes the discussion and conclusion of this design report. Lastly, chapter 6 includes the references. 


\section{CHAPTER 2:}

\section{CHARACTERIZATION THROUGH HEXAPOD DESIGN}

Characterization is essential in understanding material behavior. Understanding AM material behavior will be beneficial in making designs that are more oriented towards structural applications. This chapter discusses characterization through hexapod design, focusing on background and analysis on a provided design, past research completed, hexapod designs, geometries, and singularities management. These topics deal with what is best suited for a hexapod design for characterization of AM materials focusing on polymers

\subsection{Review of Robotic Manipulators}

There are two main types of manipulators, serial and parallel, and there are several subcategories with each type [14]. The difference in serial and parallel manipulators is the architecture. Serial manipulators consist of a fixed base and an end effector that is free to move. Parallel manipulators are classified as a robot that has a moving platform and is connected to a fixed platform by several "limbs or legs". Robot in this context means a machine that can carry out complex actions through a computer. Parallel manipulators are also known as platform manipulators [14]. Examples of each are provided in Figure 2.1. This research uses parallel manipulator due to the superior rigidity, accuracy, and control that is possible with closed loop manipulators as compared to serial manipulators that are opened ended [14]. 

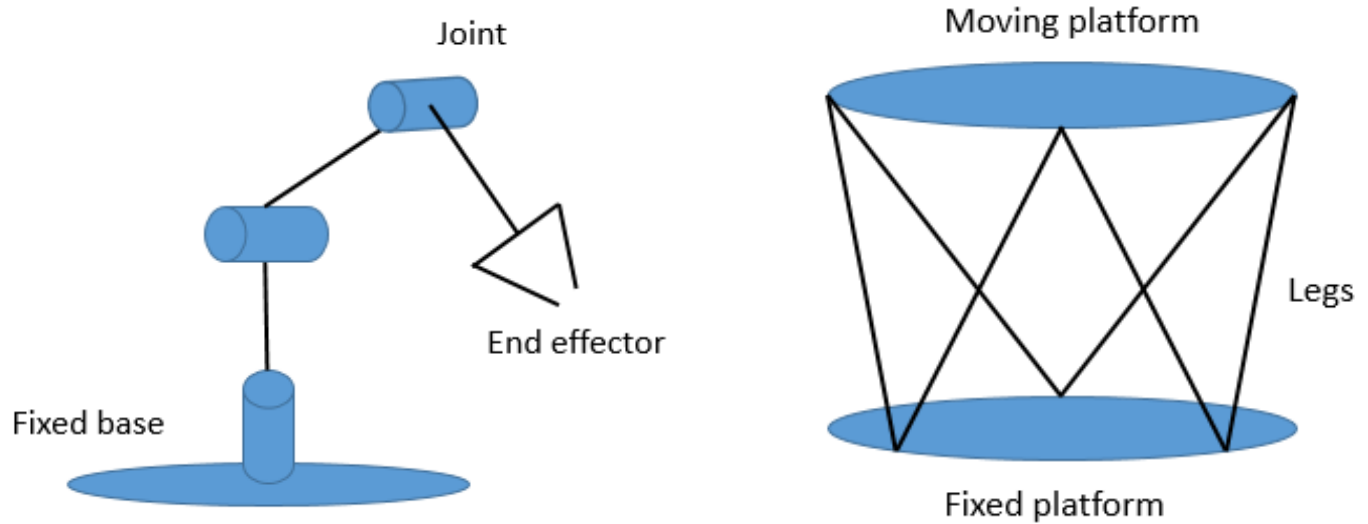

Fixed platform

Figure 2.1: Serial manipulator (left) and parallel manipulator (right) examples.

Parallel manipulators are classified into three main categories, planar, spherical, or spatial manipulators. Planar manipulators consist of planar movement, excluding any change in orientation except movement about the axis perpendicular of the plane. Spherical manipulators consist only of spherical movement, meaning movement around a central virtual point. Spatial manipulators consist of movement in any direction in which it is not only spherical or planar but can contain both types of movement. In the case of this research, translational and rotational movement is needed. Classification can also be determined by using equations 2.1 and 2.2 ,

$$
\begin{gathered}
\sum_{k=1}^{m} C_{k}=(\lambda+1) F-\lambda=7 F-6 \\
\lambda \geq C_{k} \geq F
\end{gathered}
$$

where $C_{k}$ is the connectivity of the $k$ th $\operatorname{limb}, \lambda$ is a motion parameter the manipulator within the workspace, $F$ is the degrees of freedom of the manipulator, and $m$ is the number of limbs. It must be noted that $m=F=6$ in the case of a Stewart-Gough (SG) platform. In 
the case of this research it is desired to have 6-DOF, therefore $\lambda$ is equal to 6 and the equation is shortened to the far right side of equation 2.1 [14]. This results in $C_{1 \ldots 6}=6$, with the sum of all joint freedoms being 36. Degrees of freedom of the joints depend on the classification of joints which includes: Prismatic (P), Spherical (S), Universal (U), Cylindrical (C), and Revolute (R). The associated limbs that have 6-DOF are SPS, SCS, UPS, and SSR while keeping in mind that $\mathrm{P}, \mathrm{C}$, and $\mathrm{R}$ joints have 1-DOF. S joints have 3DOF and $\mathrm{U}$ joints have 2-DOF.

\subsection{Stewart-Gough Platform}

An example of a parallel manipulator that is ideal for material characterization is the Stewart-Gough (SG) platform. To test materials accurately, precision and rigidity are key in designing a machine that can apply the proper loading to a specimen. It has already been discussed in Section 2.1 that parallel manipulators are more accurate and rigid than serial manipulators. Of the types of parallel manipulators, SG platforms provide the accuracy and strength needed.

\subsubsection{Kinematics of a General Stewart-Gough Platform}

A SG platform is classified as a spatial manipulator using a combination of limbs such that 6 degrees of freedom are achieved for the moving platform. A generic SG platform consists of a SPS or SPU configuration. Figure 2.2 shows a basic SG platform, whereas the variables labeled are referenced in later equations. The joints labeled are for each limb. 


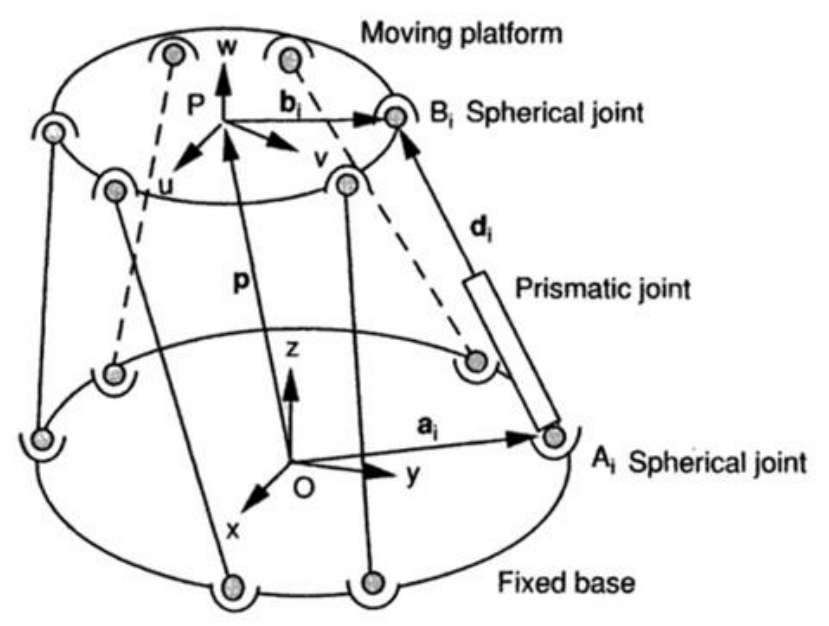

Figure 2.2: Stewart-Gough platform with SPS configuration. [14]

The kinematics are analyzed using vector loop equations, orthogonal conditions, and a rotation matrix. The moving platform consists of the reference frame $B$, with unit vectors of $u, v$, and $w$, and the fixed platform consists of the fixed frame $A$. The variables, $A_{i}$ and $B_{i}$ represent the bottom and top platforms respectively, where $i=1,2, \ldots 6$. The variables $O$ and $P$ are the bottom and top platform origin points respectively. The vectors $\boldsymbol{a}_{\boldsymbol{i}}$ and $\boldsymbol{b}_{\boldsymbol{i}}$ are the vectors originating from the origin points to the associated limb. The vector loop equation results in the equation below,

$$
\overline{A_{l} B_{l}}=p+R_{B}^{A} b_{i}-a_{i}
$$

Where $\overline{A_{l} B_{l}}$ consists of each line going from the bottom joint of link $i$ to the top joint of link $i$ in Figure 1.2, $\boldsymbol{p}$ is the vector from the origin of the fixed frame to the origin of the moving frame, and $R_{B}^{A}$ is the rotation matrix of the moving platform, which is shown below.

$$
R_{B}^{A}=\left[\begin{array}{lll}
u_{x} & v_{x} & w_{x} \\
u_{y} & v_{y} & w_{y} \\
u_{z} & v_{z} & w_{z}
\end{array}\right]
$$


The variables within the matrix are unit vectors of the moving frame $B$ in respect to $x$, $y$, and $z$ of the fixed frame $A$. The variable $u$ represents the new x-axis, $v$ represents the new $\mathrm{y}$-axis, and $w$ represents the new $\mathrm{z}$-axis. The variable $u_{x}$ represents the reflection of the new $\mathrm{x}$-axis on the original $\mathrm{x}$-axis, and $v_{x}$ represents the reflection of the new $\mathrm{y}$-axis with respect to the original $\mathrm{x}$-axis and so on. Since Cartesian frames are orthogonal there are a set of equations that must hold true for any rotation, indicated in equations 1.6-1.11. To find the length of a limb, equation 2.3 is used by taking the dot product of itself to obtain the equation below, where $d_{i}$ represents the length of the associated limb.

$$
d_{i}^{2}=\left[p+R_{B}^{A} b_{i}-a_{i}\right]^{T}\left[p+R_{B}^{A} b_{i}-a_{i}\right]
$$

For the inverse kinematics, the unknown variable is $d_{i}$ is unknown and the vector $\boldsymbol{p}$ and the rotation matrix are the input variables, resulting in 6 unknowns. It should be noted that the positive value is taken as the actual limb length as a negative limb length is not logical. The direct kinematics problem involves solving for $\boldsymbol{p}$ and the rotation matrix, which follows the orthogonal conditions shown below and accounts for 6 of the 12 equations:

$$
\begin{gathered}
u_{x}^{2}+u_{y}^{2}+u_{z}^{2}=1 \\
v_{x}^{2}+v_{y}^{2}+v_{z}^{2}=1 \\
w_{x}^{2}+w_{y}^{2}+w_{z}^{2}=1 \\
v_{x} w_{x}+v_{y} w_{y}+v_{z} w_{z}=0 \\
u_{x} v_{x}+u_{y} v_{y}+u_{z} v_{z}=0 \\
u_{x} w_{x}+u_{y} w_{y}+u_{z} w_{z}=0
\end{gathered}
$$

Since the direct kinematic equations are highly nonlinear, there are multiple solutions, specifically 4,096 solutions, if the equations are solved using the equations below for $i=$ 
$2, \ldots 6$ (equations 2.12 and 2.13), assuming the origin for the moving frame is located at $\mathrm{A}_{1}$ and the origin of the fixed frame is at $\mathrm{B}_{1}$, resulting in the values, $a_{i z}, b_{i w}, a_{1 x}, a_{1 y}, a_{1 z}, b_{1 u}$, $b_{1 v}$, and $b_{1 w}$ being equal to zero. The variables $p_{x}, p_{y}$, and $p_{z}$ are the scalar values of vector p. Raghavan, [15], reduced the number of solutions to 40 solutions.

$$
\begin{gathered}
d_{i}^{2}=p_{x}^{2}+p_{y}^{2}+p_{z}^{2} \\
b_{i u}\left(p_{x} u_{x}+p_{y} u_{y}+p_{z} u_{z}\right)+b_{i v}\left(p_{x} v_{x}+p_{y} v_{y}+p_{z} v_{z}\right)+b_{i w}\left(p_{x} w_{x}+p_{y} w_{y}+p_{z} w_{z}\right) \\
-a_{i x} p_{x}-a_{i y} p_{y}-a_{i z} p_{z}-b_{i u}\left(a_{i x} u_{x}+a_{i y} u_{y}+a_{i z} u_{z}\right) \\
-b_{i v}\left(a_{i x} v_{x}+a_{i y} v_{y}+a_{i z} v_{z}\right)-b_{i w}\left(a_{i w} w_{x}+a_{i y} w_{y}+a_{i z} w_{z}\right) \\
+\frac{\left(a_{i x}^{2}+a_{i y}^{2}+a_{i z}^{2}+b_{i u}^{2}+b_{i v}^{2}+b_{i w}^{2}+d_{1}^{2}+d_{i}^{2}\right)}{2}=0
\end{gathered}
$$

\subsection{Jacobian Analysis of Stewart-Gough Platform}

A major disadvantage of parallel manipulators is the existence of singularities within the workspace. Singularities are defined as the manipulator gaining or losing 1 or more degrees of freedom, in other words the control of the manipulator is lost. The authors of $[16,17]$ analyze the Jacobian matrix for inverse and direct kinematic singularities. According to Tsai [14], there are three types of singularities, inverse kinematic, direct kinematic, and combined singularities. Inverse kinematic singularities cause the manipulator to not move infinitesimally in some directions and direct kinematic singularities cause the actuators to lock while the manipulator is able to move infinitesimally in some directions. Combined singularities occur when both inverse and direct kinematic singularities occur and are rare.

The Jacobian is calculated by analyzing the velocity vector loop equations in which the velocities are shown in Equations 2.14 and 2.15, 


$$
\begin{gathered}
\dot{\boldsymbol{q}}=\left[\dot{d}_{1}, \dot{d}_{2}, \ldots, \dot{d}_{6}\right] \\
\dot{\boldsymbol{x}}=\left[\begin{array}{c}
\boldsymbol{v}_{\boldsymbol{p}} \\
\boldsymbol{\omega}_{\boldsymbol{B}}
\end{array}\right]
\end{gathered}
$$

where $\dot{\boldsymbol{q}}$ contains the velocity of each of the limbs, and $\dot{\boldsymbol{x}}$ contains the velocity of the point $P$ in Figure 2.2 and the angular velocity of the moving platform. By writing the vector loop equation for velocity, differentiating with respect to time, and multiplying both sides of the equation with $s_{i}$ results in equation 1.16 .

$$
\boldsymbol{s}_{i} \cdot \boldsymbol{v}_{\boldsymbol{p}}+\left(\boldsymbol{b}_{i} \times \boldsymbol{s}_{\boldsymbol{i}}\right) \cdot \boldsymbol{\omega}_{B}=\dot{d}_{\boldsymbol{\imath}}
$$

The above equation can be written for each limb and equations 1.14 and 1.15 can be taken out to result equation 2.17 in which $J_{x}$ is the direct kinematic Jacobian and $J_{q}$ is the inverse kinematic Jacobian.

$$
J_{x} \dot{\boldsymbol{x}}=J_{q} \dot{\boldsymbol{q}}
$$

For the above equation, $J_{q}$ is an identity matrix and $J_{x}$ is defined by Equation 1.18.

$$
J_{x}=\left[\begin{array}{cc}
\boldsymbol{s}_{1}^{T} & \left(\boldsymbol{b}_{1} \times \boldsymbol{s}_{1}\right)^{T} \\
\vdots & \vdots \\
\boldsymbol{s}_{6}^{T} & \left(\boldsymbol{b}_{6} \times \boldsymbol{s}_{6}\right)^{T}
\end{array}\right]
$$

One of the most important aspects of parallel manipulators is the analysis of singularities as singularities can greatly affect the performance of the hexapod. The Jacobian matrix is used to evaluate the controllability of a hexapod [14]. Several researchers have looked and provided several ways of evaluating singularities within the workspace, but singularities within the workspace are still widely not understood. It is also impossible to find all the possible singularities besides the basic types. These basic types include the inverse kinematic, direct kinematic, and combined singularities. 
Inverse kinematic singularities occur at the workspace boundary and do not occur within the workspace of the hexapod. This is since the Jacobian matrix for the leg (actuator) velocities, $J_{q}$ is an identity matrix shown in equation 2.17 . Direct kinematics are the most difficult to find with a few exceptions by analyzing the Jacobian matrix, $J_{x}$, and the following conditions: (1) the top and bottom platform geometry is the same, (2) when all limb lengths are equal, (3) and all limbs are parallel. Lastly combined singularities do not occur with SG platforms due to the identity matrix, $J_{q}[14]$.

\subsection{Review of Material Characterization Using Multiaxial Testing}

Since material characterization includes a significant amount of subject areas and information, focus is taken on characterization of mechanical properties. Discussion into the background of material characterization will shed light onto the reasoning for characterization through multiaxial testing machines. Material characterization has grown because of the capabilities of additive manufacturing with creating shapes and material properties that are not available through other traditional methods. The issue at hand are designs that allow engineers and scientists to study these properties. In some cases, activating these material properties require testing in multiple directions and multiaxial testing allows this.

\subsubsection{CSM Design Solution}

A senior design team at the Colorado School of Mines over the course of two semesters designed a solution for a hexapod design for characterization of AM materials 
shown in Figure 2.3. This design is 0.5 s meter wide and 0.47 meters tall and consists of a LVDT, spherical joints, cameras, grips, and a 6-axis force sensor.

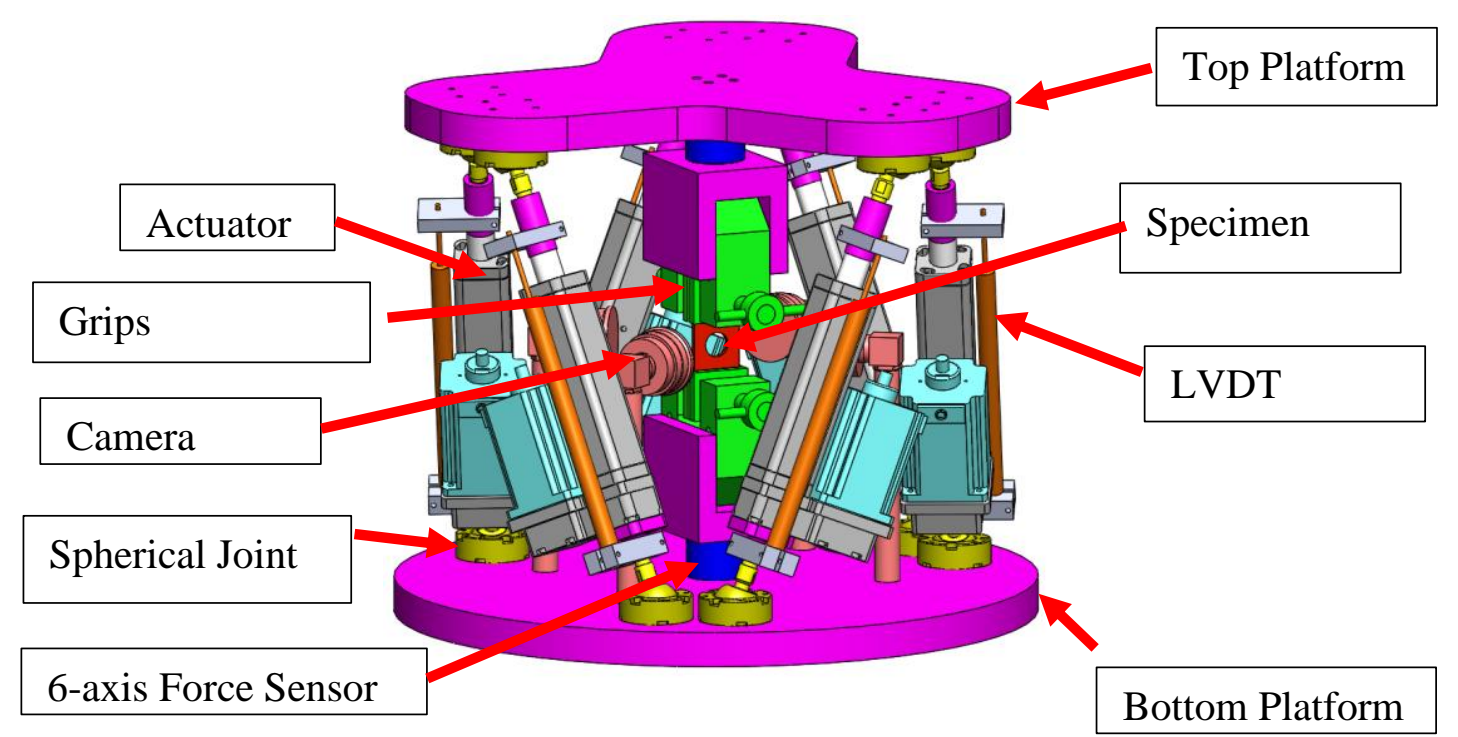

Figure 2.3: CSM hexapod design.

At the start of this work, this solution was provided, and an analysis was conducted to determine the validity of the design. Initial validation was completed by Dr. John Stueben of the Naval Research Laboratory (NRL) and resulted in the following, taken from email [18]:

1. The monolithic platens in the original design are extremely heavy and far too compliant to permit testing of metallic or composite materials. We have developed a better design which is far more rigid and weighs less. 
2. The kinematic singularities of Stewart-Gough platforms are very badly understood. The "home" pose of the current design is nearly singular and presents control problems.

3. The forces and displacements applied to the test specimens are extremely, and I mean extremely, sensitive to variations in the asbuilt geometry of the test frame. This implies that either the machine must be built with superlative tolerances, or we need to monitor the relative displacement of the grips using an optical technique (instead of using LVDTs on the actuators and propagating those measurements through the forward kinematic transforms).

4. I think that the grips selected in the original design are inadequate to support bending and torsional loads. We should give some thought to finding or designing a better option.

Note that the "home" pose is the position of the hexapod in Figure 2.3, in which no stresses are applied to the specimen and represents the starting position for any material testing. To clarify on the points addressed, the first point states that the top and bottom platform design is too compliant and heavy, and heavy in this case means heavy compared to the load capabilities of the actuators. The second point states that the CSM design is highly uncontrollable due to the 'home' pose being a singularity. 
After the initial evaluation, another analysis was completed at the start of this research to identify other possible issues. Several issues were identified. The undergraduate design team chose a PC40 precision linear actuator from Thomson Linear. This model of the series has a max stroke of $1200 \mathrm{~mm}$. Looking at [19] and using the length of the actuator chosen, the stroke the team chose is $60 \mathrm{~mm}$, which provides very little movement for testing more compliant materials. Using the original specimen design of a thickness of $5 \mathrm{~mm}$, height of $50 \mathrm{~mm}$, and a width of $50 \mathrm{~mm}$, shown in the figure below. Tests for specimen deflection where done assuming a full rectangular specimen without defects to see if this design can reach the deflection limits of the specimen. Table 1 shows the deflection results for pure

$$
\begin{gathered}
\theta=\frac{F l^{2}}{2 E I} \\
y_{\text {max }}=-\frac{F l^{3}}{3 E I}
\end{gathered}
$$

bending using cantilever beam Equations 2.19and 2.20 in [20].

Based on the values in Table 2.1, and the limited range of the chosen actuators, shown in, this part of the CSM design is not suitable and suggests that specimen redesign and larger actuator stroke is desired. It also suggests that a boundary singularity will be reached well before the max deflection points are reached. Another issues with the actuator assembly is the use of spherical joints on both ends of the actuator. This causes the actuators to gain a degree of freedom and be able to rotate along the axis of the cylinder rod. A quick fix for this is to use a universal joint at one end of the actuator. 
Table 2.1: Deflection predictions for bulk materials. Material properties are from SolidWorks.

\begin{tabular}{|c|c|c|}
\hline Material & Max Deflection $[\mathrm{mm}]$ & Angle $\left.{ }^{\circ}\right]$ \\
\hline ABS-ESD7 & -42.36 & -72.81 \\
\hline PLA & -38.10 & -57.30 \\
\hline PC & -75.36 & -135.43 \\
\hline 6061-T6 & -10.34 & -17.77 \\
\hline
\end{tabular}

Another issue is the choice of spherical joint which has an inadequate load rating. The CSM team chose the SRJ024C model with a static load rating of $3920 \mathrm{~N}$. As noted in [21], the static load should not exceed $80 \%$ of the static load rating for long periods, and the load should not be applied for long periods if the shaft of the joint is not concentric with the body. Initial tensile test calculations suggest that a greater load rating is needed considering results show forces of $17000 \mathrm{~N}$ up to $30000 \mathrm{~N}$ and each leg would take $1 / 6^{\text {th }}$ of the load or greater depending on the location and orientation. Looking at Figure 2.4, there is only roughly $16 \mathrm{~mm}$ between the camera and the actuator, suggesting that movement associated with more compliant materials is not likely, especially with the bending results in Table 2.1 . 


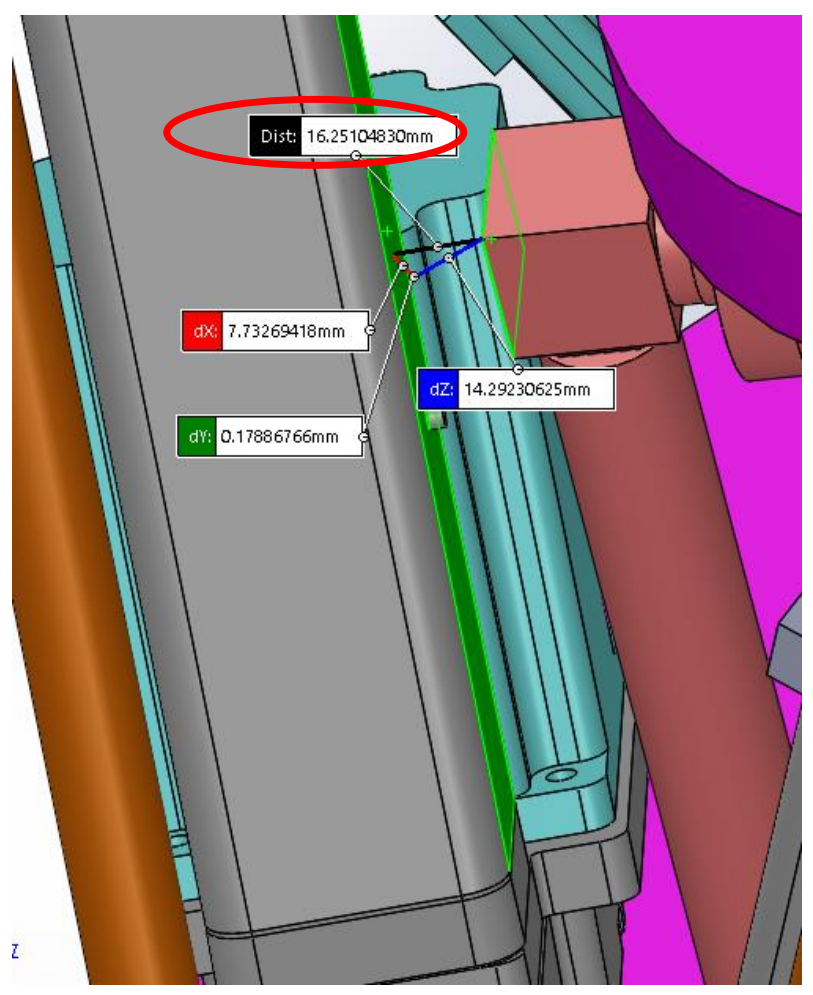

Figure 2.4: Close up of camera (red) and actuator (grey \& blue).

Upon the analysis of the given design, with the errors outlined by the NRL review, and the analysis done within the scope of this research, a choice was made to completely redesign the platform to address issues outlined in this section as well as to improve in other aspects. Past research, other platform designs, geometry, and singularities are looked at in detail to show the process leading to the final design.

\subsubsection{Naval Research Laboratory Design}

This work follows the past work completed by NRL with using robotic manipulators in characterizing the constitutive properties of materials with complex behavior. The work completed focused on characterizing composite materials using a current generation multiaxial robotic test frame, shown in $[1,7,9,10,22-26]$. The SG test frame allowed for 6 
dimensional movements with four cameras to capture the strain states in "real" time. A

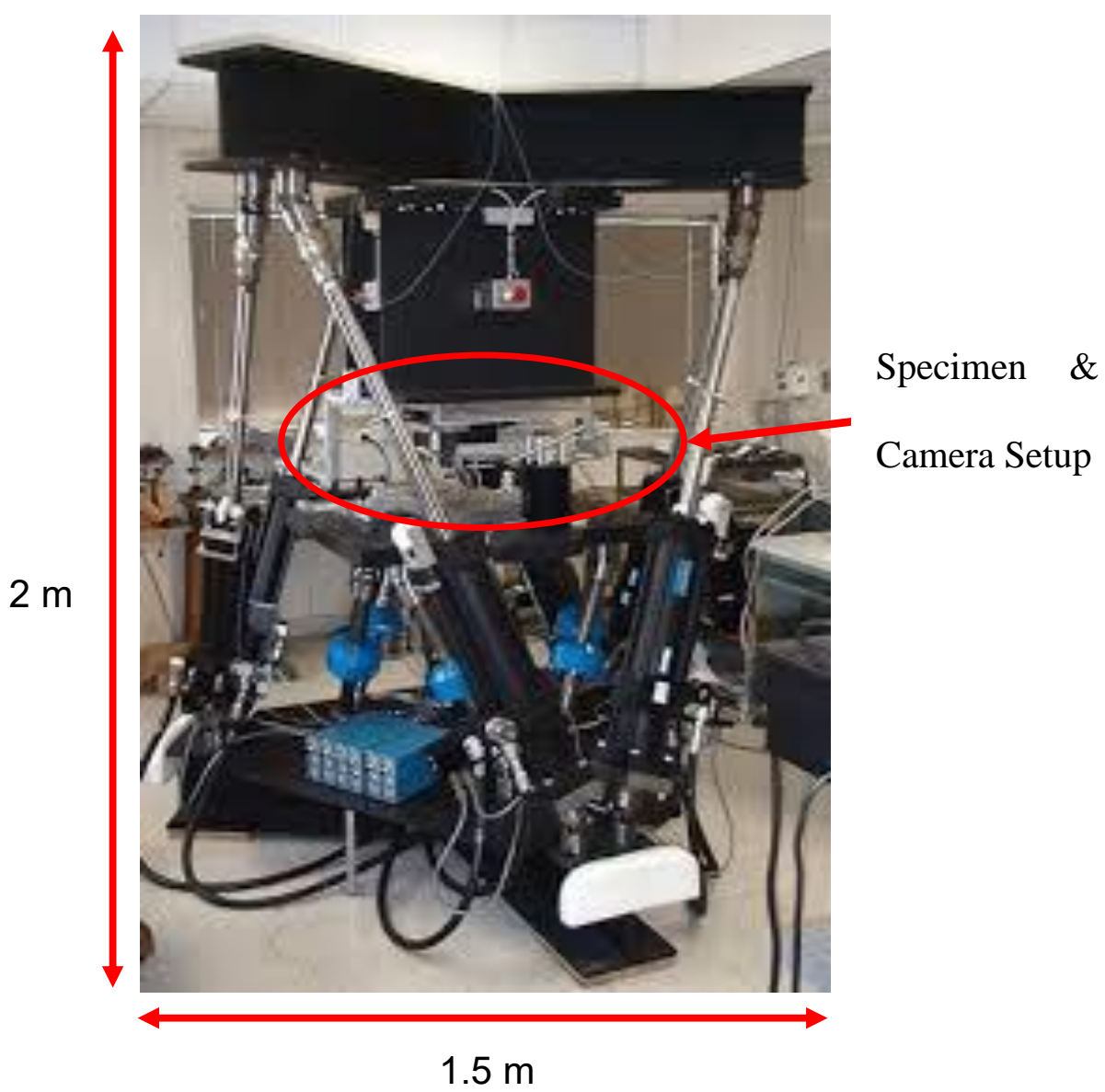

Figure 2.5: NRL 66.3 Multiaxial robotic test frame

robotic arm places the specimen in the grips and applies loading in 6-DOF. This design focuses on composite materials and for the sake of this work, the full field strain measurement system, and the SG configuration are of importance. The full field strain measurement system uses 4 cameras to measure the distance between dots placed on the specimen surface and uses that to capture the strain states and calculate the material properties using a surrogate model. The advancement in surrogate modeling has allowed 'real' time characterization with modeling occurring in less than 0.5 seconds [27]. 


\section{CHAPTER 3: DESIGN SOLUTION}

With the underlying relationships to the kinematic performance of the hexapod defined, different architectures of the top and bottom platform were evaluated (see Section I.1). A geometry was chosen based on the results of Appendix I.. The design solution aligns with the requirements.

\section{1 $\underline{\text { Requirements }}$}

To reiterate, the problem statement is as follows:

Design and fabricate a multiaxial robotic test frame that can test additive manufacturing materials, focusing on polymers and some metals, in 6 degrees-of-freedom while improving on performance and cost over the CSM design.

This section goes over the requirements for this design problem.

\subsubsection{Constraints}

Table 3.1 shows the list of constraints set out to determine a successful design according to the problem statement. The constraints were generated with the goal to make sure that the design could break a specimen, improving over the CSM design, and containing the basics for complete material characterization in the future. A full PDS is included in Appendix A:. 
Table 3.1: List of Constraints

1.

\begin{tabular}{|c|c|c|c|}
\hline No. & Requirement & Justification & Target \\
\hline 5 & $\begin{array}{l}\text { Must allow for adjustments in stationary grip } \\
\text { placement }\end{array}$ & $\begin{array}{l}\text { allowing more room for adjustment } \\
\text { adds versatility }\end{array}$ & $\begin{array}{l}1 \text { set of } \\
\text { removable } \\
\text { grips }\end{array}$ \\
\hline 6 & Design platform to have extra degrees of freedom & $\begin{array}{l}\text { to test materials that compliant such } \\
\text { that the hexapod cannot reach the point } \\
\text { where the specimen breaks }\end{array}$ & $>=1 \mathrm{DOF}$ \\
\hline 7 & $\begin{array}{l}\text { Design platform to test 3D printed metal } \\
\text { specimens }\end{array}$ & $\begin{array}{l}\text { additive manufacturing (not } \\
\text { considering composite) does consist of } \\
\text { metal materials }\end{array}$ & $\begin{array}{c}>=1 \\
\text { designed } \\
\text { specimen }\end{array}$ \\
\hline 10 & $\begin{array}{c}\text { The platform shall be able to break samples in all } \\
\text { loading conditions }\end{array}$ & $\begin{array}{l}\text { if it cannot do this, then the hexapod } \\
\text { cannot perform as it is meant to }\end{array}$ & $6 \mathrm{DOF}$ \\
\hline 12 & $\begin{array}{l}\text { Platform must be able to test multiple sized } \\
\text { specimens }\end{array}$ & $\begin{array}{c}\text { variability allows testing of the varying } \\
\text { designs of the additive manufacturing } \\
\text { world }\end{array}$ & $\begin{array}{c}>1 \\
\text { specimen }\end{array}$ \\
\hline 14.1 & Hexapod must fit through the lab door frame & goes against transporting easily & $80 " x 60 "$ \\
\hline 17 & $\begin{array}{l}\text { Design must be based on a Stewart-Gough } \\
\text { platform }\end{array}$ & $\begin{array}{l}\text { serial manipulators lack stiffness and } \\
\text { accuracy needed, other parallel } \\
\text { manipulators provide issues in degrees } \\
\text { of freedom and mechanics }\end{array}$ & $\begin{array}{l}1 \mathrm{SG} \\
\text { platform }\end{array}$ \\
\hline 18 & $\begin{array}{l}\text { The platform must be able to perform standard } \\
\text { tests }\end{array}$ & $\begin{array}{l}\text { would not function as intended if this is } \\
\text { not met }\end{array}$ & $>=3 \mathrm{DOF}$ \\
\hline 18.1 & hexapod must perform a standard tensile test & $\begin{array}{l}\text { would not function as intended if this is } \\
\text { not met }\end{array}$ & $\begin{array}{l}1 \text { tensile } \\
\text { test }\end{array}$ \\
\hline 18.2 & hexapod must perform a standard torsion test & $\begin{array}{l}\text { would not function as intended if this is } \\
\text { not met }\end{array}$ & $\begin{array}{l}1 \text { torsion } \\
\text { test }\end{array}$ \\
\hline 18.3 & hexapod must perform a standard bending test & $\begin{array}{l}\text { would not function as intended if this is } \\
\text { not met }\end{array}$ & $\begin{array}{l}1 \text { bending } \\
\text { test }\end{array}$ \\
\hline 18.4 & $\begin{array}{l}\text { hexapod must perform a combination of two or } \\
\text { more of the mentioned standard tests }\end{array}$ & $\begin{array}{l}\text { would not function as intended if this is } \\
\text { not met }\end{array}$ & $\begin{array}{l}>1 \\
\text { standard } \\
\text { tests }\end{array}$ \\
\hline 19 & $\begin{array}{l}\text { The gripping system must not interfere with full } \\
\text { field strain measurements }\end{array}$ & $\begin{array}{l}\text { hexapod would not work as intended } \\
\text { otherwise }\end{array}$ & $\begin{array}{l}1 \text { specimen } \\
\text { in } 360 \text { deg } \\
\text { view }\end{array}$ \\
\hline 20 & Device must perform repeatable tests & Would not function as intended & $>2$ tests \\
\hline 21 & $\begin{array}{c}\text { Must have a greater workspace than the CSM } \\
\text { design }\end{array}$ & $\begin{array}{l}\text { CSM design does not have have the } \\
\text { capability to do tests on the specimen } \\
\text { size indicated }\end{array}$ & \\
\hline 22 & Must provide a way to measure actuator stroke & To control the design & $\begin{array}{c}1 \\
\text { measuring } \\
\text { device }\end{array}$ \\
\hline
\end{tabular}




\subsubsection{Criteria}

This section shows a list of criteria set out for the problem statement. The goal here is to improve on the design further in a way that does not prevent a successful design if the requirement(s) are not met. Weights are applied to show the importance with 1 meaning the least important, 3 is the median, and 9 means a high desirability. 
Table 3.2: List of Criteria

\begin{tabular}{|c|c|c|c|c|}
\hline No. & Requirement & Weight & Justification & Target \\
\hline 1 & $\begin{array}{l}\text { Design Stewart } \\
\text { platform for low cost }\end{array}$ & 1 & $\begin{array}{l}\text { the lower the cost, while not } \\
\text { losing functionality, the } \\
\text { better it looks for companies } \\
\text { to use }\end{array}$ & $<\$ 36,000$ \\
\hline 2 & $\begin{array}{l}\text { Platform design should } \\
\text { be sufficient size based } \\
\text { on singularity analysis }\end{array}$ & 9 & $\begin{array}{l}\text { minimize singularities to } \\
\text { make sure performance does } \\
\text { not degrade on a pathway } \\
\text { after the specimen breaks }\end{array}$ & $\begin{array}{l}\text { top platform } \\
\text { smaller than bottom } \\
\text { platform }\end{array}$ \\
\hline 3 & $\begin{array}{l}\text { Should allow platform } \\
\text { to change kinematics }\end{array}$ & 9 & $\begin{array}{c}\text { if singularity is in the path, } \\
\text { this method can provide a } \\
\text { way to where there is no } \\
\text { singularity }\end{array}$ & $>1$ geometry setup \\
\hline 4 & $\begin{array}{l}\text { Should allow the } \\
\text { ability to change grips }\end{array}$ & 3 & $\begin{array}{l}\text { for special testing of unique } \\
\text { specimens }\end{array}$ & $\begin{array}{l}1 \text { set of removable } \\
\text { grips }\end{array}$ \\
\hline 8 & $\begin{array}{l}\text { Platform should be } \\
\text { easy to maintain }\end{array}$ & 3 & $\begin{array}{l}\text { minimal maintenance means } \\
\text { more time towards testing } \\
\text { and in a manufacturing, } \\
\text { environment means less } \\
\text { downtime }\end{array}$ & \\
\hline 8.1 & $\begin{array}{l}\text { platform should have } \\
\text { easy access to } \\
\text { electronics }\end{array}$ & 3 & $\begin{array}{l}\text { Testing can be done } \\
\text { efficiently }\end{array}$ & \\
\hline 8.2 & $\begin{array}{c}\text { Should minimize } \\
\text { needed maintenance } \\
\text { for components of the } \\
\text { platform }\end{array}$ & 3 & See 8 & \\
\hline 9 & $\begin{array}{l}\text { Loading specimen } \\
\text { should be easy as just } \\
\text { placing it in the grips }\end{array}$ & 3 & $\begin{array}{l}\text { more time spent setting up } \\
\text { the specimen takes time away } \\
\text { from testing, saves time in a } \\
\text { manufacturing environment }\end{array}$ & 3 steps \\
\hline 11 & $\begin{array}{l}\text { Platform should be } \\
\text { ergonomic such that } \\
\text { human use is } \\
\text { accounted for }\end{array}$ & 9 & $\begin{array}{c}\text { the easier to use, the less time } \\
\text { it takes for new people to } \\
\text { learn or experience users to } \\
\text { test }\end{array}$ & $\begin{array}{l}\text { no extraneous } \\
\text { activity needed }\end{array}$ \\
\hline 13 & $\begin{array}{c}\text { Device should be easy } \\
\text { to transport }\end{array}$ & 3 & $\begin{array}{l}\text { In case machine needs to be } \\
\text { moved }\end{array}$ & 2 people minimum \\
\hline 14 & $\begin{array}{l}\text { Parts should not } \\
\text { exceed } 30 \mathrm{lbs} \text {. } \\
\text { individually }\end{array}$ & 3 & $\begin{array}{l}\text { easy transport to the lab and } \\
\text { easy transport in the future }\end{array}$ & $30 \mathrm{lbs}$. \\
\hline 15 & $\begin{array}{l}\text { Device should be able } \\
\text { to function with at least } \\
\text { one user }\end{array}$ & 3 & $\begin{array}{l}\text { less manpower if only one } \\
\text { person can use it }\end{array}$ & 1 user \\
\hline 16 & $\begin{array}{l}\text { Device should be } \\
\text { designed for minimum } \\
\text { construction difficulty }\end{array}$ & 9 & $\begin{array}{l}\text { easy to take apart for } \\
\text { maintenance, transporting, } \\
\text { easy for machinists }\end{array}$ & \\
\hline
\end{tabular}




\subsection{Overview of Design}

This section provides the details of the final design. The design is split into assembly sections: actuator, camera, top frame, bottom frame, and top platform. Figure 3.1 shows the solution.

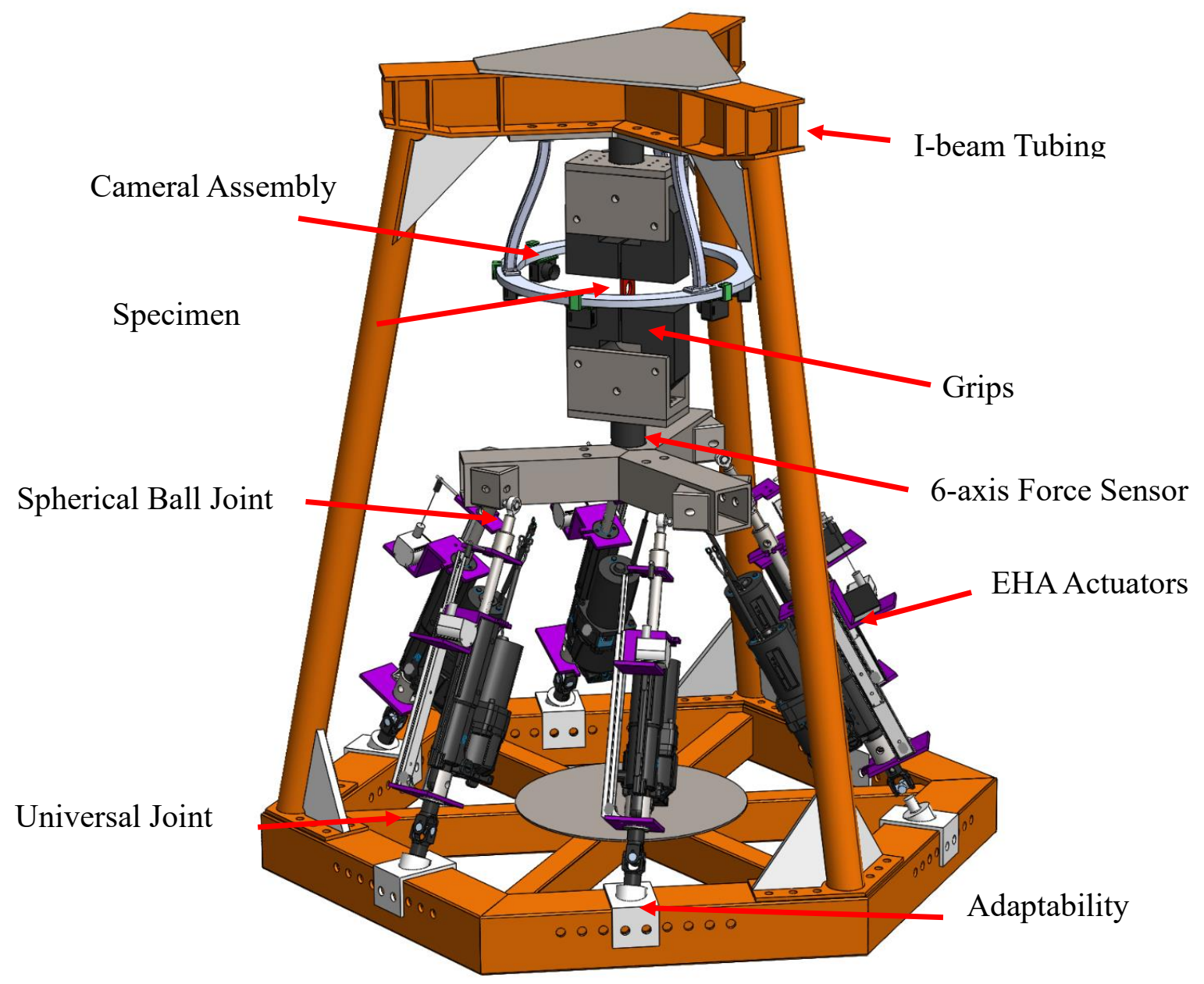

Figure 3.1: Solution 
Looking at Figure 3.1, one noticeable difference between this solution and that of the CSM design is that the location of the specimen is above the moving platform rather than in between the moving platform and the bottom platform. Inverting the location allows a greater workspace when doing pure bending scenarios. The bottom spherical joint that the CSM design contains has been replaced with a universal joint to eliminate the extra degree of freedom. This extra degree of freedom allows the actuators to rotate about the cylinder rod. This improves on the performance as compared to the CSM design (requirement 21). Electrohydraulic actuators (EHA) where chosen and were a significant improvement over the CSM actuators (requirements $18-18.4 \& 21$ ). Adaptability refers to the ability to move the location of the universal joints, pertaining to requirement 3 .

\subsubsection{EHA Actuators}

New actuators needed to be chosen as the original choice of CSM design did not have enough stroke to account for the compliance of polymers of AM materials. While the PC series of linear actuators of Thomson Linear, the compact EHA (Electro-hydraulic actuator) model from Parker was chosen due to the load capacity being four times the value of the PC 40 [28]. It was also chosen because the motor is included and there is no need for a setup of hydraulic hoses. All of this improves on the performance and increases the workspace (requirements 18-18.4 \& 21). 


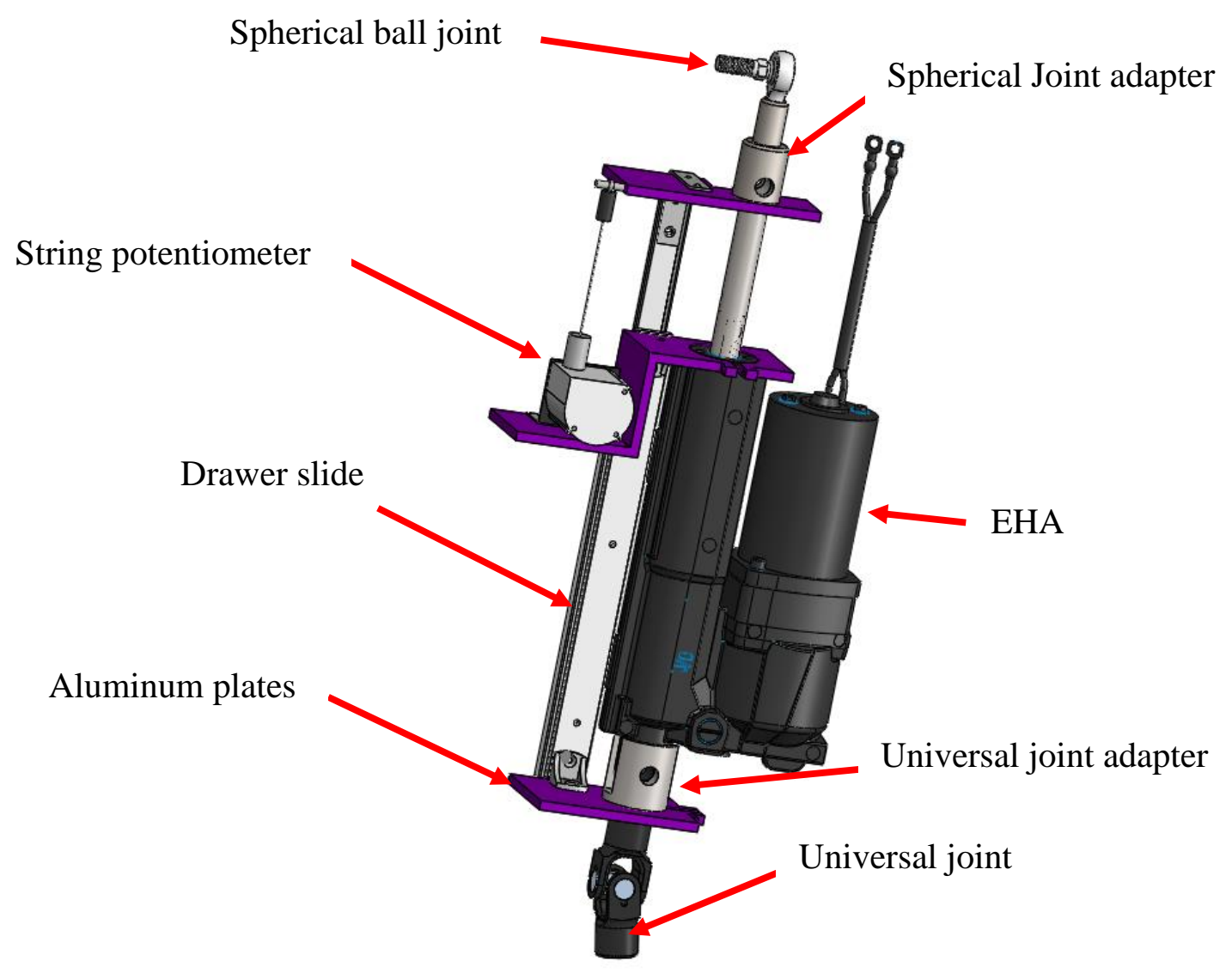

Figure 3.2. Actuator Assembly.

The actuator assembly, Figure 3.2 consists of the spherical ball joint, the aluminum plates, the spherical joint adapter, the string potentiometer, the drawer slide, the universal joint adapter, and the universal joint. The aluminum plates' purpose is to keep the cylinder rod of the EHA actuator from rotating along the cylinder rod axis. The plates are clamped to the actuator with the LMPMT attached on the middle plate so the actuator stroke can be measured (requirement 22). The LMPMT has a stroke of 12.5 in $(317.5 \mathrm{~mm})$ which accounts for the $203 \mathrm{~mm}$ stroke of the actuators. The load capacity of the chosen ball joint is $10,250 \mathrm{lbs}$. in the static radial direction, and it has a max swivel angle of $50^{\circ}$. 


\subsubsection{Bottom Frame}

The bottom frame assembly, shown in Figure 3.3, consists of the tubing frame, the actuator adapter, and the leveling mounts. Additional mounting holes were implemented to change the workspace and therefore the singularity map to accommodate for the path planning for the specimen.

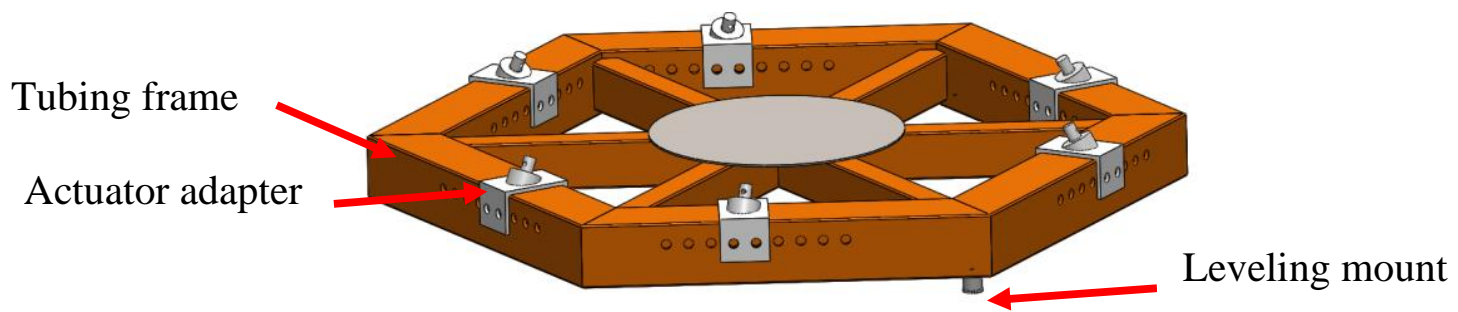

Figure 3.3: Bottom frame assembly

\subsubsection{Top Frame}

In-plane bending, and in-plane shear was determined to be the testing scenarios with the highest loads. To account for this, the I-beam design was used with the addition of gussets. The angled plate at the end of the I-beam was removed and the original straight portion of the I-beam was kept as strength is lost in the I-beam if an angled cut was implemented and welded. 


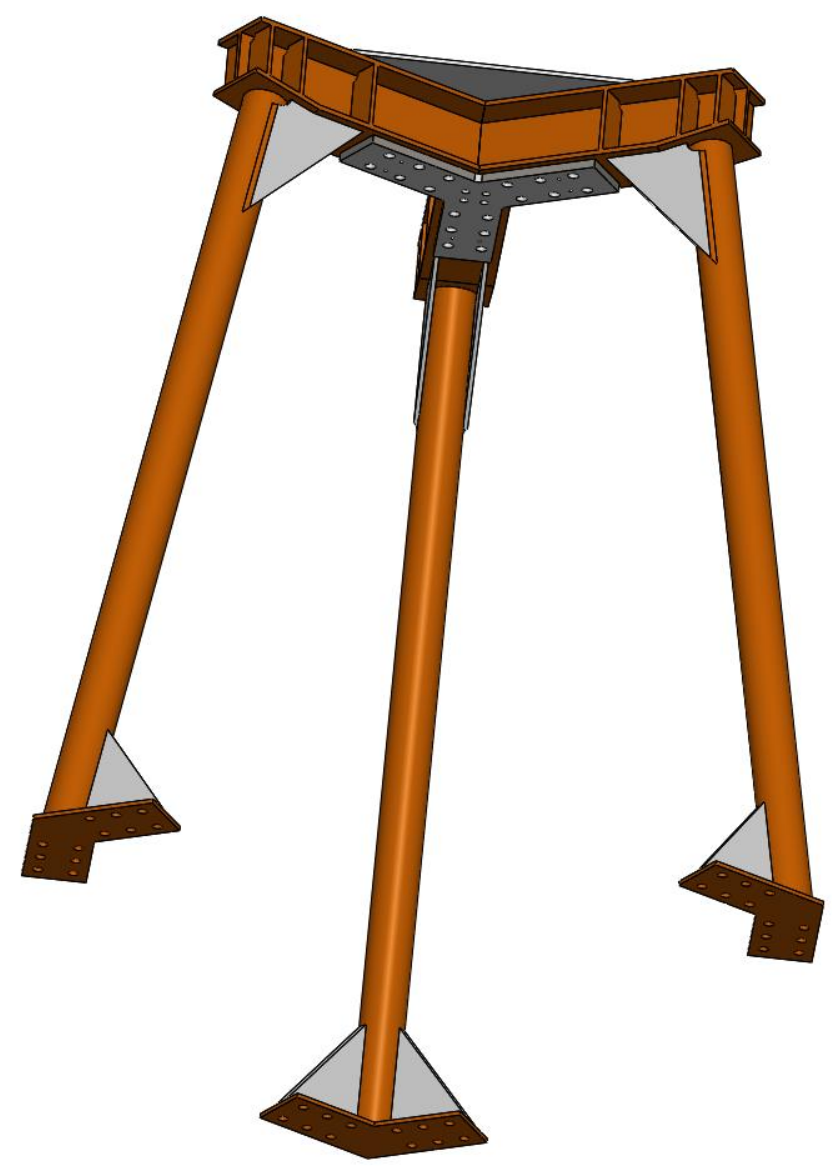

Figure 3.4: Top frame assembly

\subsubsection{Grip Assembly}

The grip assembly consists of the top frame adapter, the grip adapters, the grips, 6-DOF sensor (bottom black), and the adapter from the sensor to the top frame. Figure 3.5 shows the grip assembly. This setup bolts to the top frame and the moving platform via bolts. This allows new grips to be designed and allows adapters to be designed that allow testing of non-traditional test specimens (requirements 4, 5, 12). 


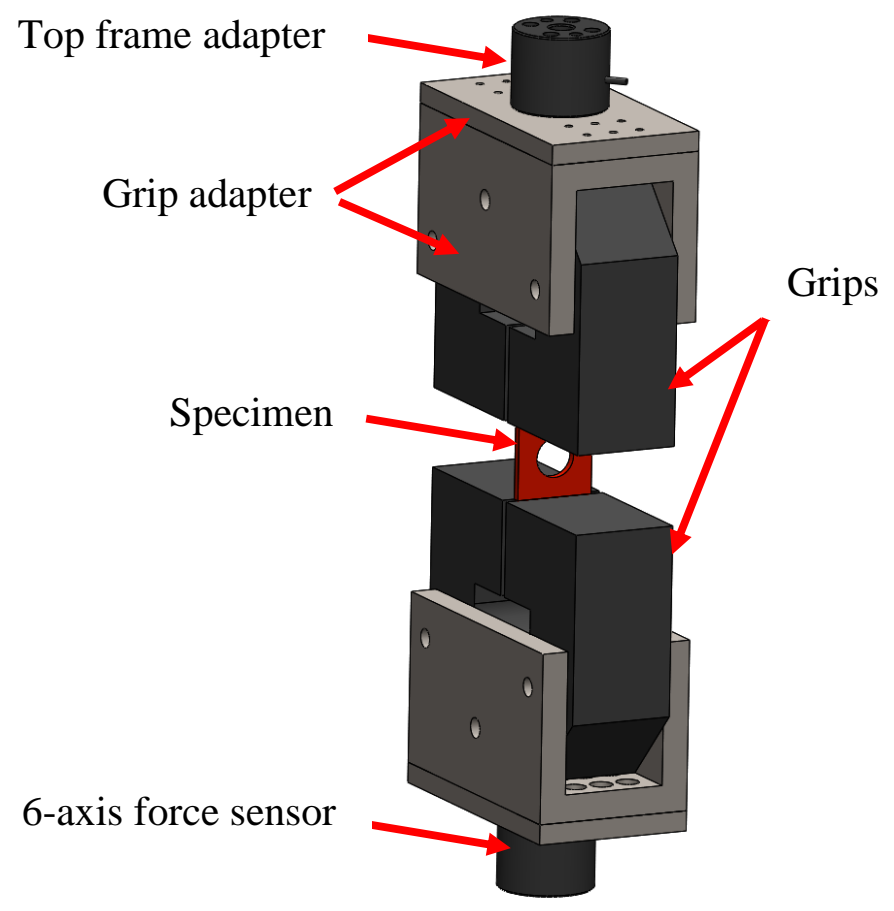

Figure 3.5: Grip assembly

\subsubsection{Camera Setup}

The camera assembly involves a NOGA heavy duty holder with a magnetic base to attach to the grips or the adapters, 3D printed adapters, and the Chameleon3 cameras. Initially, 4 cameras will be used until more are needed. More may be needed to address camera singularities with the full field strain measurements involved with compliant materials. The adapters allow two cameras to be mounted and adjusted via the 2 NOGA holders to adjust the angle at which the cameral is oriented to the face of the specimen. This setup allows the cameras to be attached to any position and to be adjusted accordingly. The camera system has not been implemented and will not be until the future work (Section 5.5). Figure 3.6 shows the NOGA holder. 


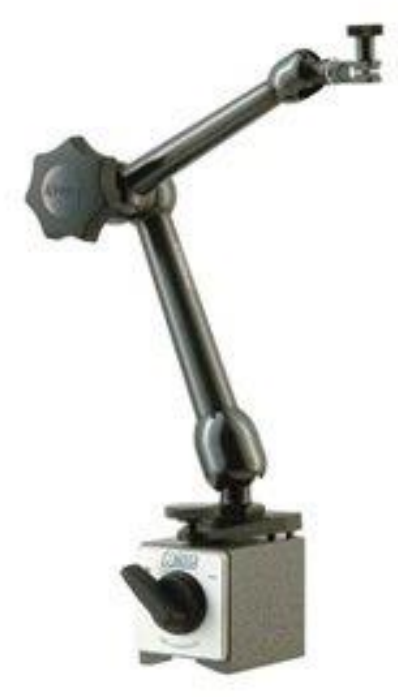

Figure 3.6: NOGA holder.

\subsubsection{Top Platform}

Shown in Figure 3.7, the top platform assembly consists of two parts, the actuator adapters (prism) and the tubing. The actuator adapter attaches to the spherical ball joint and the top platform connects to the adapter underneath the 6-axis force sensor. FEA results are shown in Section 4.7.

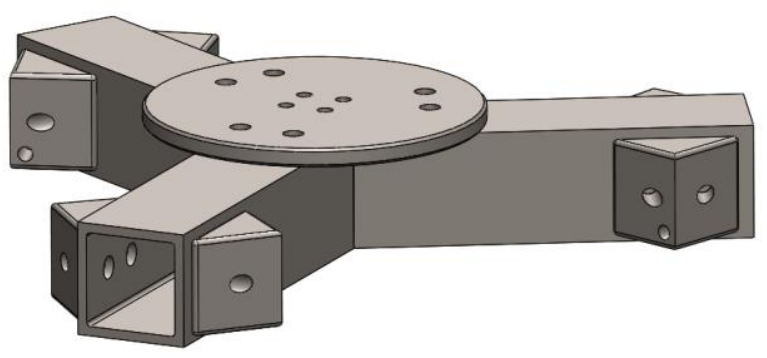

Figure 3.7: Top platform assembly 


\subsection{Hexapod Workspace}

The start of this research involved an analysis on the validity of the previously developed design (see Section 2.4.1). The analysis determined that the workspace of the CSM design was not large enough for testing of compliant materials and a new design was needed with a greater workspace (requirement 21). Note that the data shown on the graphs are data points and not continuous lines.

\subsubsection{Translation}

While it is unknown what the specimen designs will be and the failure behavior of tests with different additive manufacturing materials, especially polymers, a constraint was set in which the new design must have an increased workspace volume. As a reminder, workspace in this case is defined as the volumetric space in which the centroid of the hexapod can reach. 


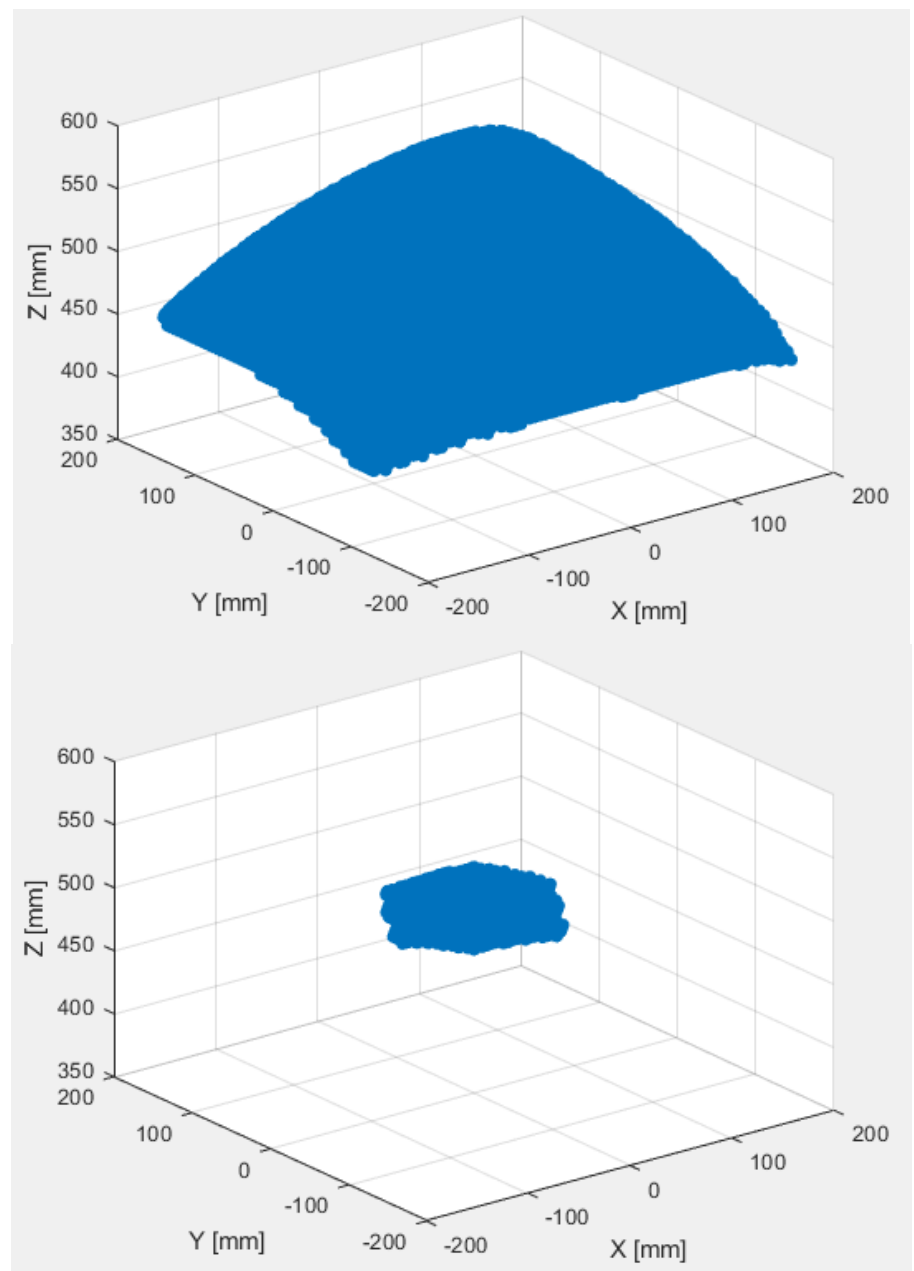

Figure 3.8: Workspace comparison, CSM (bottom) and 66.1 Tiger (top)

Figure 3.8 shows the difference between the reachable workspace of the CSM design versus the new design, the 66.1 Tiger. The 66.1 Tiger has a much wider range with translation in the $\mathrm{x}, \mathrm{y}$, and $\mathrm{z}$ directions. 


\subsubsection{Rotation}
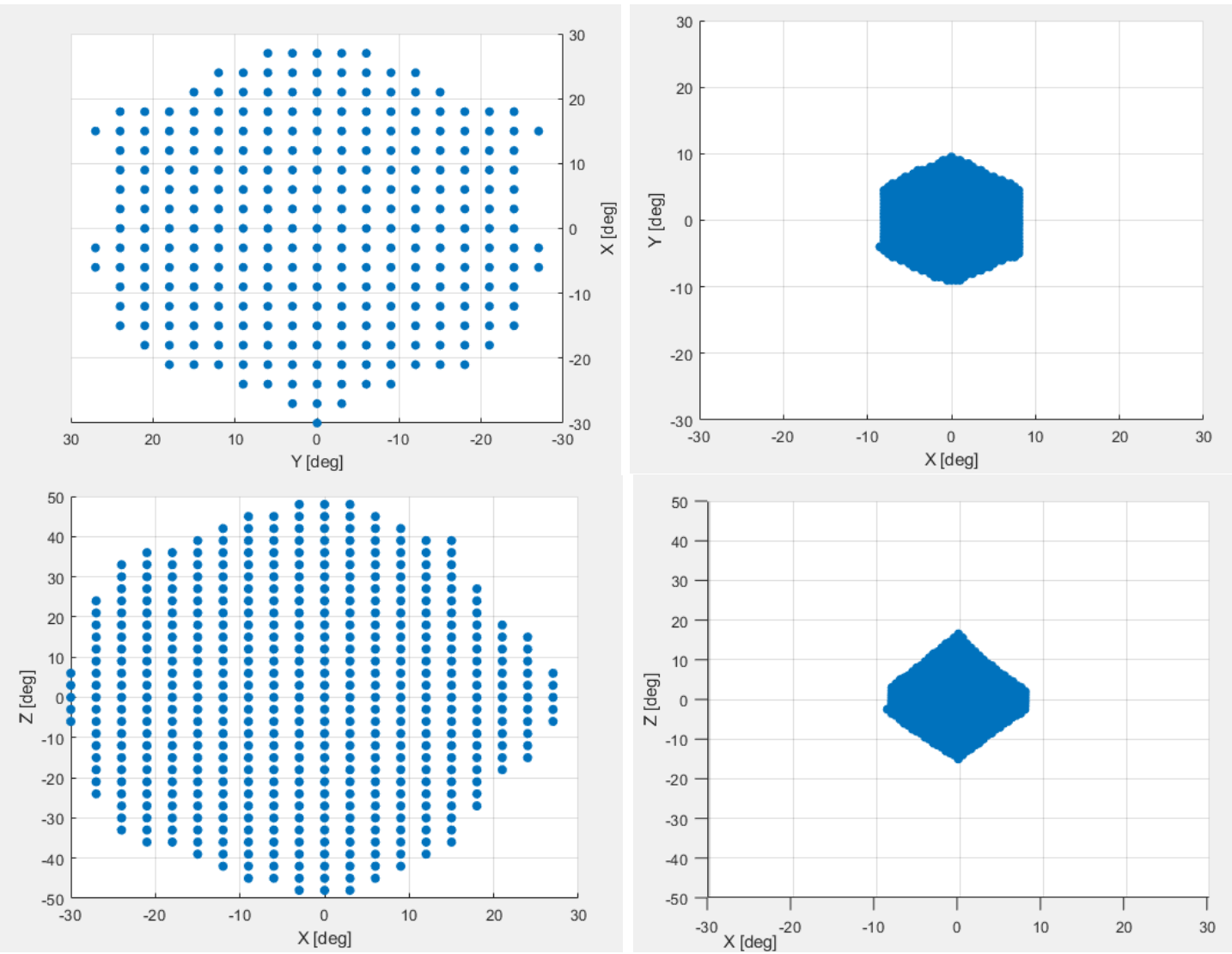

Figure 3.9 shows the rotation only comparison between the two designs with the clear indication of improvement with the new design. There is a drastic difference between the purely rotational workspace. Purely rotation in this case means rotation about the origin point of the top platform of the hexapod. 

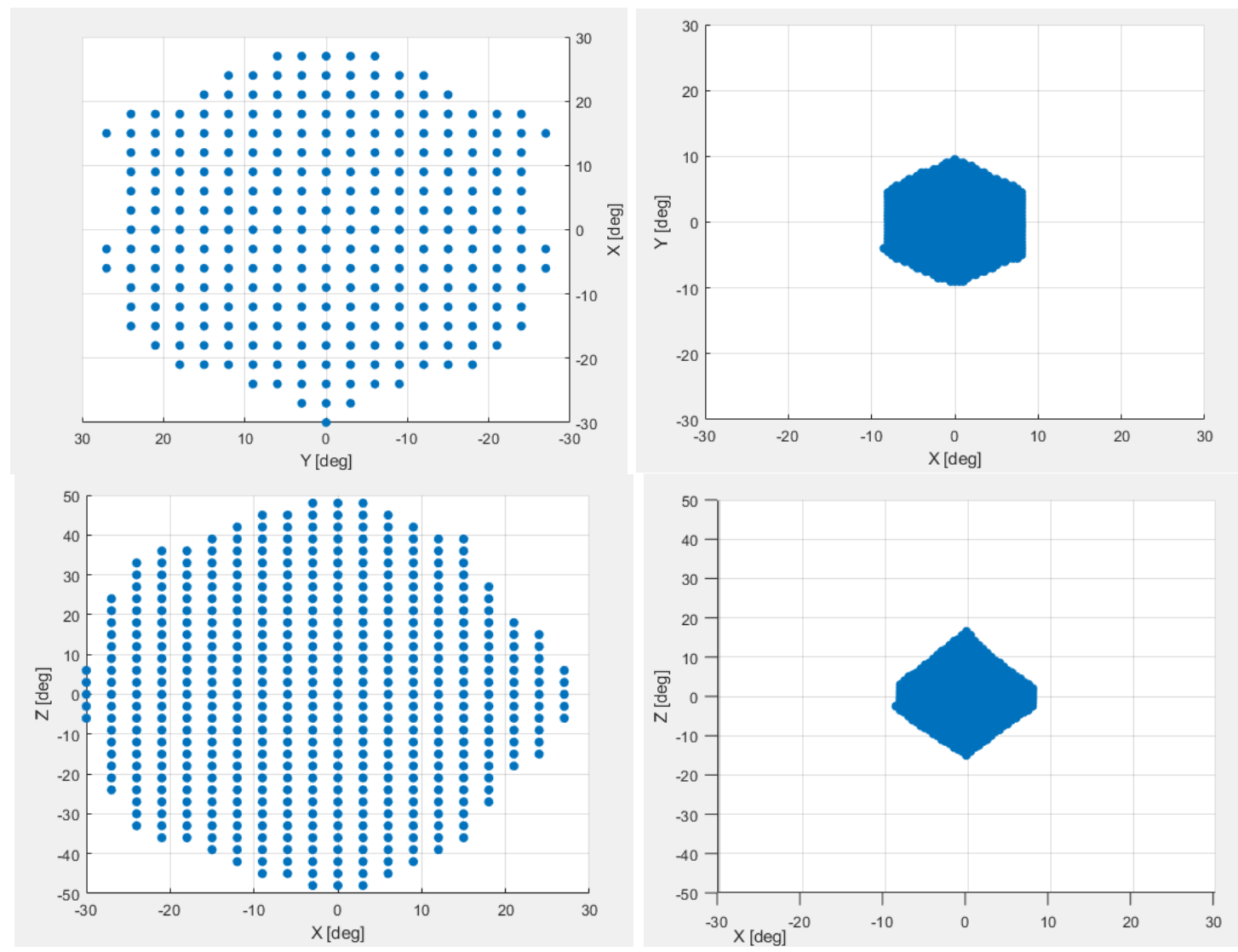

Figure 3.9: Rotation only comparison, 66.1 Tiger (left) and CSM (right).

One other comparison to look at with the reachable workspace involves pure bending loading tests as shown in Figure 3.9. The max angles the 66.1 Tiger can reach are roughly 50 degrees in the $\mathrm{Z}$ direction and 28 degrees in the $\mathrm{X}$ and $\mathrm{Y}$ direction. It can be noted that in torsion tests, the hexapod can reach a total of $100^{\circ}$ by pre-loading in the negative direction (or positive) and starting the test from there. 


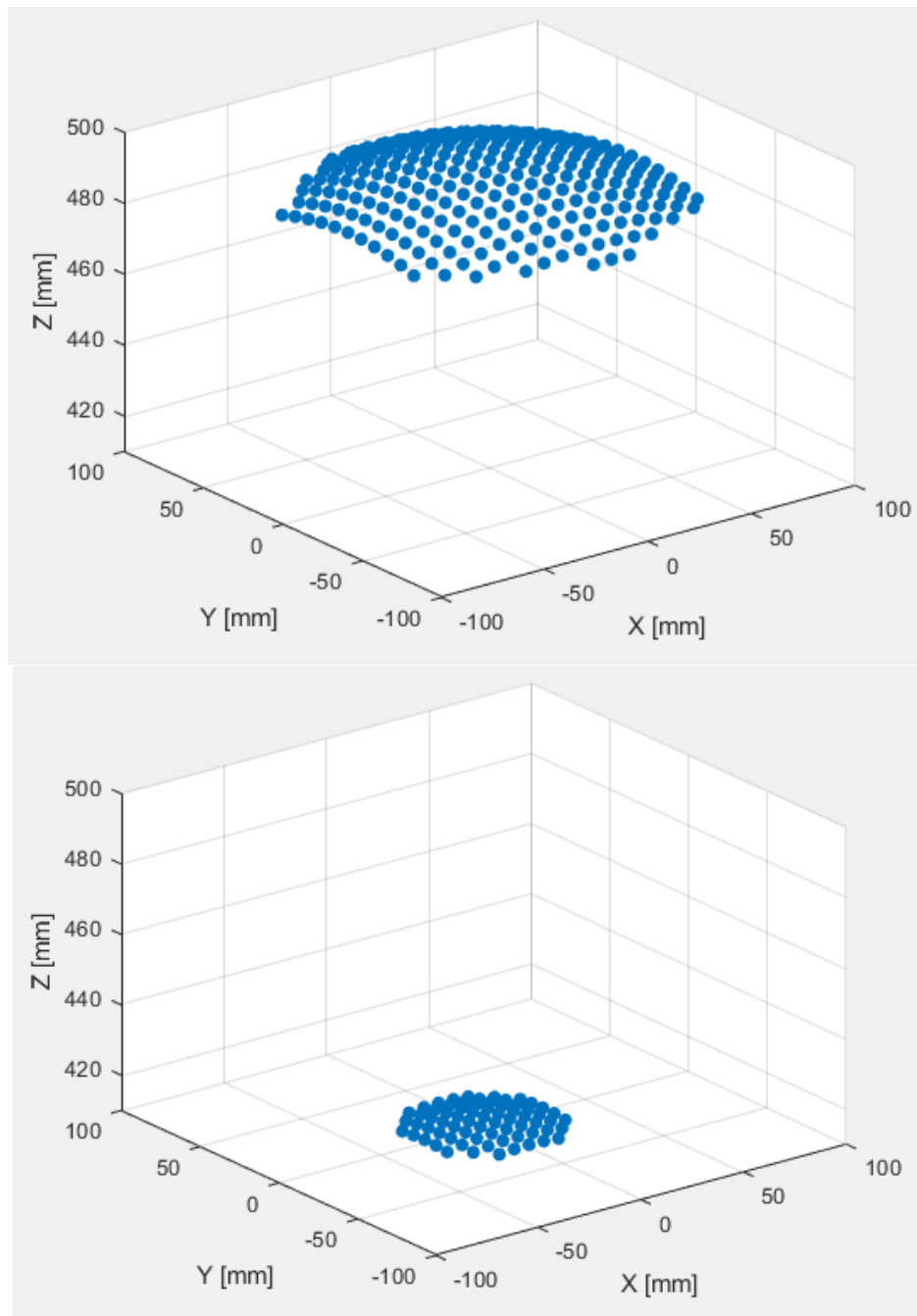

Figure 3.10: Pure bending comparison, 66.1 Tiger (top) and CSM (bottom).

Figure 3.11 shows the difference of the reachable workspace in a pure bending scenario (requirement 23) of a tradition hexapod material characterization setup like that of the NRL 66.3 in Figure 2.5. The tradition setup results in a max of $85 \mathrm{~mm}$ in the $\mathrm{x}$ direction and 72 $\mathrm{mm}$ in the y direction. The inverted setup, which is shown in Figure 3.1, has a max of 116 $\mathrm{mm}$ in the $\mathrm{x}$ direction and 131 in the $\mathrm{y}$ direction. 

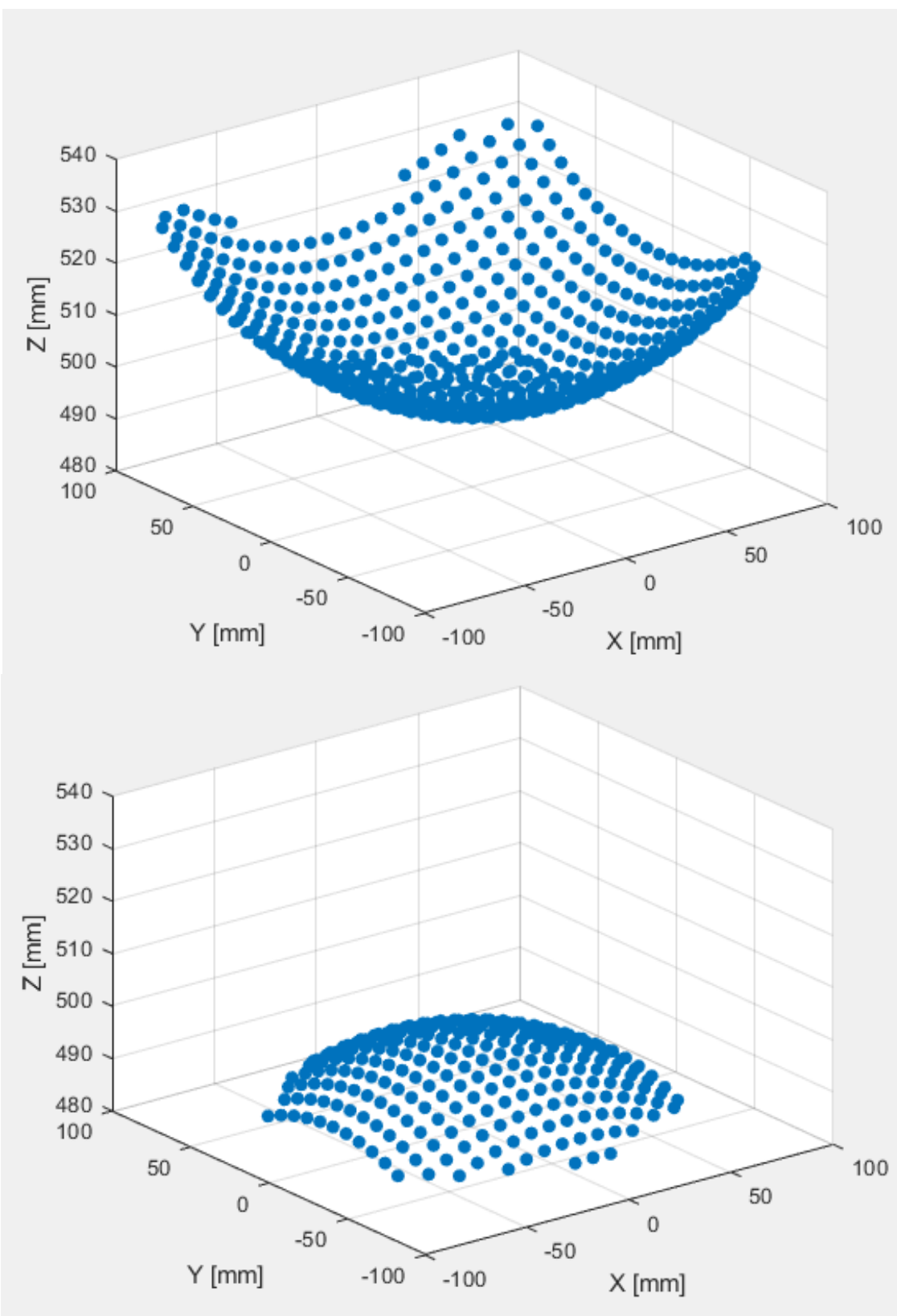

Figure 3.11: Difference between the traditional hexapod setup and the inverted hexapod setup. 


\subsection{Component Details}

While the major sub-assemblies have been identified in the previous sections, this section goes over the components of the major assemblies that contain sensors and other electronics. These directly relate to the performance requirements (requirements 10, 12, $15,18-18.4,20,22)$.

\subsubsection{Camera Assembly}

Going from top to bottom, the first component are the cameras. The camera chosen is the Chameleon 3 model. Table 3.3 shows the specifications of the camera along with the specific model number.

\section{Table 3.3: Camera Specs}

$\begin{array}{cc}\text { Model \# } & \text { CM3-U3-13Y3C-CS } \\ \text { Type } & \text { Color } \\ \text { MP } & 1.3 \\ \text { Sensor Description } & \text { ON Semi PYTHON } 1300 \text { CMOS, } 1 / 2 ", 4.8 \mu \mathrm{m} \\ \text { Shutter } & \text { Global Shutter } \\ \text { Max Resolution } & 1280 \times 1024 \\ \text { Max FPS } & 149\end{array}$

\subsubsection{Grip Assembly}

Included in the components of the grip assembly are the grips and the 6-axis force/torque sensor, in which the grips are from ADMET and Sunrise Instruments respectively. The ADMET grips are of the GV-50T model with the specifications in Table 3.4 . 
Table 3.4: Grip Specifications

$\begin{array}{cc}\text { Tensile Force } & 50 \mathrm{kN} \\ \text { Opening } & 0-30 \mathrm{~mm} \\ \text { Clamping Surface Size } & 60 \times 66 \mathrm{~mm} \\ \text { Clamping Surface } & \text { Plain/Flat }\end{array}$

The 6-axis force/torque sensor chosen includes the specs in Table 3.5. This sensor was chosen due to the load capacity, pricing, and size. The data sheet for the sensor is in Appendix E.

Table 3.5: Force/Torque Sensor Specifications

Capacity

$\begin{array}{rccc}\mathbf{F}_{\mathbf{x}}, \mathbf{F}_{\mathbf{y}} & \mathbf{F}_{\mathbf{z}} & \mathbf{M}_{\mathbf{x}}, \mathbf{M}_{\mathbf{y}} & \mathbf{M}_{\mathbf{z}} \\ 16.2 \mathrm{kN} & 32.4 \mathrm{kN} & 660 \mathrm{Nm} & 530 \mathrm{Nm}\end{array}$

\subsubsection{Actuator Assembly}

The actuator assembly includes two total components: actuator and linear transducer. Specific models include Compact EHA (Electro-Hydraulic Actuator), and the LMPMT (Linear Motion Position-Measuring Transmitters). The actuators were chosen due to the load rating, compact size, and the stroke availability. The LMPMT was chosen due to the price and the avoidance of an actuator-like transducer. Mounting a linear transducer on the actuator required a more complex design for mounting clamps. Data for the actuator and transmitter are shown in Table 3.6 and Table 3.7 respectively. The datasheet for the actuators can be found in Appendix E. 
Table 3.6: Actuator Specifications

$\begin{array}{ccc}\text { Force } & \text { Max Stroke } & \text { Max Speed } \\ 21.3 \mathrm{kN} & 203 \mathrm{~mm} & 85 \mathrm{~mm} / \mathrm{s}\end{array}$

3.

Table 3.7: LMPMT Specifications

\begin{tabular}{|c|c|c|c|c|}
\hline Stroke & $\begin{array}{c}\text { Accuracy } \\
\text { Range }\end{array}$ & Repeatability & Resolution & $\begin{array}{c}\text { Cable } \\
\text { Material }\end{array}$ \\
\hline $12.5 \mathrm{in}$ & $\pm 0.25 \%$ & $\pm 0.05 \%$ & $0.0001 \mathrm{mV}$ & $\begin{array}{c}\text { Nylon- } \\
\text { coated } \\
\text { Stainless } \\
\text { Steel }\end{array}$ \\
\hline
\end{tabular}

\subsubsection{Data Acquisition}

Included in the data acquisition is the DAQ card, motor controller, Arduino Due, and the specs of the computer that will be used to control and collect the data. The motor controller chosen is the RoboteQ FDL3260 and the datasheet is in Appendix E. This controller can control three brushless DC motors or in this case, three actuators. This requires two controllers total. Both controllers are connected to an Arduino Due to be controlled using Arduino coding and an Intel NUC with the specifications in Table 3.8. 
Table 3.8: Computer Specifications

$\begin{array}{ccccc}\text { Processor } & \text { RAM } & \text { Memory Speed } & \text { Hard Drive } & \begin{array}{c}\text { Graphics } \\ \text { Card }\end{array} \\ \text { Intel Core i7 } & 32 \mathrm{~GB} & 3.1 \mathrm{GHz} & 128 \mathrm{~GB} \text { SSD } & \begin{array}{c}\text { AMD Radeon } \\ \text { RX Vega M } \\ \text { GH }\end{array}\end{array}$

The DAQ system consists of an Arduino Due where each string potentiometer will be connected to two ADS1115's since one can only read for sensors at a time. The data sheet of the Arduino Due and ADS1115 are in Appendix E and Appendix F respectively. The string potentiometers need 30 volts to have enough power for more accurate results. The Arduino 5-volt supply is not enough. Since the ADS1115 can only except up to 5 volts due to the power it receives from the Arduino Due, a voltage divider is provided between the output of the string potentiometers and the ADS1115. The code to control the hexapod is shown in Appendix G:. 


\section{CHAPTER 4: DESIGN JUSTIFICATION}

This chapter focuses on the justification for design choices for the detailed design of the robotic test frame. The constraints and criteria are laid out and discussed on what was met, what will be verified in future work, and what requirements were not met. The actuators, FEA results, workspace results, the singularity analysis, sensors, and data collection all contribute to the satisfaction of the set requirements, see PDS in Appendix A. Table 4.1 shows the specific constraints that were met, and Table 4.2 shows the results of the criteria. In summation, this section discusses the requirements and how the driving requirements were met.

\subsection{Constraints}

This section goes over the constraints, or the needs, of the design. The constraints that were met are presented in Table 4.1, and the full requirement format is presented in Appendix A. 
Table 4.1: Constraints Status.

\begin{tabular}{|c|c|}
\hline No. & Requirement \\
\hline 5 & Must allow for adjustments in stationary grip placement \\
\hline 6 & Design platform to have extra degrees of freedom \\
\hline 7 & Design platform to test 3D printed metal specimens \\
\hline 10 & The platform shall be able to break samples in all loading conditions \\
\hline 12 & Platform must be able to test multiple sized specimens \\
\hline 14.1 & Hexapod must fit through the lab door frame \\
\hline 17 & Design must be based on a Stewart-Gough platform \\
\hline 18 & The platform must be able to perform standard tests \\
\hline 18.1 & hexapod must perform a standard tensile test \\
\hline 18.2 & hexapod must perform a standard torsion test \\
\hline 18.3 & hexapod must perform a standard bending test \\
\hline 18.4 & $\begin{array}{l}\text { hexapod must perform a combination of two or more of the mentioned } \\
\text { standard tests }\end{array}$ \\
\hline 19 & The gripping system must not interfere with full field strain measurements \\
\hline 20 & Device must perform repeatable tests \\
\hline 21 & Must have a greater workspace than the CSM design \\
\hline 22 & Must provide a way to measure actuator stroke \\
\hline
\end{tabular}

Requirement 5 was met with the ability to change the location of the universal joints, or the bottom joints of the actuator assemblies. Requirement 6 was determined by the uniqueness that additive manufacturing to designs. Allowing the possibility of adding more degrees of freedom down the road will allow testing of significantly compliant materials 
that the hexapod could not test with the given workspace. This is possible with having the grip assemblies to be taken apart or taken off. Requirement 7 deals with the possibility of testing metal AM parts. While the focus of this design is for polymers, AM deals with metals as well and it is becoming more and more popular. This was determined to be a constraint and has been met by the FEA of the design (Section 4.3) and testing (Section 5.4). Requirements $10,12,14.1,17-18.4,19,20$, and 21 all deal with simply testing if the requirement is met or not. Requirements $12,17-18.4$ all deal with basic functionality and research conducted at the start of this work. Requirement 19 is meant to make sure the full field strain measurement with the 4 cameras can be completed without obstruction and has been met.

The requirements presented in this section are those that allow for a successful testing machine. This work includes up to the ability of the platform to move and be cable of coordinated movement shown by simple tests. Section 5.4.1 provides more detail.

\section{2 $\underline{\text { Criteria }}$}

This section discusses the criteria or wants of the design. Table 4.2 presents the criteria that are met, not met, and the criteria that require validation before it is determined if it is met or not. Requirements that were met are labeled green, and the requirements that were not met are labeled in red. 
Table 4.2: Criteria that are met/not met

\begin{tabular}{|c|c|c|c|}
\hline No. & Requirement & Weight & \\
\hline 1 & Design Stewart platform for low cost & 1 \\
\hline 2 & Platform design should be sufficient size based on singularity analysis & 9 & 9 \\
\hline 3 & Should allow platform to change kinematics & 3 \\
\hline 4 & Should allow the ability to change grips & 3 & \\
\hline 8 & Platform should be easy to maintain & 3 \\
\hline 8.1 & platform should have easy access to electronics & 3 \\
\hline 8.2 & Should minimize needed maintenance for components of the platform & 3 \\
\hline 9 & Loading specimen should be easy as just placing it in the grips & 3 & \\
\hline 11 & Platform should be ergonomic such that human use is accounted for & 9 & \\
\hline 13 & Device should be easy to transport & 3 & \\
\hline 14 & Parts should not exceed 30 lbs. individually & 3 & \\
\hline 15 & Device should be able to function with at least one user & 3 & \\
\hline 16 & Device should be designed for minimum construction difficulty & 9 \\
\hline
\end{tabular}

Requirement 1 was met by the significant price drop of developing a hexapod. The CSM design was estimated at $\$ 36,000$ while this design falls around $\$ 25,000$. Requirement 2 was met by the singularity analysis in Appendix I.. It was determined that a top platform that has a bigger radius performs better and with the singularity analysis of the normalized Jacobian, the ratio of top platform vs bottom platform was determined. Requirement 3 was met by adding the ability to move the universal joints on the designated bolt locations on the bottom frame in Figure 3.1. 


\subsection{FEA Results}

This section presents the deflection and FEA results of the top frame and the bottom frame of the SG platform design. The directions of the forces are indicated by the purple arrows shown in the respective figures and the fixed geometries are indicated by green and orange arrows. All FEA results were conducted using with the force values found in Section 3.3 for 6061-T6. For each analysis, an h-adaptive method was used with a target accuracy of $98 \%$, accuracy bias in the middle, and a maximum number of loops of 5 for the mesh adaptation. The factor of safety (FOS) for the frame analyses are taken as the yield strength over the maximum load in which all analyses have the FOS well above a reasonable amount.

\subsubsection{Top Frame FEA}

The final top frame FEA results are depicted in Figure 4.1. It can be noted that there are no stress concentrations and the stresses stay well below the yield stress of the material used, which is 4130 steel, and results in a safety factor of 7 . The gussets were added to reduce the deflection and avoid stress concentrations around the connection of the legs and I-beams and the bottom portion of the legs connecting to the bottom frame. To account for the cylinder and grips, a straight cylinder was extruded from the bottom of the I-beams. For bending and torsion scenarios, a reference axis is added so that the bottom of the cylinder can rotate about the axis. Table 4.3 shows the deflection results of the final design. 
Table 4.3: Deflection results for top frame

\section{Scenario}

Shear

Tensile

Moment (Z)

Moment (X)

Moment (Y)
Deflection (mm)

0.3453

0.3305

0.001335

0.007857

N/A
Force/Moment

$3000 \mathrm{~N}$

$30000 \mathrm{~N}$

$30 \mathrm{Nm}$

$100 \mathrm{Nm}$

$25 \mathrm{Nm}$
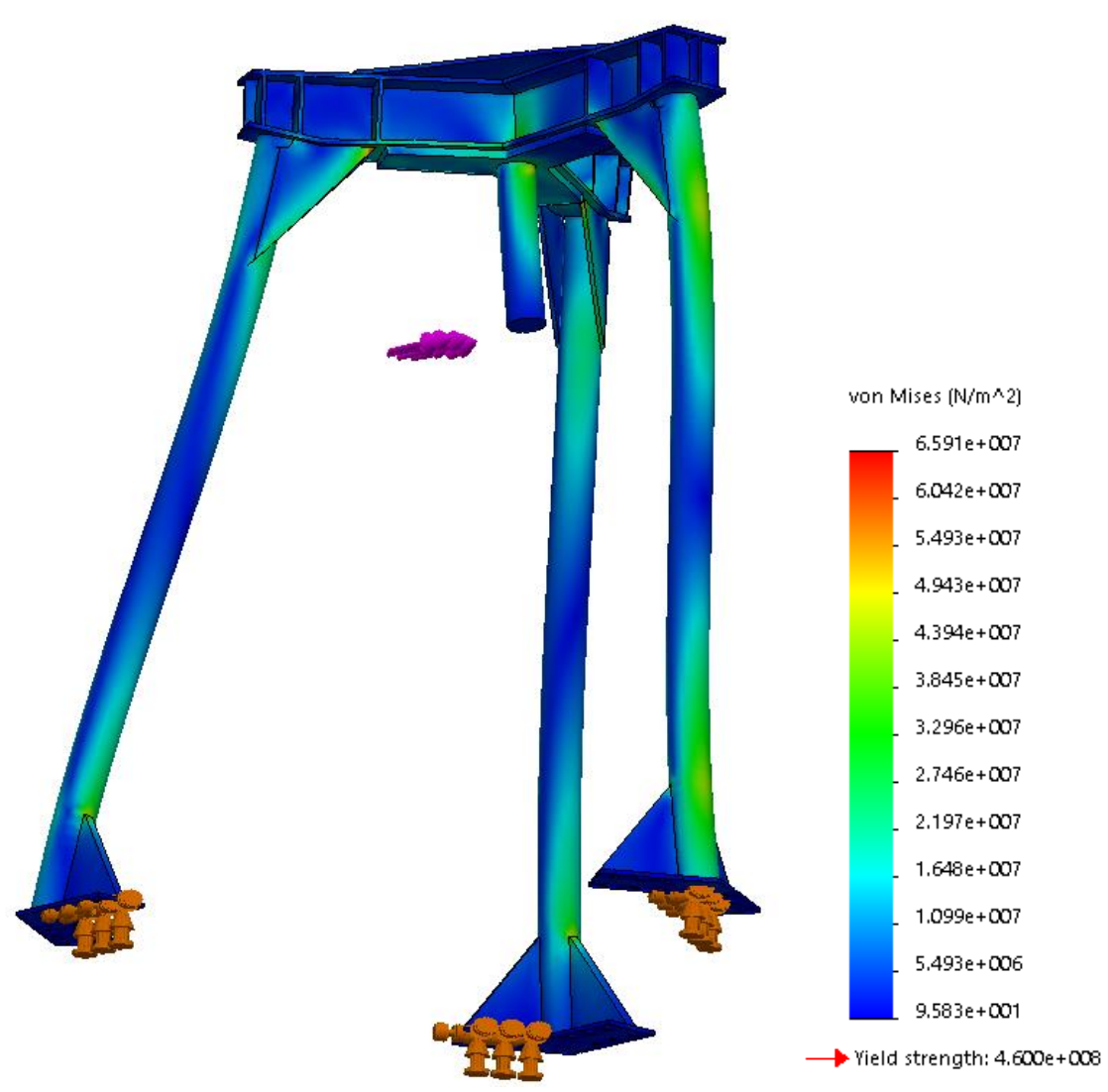

Figure 4.1: FEA of top frame $(\mathrm{FOS}=7)$ 


\subsubsection{Bottom Frame FEA}

The final bottom frame FEA is shown in Figure 4.2. Most of the stress is located around the joint locations and the area where the top frame connects. The adapters to the actuators are included so that the forces acting on the actuators can be applied to the correct direction. The actuator forces required are calculated using the force equation for a general SG platform [14]. The high deflection is in the bottom frame for the shear loading scenario in Table 4.4: Deflection results for bottom frame.

Table 4.4: Deflection results for bottom frame

\begin{tabular}{|c|c|c|}
\hline Scenario & Deflection (mm) & Force/Moment \\
\hline Shear & 3.671 & $3000 \mathrm{~N}$ \\
\hline Tensile & 0.502 & $30000 \mathrm{~N}$ \\
\hline Moment (Z) & N/A & $30 \mathrm{Nm}$ \\
\hline Moment (X) & 0.00905 & $100 \mathrm{Nm}$ \\
\hline Moment (Y) & N/A & 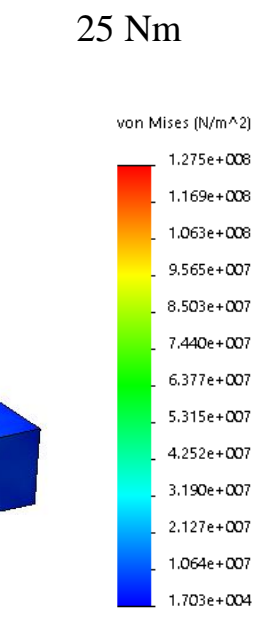 \\
\hline
\end{tabular}

Figure 4.2: FEA of bottom frame $(\mathrm{FOS}=3.6)$ 


\subsubsection{Top Plate FEA}

The final top plate FEA is shown in Figure 4.3: FEA of top plate $(\mathrm{FOS}=1.7)$ in which the factor of safety is 1.7 , and the maximum deflections are indicated in Table 4.5. For results that were significantly small, the result was given N/A. The same procedure applied in Section 4.3.2 also was used for the top plate FEA in this section. The forces for each actuator were determined as well as the direction in which the force is applied.

Table 4.5: Deflection results for top plate

$\begin{array}{ccc}\text { Scenario } & \text { Deflection }(\mathbf{m m}) & \text { Force/Moment } \\ \text { Shear } & 0.3517 & 3000 \mathrm{~N} \\ \text { Tensile } & 0.1798 & 30000 \mathrm{~N} \\ \text { Moment }(Z) & \text { N/A } & 30 \mathrm{Nm} \\ \text { Moment (X) } & \text { N/A } & 100 \mathrm{Nm} \\ \text { Moment (Y) } & \text { N/A } & 25 \mathrm{Nm} \\ 4 . & & \end{array}$




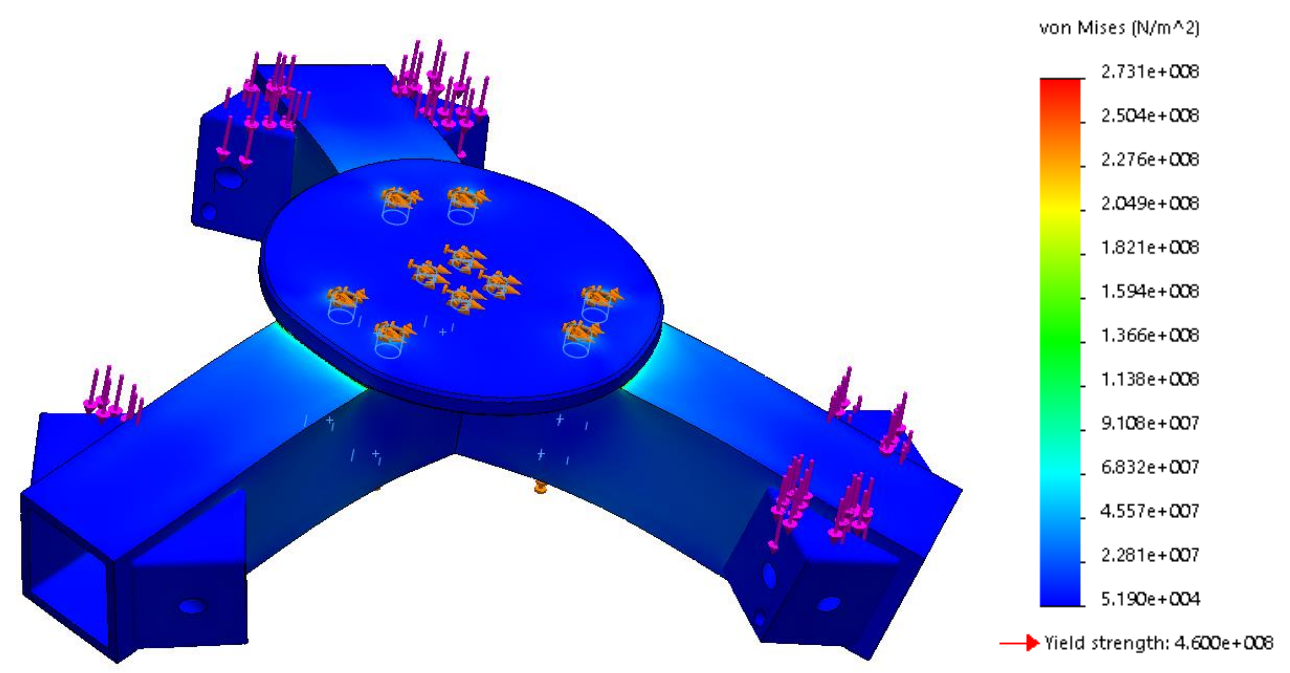

Figure 4.3: FEA of top plate $(\mathrm{FOS}=1.7)$

\subsection{CSM vs. 66.1 Tiger Singularity Map}

Based on the work done in Appendix I:, the singularity map was applied to the CSM design and the 66.1 Tiger. Pure translation (Figure 4.4), and pure rotation (Figure 4.5) were looked at for comparison. There is a significant difference between the two designs. For the CSM design, the condition numbers for pure translation were all considerably higher than the 66.1 Tiger with values in $10^{18}$ and above. The values for the 66.1 Tiger all fall below 1,100. The MATLAB results for the CSM design also gave warnings that the Jacobian matrices were often close to being singular. This correlates with the review from NRL in Section 2.1 and the statement from the authors of [14] about singularities caused by similar geometries for the top and bottom plate. Table 4.6 shows the color-coded scheme. 
Table 4.6: Color coding scheme.

\section{Color}
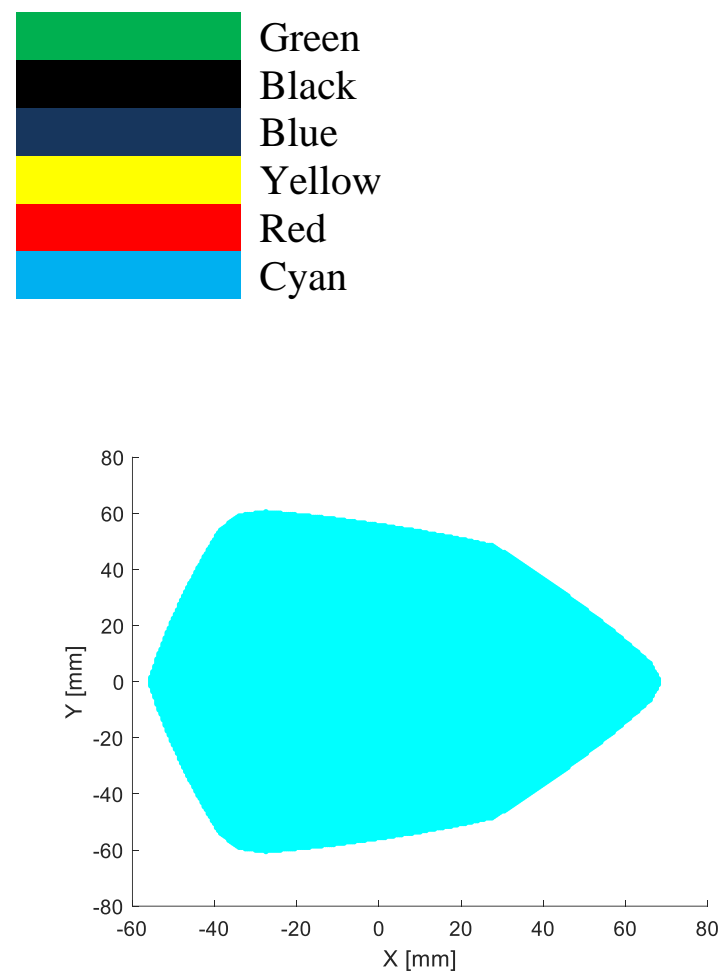

\section{Condition Number Range}

$$
\begin{gathered}
<=50 \\
>50 \&<=100 \\
>100 \&<=250 \\
>250 \&<=500 \\
>500 \&<=100000 \\
>100000
\end{gathered}
$$

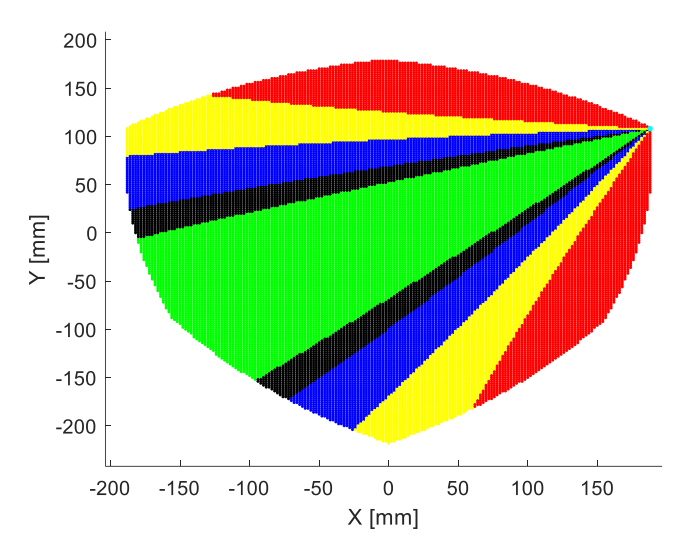

Figure 4.4: Singularity map of pure translation of the CSM (top) and 66.1 Tiger (bottom) designs.

The results for Figure 4.5 are similar to that of Figure 4.4 in that the CSM design has condition numbers on the order of $10^{18}$ and the 66.1 Tiger has condition numbers on the order of $10^{3}$. The reduction in the magnitude of the condition number translates into a significant improvement in system controllability. As for the singularity map, it shows the relative change based on the min and max condition number on the workspace that is evaluated. While there is a lot of green in the top of Figure 4.5, the relative condition numbers are much higher in the CSM design than the 66.1 Tiger. It should be noted that 
the high condition numbers (shown as cyan) are dispersed towards the outside regions of the workspace rather than near the "home" position of the hexapod $(\mathrm{Rx}=0, \mathrm{Ry}=0)$.
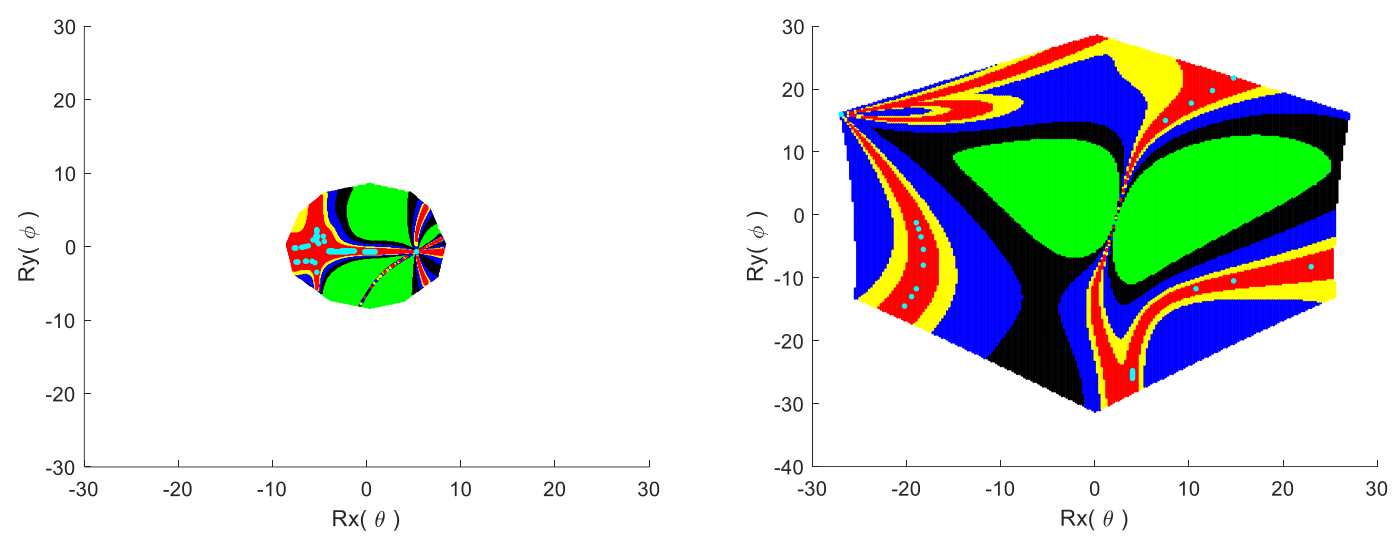

Figure 4.5: Pure rotation scenarios for the singularity map of the 66.1 Tiger (right) and the CSM (left) designs.

\subsection{Distance Measurement Analysis}

Work was completed during an internship at NRL to determine if an inaccurate actuator could be controlled with a PID such that the actuator can be accurate in combination with a string potentiometer to measure the stroke. Several Arduino IDE libraries from www.github.com were used to develop a code to control the electrohydraulic actuators.

The results from Table 4.7 and Table 4.8 show that the proportional, integral, and derivative terms of the PID controller vary based on the speed of the actuator. It was initially believed that the smallest distance that could be measured was 50 microns, but with the work completed, the code (Appendix D:) was able to bring the smallest displacement to roughly 5 microns and the lowest speed to 1 micron per second. These results give an option for slower and more accurate material testing. A circular buffer in 
included with the code to showcase steadier results while running. For the sake of determining the slowest speed and displacement, the moving average was disabled.

Table 4.7: Positive speed PID control values for Parker EHA.

\begin{tabular}{|c|c|c|c|c|}
\hline Moving Average Value & Speed (um/s) & Kp & Ki & Kd \\
\hline \multirow{11}{*}{ 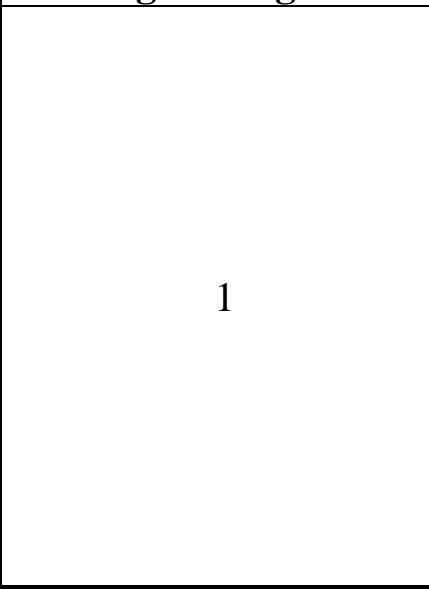 } & 1 & 70 & 40 & 10 \\
\hline & 3 & 90 & 40 & 10 \\
\hline & 6 & 90 & 40 & 10 \\
\hline & 24 & 90 & 30 & 10 \\
\hline & 48 & 90 & 30 & 30 \\
\hline & 100 & 90 & 30 & 30 \\
\hline & 500 & 90 & 30 & 30 \\
\hline & Speed $(\mathrm{mm} / \mathrm{s})$ & Kp & $\mathbf{K i}$ & Kd \\
\hline & 1 & 50 & 50 & 10 \\
\hline & 5 & 50 & 50 & 10 \\
\hline & 15 & 50 & 50 & 10 \\
\hline
\end{tabular}

Table 4.8: Negative speed PID control values for Parker EHA.

\begin{tabular}{|r|r|r|r|r|}
\hline Moving Average Value & Speed (-um/s) & Kp & Ki & Kd \\
\hline & 1 & 280 & 50 & 10 \\
\cline { 2 - 5 } & 3 & 280 & 50 & 10 \\
\cline { 2 - 5 } & 6 & 280 & 50 & 10 \\
\cline { 2 - 5 } & 24 & 280 & 50 & 10 \\
\cline { 2 - 5 } & 48 & 280 & 50 & 50 \\
\cline { 2 - 5 } & 100 & 280 & 50 & 50 \\
\cline { 2 - 5 } & 250 & 180 & 50 & 10 \\
\cline { 2 - 5 } & Speed (-mm/s) & 180 & 50 & 10 \\
\cline { 2 - 5 } & 1 & 700 & $\mathbf{K i}$ & $\mathbf{K d}$ \\
\cline { 2 - 5 } & 5 & 70 & 10 & 10 \\
\cline { 2 - 5 } & 15 & 70 & 10 & 10 \\
\hline
\end{tabular}




\section{CHAPTER 5: DISCUSSION AND CONCLUSION}

Chapter 5 includes the discussion and conclusion of this thesis and more specifically the hexapod design. The limitations of the design, the strengths of the design as compared to the CSM design, the fabrication and functionality of the design, and the future work are discussed moving forward.

\subsection{Limitations of Design}

The 66.1 Tiger includes a few limitations of note. For one, the specimen design is limited if metal AM materials are studied, and composite materials cannot be tested due to the way the hexapod is designed with the inverted style as compared to the CSM design and that composite materials have significantly higher yield strengths and large loads needed for failure. The inverted style introduces more deflection than that of the traditional design and reduces the amount of force the hexapod frame can withstand without excessive deflections.

Another limitation is the uncertainty of the singularities within the hexapod workspace, although a method to 'map' the singularities is provided, further research will need to be conducted to determine the correlation of the maps with the controllability of the hexapod.

Two more limitations involve requirements 9 and 14 (Appendix A:), both of which were criteria. Requirement 9 (loading the specimen should be easy) was not satisfied but does not limit the design in its performance. The specimen can be inserted by hand rather than by a 6-DOF robotic hand. If this design was to be used in an industrial setting, a 6DOF robotic hand can be implemented to decrease the time required to do it manually. It 
also takes time to adjust and align both grips so that no load is applied before testing. Requirement 14, stating that the design should not have components exceeding 30 lbs., was not satisfied, but the components of the hexapod can be transported easily with a pallet jack.

\subsection{Strengths of Design}

There are several aspects about the 66.1 Tiger that improve it upon the sense of a traditional design than that of the CSM design. For one, the inverted design allows the hexapod to have a larger workspace than if it was designed like the other two other designs.

The ability to move the bottom frame joints to several locations allows the user to change the singularity 'map' to their choosing. For example, if it is known that a singularity exists at the end of test when the specimen breaks, one or more joint(s) can be moved to change the singularity 'map' such that there is no singularity at that point. This is a good capability considering the consequences of the hexapod reaching a singularity near a failure

point and the possible loss of control as a result which may lead to possible damage to the machine and the user having to move the machine out of the singularity. Another strength of the design is its modularity, several of the key components of the design are bolted together which allows for modular replacement components to be fabricated. For example, to test a unique specimen that the chosen grips cannot secure, the user can either design an attachment or install a different style of grips. Another example is the location of the 6axis force sensor, the hexapod was designed so that the sensor can either be inserted with the top grip or the bottom grip. Considering it is unknown currently which spot is better 
(or even if using two sensors is better), this allows an easy configuration of the system to maximize resolution or performance. The implications of the different locations will be determined in future work during system calibration.

\subsection{Fabrication of Design}

During fabrication of the design, some changes were made based on the feedback from the machinist at Machining and Technical Services (MTS) on the Clemson University campus. The slanted metal pieces at the ends of the I-beams in Figure 3.1 were removed because it was noted by the machinists that it would be easier to fabricate the top frame without it. It was also noted that it would increase the strength in that area due to the reduction in welding that would be needed if this aspect was kept. Another change was removing the design of the cameral adapter ring originally shown in Figure 3.1, this design was bolted in the top frame and presented an issue with deflection that can occur in the area. To resolve this issue, NOGA holders (Figure 3.6) were implemented and are a much better solution since the holders can be placed anywhere on the frame and eliminate any deflection that would occur. The only issue with this decision is that deflection in the frame would move the camera, but this can be accounted for in the calculation for material properties. These design changes can be seen in Figure 5.1. 

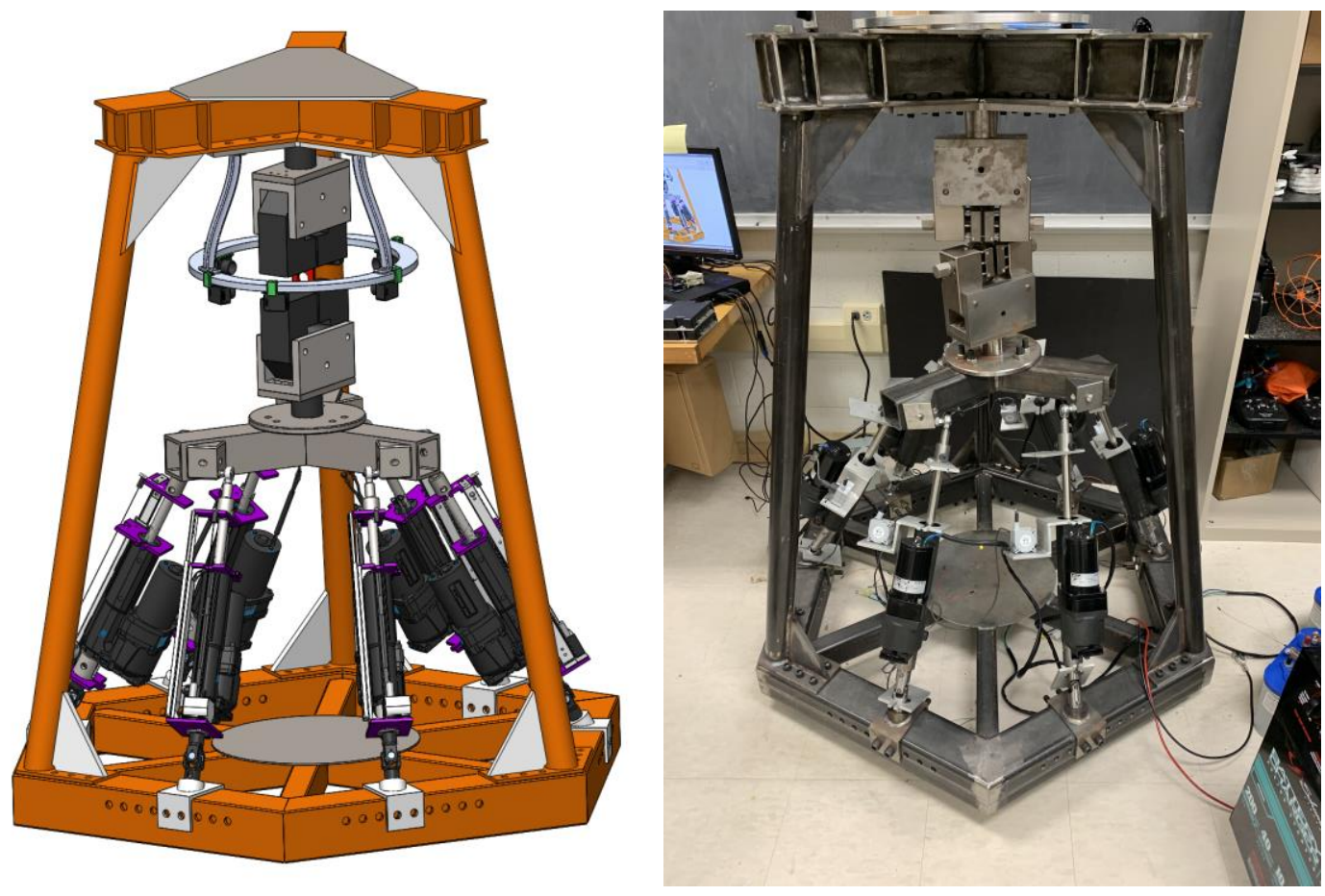

Figure 5.1: SolidWorks Image of solution (left), solution pictured in the lab (right).

\subsection{Functionality of Design}

Considering the end goal of this thesis to show that the hexapod can perform tests repeatedly and in variation, this section includes the discussion on the functionality. It must be noted that the software that uses the cameras to calculate strain states to get the material properties has already been proven to work and is provided by NRL. This leaves the end goal of the hexapod breaking specimens in general and breaking them in various loading conditions.

The code, shown in Appendix G:, uses Arduino IDE to control the 66.1 Tiger and there are several points to address and conclude on. To start, the PID control included in the code has some issues that do not affect the end goal of this thesis but do affect future work with 
testing certain specimens or materials. A variable PID control would be needed as it was discovered with the work in Section 4.5 that different PID gain values are needed based on the speed. It is unknown at this time if tests will be conducted with varying or constant speed, but for the sake of showing that the hexapod works, the PID gain values can be manually changed and further testing during the calibration portion of the future work will need to be conducted.

\subsubsection{Specimen Tests}

Testing was completed to satisfy requirements $18.1-18.4$. These tests were done to show that the hexapod can move in 6-DOF and break specimens. They were also done to test the grips and to see if slippage will be a problem in the future work. Videos were produced to show each test, with the tensile test having the most difficulty. This difficulty was due to an inaccurate print job. The initial specimen for the tensile test produced significant slippage which required adjusting the grip strength repeatedly until a test was successful. Another specimen was printed in which there were less deformities and the testing proved to be successful without slippage. The testing suggests that different grip pads should be used, or rubber paint should be applied on less uniform specimens for tensile testing. The other tests satisfying requirements $18.1-18.4$ showed no issues. The code controlling the Tiger 66.1 is shown in Appendix G:.

\subsection{Future Work}

A continuation of the work included in this thesis includes implementation of the full strain field measurement program using the camera system described in Section 3.2.5. 
Researchers at NRL have already developed a system to complete full field measurements, and this system will be implemented to the Tiger 66.1. Initial testing of the program will be conducted showing that bulk material properties are indeed different than that of the AM material properties using the same materials. Once this is completed, then calibration of the hexapod will need to be conducted to ensure accurate results and full testing can be completed.

Full testing will be possible after the accuracy of the system is determined with the error and uncertainty analysis. Random error and systematic error will need to be reduced as much as possible. There is already some evidence of systematic error with the hexapod returning to the 'home' position. There are some inaccuracies with the PID controller as the actuators behave differently when extending vs. extracting. Calibration of the PID values will need to be conducted to eliminate this error. The uncertainty analysis would consider the error of the string potentiometers, actuators, cameras, and the 6-axis force sensor. Some factors that will be considered to affect measurements are noise, nonlinearity, non-uniformity, and random error. Ultimately the 6-axis force sensor will be used to control the actuators during testing as the direction and magnitude of the force(s) on the specimen is the end goal, but the actuator measurement control will need to be used to reset the machine or to place it in the desired position before testing starts.

A sensitivity analysis will need to be conducted as well to determine how the hexapod calculations are affected by the different measurements discussed. There are three possible types in which one or more may be used and include numerical, experimental, and mathematical. An example of the experimental method would be to do repeated tests on 
bulk materials to determine the change in output. The mathematical determination can be found through the SG platform mathematics. Another step includes addressing the issue of singularities with the full field strain measurement system. Even with the addition of two (total of 6) cameras, there may still be singularities where the cameras will lose track of the dots placed on the specimen.

Once the hexapod has been properly calibrated then research can be conducted on specific AM methods with polymers. First testing will be conducted on FDM printed specimens to study the effect 3D printing versus bulk material properties. Next would be to conduct and study specimens made from other methods such as SLA (stereolithography), DLP (digital light processing), SLS (selective laser sintering), SLM (selective laser melting), EBM (electronic beam melting), LOM (laminated object manufacturing), and others.

\subsubsection{Possible Research Questions}

Once the 66.1 Tiger is calibrated and can perform full characterization tests, there are some research questions that can be looked at.

1. In what ways do the bulk material properties differ from the printed material properties for an FDM printed specimen?

2. In what ways do different infill patterns for FDM printed specimens affect the material properties?

3. In what ways can singularities with the camera setup be addressed for more compliant materials? 
4. How can topology optimization be used as an infill pattern generator to increase the desired properties of a FDM printed specimen?

5. How do other printing methods differ to bulk material properties?

\section{6 $\underline{\text { Conclusion }}$}

Going back to Section 1.2, the design statement states the following:

Design and fabricate a multiaxial robotic test frame that can test additive manufacturing materials, focusing on polymers and some metals, in 6 degrees-of-freedom while improving on performance and cost over the CSM design.

This design statement has been satisfied by the completion of the requirements set out by the PDS. The major requirements involving completed successful tests showing the range and degrees-of-freedom of the hexapod (Req 18.1-18.4). It has been shown in Section 3.3 that the Tiger 66.1 has a significantly greater workspace than that of the CSM design. Section 4.4 shows that the singularity "map" of the Tiger 66.1 has much lower condition number values than the CSM design showing an improvement on the controllability. Comparing the cost of the CSM design, Appendix H:, and the cost of the Tiger 66.1, Appendix F:, there is a difference of roughly $\$ 10,000$ with the Tiger 66.1 costing less. With these main points, it can be said the design statement has been satisfied. 


\section{CHAPTER 6: REFERENCES}

[1] Mast P. W., Nash G. E., Michopoulos J. G., Thomas R., Badaliance R., and Wolock I., 1995, "Characterization of strain-induced damage in composites based on the dissipated energy density part I. Basic scheme and formulation," Theor. Appl. Fract. Mech., 22(2), pp. 71-96.

[2] Mast P. W., Nash G. E., Michopoulos J. G., Thomas R., Badaliance R., and Wolock I., 1995, "Characterization of strain-induced damage in composites based on the dissipated energy density Part III. General material constitutive relation," Theor. Appl. Fract. Mech., 22(2), pp. 115-125.

[3] Mast P. W., Nash G. E., Michopoulos J. G., Thomas R., Badaliance R., and Wolock I., 1995, "Characterization of strain-induced damage in composites based on the dissipated energy density part II. Composite specimens and naval structures," Theor. Appl. Fract. Mech., 22(2), pp. 97-114.

[4] Mast P. W., Beaubien L. A., Clifford M., Mulville D. R., Sutton S. A., Thomas R. W., Tirosh J., and Wolock I., 1983, “A semi-automated in-plane loader for materials testing," Exp. Mech., 23(2), pp. 236-241.

[5] Michopoulos J. G., and Furukawa T., 2008, "Towards hierarchical design optimization for simultaneous composite material characterization and adjustment of the corresponding physical experiments," Inverse Problems in Science and 
Engineering, pp. 763-775.

[6] Michopoulos J., 2003, Recent Advances in Composite Materials, Springer Netherlands, Dordrecht.

[7] Michopoulos J., 2004, "Mechatronically Automated Characterization of Material Constitutive Respone," Proc. 6th World Congr. Comput. Mech., (January 2004), pp. 486-491.

[8] Michopoulos J. G., Hermanson J. G., and Dc W., 2011, "On the Constitutive Response Characterization for Comosite Materials Via Data-Driven Design Optimization," Proc. ASME 2011 Int. Des. Eng. Tech. Conf. Comput. Inf. Eng. Conf., pp. 1-13.

[9] Michopoulos J., Hermanson J., and Iliopoulos A., 2012, "First industrial strength multi-axial Robotic testing campaign for composite material characterization," Notes, pp. 1-11.

[10] Iliopoulos A., and Michopoulos J. G., 2016, "On the feasibility of crack propagation tracking and full field strain imaging via a strain compatibility functional and the Direct Strain Imaging method," Int. J. Impact Eng., 87(May), pp. 186-197.

[11] Michopoulos J. G., and Iliopoulos A., 2012, "Complete High Dimensional Inverse Characterization of Fractal Surfaces and Volumes," J. Comput. Inf. Sci. Eng., 13(1), p. 011001.

[12] Michopoulos J., Iliopoulos A., and Hermanson J. C., 2012, "Preliminary Validation 
of Composite Material Constitutive Characterization," Proc. ASME 2012 Int. Des. Eng. Tech. Conf. Comput. Inf. Eng. Conf. IDETC/CIE, August 12-15, 2012, Chicago, IL, USA, pp. 1-10.

[13] Allen J., Hentges B., Hulse A., Parsons T., and Tillery S., 2014, “6DOF Material Test Frame," p. 95.

[14] Tsai L., 1999, "Robot analysis: the mechanics of serial and parallel manipulators," Mech. Ser. Parallel Manip., p. 520.

[15] Raghavan M., 1993, "The Stewart Platform of General Geometry Has 40 Configurations," J. Mech. Des., 115(2), pp. 277-282.

[16] Gosselin C., and Angeles J., 1990, "Singularity Analysis of Closed Kinematic Chains," J. Mech. Des., 6(3), pp. 281-290.

[17] Zlatanov D., 1994, "Singularity Analysis of Mechanisms and Robots via a MotionSpace Model of the Instantaneous Kinematics," IEEE International Conference on Robotics \& Automation, pp. 986-991.

[18] Steuben J., "AM 6DOF Testing System 'Email..”

[19] "PC Series ${ }^{\mathrm{TM}}$ Precision Linear Actuators Unmatched Power Density, Speed and Stroke Length," Thomas Linear [Online]. Available: https://www.thomsonlinear.com/downloads/actuators/PC_Series_Precision_Linear _Actuators_bren.pdf. [Accessed: 12-Apr-2017]. 
[20] Budynas R. G., and Nisbett J. K., 2015, Mechanical Engineering Design.

[21] 2008, "Spherical Rolling Joints," Myostat, pp. 2-3 [Online]. Available: http://www.myostat.ca/cmCart_files/repo/download/SR Joint Brochure.pdf. [Accessed: 12-Apr-2017].

[22] Iliopoulos A., and Michopoulos J., 2012, “Direct Strain Imaging For Full Field Measurements," ASME 2012 International Design Engineering Technical Conferences \& Computers and Information in Engineering Conference IDETC/CIE, August 13-15, 2012, Chicago, IL, USA, pp. 1-11.

[23] Michopoulos J. G., Hermanson J. C., Iliopoulos A., Lambrakos S. G., and Furukawa T., 2011, "Data-driven design optimization for composite material characterization," J. Comput. Inf. Sci. Eng., 11(2).

[24] Iliopoulos A. P., and Michopoulos J. G., 2014, "Meshless methods for full field displacement and strain measurement," Adv. Comput. Inf. Eng. Res., 1(February), pp. $97-124$.

[25] Michopoulos J. G., Hermanson J. C., and Furukawa T., 2008, "Towards the robotic characterization of the constitutive response of composite materials," Compos. Struct., 86(1-3), pp. 154-164.

[26] Michopoulos J. G., Hermanson J. C., and Iliopoulos A., 2010, “Towards a recursive hexapod for the multidimensional mechanical testing of composites," Proceedings of the ASME 2010 International Design Engineering Technical Conferences \& 
Computers and Information in Engineering Conference IDETC/CIE 2010, pp. 9199.

[27] Steuben J., Michopoulos J., Iliopoulos A., and Turner C., 2015, "Inverse characterization of composite materials via surrogate modeling," Compos. Struct., 132, pp. 694-708.

[28] 2018, "Compact Electro-Hyrdaulic Actuator (EHA)" [Online]. Available: http://ph.parker.com/us/17560/en/compact-electro-hydraulic-actuator. [Accessed: 02-Dec-2018].

[29] Stratasys, 2017, “ABS-ESD7: Production-Grade Thermoplastic for Fortus 3D Production Systems" [Online]. Available: http://www.stratasys.com/materials/fdm/abs-esd7. [Accessed: 01-Feb-2017].

[30] Shigley J. E., Mischke C. R., and Budynas R. G., 2002, Mechanical Engineering Design.

[31] Bonev I., and Zlatanov D., 2001, "The Mystery of the Singular SNU Translational Parallel Robot."

[32] Ma O., and Angeles J., 1991, "Optimum architecture design of platform manipulators," Fifth International Conference on Advanced Robotics 'Robots in Unstructured Environments.

[33] Fattah a., and Hasan Ghasemi A. M., 2002, "Isotropic Design of Spatial Parallel Manipulators," Int. J. Rob. Res., 21, pp. 811-824. 
[34] Ropponen T., and Arai T., "Accuracy analysis of a modified Stewart platform manipulator," Proceedings of 1995 IEEE International Conference on Robotics and Automation, IEEE, pp. 521-525.

[35] Merlet J. P., 2006, “Jacobian, Manipulability, Condition Number, and Accuracy of Parallel Robots," J. Mech. Des.

[36] Fry S. T., and Turner C. J., 2016, "Design of a Stewart-Gough Platform for Engineering Material Characterization," Proceedings of the ASME 2016 International Mechanical Engineering Congress \& Exposition, IMECE 2016, November 11-17, 2016, Pheonix, Arizona, USA, pp. 1-9. 
APPENDICES 


\section{Appendix A: Product Design Specification}

\begin{tabular}{|c|c|c|c|c|c|c|c|}
\hline No. & Req. & Constraint & $\begin{array}{l}\text { Crit. } \\
\text { Wt. } \\
(1,3,9)\end{array}$ & Justification & Value & Verification & $\begin{array}{l}\text { Checked } \\
\text { On }\end{array}$ \\
\hline 1 & Design Stewart platform for low cost & & 1 & $\begin{array}{l}\text { the lower the cost, while not } \\
\text { losing functionality, the better it } \\
\text { looks for companies to use }\end{array}$ & $<\$ 70,000$ & BOM & \\
\hline 2 & Platform design should be a sufficient size based on singularity analysis & & 9 & $\begin{array}{l}\text { minimize singularities to make } \\
\text { sure performance does not } \\
\text { degrade on a pathway after the } \\
\text { specimen breaks }\end{array}$ & $\begin{array}{l}\text { top platform } \\
\text { smaller than } \\
\text { bottom platform }\end{array}$ & $\begin{array}{c}\text { SolidWorks } \\
\text { measurements/Matlab } \\
\text { program }\end{array}$ & \\
\hline 3 & Should allow platform to change kinematics & & 9 & $\begin{array}{l}\text { if singularity is in the path, this } \\
\text { method can provide a way to } \\
\text { where there is no singularity }\end{array}$ & $\begin{array}{l}>1 \text { geometry } \\
\text { setup }\end{array}$ & test & \\
\hline 4 & Should allow the ability to change grips & & 3 & $\begin{array}{l}\text { for special testing of unique } \\
\text { specimens }\end{array}$ & $\begin{array}{c}1 \text { set of removable } \\
\text { grips }\end{array}$ & sight check & \\
\hline 5 & Must allow for adjustments in stationary grip placement & YES & & $\begin{array}{l}\text { allowing more room for } \\
\text { adjustment adds versatility }\end{array}$ & bolt setup & sight check & \\
\hline No. & Req. & Constraint & $\begin{array}{l}\text { Crit. } \\
\text { Wt. } \\
(1,3,9)\end{array}$ & Justification & Value & Verification & $\begin{array}{l}\text { Checked } \\
\text { On }\end{array}$ \\
\hline 6 & Design platform to have extra degrees of freedom & YES & & $\begin{array}{l}\text { to test materials that compliant } \\
\text { such that the hexapod cannot } \\
\text { reach the point where the } \\
\text { specimen breaks }\end{array}$ & $>=1 \mathrm{DOF}$ & sight check & \\
\hline 7 & Design platform to test $3 \mathrm{D}$ printed metal specimens & YES & & $\begin{array}{l}\text { additive manufacturing (not } \\
\text { considering composite) does } \\
\text { consist of metal materials }\end{array}$ & $\begin{array}{l}>=1 \text { designed } \\
\text { specimen }\end{array}$ & test & \\
\hline 8 & Platform should be easy to maintain & & 3 & $\begin{array}{l}\text { minimal maintenance means } \\
\text { more time towards testing and in } \\
\text { a manufacturing environment } \\
\text { means less downtime }\end{array}$ & N/A & Multiple tests & \\
\hline 8.1 & platform should have easy access to electronics & & & for maintenance, see above & & sight check & \\
\hline
\end{tabular}




\begin{tabular}{|c|c|c|c|c|c|c|c|}
\hline No. & Req. & Constraint & $\begin{array}{c}\text { Crit. } \\
\text { Wt. } \\
(1,3,9)\end{array}$ & Justification & Value & Verification & $\begin{array}{l}\text { Checked } \\
\text { On }\end{array}$ \\
\hline 8.2 & Should minimize needed maintenance for components of the platform & & & see above & $\begin{array}{l}\text { all components } \\
\text { require no } \\
\text { maintenance }\end{array}$ & test over one semester & \\
\hline 9 & Loading specimen should be easy as just placing it in the grips & & 3 & $\begin{array}{l}\text { more time spent setting up the } \\
\text { specimen takes time away from } \\
\text { testing, saves time in a } \\
\text { manufacturing environment }\end{array}$ & 1 step & test & \\
\hline 10 & The platform shall be able to break samples in all loading conditions & YES & & $\begin{array}{l}\text { if it cannot do this, then the } \\
\text { hexapod cannot perform as it is } \\
\text { meant to }\end{array}$ & 6DOF & test & \\
\hline 11 & Platform should be ergonomic such that human use is accounted for & & 9 & $\begin{array}{l}\text { the easier to use, the less time it } \\
\text { takes for new people to learn or } \\
\text { experience users to test }\end{array}$ & $\begin{array}{l}\text { no extrenous } \\
\text { activity needed }\end{array}$ & test & \\
\hline No. & Req. & Constraint & $\begin{array}{c}\text { Crit. } \\
\text { Wt. } \\
(1,3,9)\end{array}$ & Justification & Value & Verification & $\begin{array}{l}\text { Checked } \\
\text { On }\end{array}$ \\
\hline 12 & Platform must be able to test multiple sized specimens & YES & & $\begin{array}{l}\text { variablity allows testing of the } \\
\text { varying designs of the addittive } \\
\text { manufacturing world }\end{array}$ & $>1$ specimen & test & \\
\hline 13 & Device should be easy to transport & & 3 & & $\begin{array}{l}2 \text { people } \\
\text { minimum }\end{array}$ & test & \\
\hline 14 & Parts should not exceed $30 \mathrm{lbs}$. individually & & 3 & $\begin{array}{l}\text { easy transport to the lab and } \\
\text { easy transport in the future }\end{array}$ & $30 \mathrm{lbs}$ & test & \\
\hline 14.1 & Hexapod must fit through the lab door frame & YES & & goes against transporting easily & $80 " x 60 "$ & test & \\
\hline 15 & Device should be able to function with at least one user & & 3 & $\begin{array}{l}\text { less manpower if only one person } \\
\text { can use it }\end{array}$ & 1 user & test & \\
\hline
\end{tabular}




\begin{tabular}{|c|c|c|c|c|c|c|c|}
\hline 16 & Device should be designed for minimum construction difficulty & & 9 & $\begin{array}{l}\text { easy to take apart for } \\
\text { maintenance, transporting, easy } \\
\text { for machinists }\end{array}$ & $\mathrm{N} / \mathrm{A}$ & fabrication test & \\
\hline No. & Req. & Constraint & $\begin{array}{c}\text { Crit. } \\
\text { Wt. } \\
(1,3,9)\end{array}$ & Justification & Value & Verification & $\begin{array}{l}\text { Checked } \\
\text { On }\end{array}$ \\
\hline 17 & Design must be based on a Stewart-Gough platform & YES & & $\begin{array}{l}\text { serial manipulators lack stiffness } \\
\text { and accuracy needed, other } \\
\text { parallel manipulators provide } \\
\text { issues in degrees of freedom and } \\
\text { mechanics }\end{array}$ & $1 \mathrm{SG}$ platform & sight check & \\
\hline 18 & The platform must be able to perform standard tests & YES & & $\begin{array}{l}\text { would not function as intended if } \\
\text { this is not met }\end{array}$ & $>=3$ DOF & test & \\
\hline 18.1 & hexapod must perform a standard tensile test & YES & & $\begin{array}{l}\text { would not function as intended if } \\
\text { this is not met }\end{array}$ & 1 tensile test & test & \\
\hline 18.2 & hexapod must perform a standard torsion test & YES & & $\begin{array}{l}\text { would not function as intended if } \\
\text { this is not met }\end{array}$ & 1 torsion test & test & \\
\hline 18.3 & hexapod must perform a standard bending test & YES & & $\begin{array}{l}\text { would not function as intended if } \\
\text { this is not met }\end{array}$ & 1 bending test & test & \\
\hline 18.4 & hexapod must perform a combination of two or more of the mentioned standard tests & YES & & goes along with req. 19 & 1 standard tests & test & \\
\hline 19 & The gripping system must not interfere with full field strain measurements & YES & & $\begin{array}{l}\text { hexapod would not work as } \\
\text { intended otherwise }\end{array}$ & $\begin{array}{c}1 \text { specimen in } 360 \\
\text { deg view }\end{array}$ & sight check & \\
\hline No. & Req. & Constraint & $\begin{array}{c}\text { Crit. } \\
\text { Wt. } \\
(1,3,9)\end{array}$ & Justification & Value & Verification & $\begin{array}{l}\text { Checked } \\
\text { On }\end{array}$ \\
\hline 20 & Device must perform repeatable tests & YES & & $\begin{array}{l}\text { hexapod would not work as } \\
\text { intended otherwise }\end{array}$ & $\begin{array}{l}>3 \text { repeatable } \\
\text { tests }\end{array}$ & test & \\
\hline
\end{tabular}




\begin{tabular}{|c|c|c|c|l|l|}
\hline 21 & Must have a greater workspace than the CSM design & YES & $\begin{array}{l}\text { CSM design does not have } \\
\text { have the capability to do tests } \\
\text { on the specimen size indicated }\end{array}$ & Matlab Graphs \\
\hline 22 & Must provide a way to measure actuator stroke & YES & To control the actuators & $\begin{array}{c}1 \text { measurement } \\
\text { device }\end{array}$ & YES \\
\hline 23 & Must have the specimen located above the moving platform & Greater workspace can be & \\
\hline
\end{tabular}


Appendix B: Design drawings

4

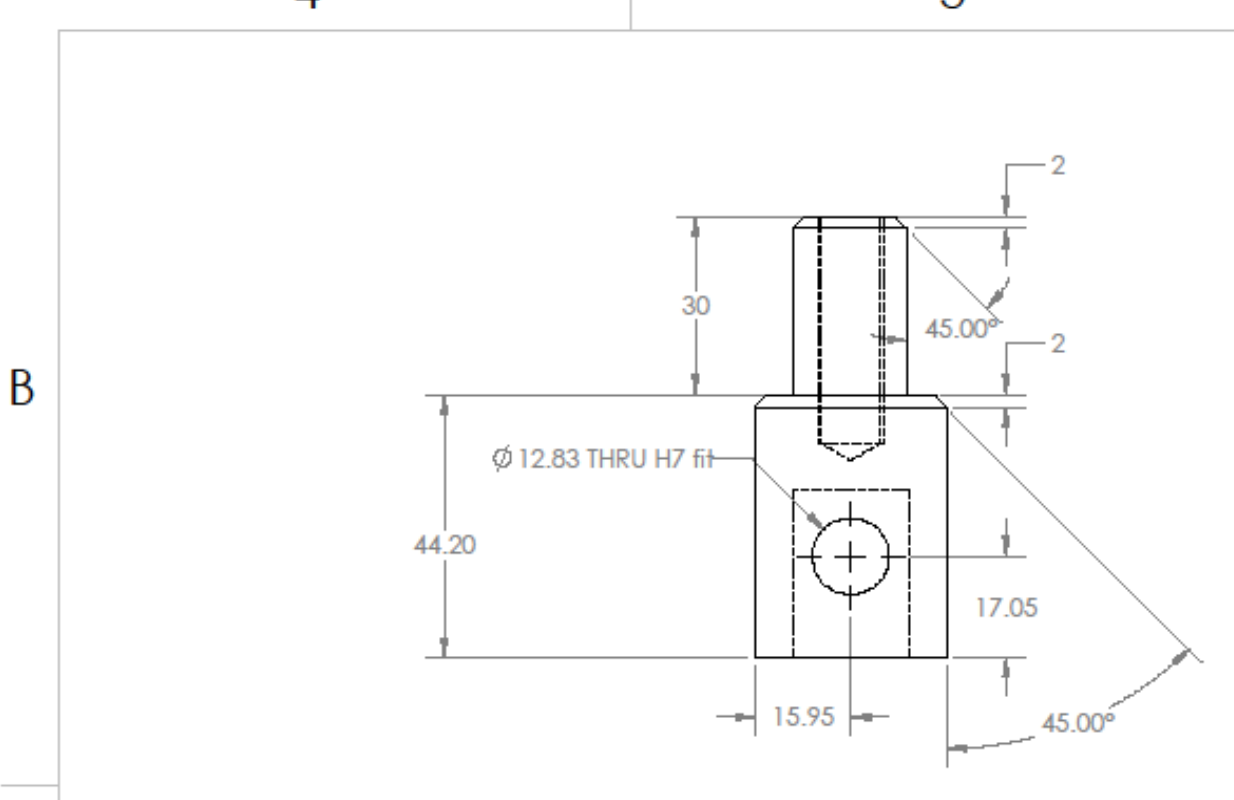

B

A

4

3 $\emptyset 9.92 \rrbracket 38.10$
7/16-20 UNF $¥ 38.10$

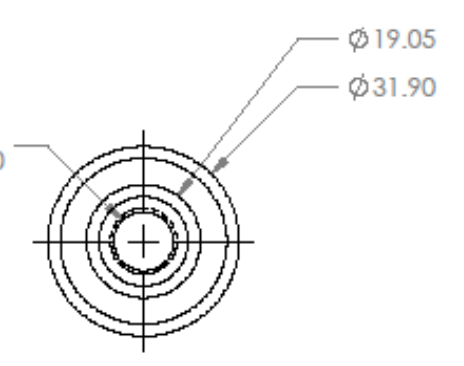

3
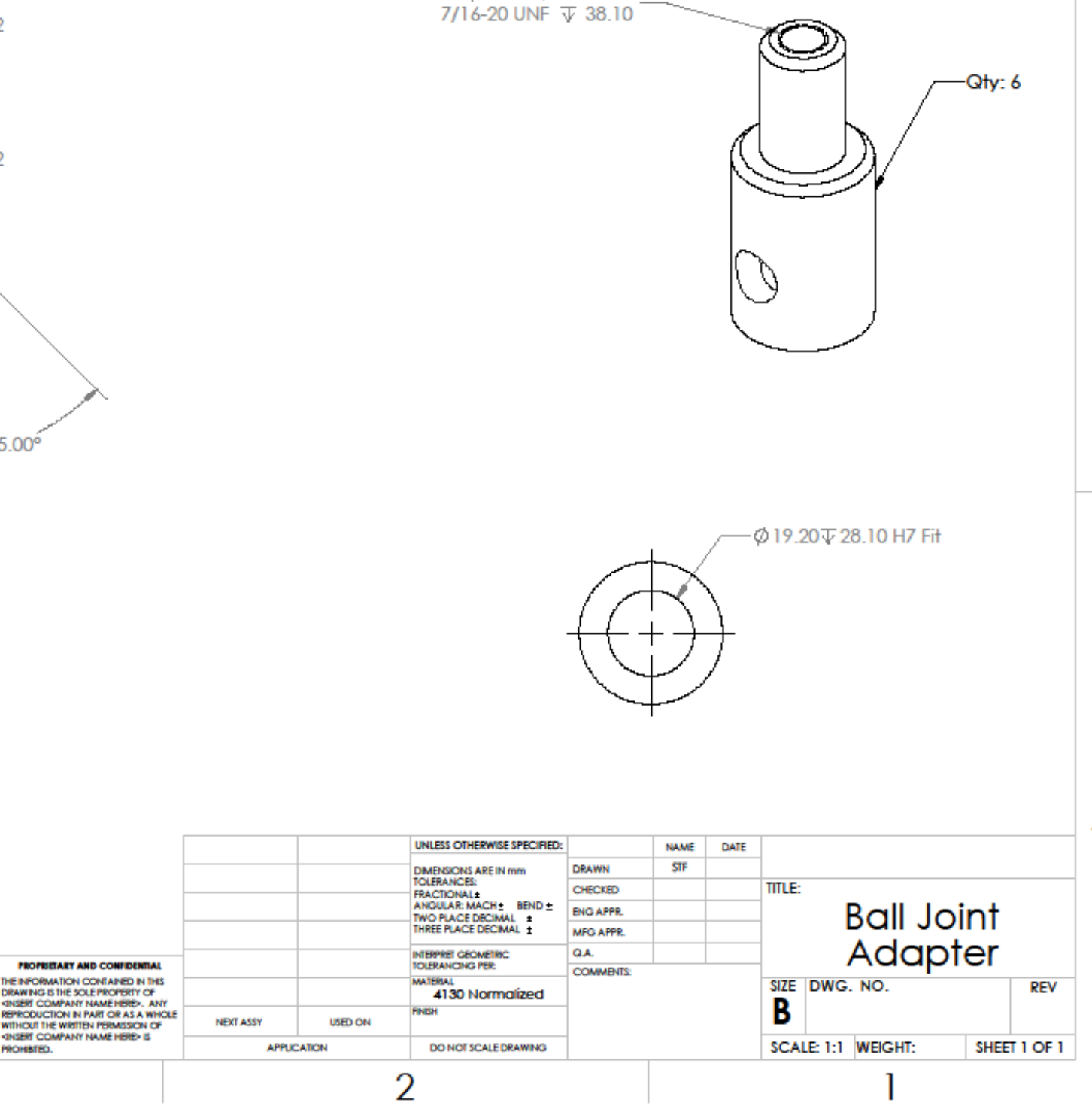

A 


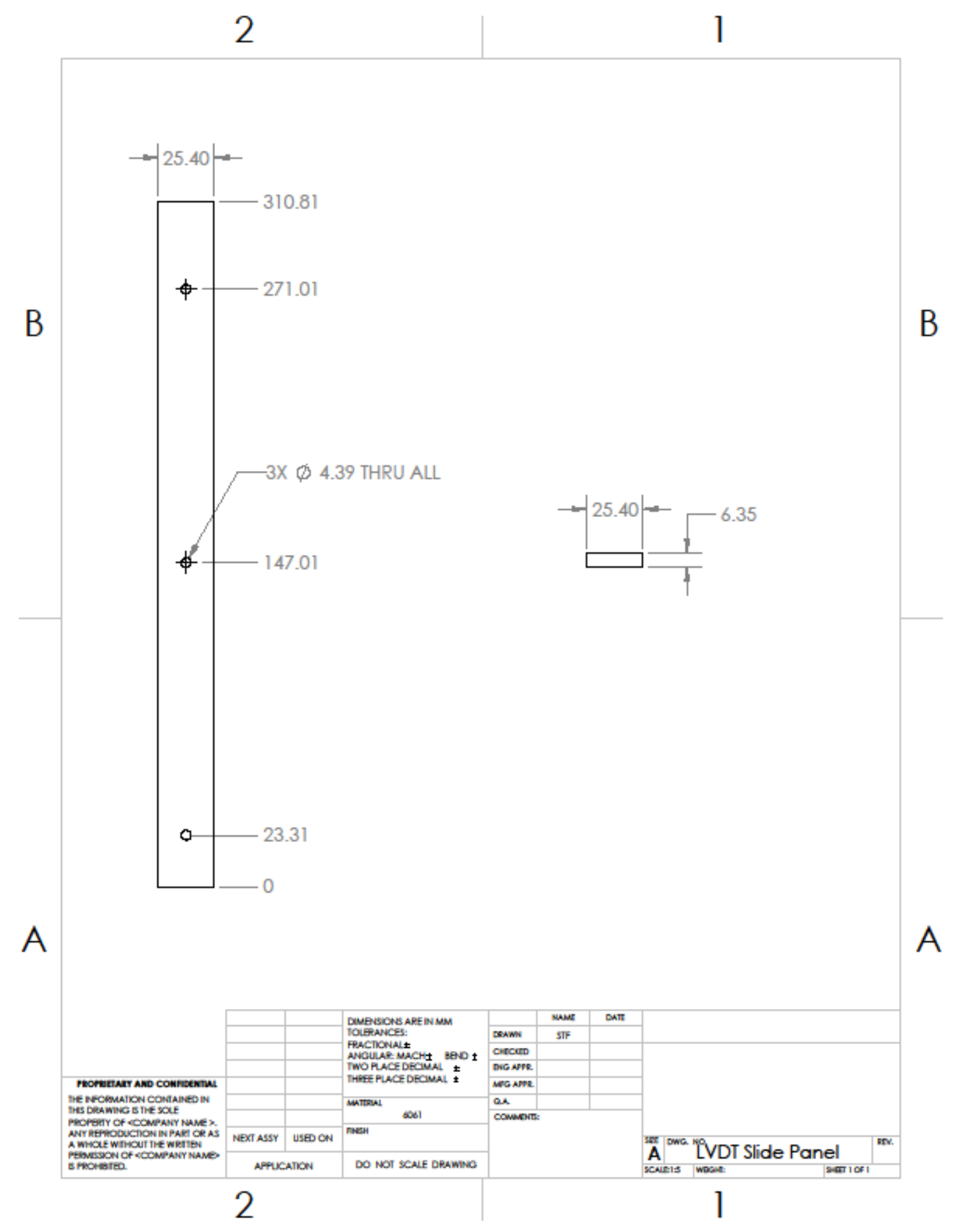



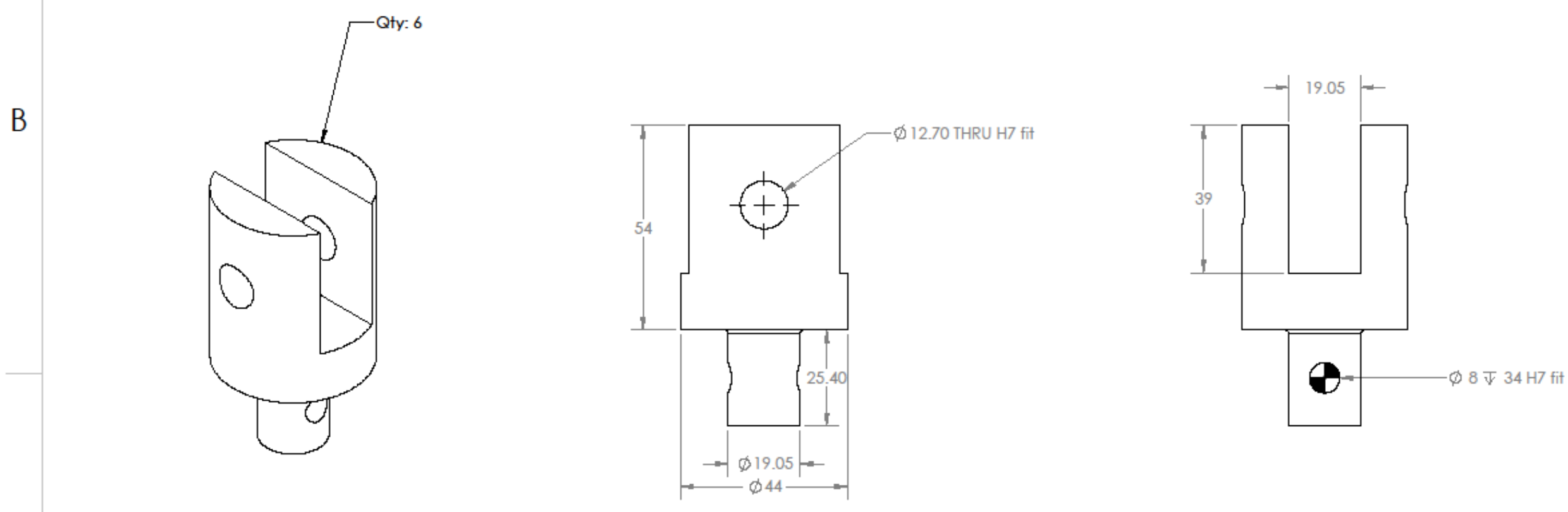

A

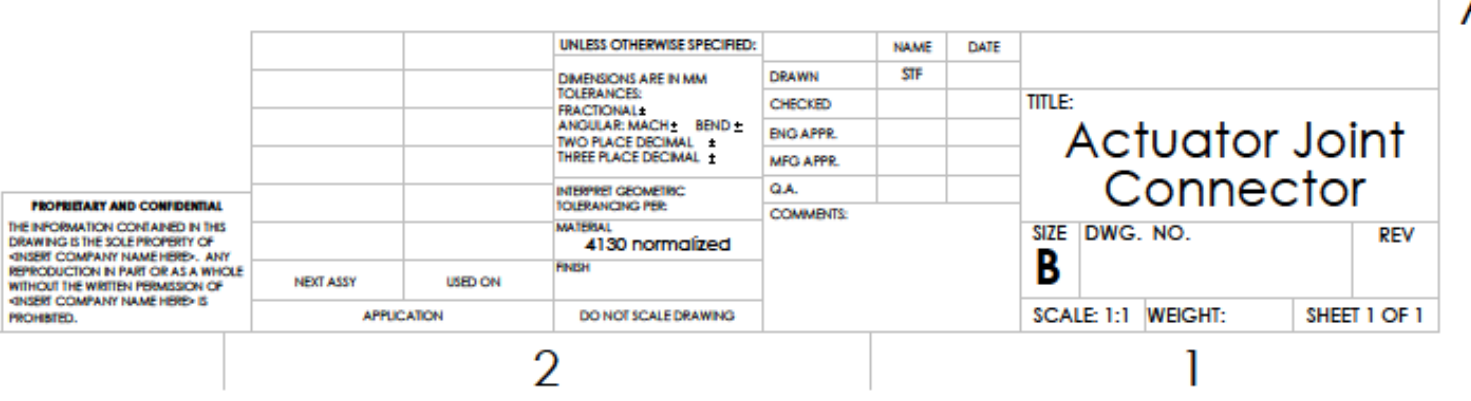

A 


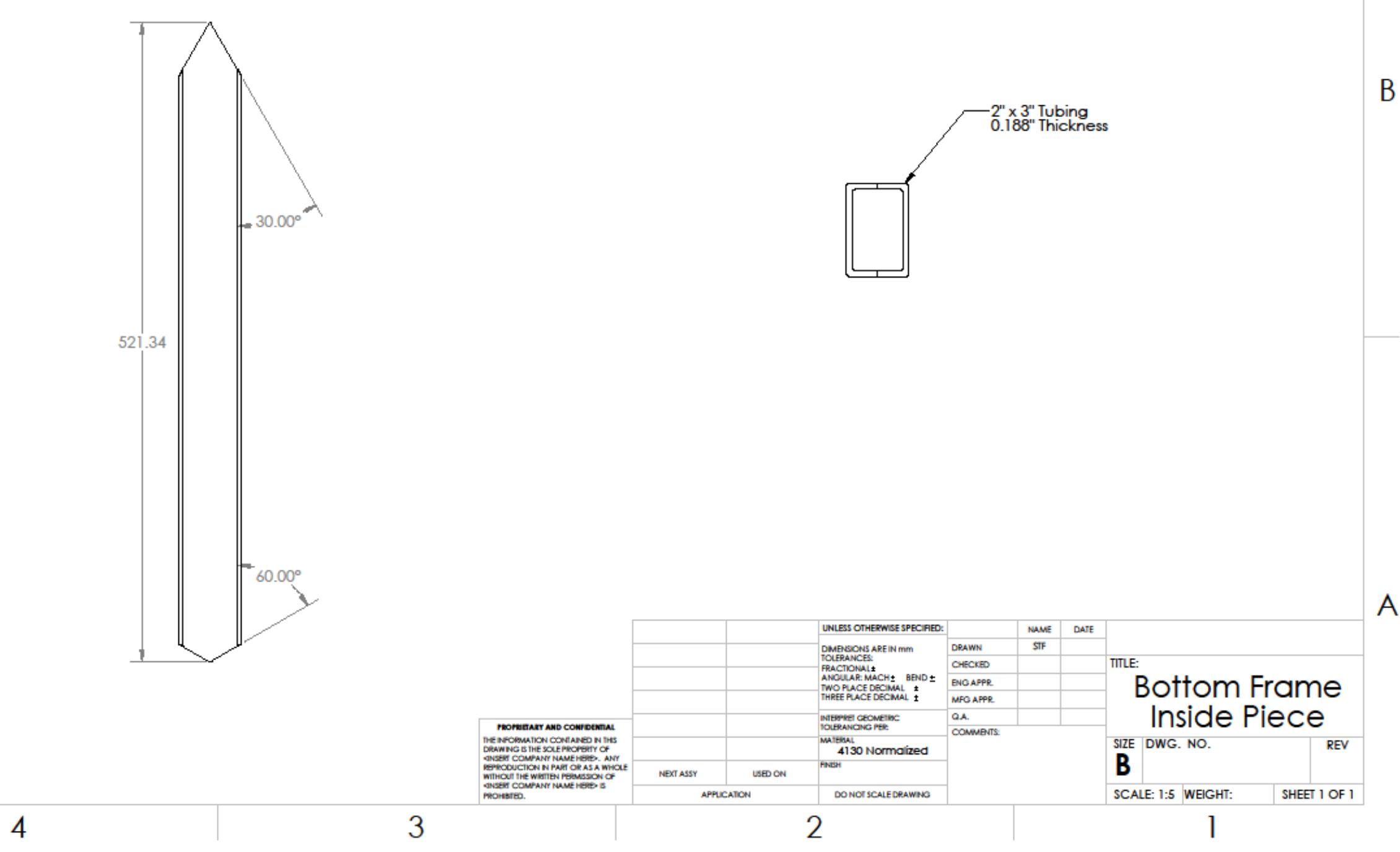

A 
B

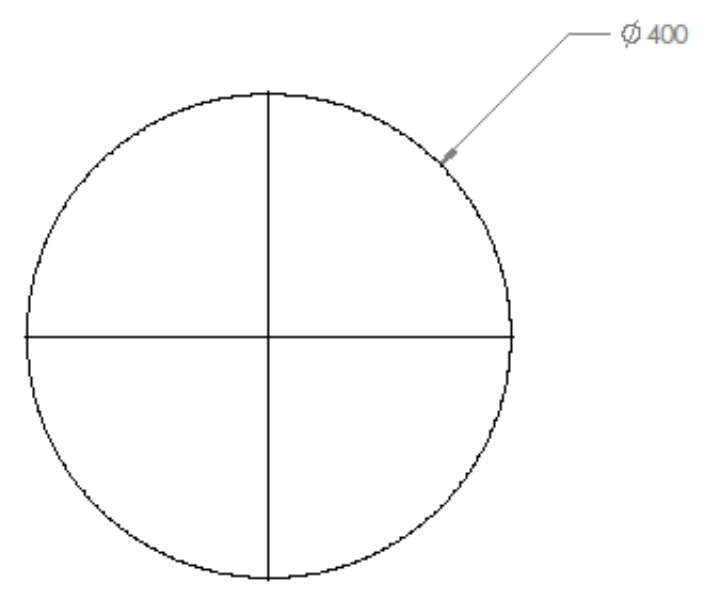

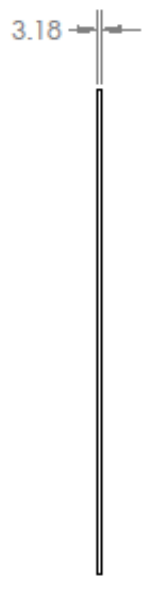

B

A

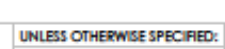

\begin{tabular}{|l|l|}
\hline ERDAWN \\
\hline OAGCKED \\
\hline ENOAPPR \\
\hline MFO APPR \\
\hline OA. \\
\hline COMUENAS \\
\hline
\end{tabular}

MaME DafE Brie: Bottom Frame Plate \begin{tabular}{l|l} 
SIZE DWG. NO. REV &
\end{tabular} B

SCALE: 1:5 WEIGHT; SHEET 1 OF 1

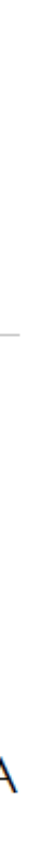

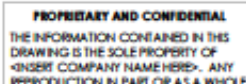

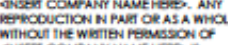

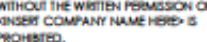

Next assr
DONOC SCCLE DReawnO

2 
1
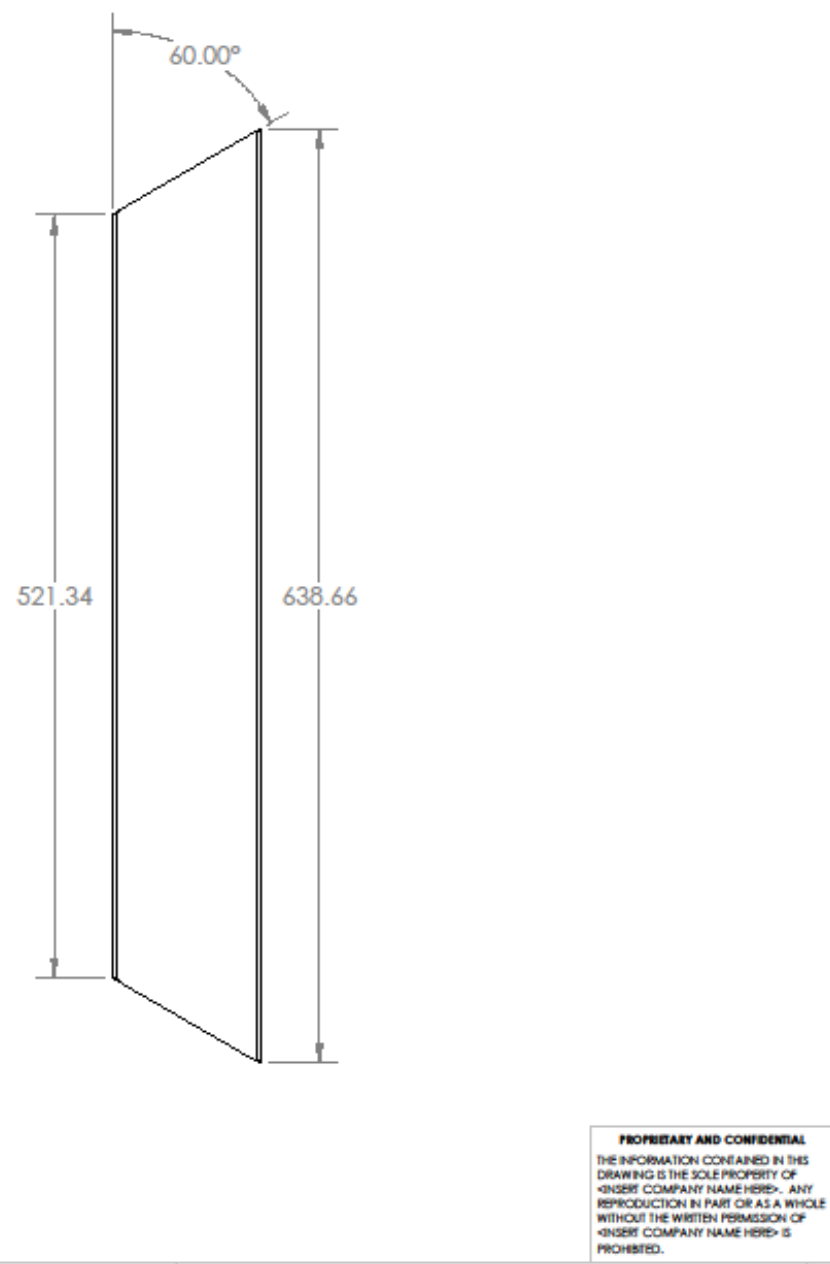

NEXT AssY

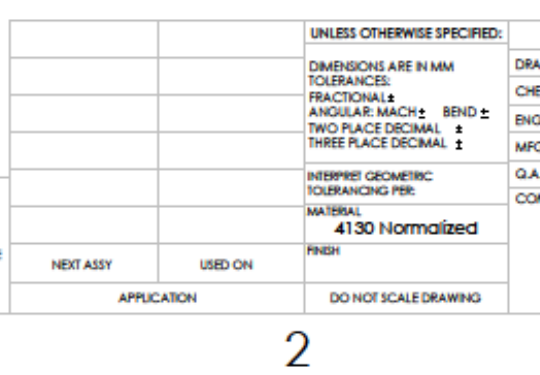$$
\text { TITLE: }
$$

V2.1 Bottom Hex Frame Piece \begin{tabular}{l|l|l|}
\hline SIZE & DWG. NO. & REV \\
\hline S & & \\
\hline SCALE: 1:5 WEIGHT: & SHEET I OF \\
\hline
\end{tabular} 1

4" Square Tubing

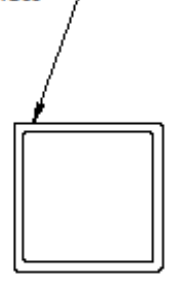



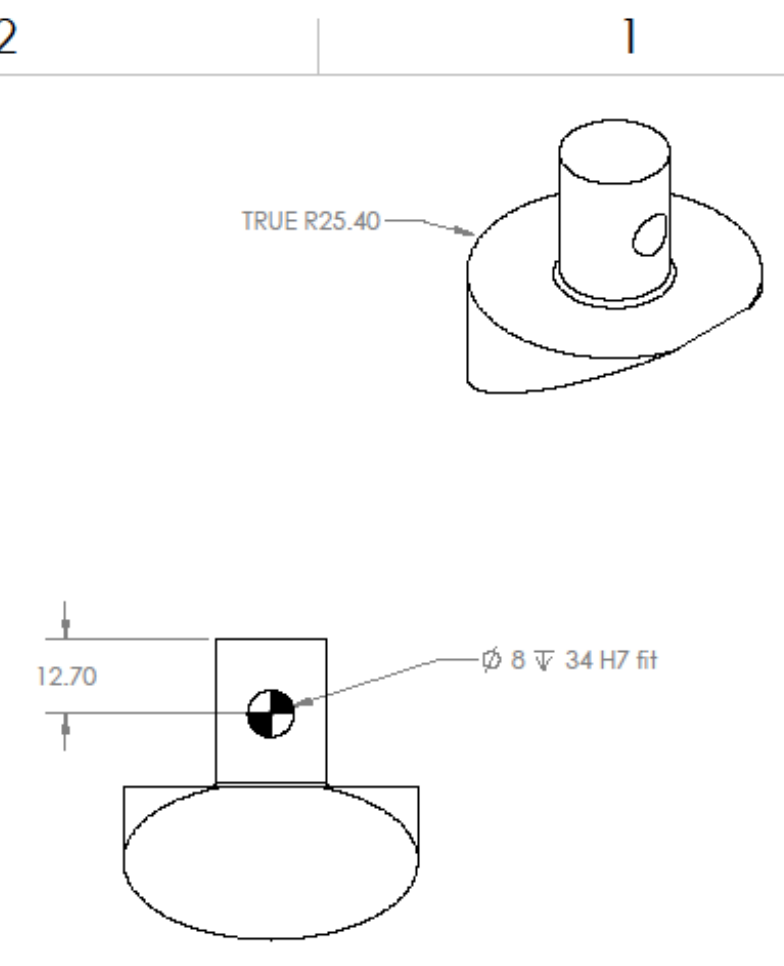

A

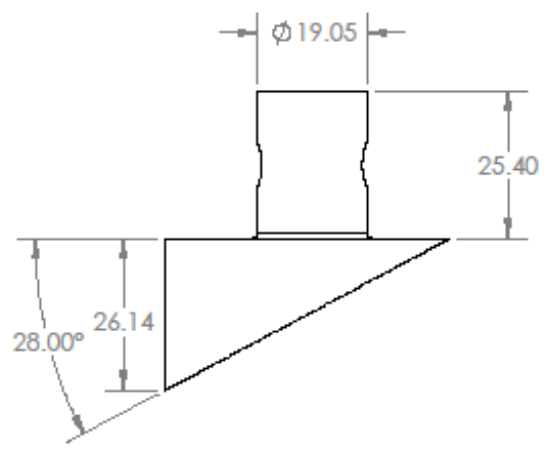

B

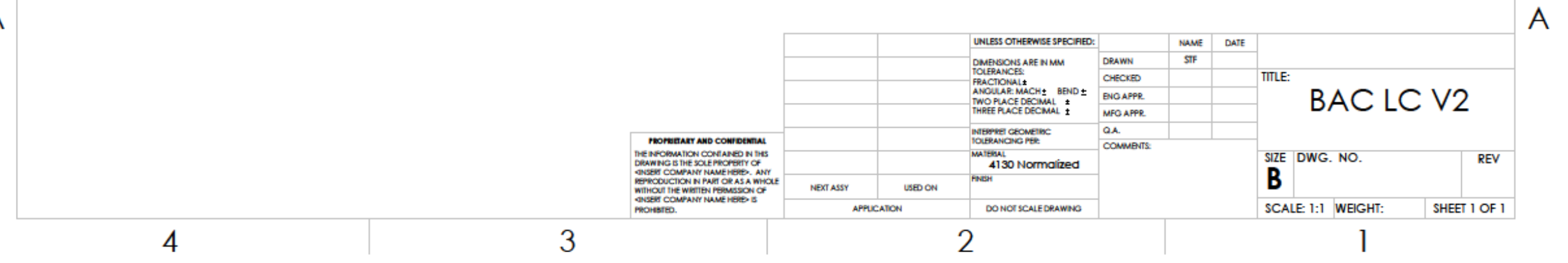




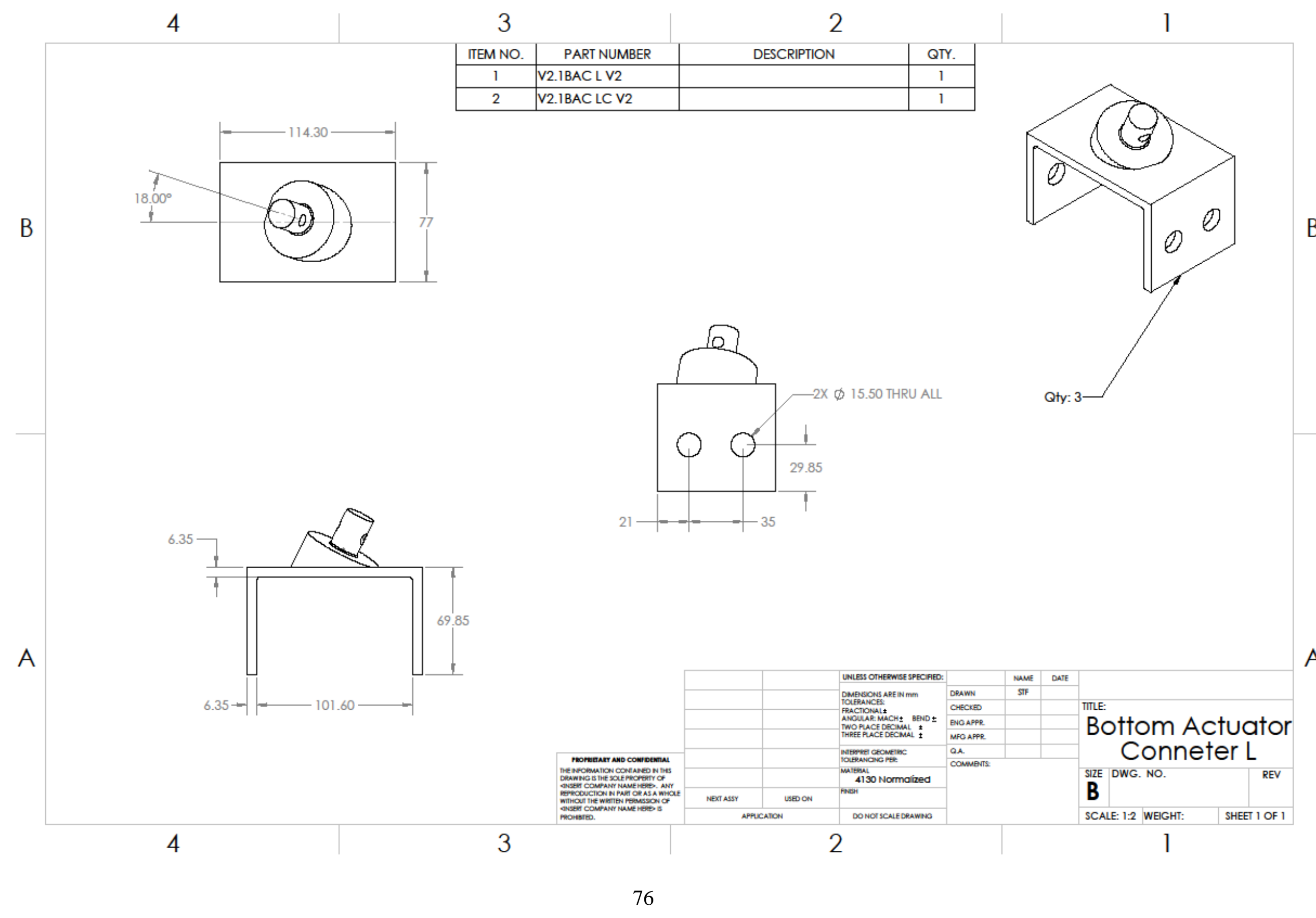




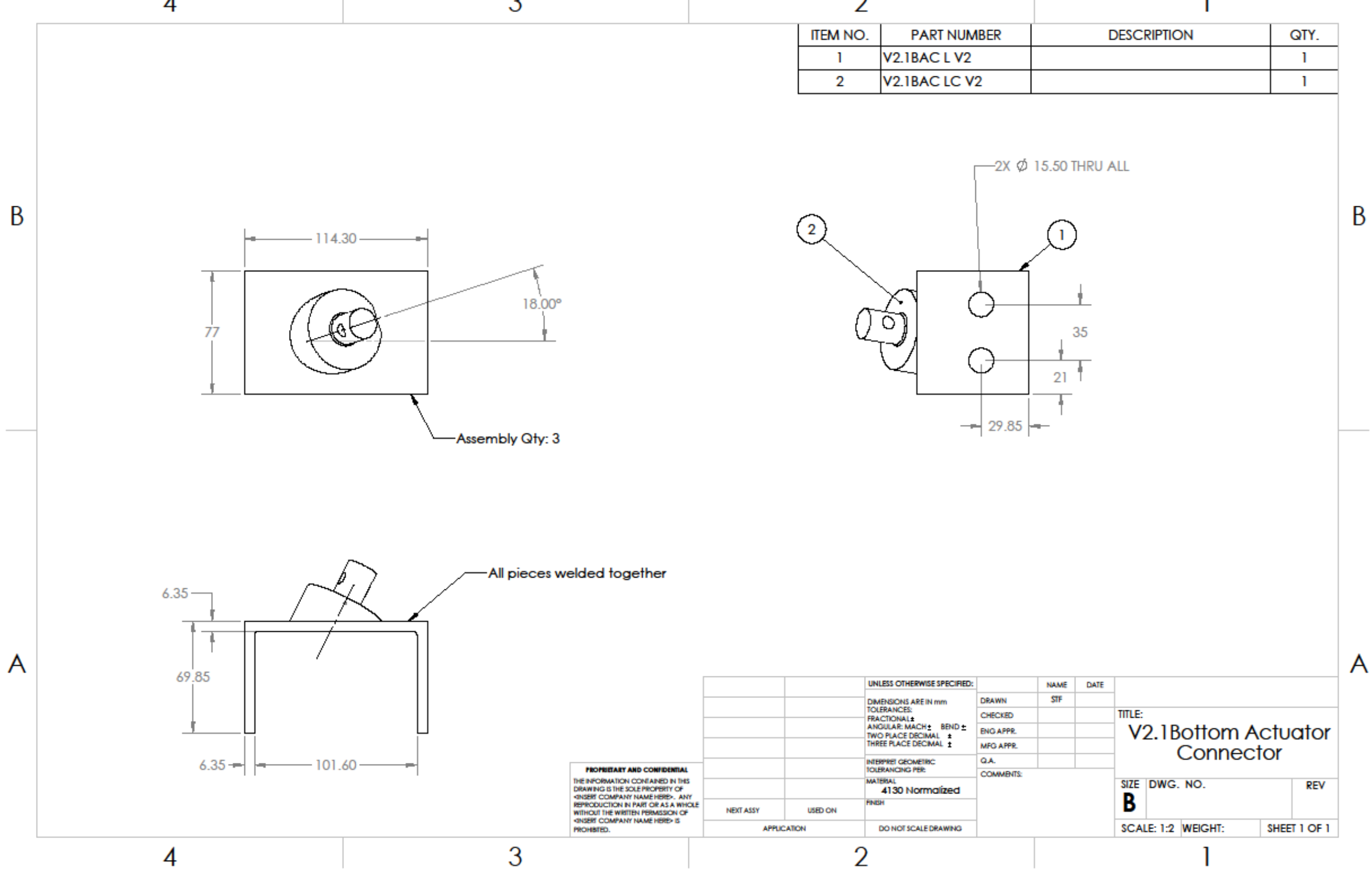



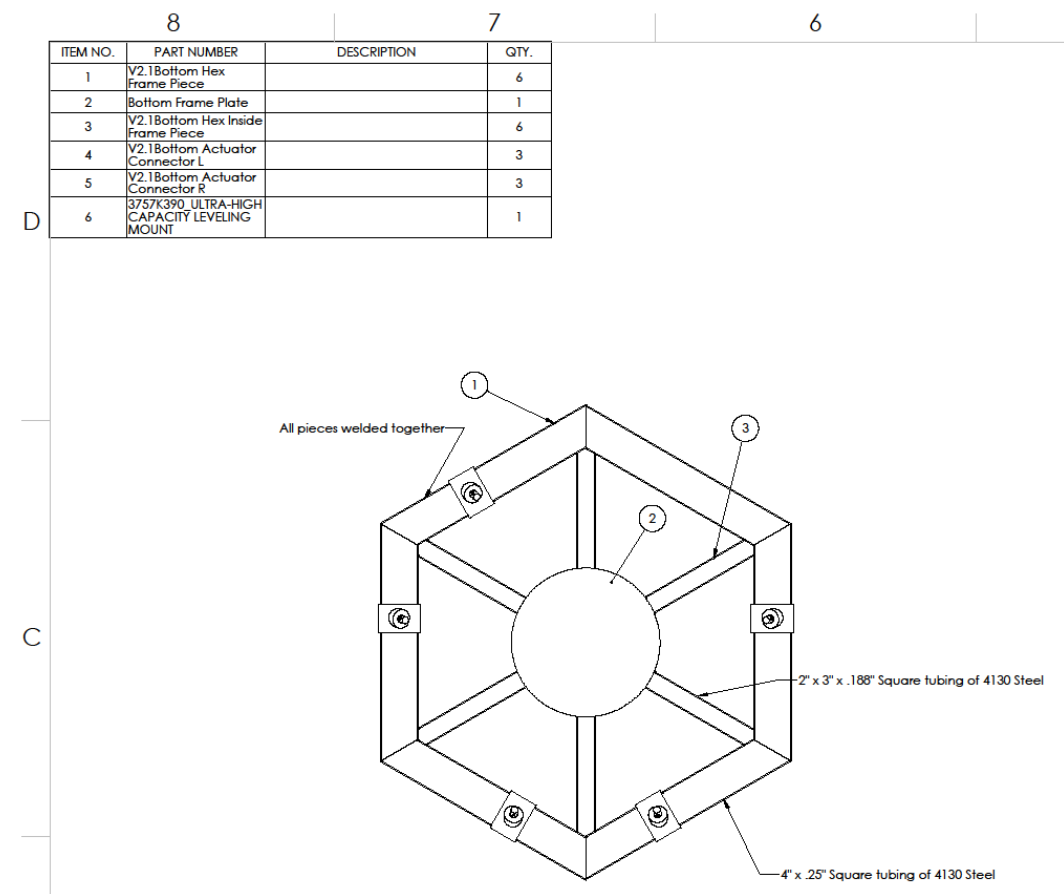

B

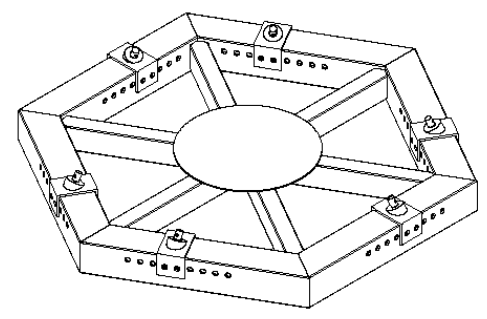

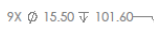
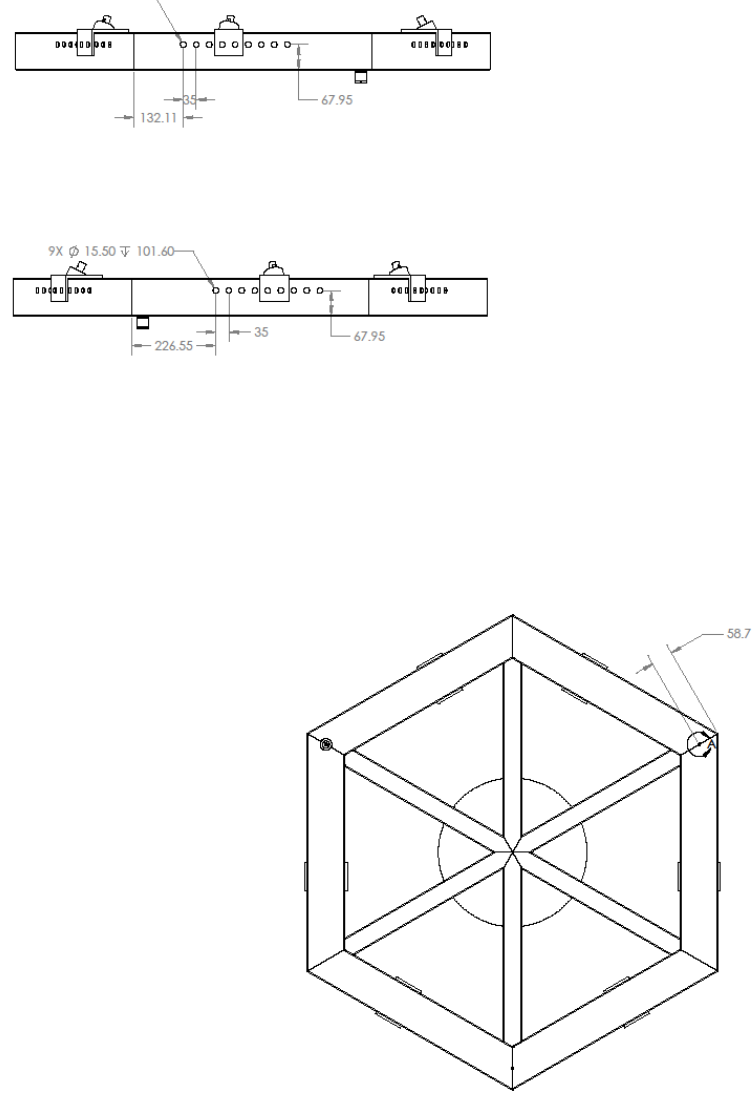

D

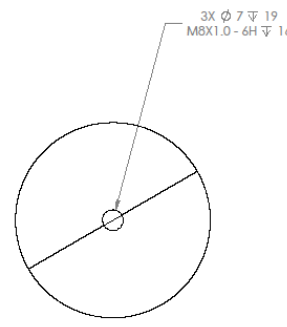

DEAAAA

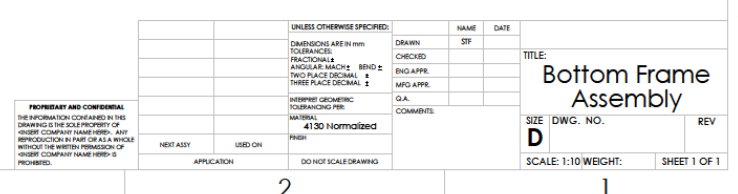




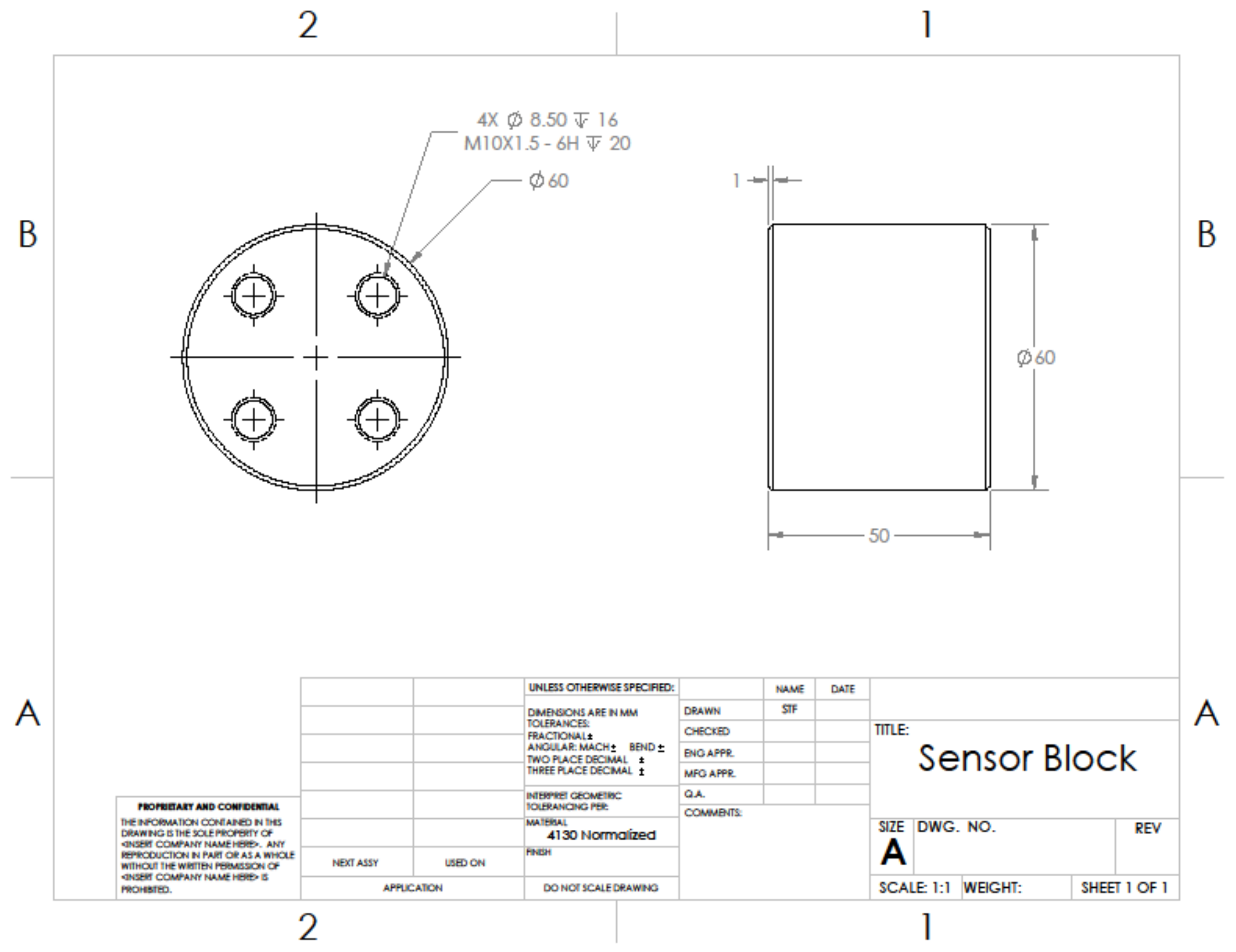



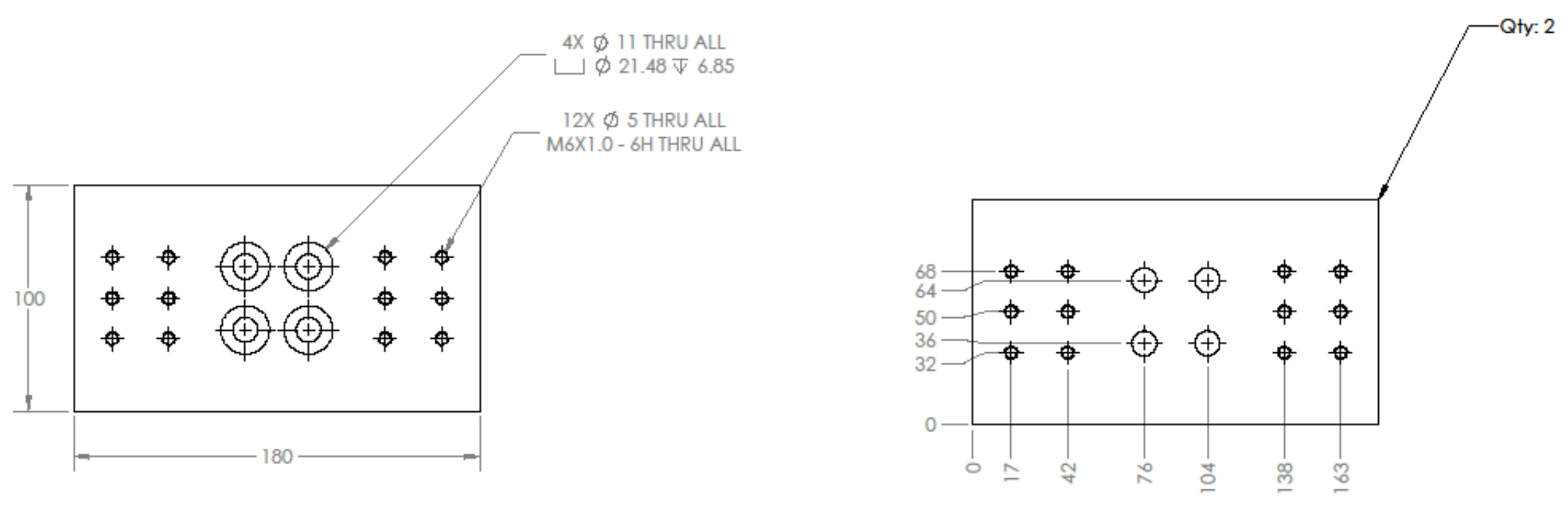

B

A
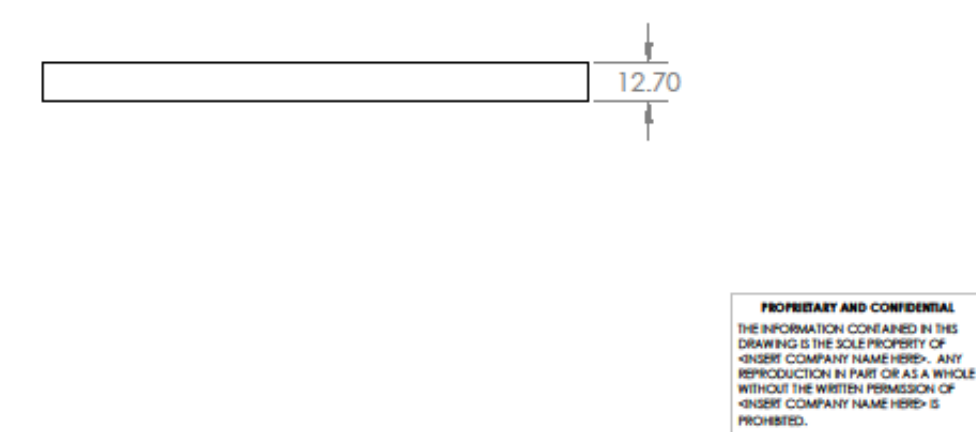
3

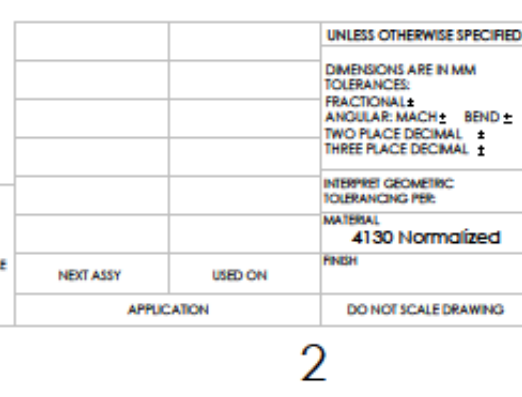

\begin{tabular}{|c|c|c|}
\hline & ReME & DATE \\
\hline DRAWN & S्ञाF & \\
\hline CAECKED & & \\
\hline ENO APPR & & \\
\hline MFO APPR & & \\
\hline as. & & \\
\hline Converrs & & \\
\hline
\end{tabular}

A Grip Adapter 2 BIII DWG. No. Adapter $2^{\text {REV }}$ SCALE: 1:2 WEGGH: SHEE 1 OF 1 
D

C
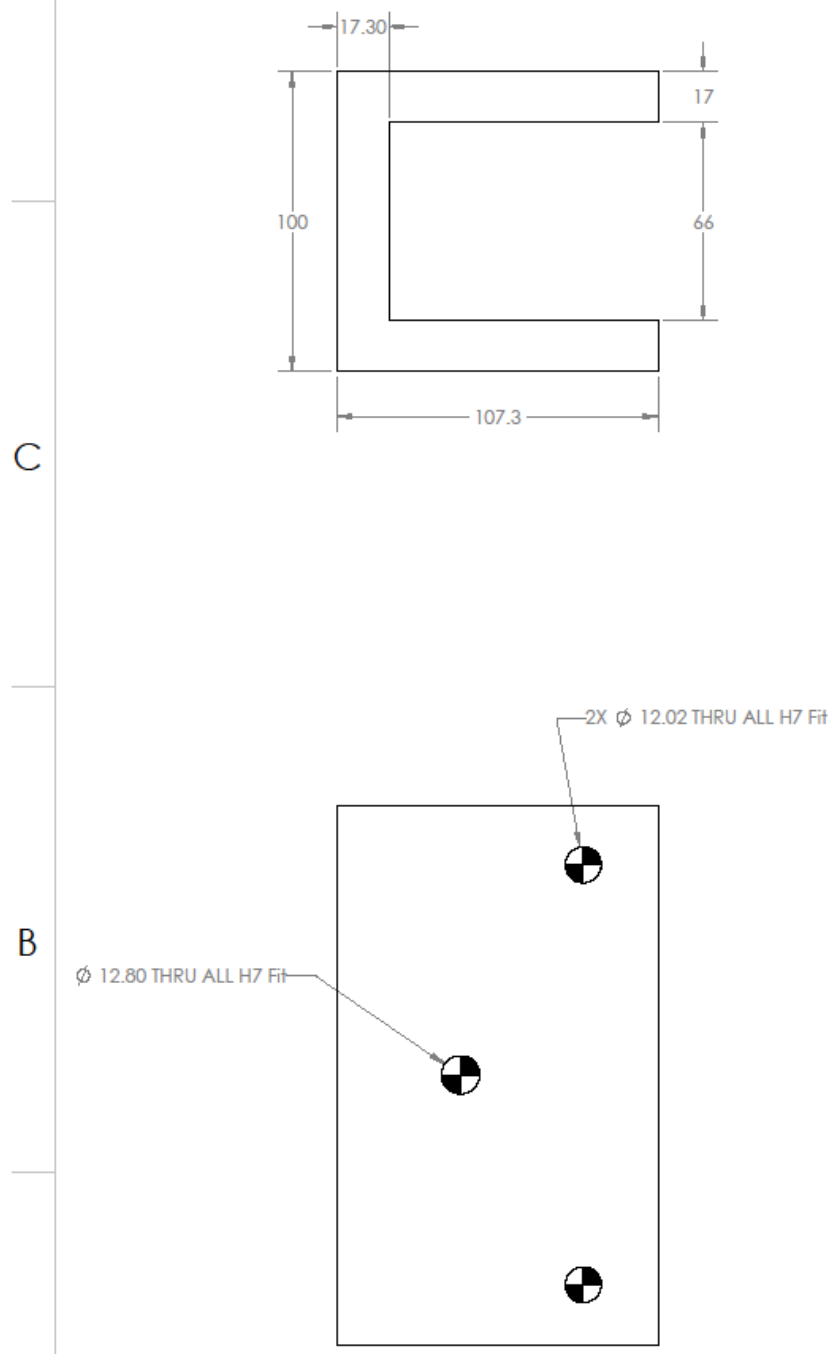

A

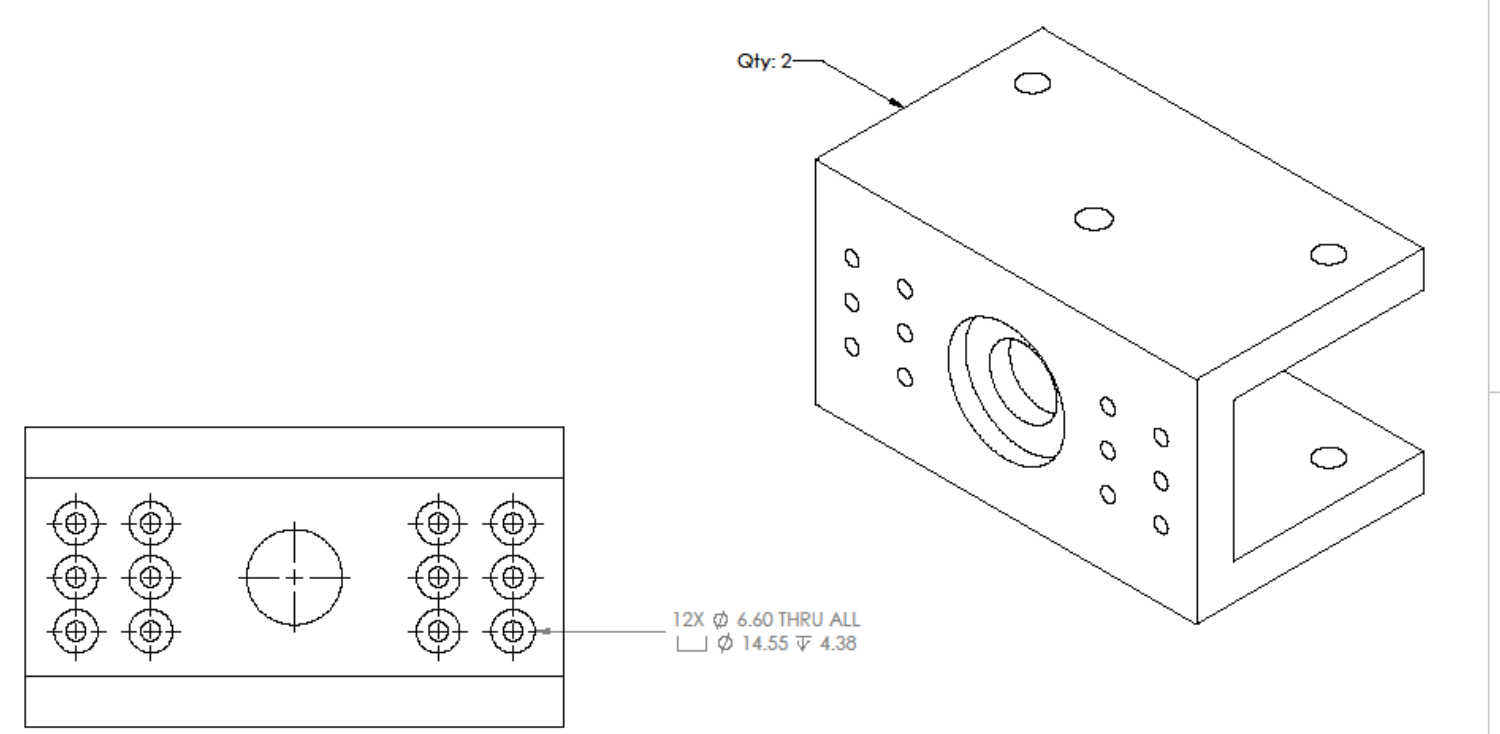

C
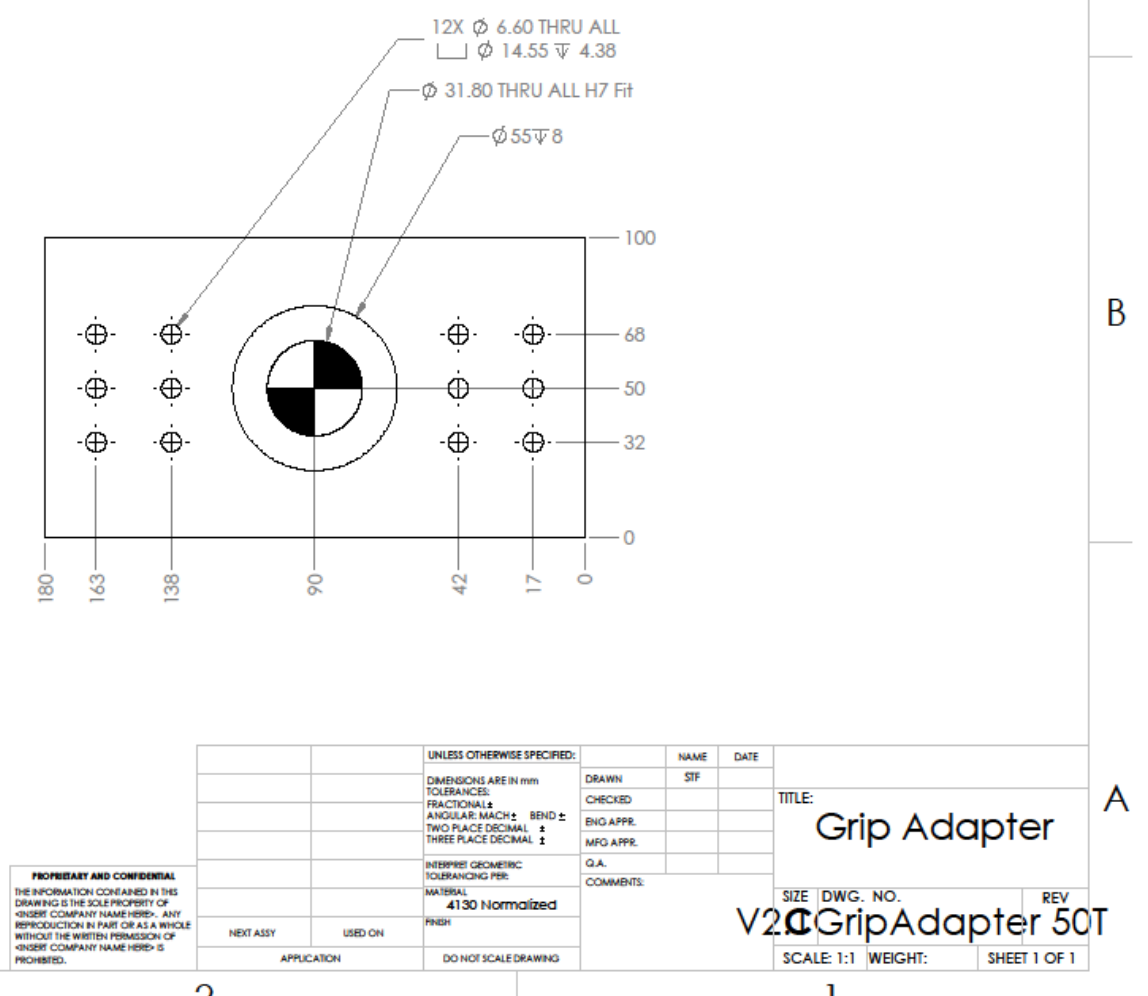


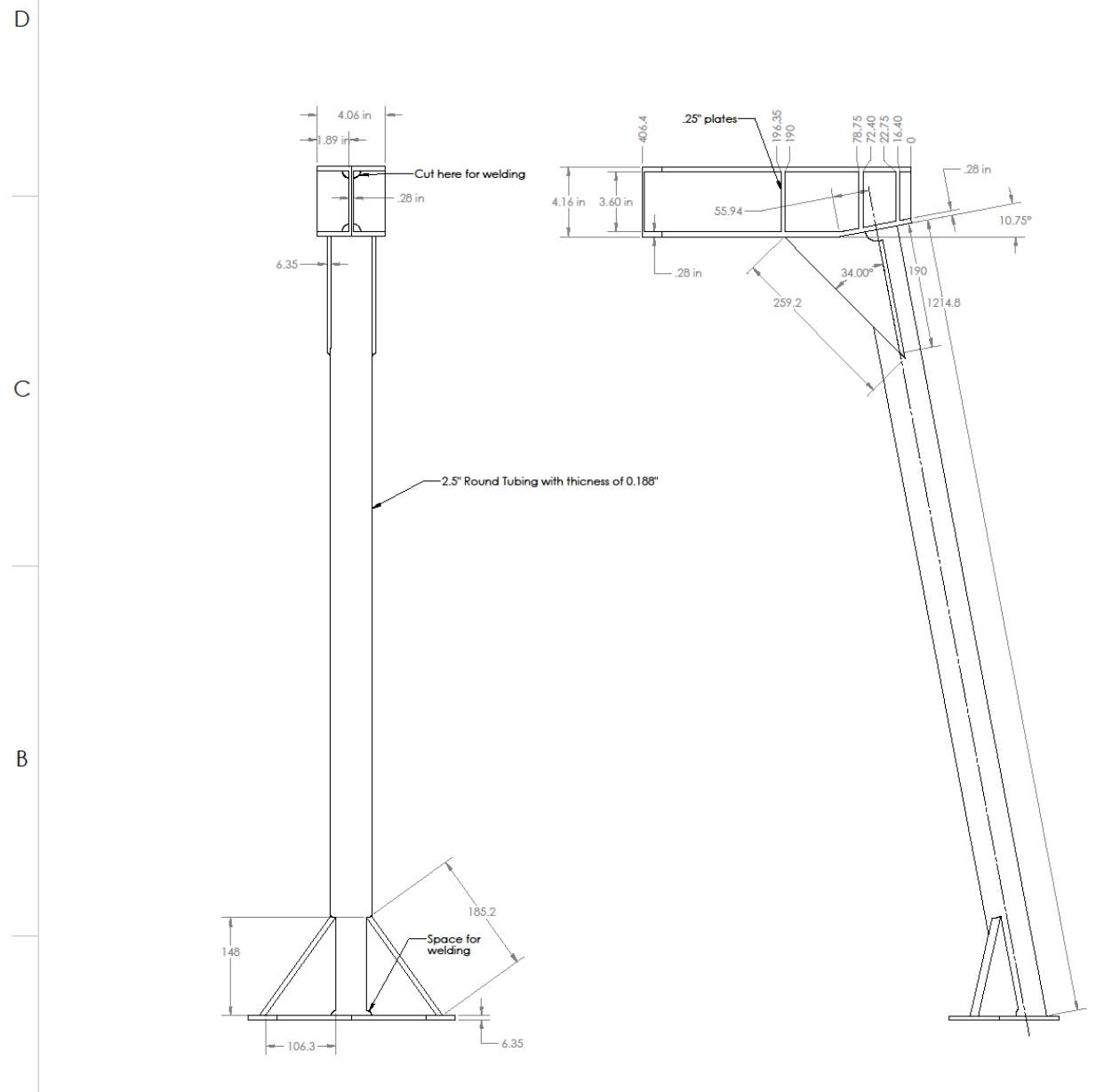

A

|

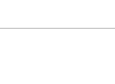

$+2$

$\mid+2 \cdot+2$

5

4

7

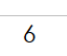

6

5
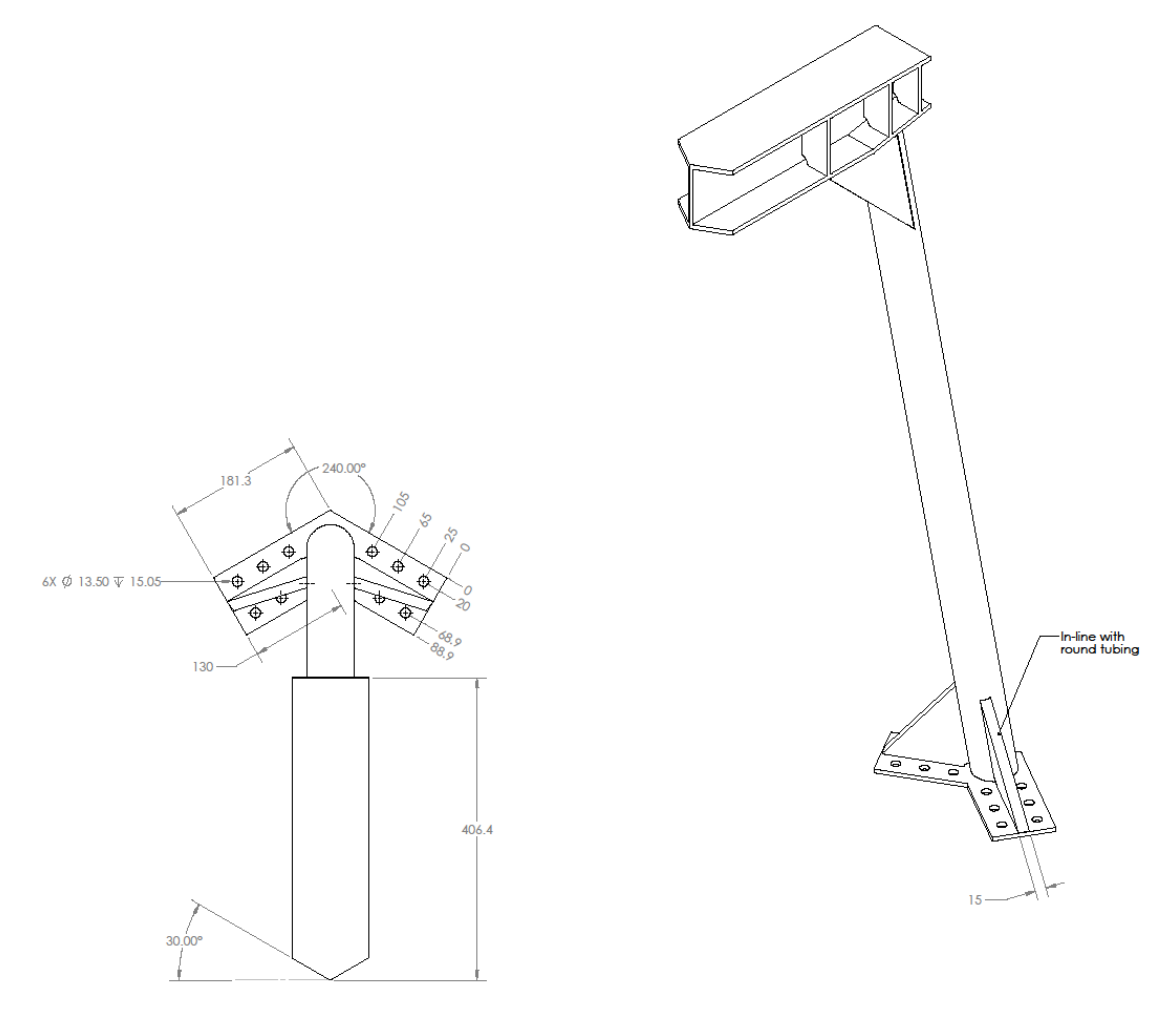

D

C

B

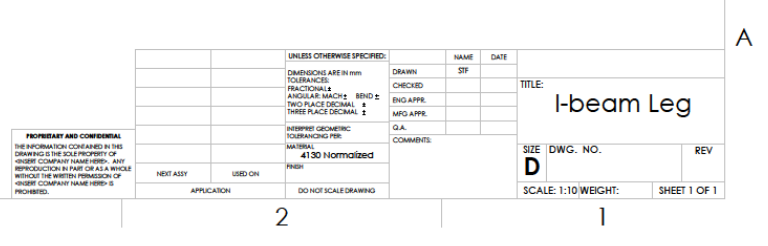




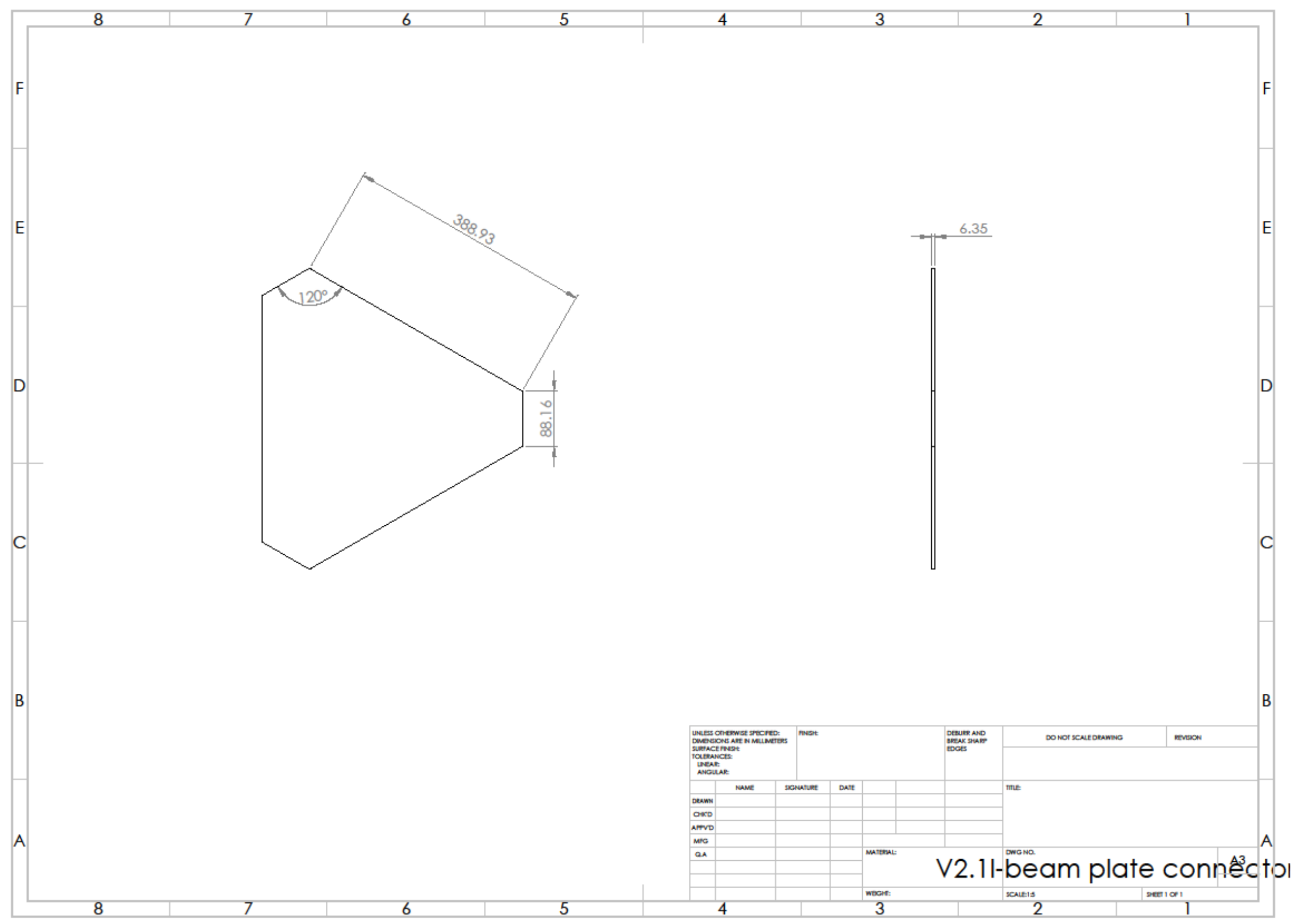



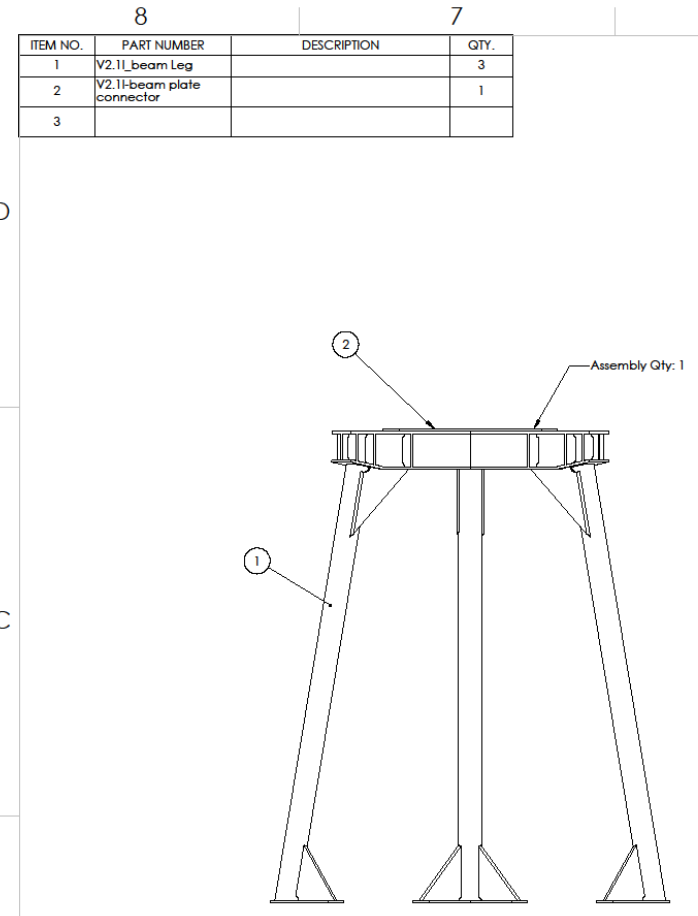
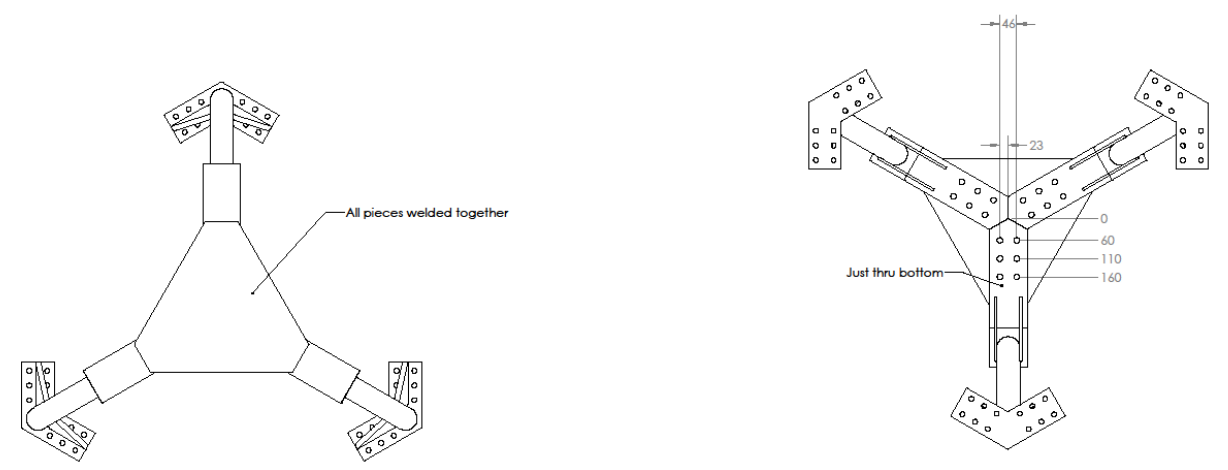

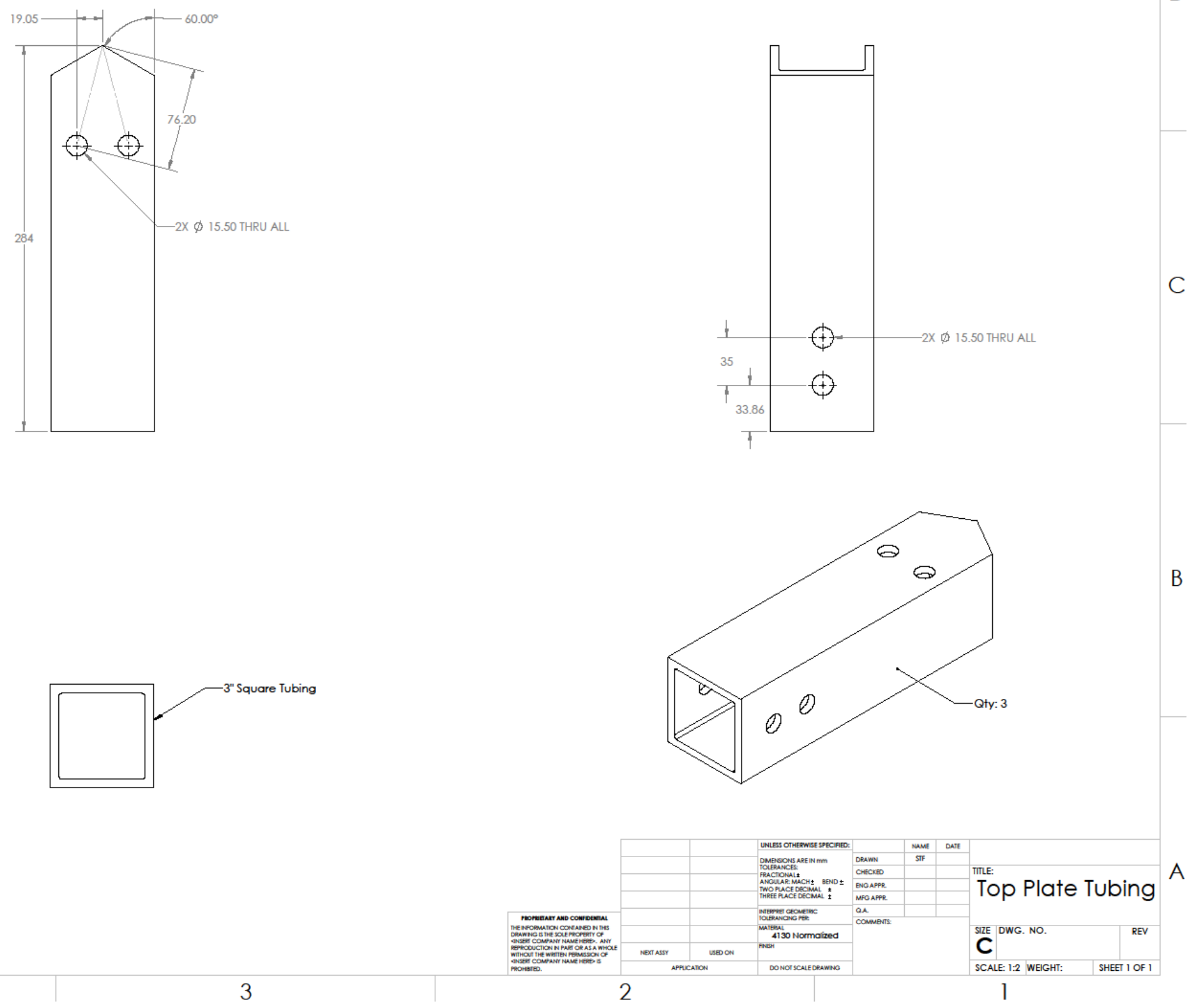

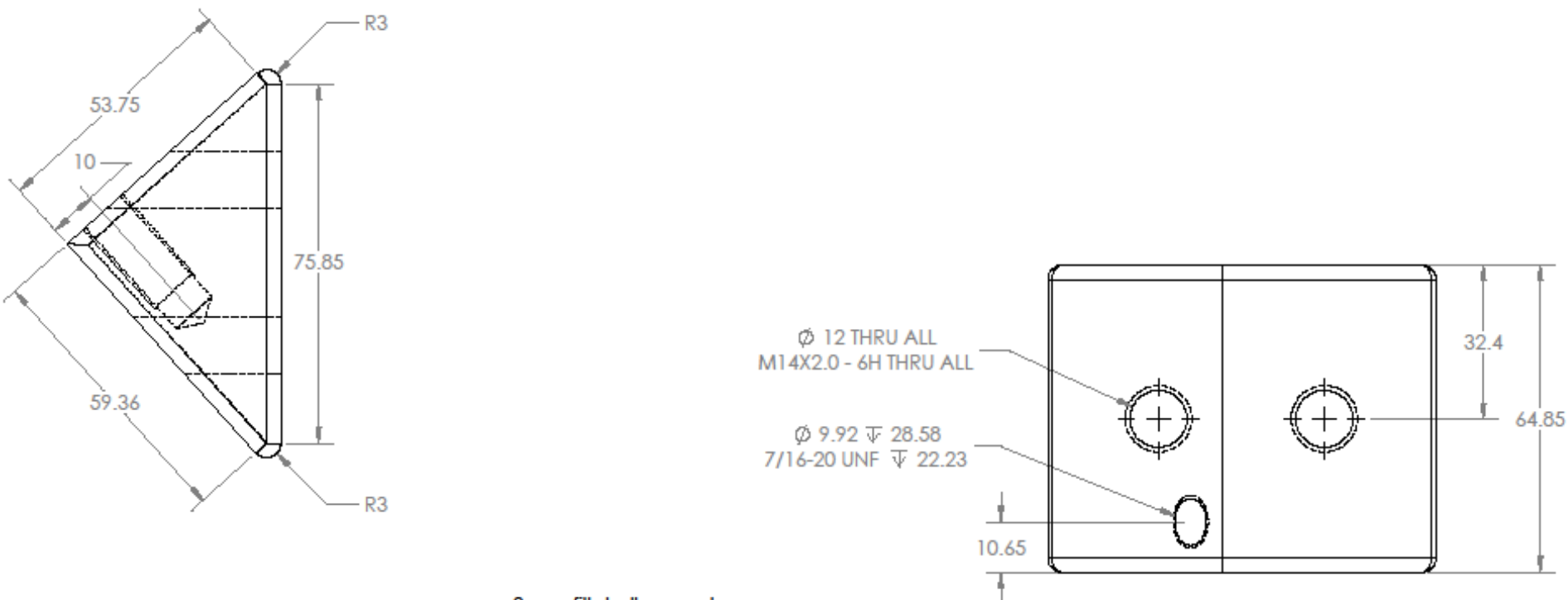

A

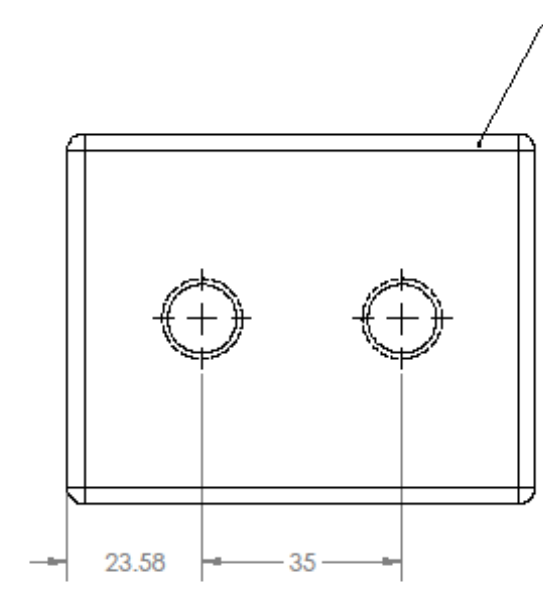

4
3

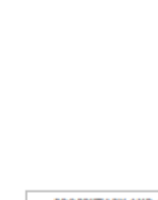

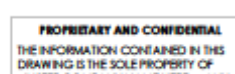

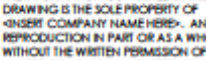

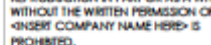

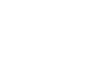

3

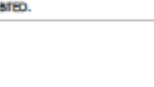

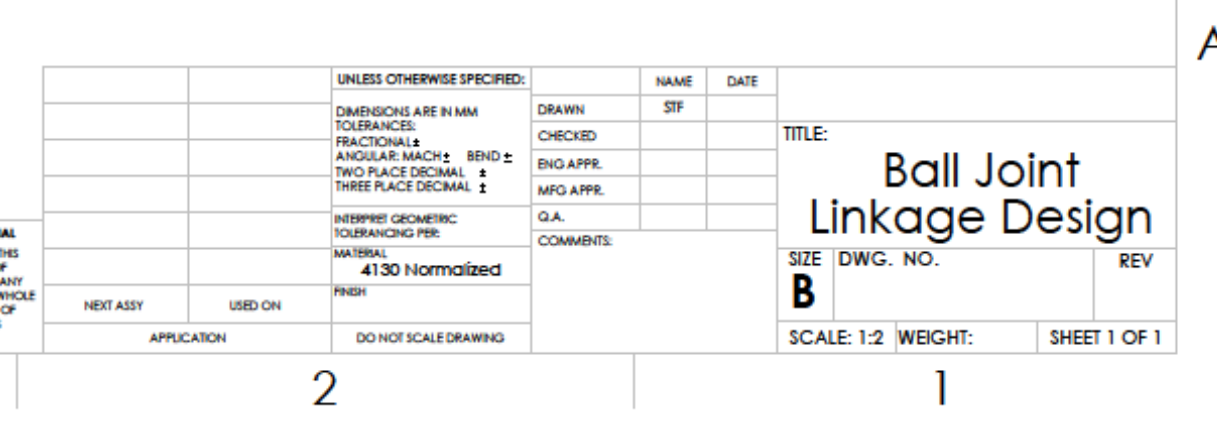


B

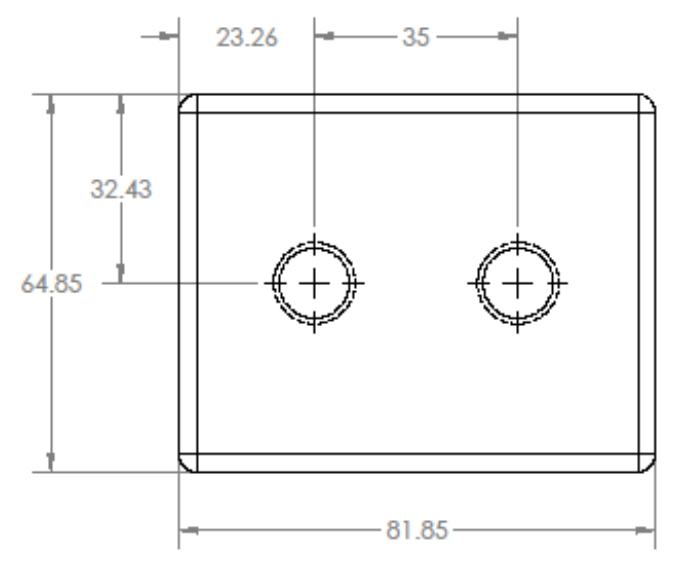

A

4

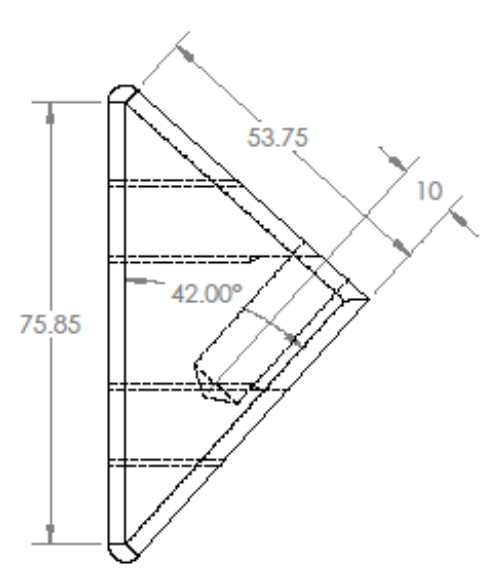

3

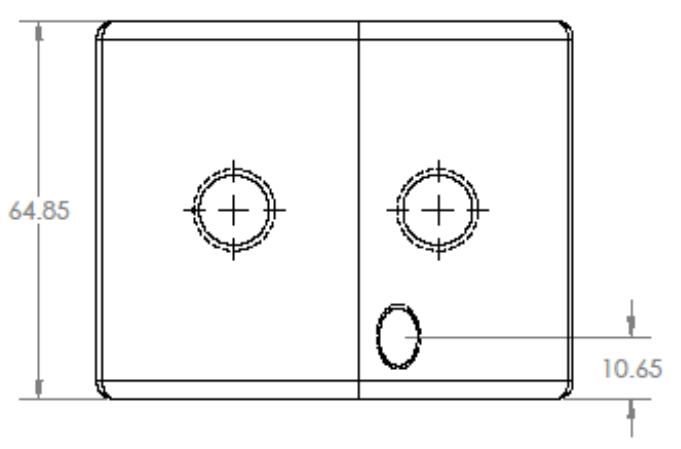

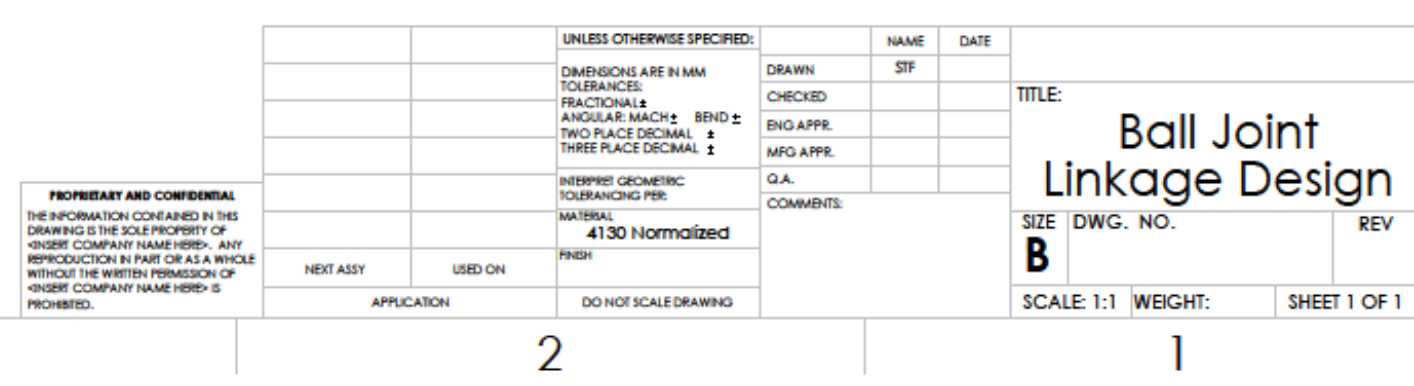




\begin{tabular}{|c|c|c|c|}
\hline IIEM NO. & PART NUMBER & DESCRIPTION & QTY. \\
\hline 1 & 2 V2.1Top Plate $\mathrm{F}$ & & 3 \\
\hline & & & \\
\hline & & & \\
\hline
\end{tabular}

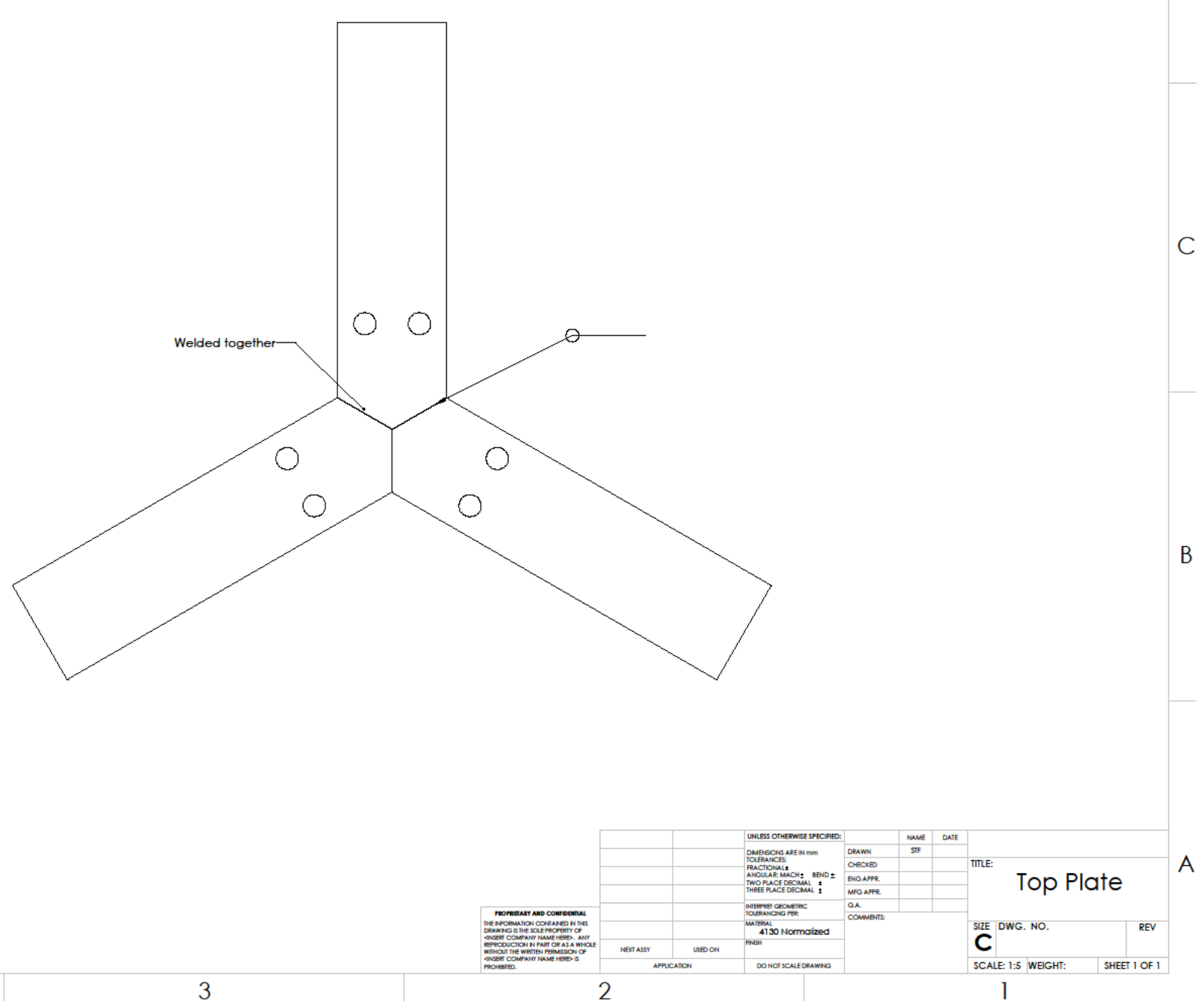




\section{Appendix C: Matlab Code for Singularity analysis}

\section{Main File:}

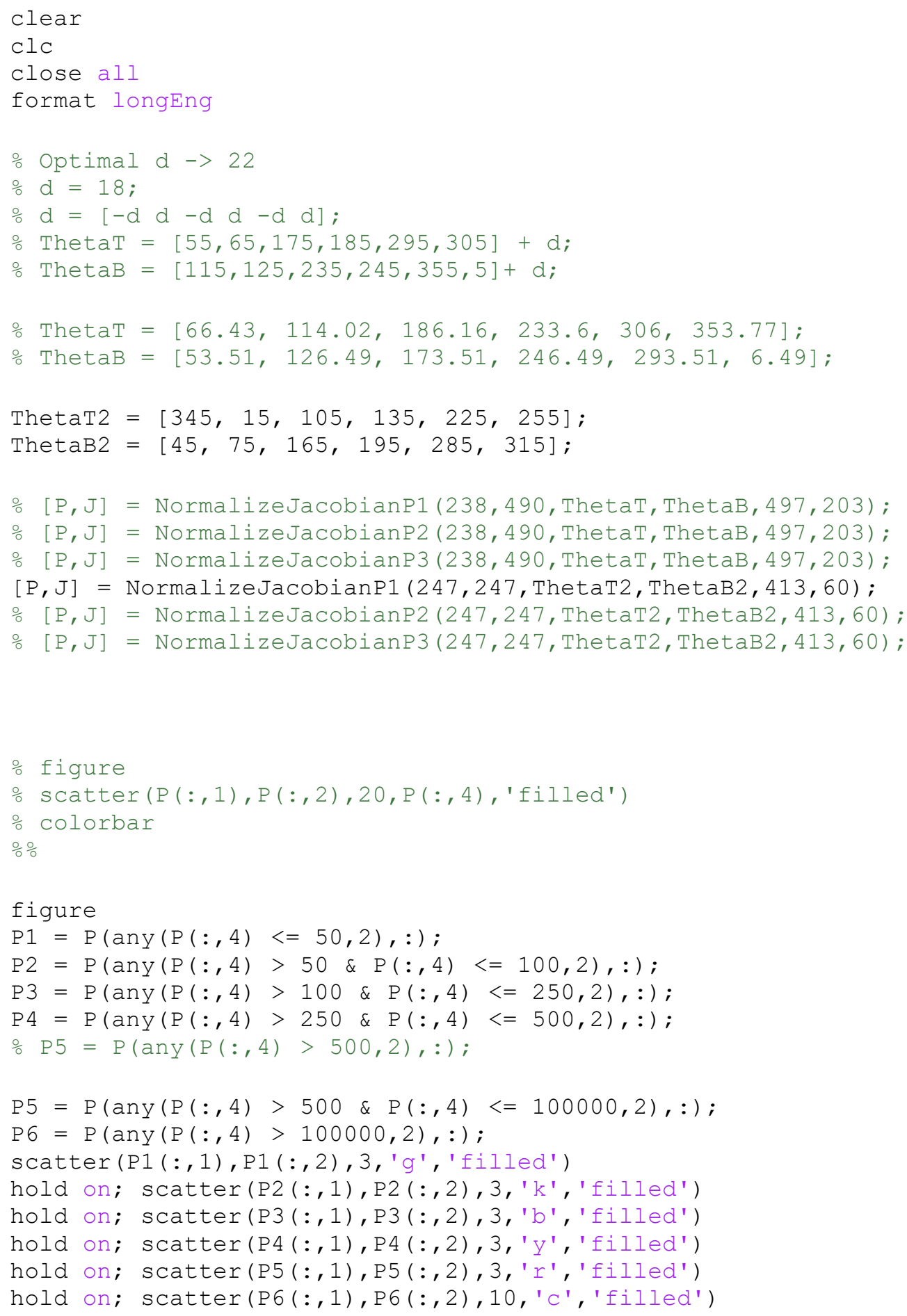




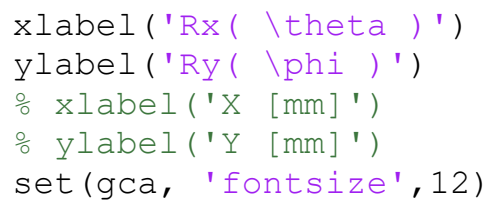

\section{Second File: NormalizeJacobianP2}

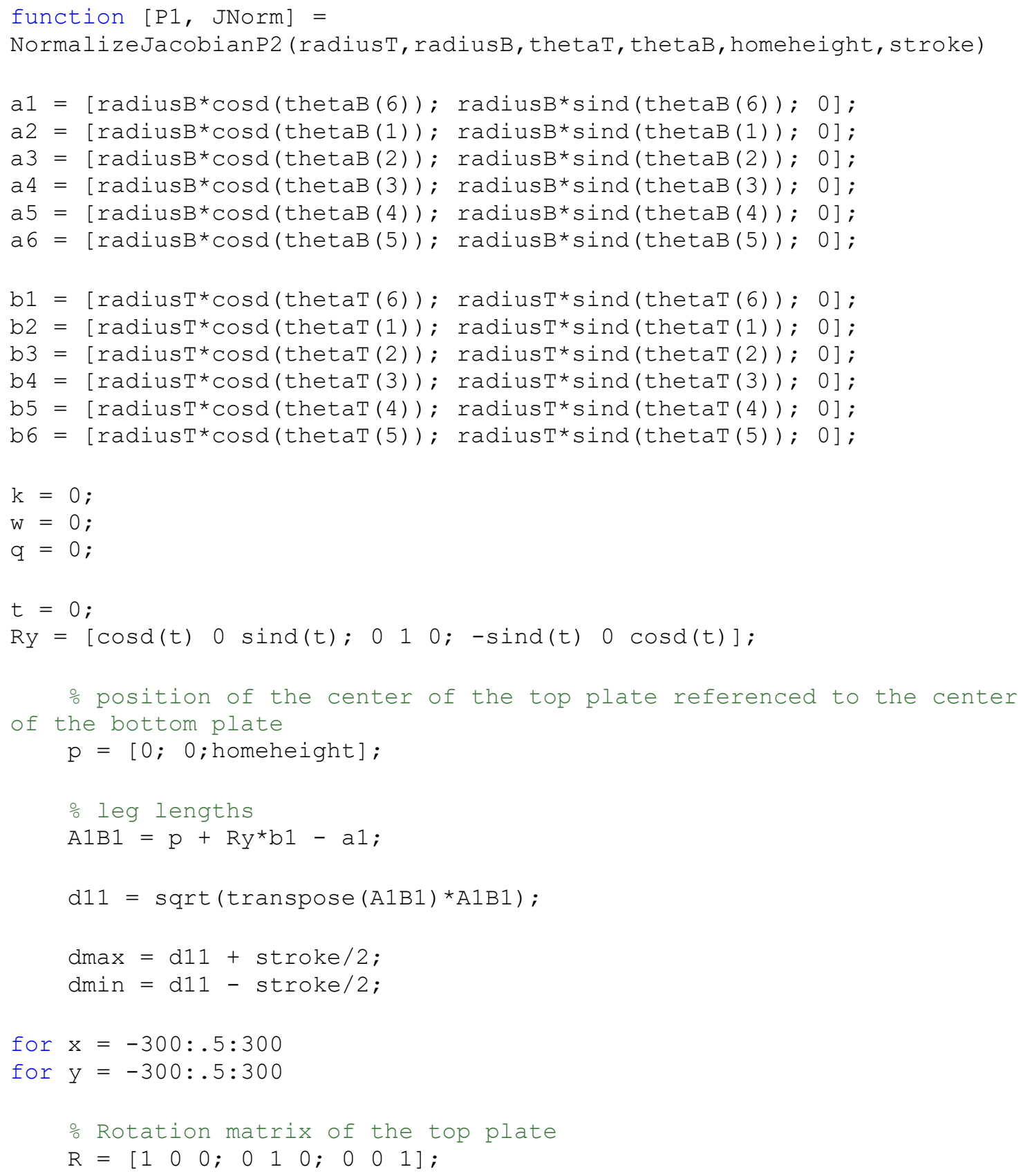




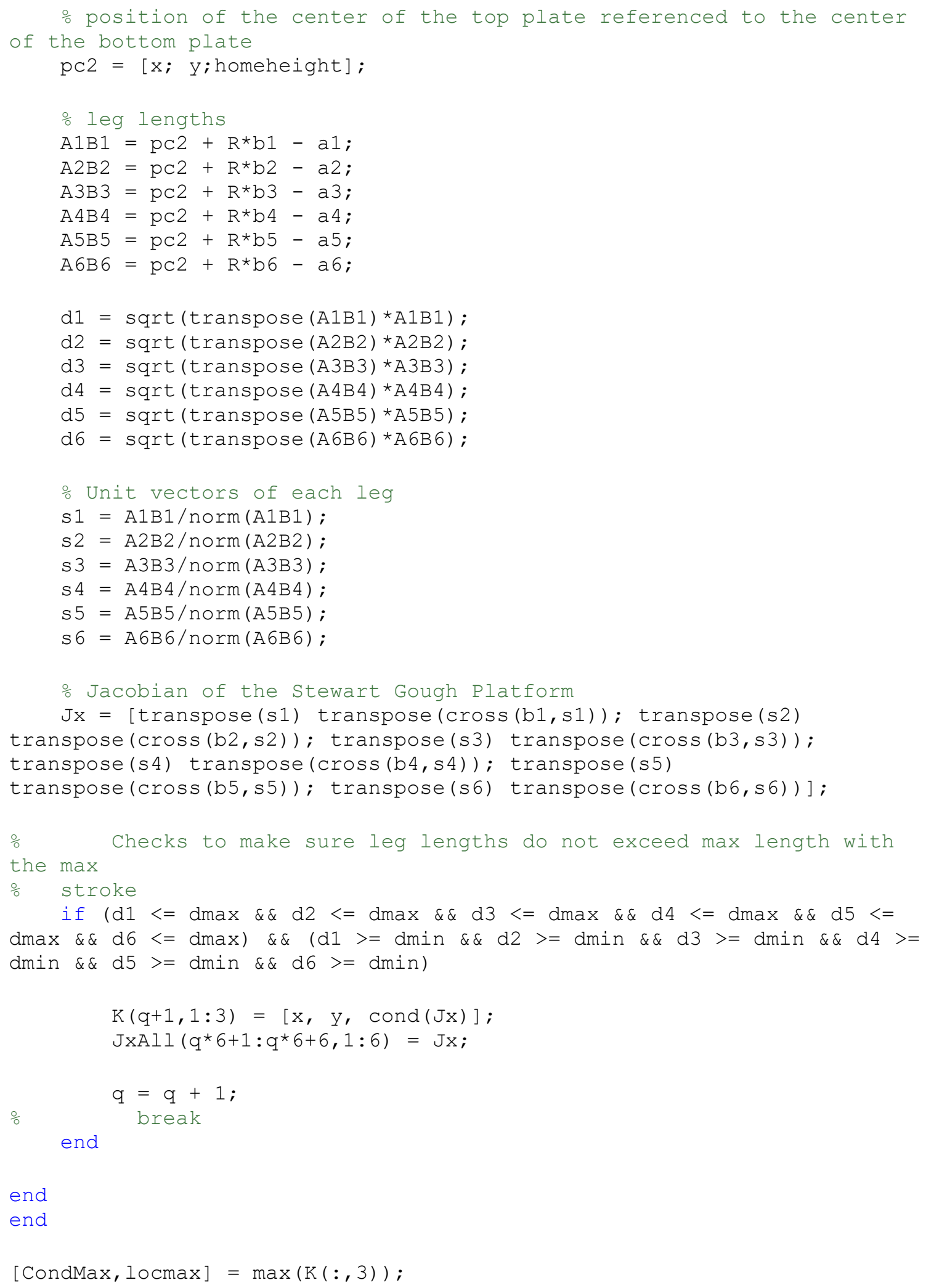




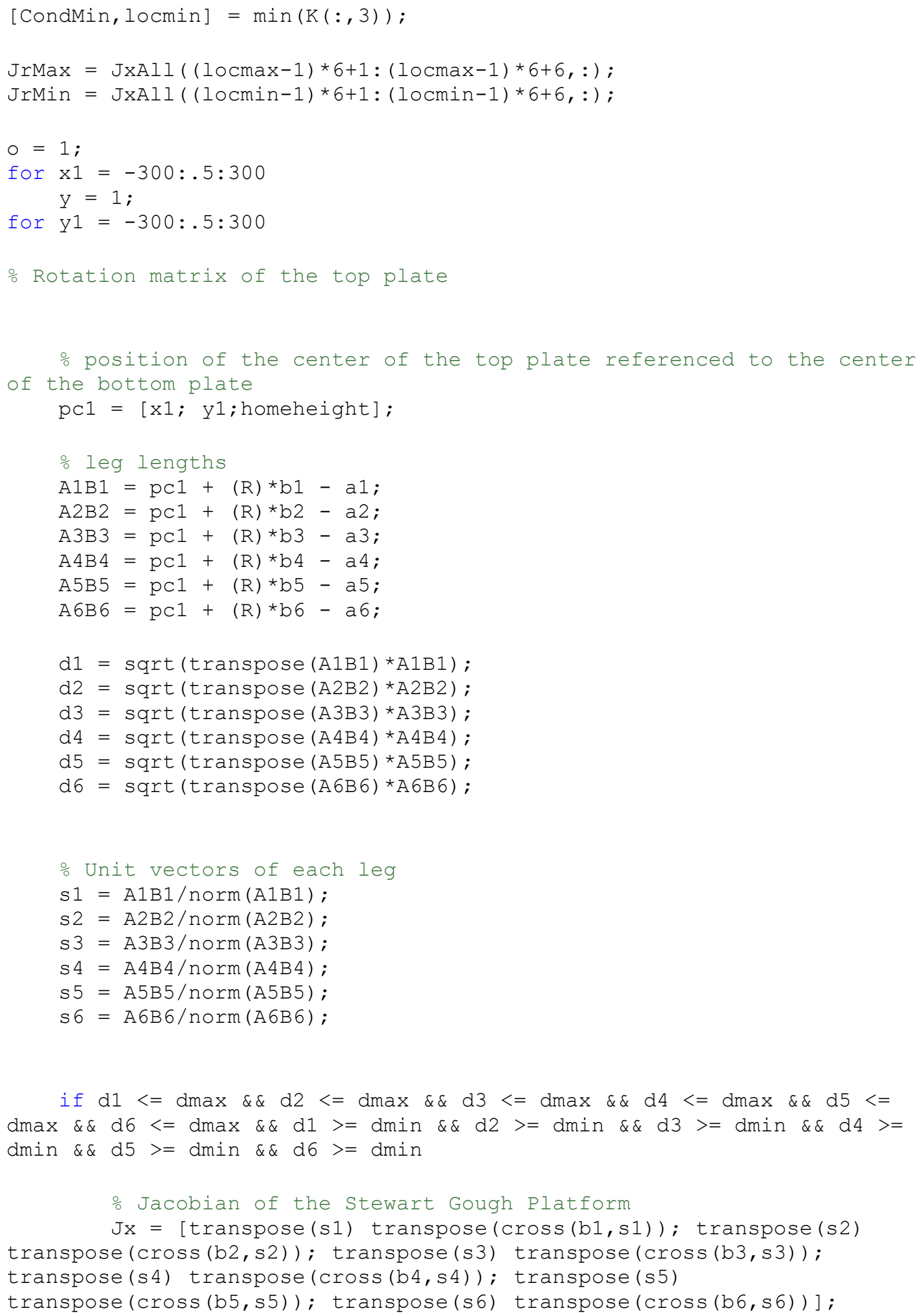




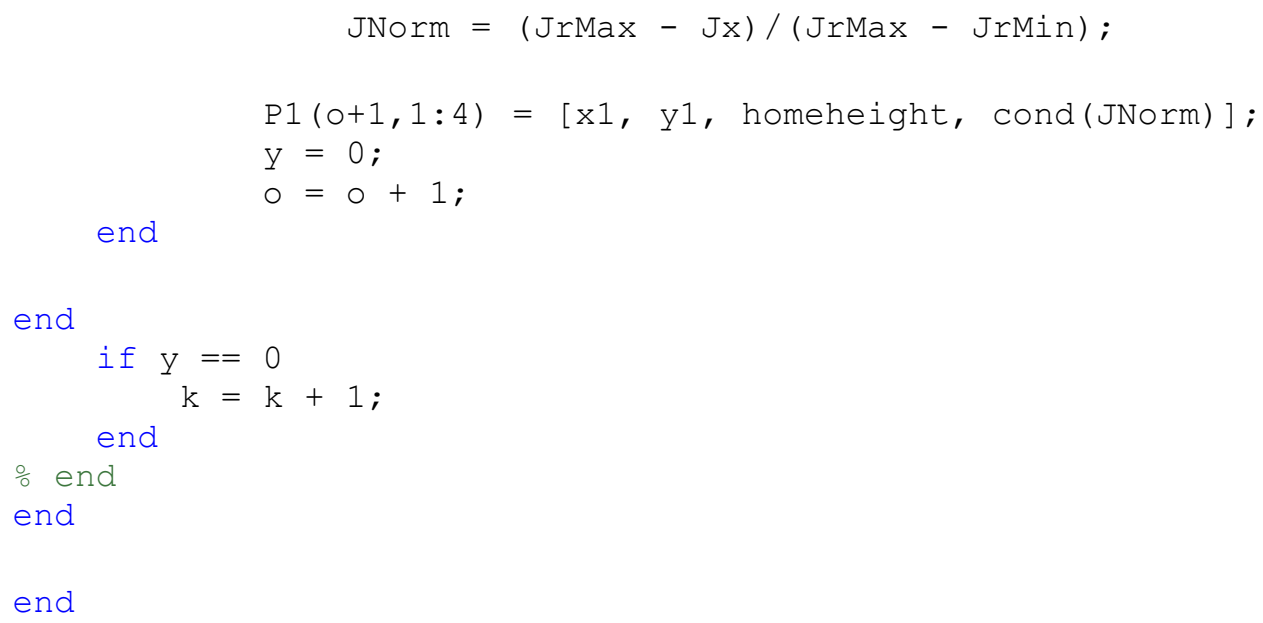

\section{Third File: NormalizeJacobianP1}

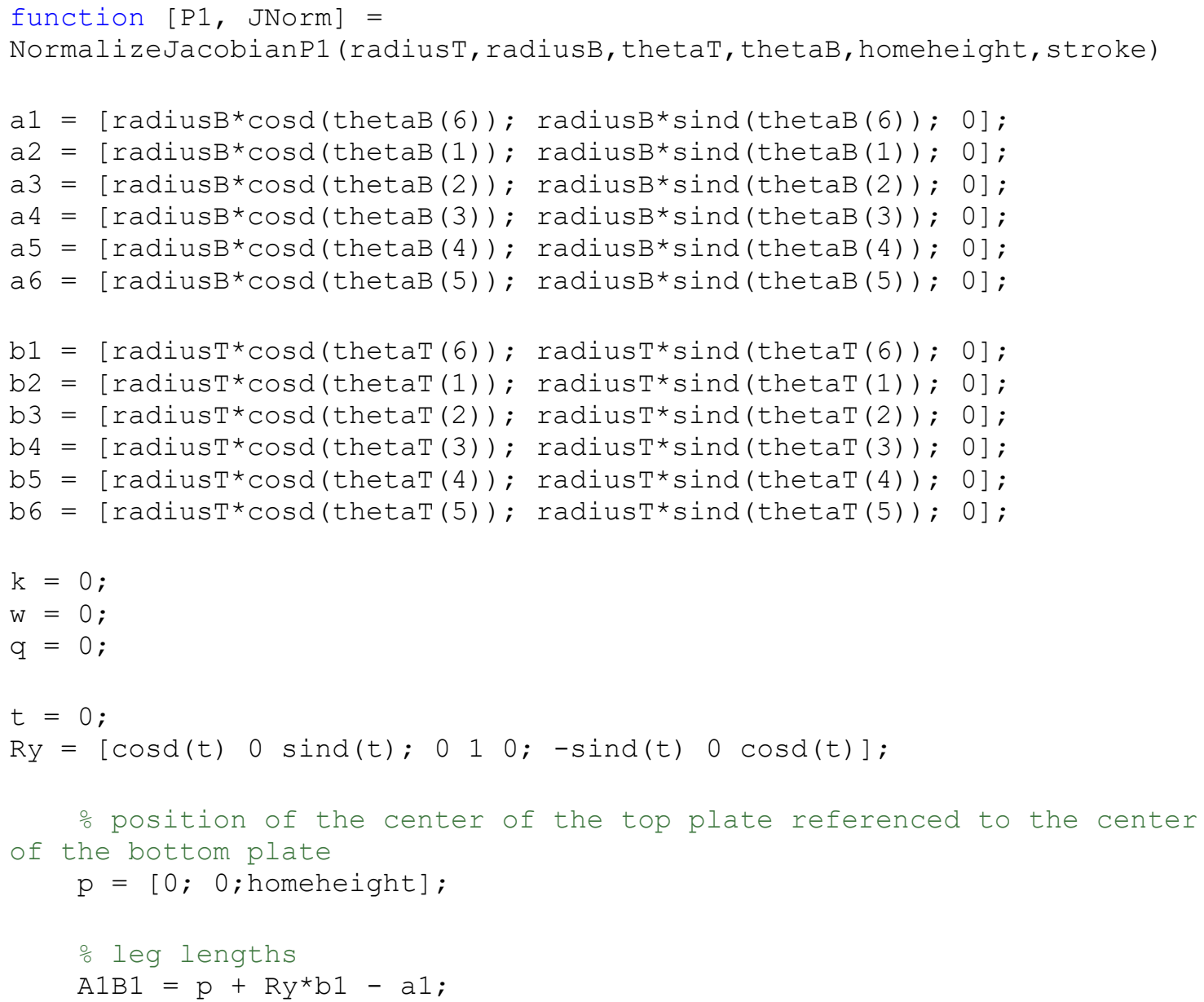




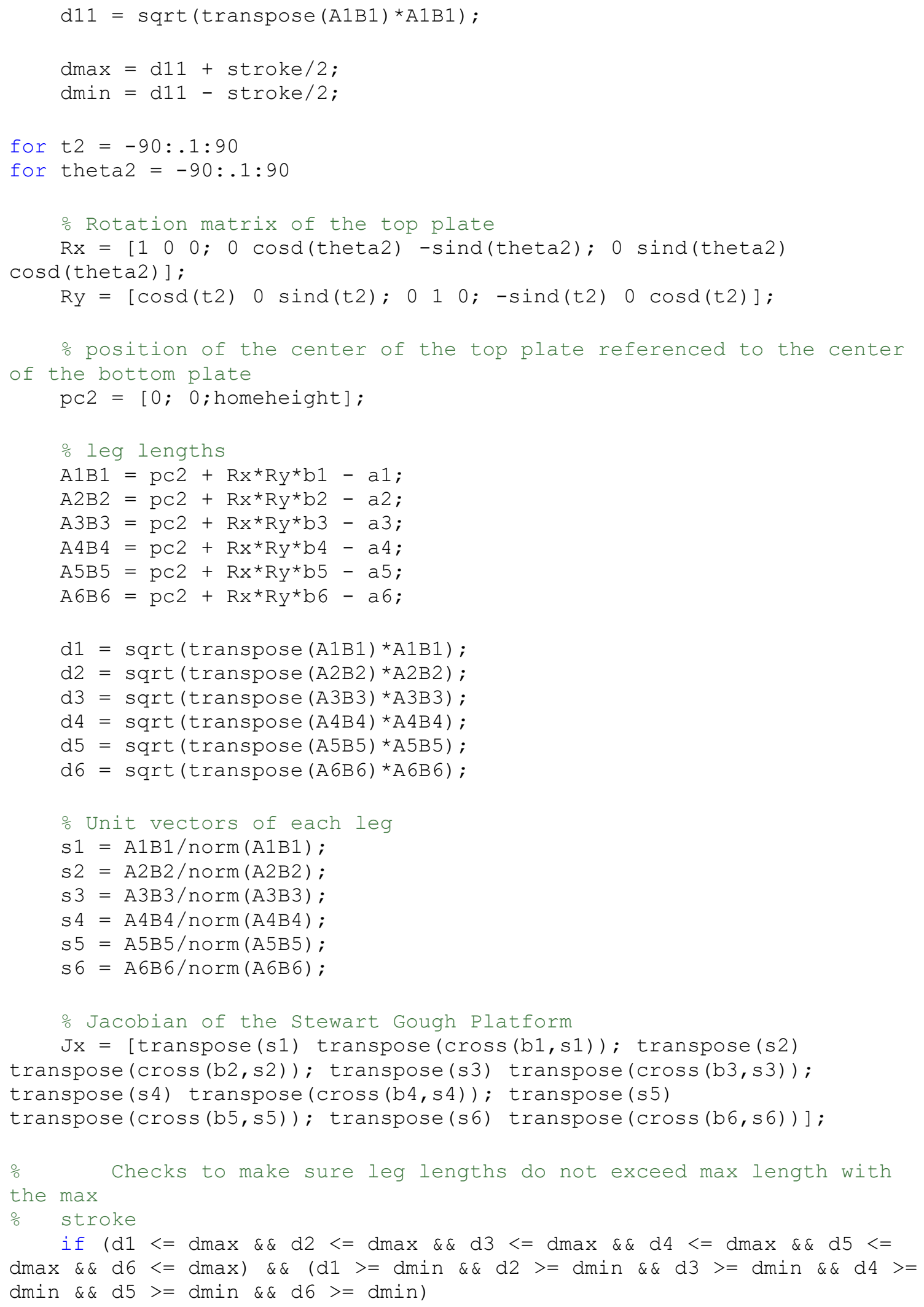


$\mathrm{K}(\mathrm{q}+1,1: 3)=[\mathrm{t} 2$, theta2, $\operatorname{cond}(\mathrm{Jx})]$; $\operatorname{JxAll}(q * 6+1: q * 6+6,1: 6)=\mathrm{Jx}$;

end

$q=q+1$

end

end

$[$ CondMax, locmax $]=\max (\mathrm{K}(:, 3))$;

$[$ CondMin, locmin $]=\min (\mathrm{K}(:, 3))$;

$\operatorname{JrMax}=\operatorname{JxAll}((\operatorname{locmax}-1) * 6+1:(\operatorname{locmax}-1) * 6+6,1: 6) ;$

JrMin $=\operatorname{JxAll}((\operatorname{locmin}-1) * 6+1:(1 \circ \mathrm{cmin}-1) * 6+6,1: 6) ;$

$0=1$

for $t=-90: .1: 90$

$\mathrm{y}=1$

for thetal $=-90: .1: 90$

\% Rotation matrix of the top plate

$\mathrm{Rx}=\left[\begin{array}{lllll}1 & 0 & 0\end{array} \mathbf{0}\right.$ cosd (thetal) -sind(thetal); 0 sind(thetal)

cosd (thetal) ];

Ry $=[\operatorname{cosd}(t) 0$ sind $(t) ; 010 ;-\operatorname{sind}(t) 0 \operatorname{cosd}(t)]$;

o position of the center of the top plate referenced to the center

of the bottom plate

pcl $=[0 ; 0 ;$ homeheight $]$;

leg lengths

$\mathrm{A} 1 \mathrm{~B} 1=\mathrm{pc1}+(\mathrm{Rx} * \mathrm{Ry}) * \mathrm{~b} 1-\mathrm{a} 1$;

$\mathrm{A} 2 \mathrm{~B} 2=\mathrm{pc} 1+(\mathrm{Rx} * \mathrm{Ry}) * \mathrm{~b} 2-\mathrm{a} 2$;

$\mathrm{A} 3 \mathrm{~B} 3=\mathrm{pc1}+(\mathrm{Rx} * \mathrm{Ry}) * \mathrm{~b} 3-\mathrm{a} 3 ;$

$\mathrm{A} 4 \mathrm{~B} 4=\mathrm{pc1}+(\mathrm{Rx} * \mathrm{Ry}) * \mathrm{~b} 4-\mathrm{a} 4 ;$

$\mathrm{A} 5 \mathrm{~B} 5=\mathrm{pc1}+(\mathrm{Rx} * \mathrm{Ry}) * \mathrm{~b} 5-\mathrm{a} 5$;

$\mathrm{A} 6 \mathrm{~B} 6=\mathrm{pCl}+(\mathrm{Rx} * \mathrm{Ry}) * \mathrm{~b} 6-\mathrm{a} 6$;

$\mathrm{d} 1=\operatorname{sqrt}($ transpose $(\mathrm{A} 1 \mathrm{~B} 1) * \mathrm{~A} 1 \mathrm{~B} 1)$;

$\mathrm{d} 2=\operatorname{sqrt}\left(\right.$ transpose $\left.(\mathrm{A} 2 \mathrm{~B} 2){ }^{*} \mathrm{~A} 2 \mathrm{~B} 2\right)$;

$\mathrm{d} 3=\operatorname{sqrt}($ transpose $(\mathrm{A} 3 \mathrm{~B} 3) * \mathrm{~A} 3 \mathrm{~B} 3)$;

$\mathrm{d} 4=$ sqrt (transpose $(\mathrm{A} 4 \mathrm{~B} 4) * A 4 B 4)$;

$\mathrm{d} 5=\operatorname{sqrt}($ transpose $(\mathrm{A} 5 \mathrm{~B} 5) * \mathrm{~A} 5 \mathrm{~B} 5)$;

$d 6=\operatorname{sqrt}($ transpose $(\mathrm{A} 6 \mathrm{~B} 6) * \mathrm{~A} 6 \mathrm{~B} 6)$;

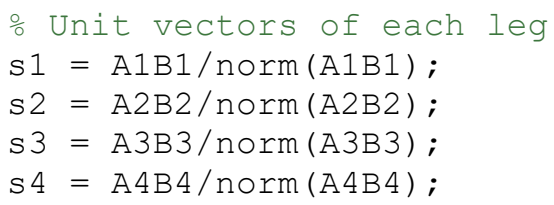




$$
\begin{aligned}
& \mathrm{s} 5=\mathrm{A} 5 \mathrm{~B} 5 / \operatorname{norm}(\mathrm{A} 5 \mathrm{~B} 5) \\
& \mathrm{s} 6=\mathrm{A} 6 \mathrm{~B} 6 / \text { norm }(\mathrm{A} 6 \mathrm{~B} 6) ;
\end{aligned}
$$

if $\mathrm{d} 1<=\mathrm{dmax} \& \& \mathrm{~d} 2<=\mathrm{dmax} \& \& \mathrm{~d} 3<=\mathrm{dmax} \& \& \mathrm{~d} 4<=\mathrm{dmax} \& \& \mathrm{~d} 5<=$

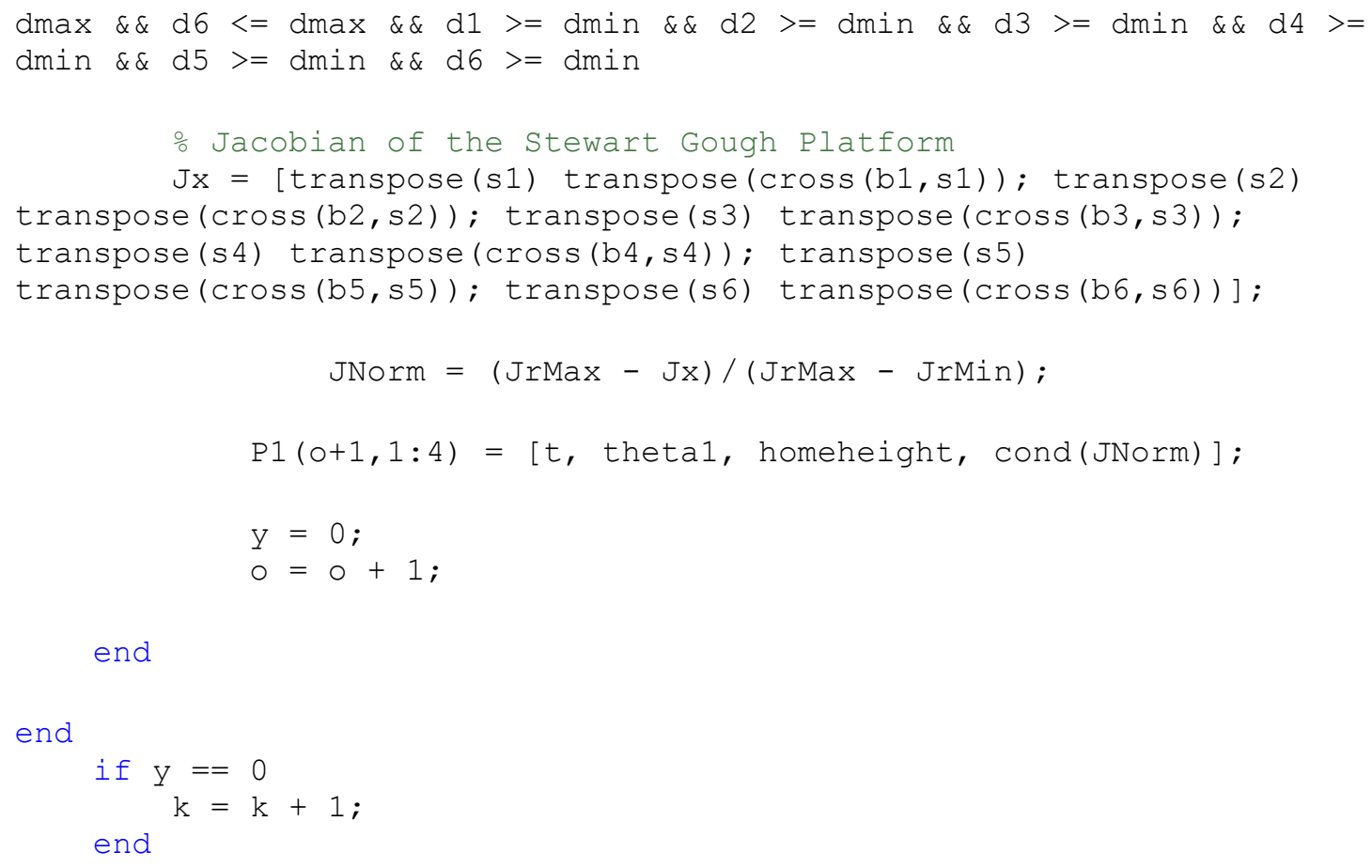

end

end

if $\mathrm{y}==0$

$\mathrm{k}=\mathrm{k}+1 ;$

end

end

end 


\section{Appendix D: Distance Measurement Package}

The code in Appendix A simply contains a PID library taken from Github (https://github.com/br3ttb/Arduino-PID-Library), optimal control for a certain speed. These values are a result of the moving average turned off. The next steps would be to implement these known values into a nonlinear control algorithm so that accurate control can be achieved as the speed changes. Hardware includes a RoboteQ FDC3260 motor controller, Arduino Due, ADS1115, an NRL based circuit board, Parker electrohydraulic actuators (EHA), and a TE SP2 string potentiometer (https://www.te.com/usa-en/product-CAT-

CAPS0068.html?q=\&d=484864\%20484868\%20484872\&type=products \&samples=N\#mdp-tabs-content) with a separate power source (12 V).

\section{CODE:}

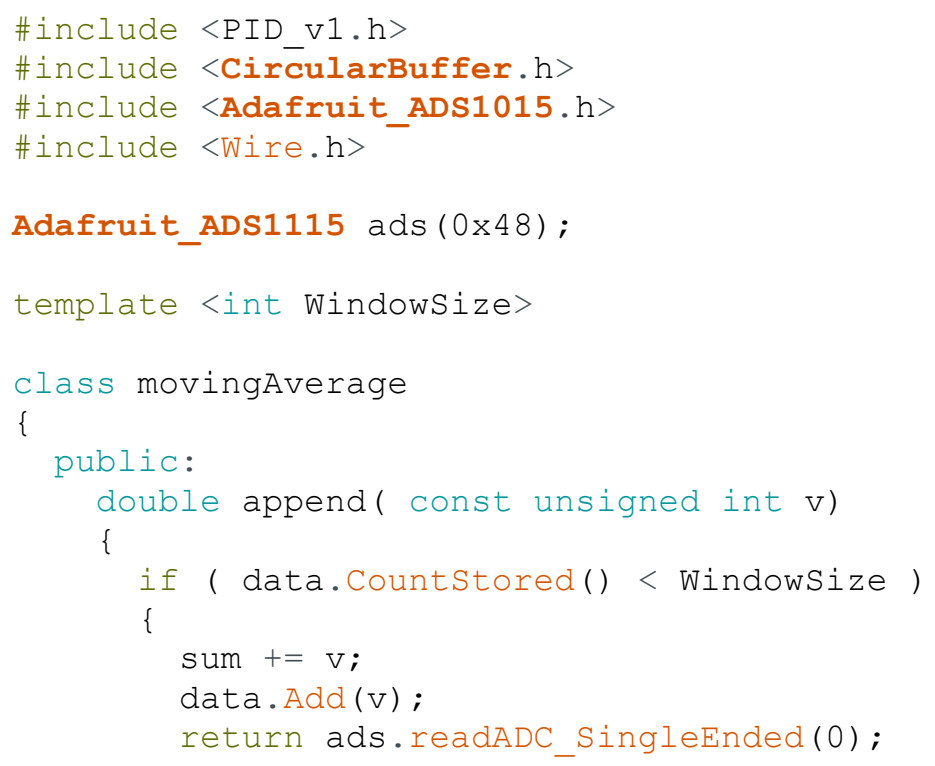




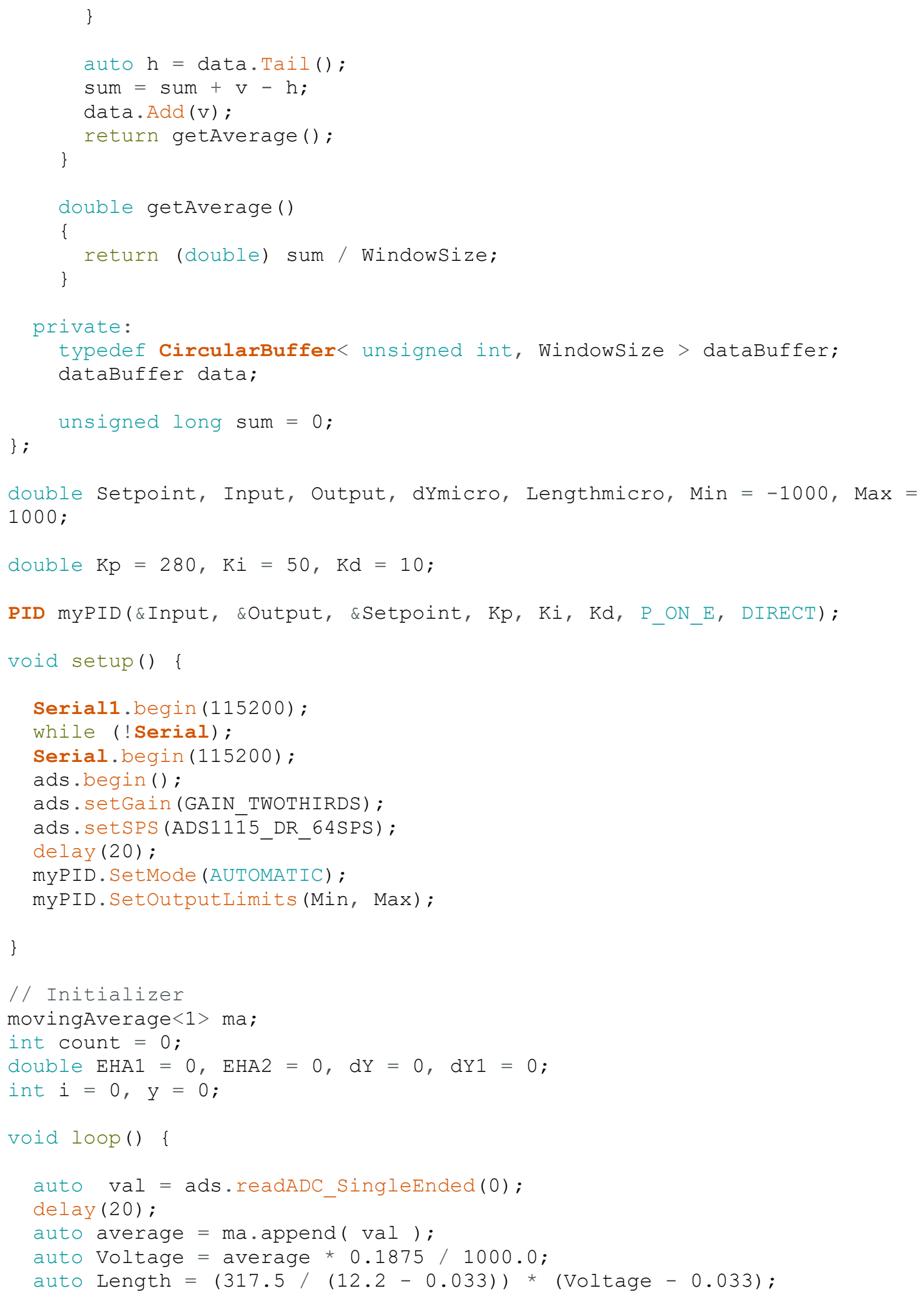




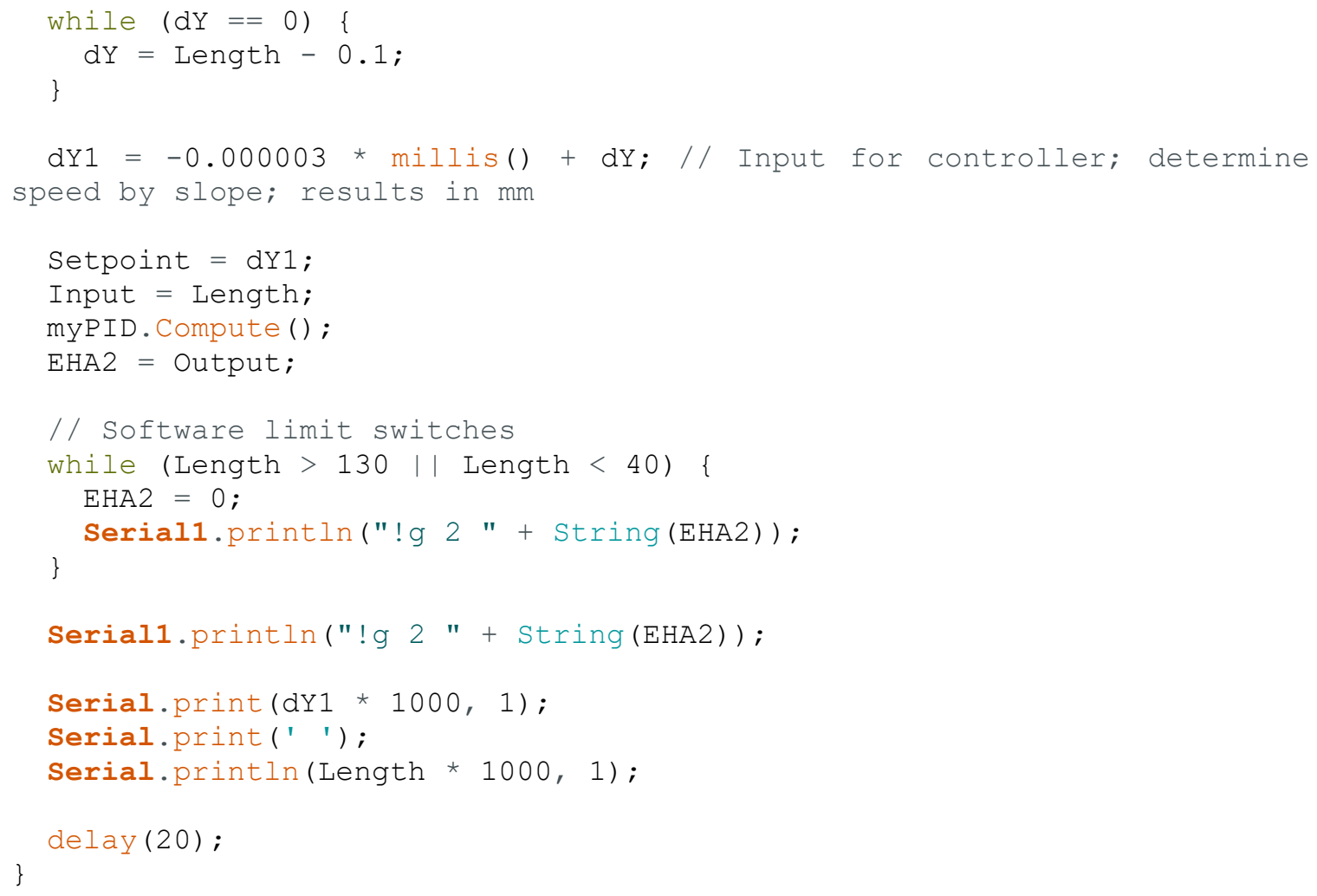




\section{Appendix E: Equipment Datasheets}

\section{SP SERIES, STRING POTS}

MEAS | MEAS SP

TE Model \# SP2

TE Internal \#: CAT-CAPS0068

View on TE.com >

Sensors > Position Sensors > Potentiometric Sensors > Cable Actuated Position Sensors

The SP2 string pot is a compact, economical and water resistant device that utilizes a flexible cable, a springloaded spool and a potentiometer to detect and measure linear position.

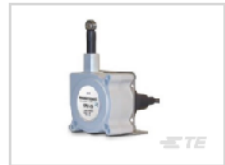

Product Type: SP Series, String Pots

Full Stroke Ranges: $101.6-1270 \mathrm{~mm}$

Output Signal: Voltage Divider (Potentiometric)

Accuracy: $.25 \%$ of FS

Repeatability: $.02 \%$ of FS

The SP2 string pot is identical to the SP1 except for an added 40-inch electrical cable with a watertight rubber strain relief.

The SP2 has been compactly designed for tight spaces and high cycle applications and generously allows for measuring cable misalignment. With 4 different ranges and a handy mounting bracket, the SP2 is a perfect solution for many applications from light industrial to OEM.

Benefits

- Encoder

- Linear Position to 50 inches $(1270 \mathrm{~mm})$

- Low-Cost, Long Life

- Rugged Polycarbonate Enclosure

- 40-in. Electrical Cable

- Free-Release Tolerant

- In Stock for Quick Delivery!

\section{Features}

Product Type Features

Product Type

SP Series, String Pots

Signal Characteristics

Output Signal

Voltage Divider (Potentiometric)

Body Features

Housing Material

Polycarbonate + Stainless Mounting

Bracket 


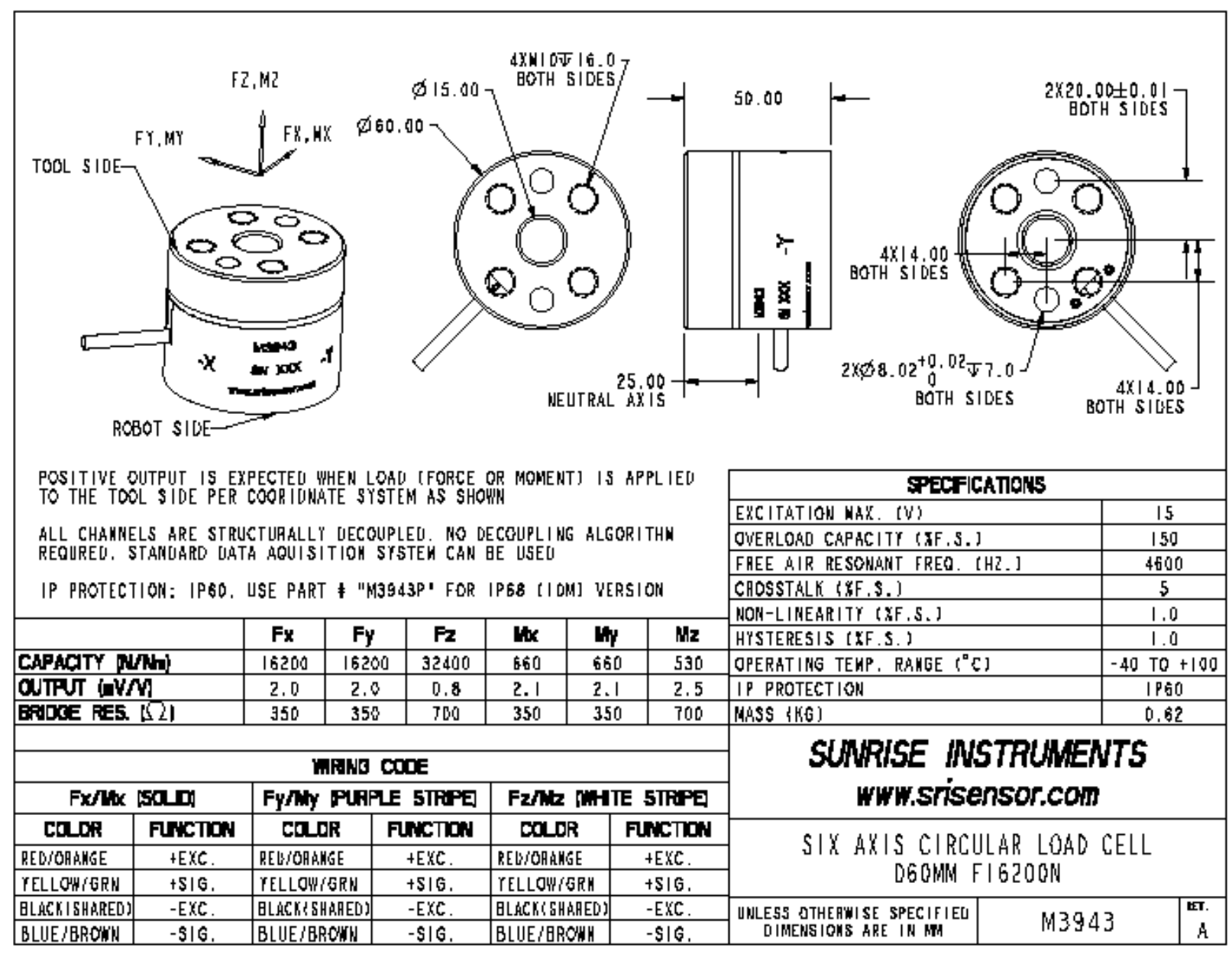




\section{ADMET}

$50 \mathrm{kN}$ Manual Vise grip

These high capacity vise grips are ideal for tensile testing of components and metal samples. Grips do not come with tightening bolts, only hex head bolts $(26 \mathrm{~mm})$. An impact gun is recommended for tightening the inserts.

\begin{tabular}{|c|c|}
\hline Item number & GV-50T \\
\hline Tensile force & $50 \mathrm{kN}$ \\
\hline Temperature range & $\begin{array}{l}0^{\circ} \mathrm{C}-+180^{\circ} \mathrm{C} \\
\text { Other temperature ranges on request }\end{array}$ \\
\hline Body & Steel, manganese phosphate coating \\
\hline Weight & $12 \mathrm{~kg}$ each grip (without jaws) \\
\hline Scope of delivery & $\begin{array}{l}1 \text { pair of grips (can also be ordered } \\
\text { separately }(0.5 \text { pair })) \text {. }\end{array}$ \\
\hline
\end{tabular}

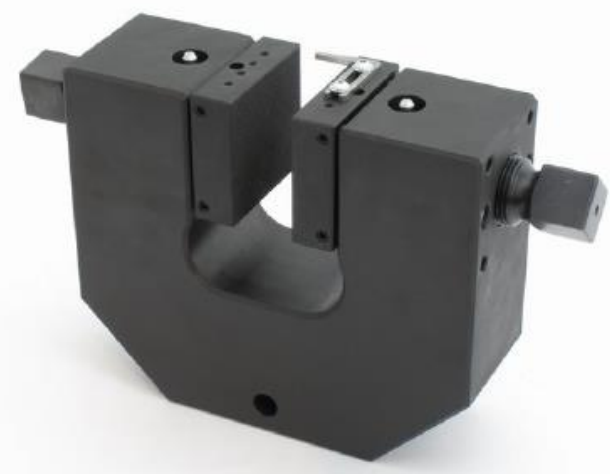

Jaws for GV-50T: Scope of delivery: 1 set $=4$ jaws

\begin{tabular}{|l|l|l|l|l|}
\hline Item No. & Surface & $\begin{array}{l}\text { Clamping } \\
\text { surface H X W }\end{array}$ & Opening & $\begin{array}{l}\text { Weiqht } \\
\text { per pair }\end{array}$ \\
\hline GV-50T-B & Blank (smooth) jaws & $60 \times 66 \mathrm{~mm}$ & $0-30 \mathrm{~mm}$ & $1.2 \mathrm{~kg}$ \\
\hline GV-50T-BP & Pyramid jaws (serrated) & $60 \times 66 \mathrm{~mm}$ & $0-30 \mathrm{~mm}$ & $1.1 \mathrm{~kg}$ \\
\hline GV-50T-BV & V-jaws & $60 \times 66 \mathrm{~mm}$ & $5-30 \mathrm{~mm}$ & $1.1 \mathrm{~kg}$ \\
\hline GV-50T-BW & Wave jaws & $60 \times 66 \mathrm{~mm}$ & $0-30 \mathrm{~mm}$ & $1.1 \mathrm{~kg}$ \\
\hline GV-50T-BD & Diamond jaws & $60 \times 66 \mathrm{~mm}$ & $0-30 \mathrm{~mm}$ & $1.1 \mathrm{~kg}$ \\
\hline GV-50T-B210 & Blank (smooth) jaws & $70 \times 210 \mathrm{~mm}$ & $0-10 \mathrm{~mm}$ & $6.6 \mathrm{~kg}$ \\
\hline GV-50T-BP210 & Pyramid jaws (serrated) & $70 \times 210 \mathrm{~mm}$ & $0-10 \mathrm{~mm}$ & $6.6 \mathrm{~kg}$ \\
\hline GV-50T-BW210 & Wave jaws & $70 \times 210 \mathrm{~mm}$ & $0-10 \mathrm{~mm}$ & $6.4 \mathrm{~kg}$ \\
\hline
\end{tabular}

Jaws with other dimensions and surface coatings available on request
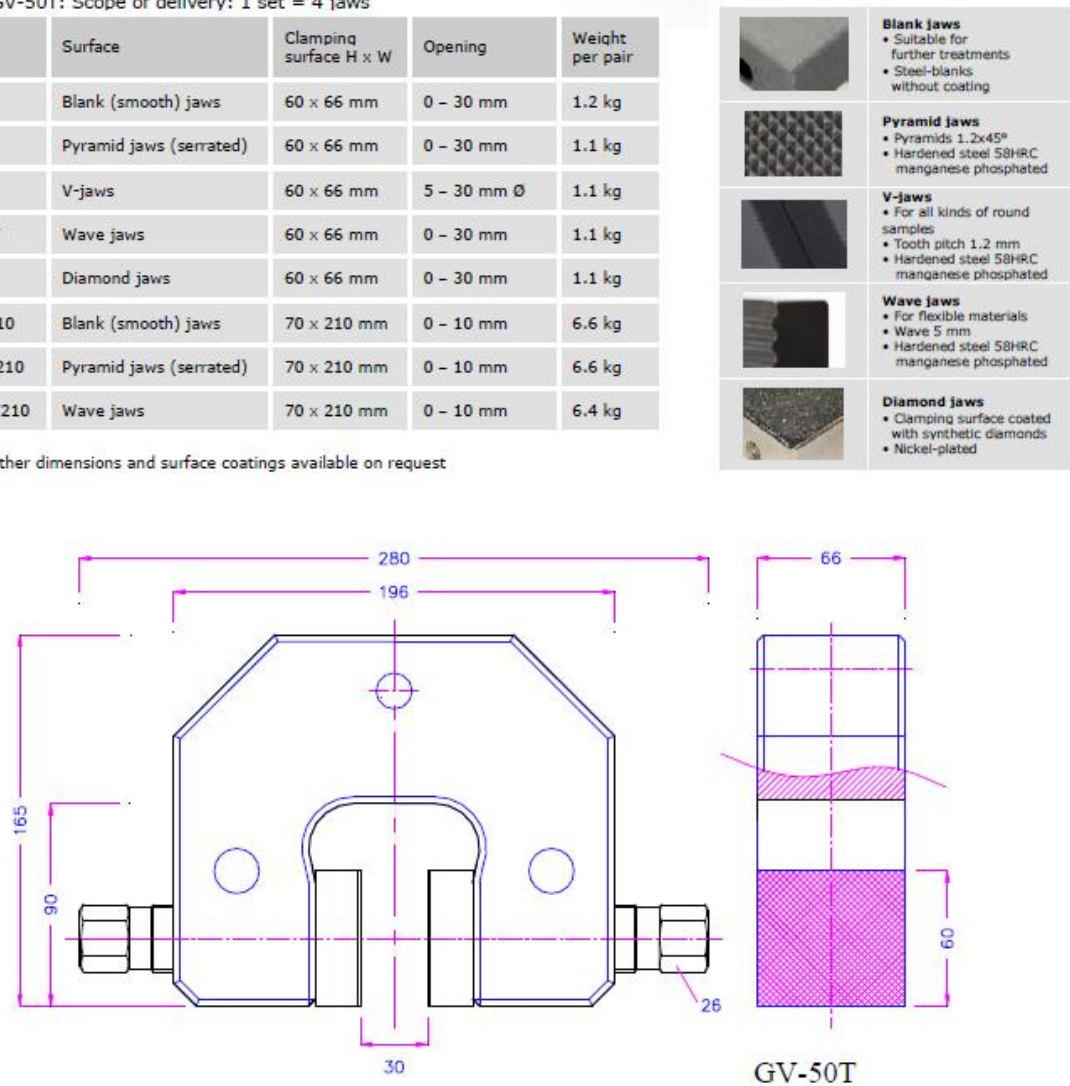


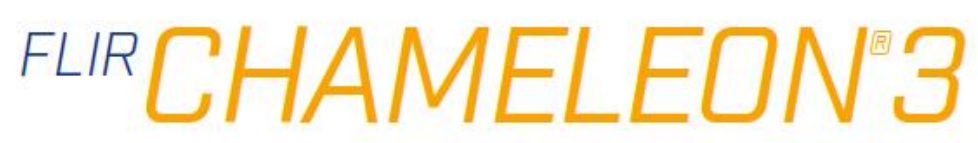

P/N: CM3-U3-13Y3, USB3 VISION
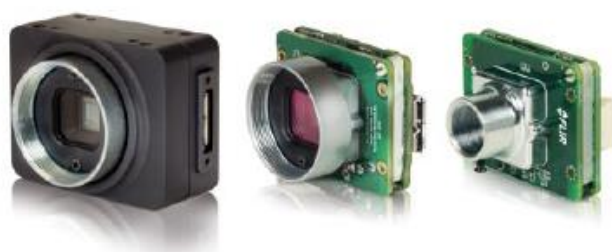

\section{FLEXIBLE FORM FACTOR + USB3 VISION}

The Chameleon 3 camera line combines the ease-of-use of USB 3.0 , the small size and flexibility of board-level, and the most popular CCD and CMOS image sensors into an affordable package. Available in a compact $44 \times 35 \times 19.5 \mathrm{~mm}$ case or as a $40 \times 31 \mathrm{~mm}$ board stack. The lightweight metal case is designed for reliability and offers multiple mounting points and a locking USB 3.0 connection. Includes on-camera frame buffer for image retransmission, opto-isolated GPIO with locking connection, and a hassle-free 3-year warranty.

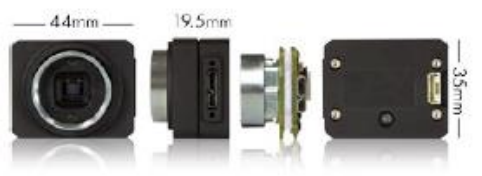

\section{KEY FEATURES}

- Boxed and board level available

- On-camera image processing: color interpolation, gamma, and LUT

- 16 MByte frame buffer, LED status indicator

\section{USS}

Board Level
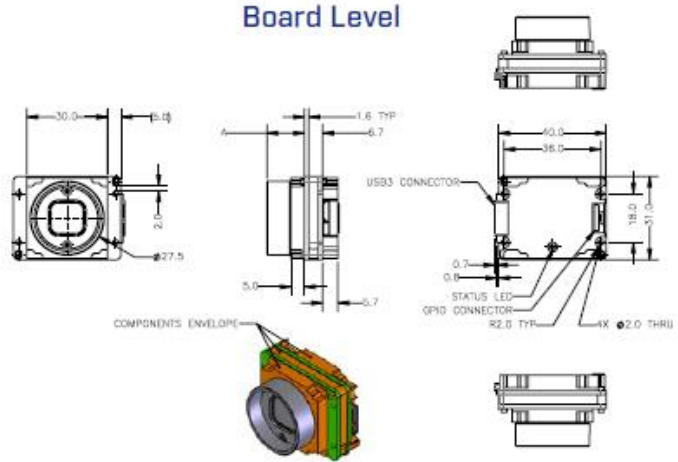

With Case
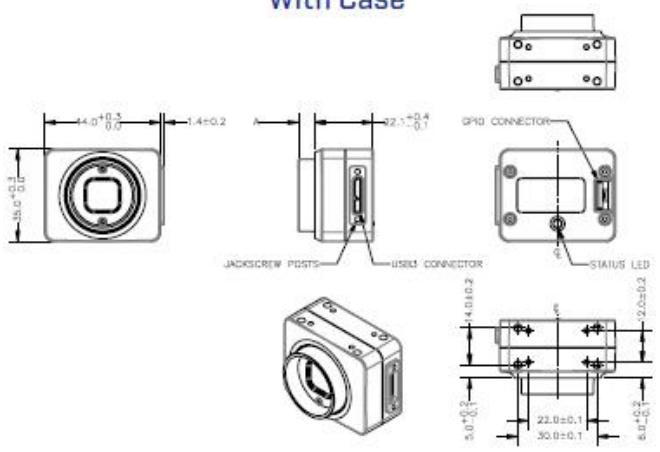
Specifications

\begin{tabular}{|c|c|c|}
\hline & См3-U3-13Y3М & CM3-U3-13Y3C \\
\hline Firmware & 1.9 .3 .0 & 19.3 .0 \\
\hline Resolution & $1280 \times 1024$ & $1280 \times 1024$ \\
\hline Frame Rate & 149 FPS & $149 \mathrm{FPS}$ \\
\hline Megapixels & $1.3 \mathrm{MP}$ & $1.3 \mathrm{MP}$ \\
\hline Chroma & Mono & Color \\
\hline Sensor & On Semi P1300, CMOS, $1 / 2^{*}$ & On Semi P1300, CMOS, 1/2" \\
\hline Readout Method & Global shutter & Global shutter \\
\hline Pixel Size & $4.8 \mu \mathrm{m}$ & $4.8 \mu \mathrm{m}$ \\
\hline Lens Mount & CS-mount (case)/(S-mount board level) & CS-mount (case)/(S-mount board level) \\
\hline $\mathrm{ADC}$ & 10-bit & 10-bit \\
\hline Gain Range & $O \mathrm{~dB}$ to $18 \mathrm{~dB}$ & $0 \mathrm{~dB}$ to $18 \mathrm{~dB}$ \\
\hline Exposure Range & $0.006 \mathrm{~ms}$ to $999.240 \mathrm{~ms}$ & $0.006 \mathrm{~ms}$ to $999.240 \mathrm{~ms}$ \\
\hline Trigger Modes & Standard, bulb, multi-shot & Standard, bulb, multi-shot \\
\hline Partial Image Modes & Poxel binning, ROI & Pixel binning, ROI \\
\hline Image Processing & Gamma, lookup table, and sharpness & Gamma, lookup table, hue, saturation, and sharpness \\
\hline HDR Sequenaing & Not supported & Not supported \\
\hline Image Buffer & $16 \mathrm{MB}$ & $16 \mathrm{MB}$ \\
\hline User Sets & 2 memory channels for custom camera settings & 2 memory channels for custom camera settings \\
\hline Flash Memory & $1 \mathrm{MB}$ non-volatile memory & $1 \mathrm{MB}$ non-volatile memory \\
\hline Opto-isolated I/O Ports & 1 input, 1 output & 1 input, 1 output \\
\hline Non-isolated I/O & 2 bi-directional & 2 bi-directional \\
\hline Auxiliary Output & $3.3 \mathrm{~V}, 150 \mathrm{~mA}$ maximum & $3.3 \mathrm{~V}, 150 \mathrm{~mA}$ maximum \\
\hline Interface & USB 3.0 & USB 3.0 \\
\hline Power Requirements & $5-24 \mathrm{~V}$ via GPIO or $5 \mathrm{~V}$ via USB 3.0 interface & $5-24 \mathrm{~V}$ via GPIO or $5 \mathrm{~V}$ via USB 3.0 interface \\
\hline Power Consumption & $<$ W maximum & $<3$ Wmaximum \\
\hline Dimensions/Mass & $\begin{array}{c}44 \mathrm{~mm} \times 35 \mathrm{~mm} \times 19.5 \mathrm{~mm} \text { (case enclosed); } 40 \mathrm{~mm} \times 31 \mathrm{~mm} \text { (board } \\
\text { level) } / 54.9 \mathrm{~g} \text { (case) } / 27.9 \mathrm{~g} \text { (board level) }\end{array}$ & $\begin{array}{c}44 \mathrm{~mm} \times 35 \mathrm{~mm} \times 19.5 \mathrm{~mm} \text { (case enclosed); } 40 \mathrm{~mm} \times 31 \mathrm{~mm} \text { (board } \\
\text { level) } / 54.9 \mathrm{~g} \text { (case) } / 27.9 \mathrm{~g} \text { (board level) }\end{array}$ \\
\hline Machine Vision Standard & USB3 Vision v1.0 & USB3 Vision v1.0 \\
\hline Compliance & CE, FCC, KCC, RoHS. The ECCN for this product is: EARO99. & CE, FCC, KCC, RoHS. The ECCN for this product is: EAR099. \\
\hline Temperature & $\begin{array}{l}\text { Operating: } 0^{\circ} \text { to } 45^{\circ} \mathrm{C} \\
\text { Storage: }-30^{\circ} \text { to } 60^{\circ} \mathrm{C} \\
\end{array}$ & $\begin{array}{l}\text { Operating: } 0^{\circ} \text { to } 45^{\circ} \mathrm{C} \\
\text { Storage: }-30^{\circ} \text { to } 60^{\circ} \mathrm{C} \\
\end{array}$ \\
\hline Humidity & $\begin{array}{l}\text { Operating: } 20 \% \text { to } 80 \% \text { (no condensation) } \\
\text { Storage: } 20 \% \text { to } 95 \% \text { (no condensation) }\end{array}$ & $\begin{array}{l}\text { Operating: } 20 \% \text { to } 80 \% \text { (no condensation) } \\
\text { Storage: } 20 \% \text { to } 95 \% \text { (no condensation) }\end{array}$ \\
\hline Warranty & 3 years & 3 years \\
\hline
\end{tabular}

FLIR Integrated Imaging Solutions

$\begin{array}{ll}\text { CANADA } & \text { EUROPE } \\ 12051 \text { Riverside Way } & \text { T: }+497141488817-0\end{array}$

Richmond, BC, Canada $\quad$ F: $+497141488817-99$

V6W 1K7 1 E: 1 , Canv-eusales@flir.com

T: +1866.765 .0827 (toll free)

$\mathrm{T}:+1604.242 .9937$

F: +1604.242 .9938$

www.flir.com/iis

CHINA

T: +861082159938

$+861082159936$

E: mv-chinasales@flir.com

For a full list of international distributors and offices visit www.flir.com/contact-us

USA +1866.765 .0827 (toll free)

ASIA
E: mv-asiasales@ptgrey.com

E: mv-na-sales@ptgrey.com

Q2017 FLIR@ Integrated Imsging Solutions Inc. All rights resenved. Names and marks sppearing on the products herein are either registered

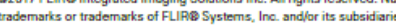




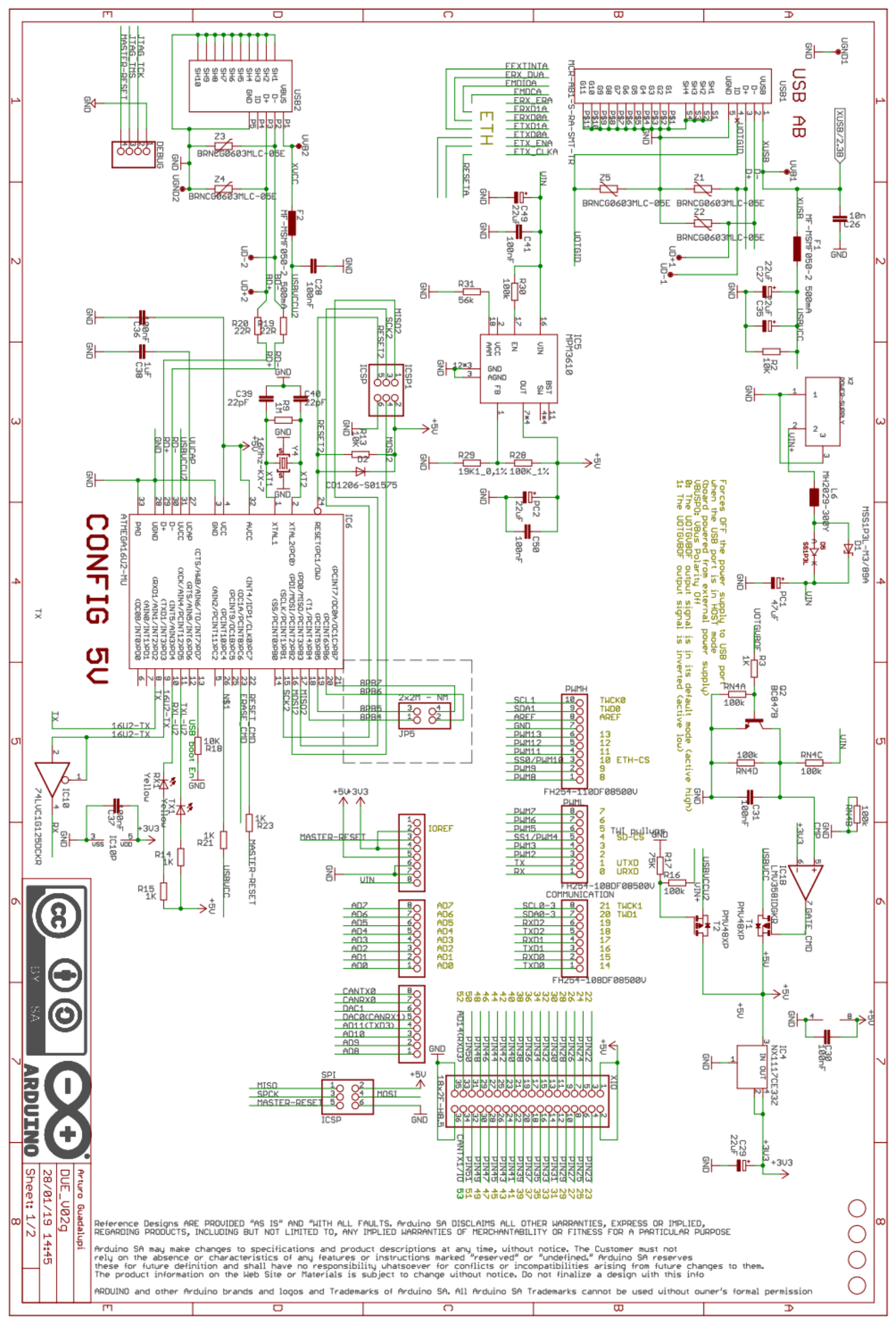




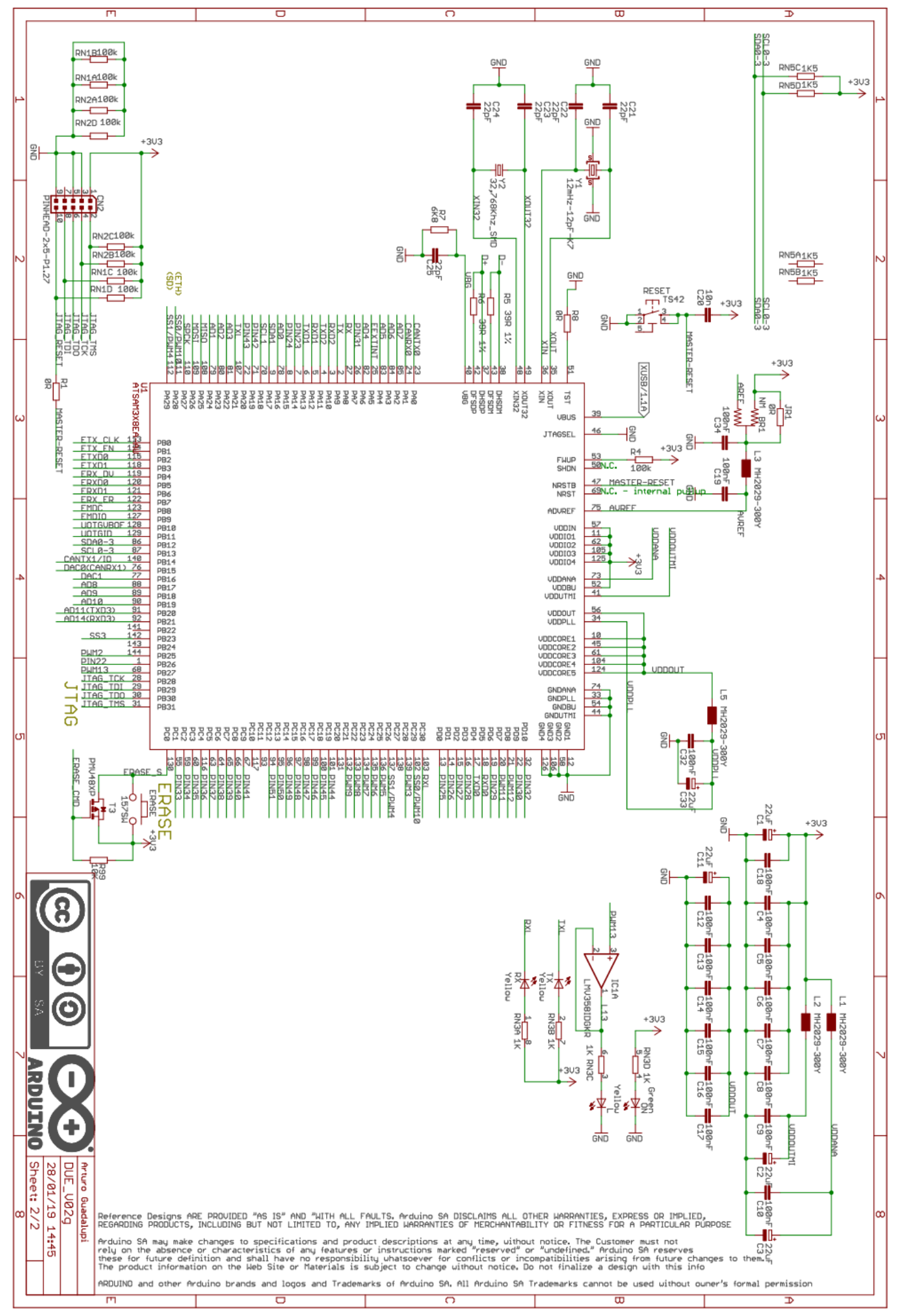




\section{Parker}

Bulletin HY22-3200A/US

\section{Instruction Manual}

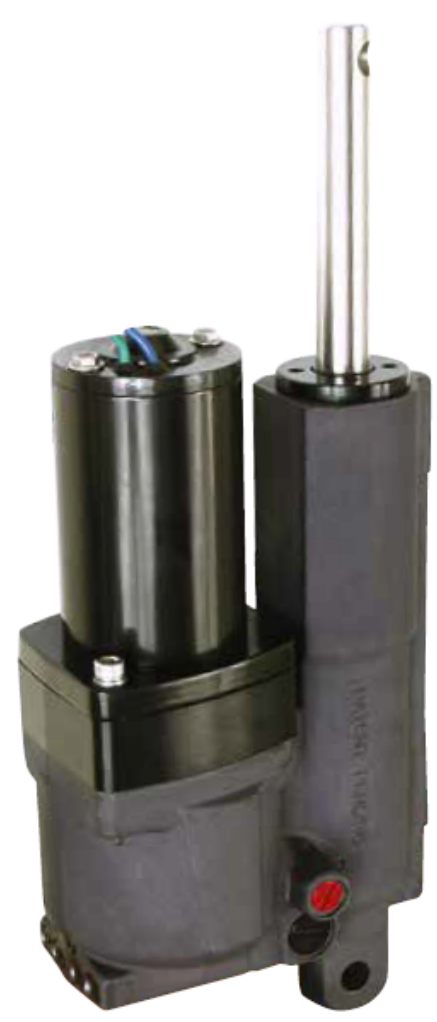

Parker Compact Electro-Hydraulic Actuator (EHA) 
Table of Contents

Introduction

Explanation of Warning Labels

Description

Preparation for Use

Installation

Start-Up Procedures

Special Tools

Safe Operating Procedures

Operation

Maintenance

Troubleshooting

Declaration of Incorporation

How to read the label on your EHA:

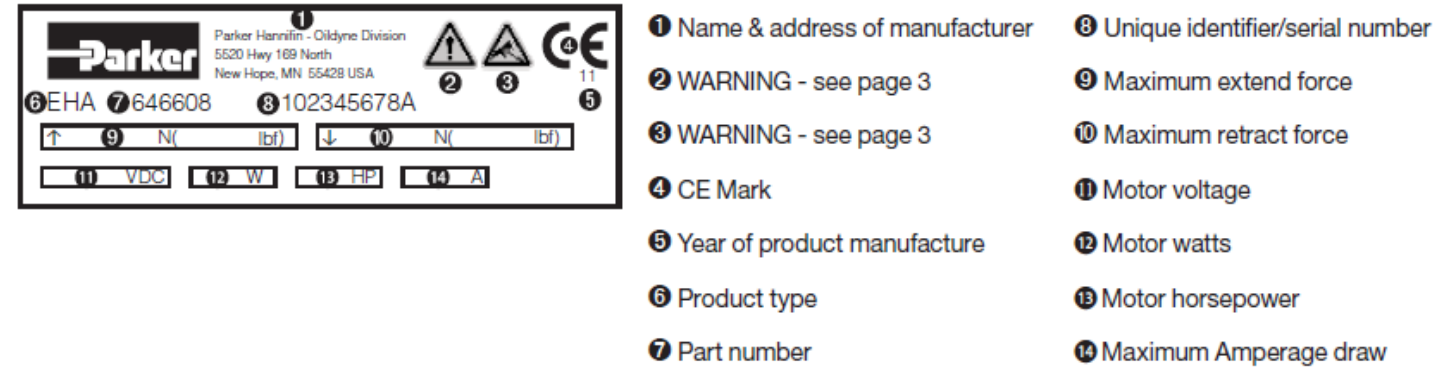

\section{$\triangle$ WARNING - USER RESPONSIBILITY}

FAILURE OR IMPROPER SELECTION OR IMPROPER USE OF THE PRODUCTS DESCRIBED HEREIN OR RELATED ITEMS CAN CAUSE DEATH, PERSONAL INJURY AND PROPERTY DAMAGE.

This document and other information from Parker-Hannifin Corporation, its subsidiaries and authorized distributors provide product or system options for further investigation by users having technical expertise. The user, through its own analysis and testing, is solely responsible for making the final selection of the system and components and assuring that all performance, endurance, maintenance, safety and warning requirements of the application are met. The user must analyze all aspects of the application, follow applicable industry standards, and follow the information concerning the product in the current product catalog and in any other materials provided from Parker or its subsidiaries or authorized distributors.

To the extent that Parker or its subsidiaries or authorized distributors provide component or system options based upon data or specifications provided by the user, the user is responsible for determining that such data and specifications are suitable and sufficient for all applications and reasonably foreseeable uses of the components or systems.

\section{Offer of Sale}

Please contact your Parker representation for a detailed 'Offer of Sale'.

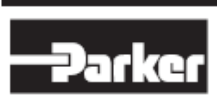


Bulletin HY22-3200A/US

Introduction and Specification

Introduction

This manual provides descriptive operation and maintenance instructions for the Parker Compact EHA (Electro-Hydraulic Actuator) manufactured by the Parker Hannifin Corporation, Oildyne Division. Any additional information may be obtained from Parker by referencing the unit's part number printed on the nameplate or by contacting your local authorized Parker Distributor.

Some of the Information in this manual may not apply to your EHA. Information about custom units may require service and application information from other sources.

\section{Warning}

This Instruction Manual should be read in its entirety and understood prior to installing and operating the Parker Compact EHA.

It is imperative that personnel involved in the installation, service, and operation of the Oildyne units should be familiar with how the equipment is to be used. They should be aware of the limitations of the system and its component parts and have knowledge of good hydraulic practices in terms of safety, installation, and maintenance.

\section{Explanation of Warning Labels}

The following labels will be used in this Instruction Manual and on all applicable Oildyne products.

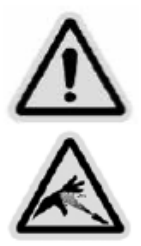

Be careful; take precautions; examine instructions before operation.

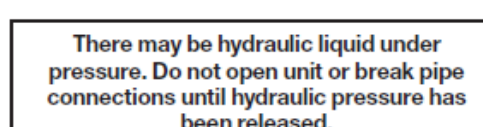
been released.

\section{Description}

The Parker Compact Electro-Hydraulic Actuator (EHA) is a selfcontained, bi-directional DC motor driven gear or gerotor pump with an integral hydraulic cylinder.

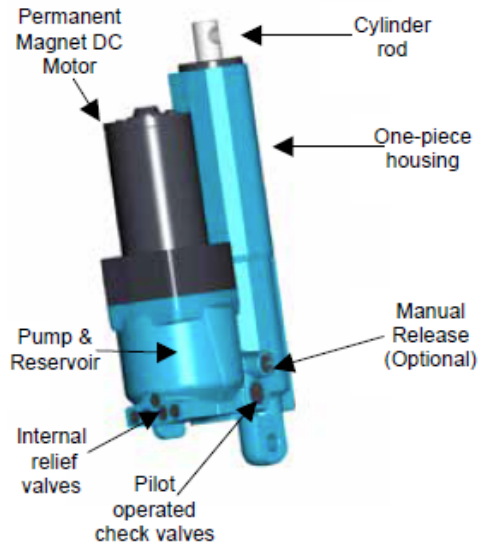

See Figures 1, 2, and 3 for dimensional drawings.The internal components are determined by the specifications provided by customers for each specific application.
Instruction Manual

Compact EHA

See Figure 4 for a hydraulic schematic.

The life expectancy of Parker Oildyne units is directly tied to the frequency of use, the product in which they are incorporated and the application.

Unit weight will fall into a range from $3.6 \mathrm{~kg}(8.0 \mathrm{lbs})$ to $5.5 \mathrm{~kg}$ (11.9 lbs) based on stroke length and motor size. See below:

$$
\text { Base unit by stroke length: }
$$

$\begin{array}{ll}102 \mathrm{~mm} \text { (4 in) } & 2.1 \mathrm{~kg} \text { (4.7 lbs) } \\ 152 \mathrm{~mm} \text { (6 in) } & 2.8 \mathrm{~kg}(6.5 \mathrm{lbs}) \\ 203 \mathrm{~mm} \text { (8 in) } & 3.5 \mathrm{~kg} \text { (7.6 lbs) }\end{array}$

Add for motor

$$
\begin{array}{ll}
12 \mathrm{VDC} \text { or } 24 \text { VDC } 245 \mathrm{~W} & +1.5 \mathrm{~kg}(3.3 \mathrm{lb}) \\
12 \mathrm{VDC} \text { or } 24 \text { VDC } 560 \mathrm{~W} & +2.0 \mathrm{~kg}(4.3 \mathrm{lb})
\end{array}
$$

EHA is intended to be used for specific applications requiring actuation defined by the customer. Listed below are the acceptable operation parameters:

Maximum forces for actuator extend: $21,350 \mathrm{Nf}(4,800 \mathrm{lbf})$ with gear pump Maximum forces for actuator retract: $16,000 \mathrm{Nf}(3,600 \mathrm{lbf})$

Note: The maximum forces listed above are the highest forces available for an EHA unit. The maximum forces listed on your unit label will match the specific unit configured for your application.

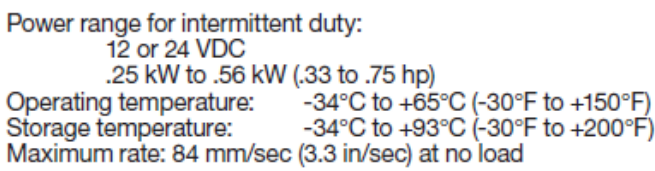

EHA is intended for intermittent use only. It is not designed for continuous operation.

Parker Hannifin Corporation takes no responsibility for safety of any unit if it is not used for the intended purposes detailed in this Instruction Manual.

Examples of Abnormal Use:

- Use of unit with pressure other than that for which it was intended

- Use with a higher or more frequent duty cycle other than that for which it was intended

- Use with higher or lower Voltage than required for optimal use

- Use in a different mounting orientation other than that for which it was intended

- Use of fluids other than those recommended

\section{Preparation for Use}

Unpacking and Checking

All units were carefully packed in boxes, and may or may not be on skids. In any case, do not remove anything from the skid or any packaging until it has been carefully checked for damage that may have occurred in transit. Report all damage immediately to the carrier and send a copy to the vendor.

\section{Storage}

If the unit is not going to be installed immediately, it should be stored indoors, covered with a waterproof sheet. 

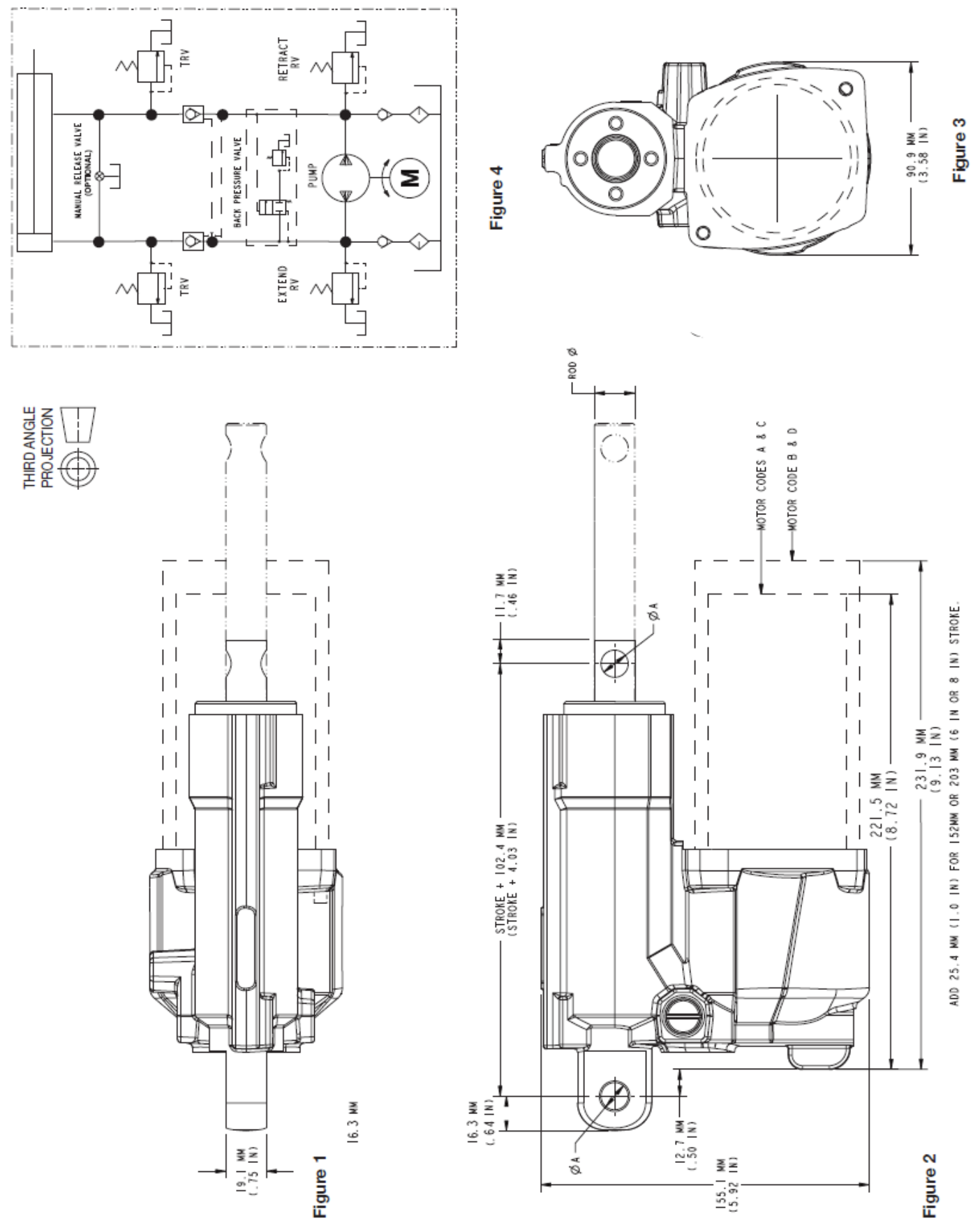

All dimensions are shown in millimetres (inches). 
Bulletin HY22-3200A/US

Installation and Commissioning

\section{Installation}

\section{Locating EHA}

The unit should preferably be installed indoors in a clean, dry environment with an ambient temperature of $16^{\circ}$ to $37^{\circ} \mathrm{C}\left(60^{\circ} \mathrm{F}\right.$ to $\left.100^{\circ} \mathrm{F}\right)$.

Parker Oildyne products should not be installed where they are at risk of objects falling from overhead or where there is any risk of impact with external objects.

\section{Mounting the Unit}

Each Parker Compact EHA is designed to be mounted and connected in a specifc way. Be sure to use the proper size mounting hardware to match the mate end on the rod or base end of the EHA.

Connect one end of the EHA unit to its corresponding mount on the machine.

The load must be supported by its own guidance system. The axis of the cylinder and that of the load should not be unduly displaced to ensure that there are no imposed side loads following installation or significant reaction forces of the cylinder. It is the user's responsibility to properly position the unit to keep the load in axial alignment with the center line of the EHA rod. The degree of accuracy needed will vary from unit to unit based on the configuration so every effort should be made to be as accurate as possible.

The unit should be positioned in the machine to ensure good ventilation.

For environmental protection a rubber gaiter or boot may be placed round the piston shaft. This serves to prevent access to the moving piston shaft but this is only an option. The provision of a rubber gaiter or boot for safety purposes is not mandatory. However it is recommended that a gaiter or boot might be fitted if the end user does not intend to provide any alternative form of protection such as guarding. The piston shaft is stainless steel and is resistent against wear. But, if a dusty environment is involved a gaiter or boot may still be used to protect seals.

If the unit has a yellow sticker designating "THIS SIDE UP" or "THIS END UP", make sure that the unit is mounted with that sticker up, or on top of the unit.

If the unit is mounted to the machine using bolts (user supplied), make sure to use the correct tightening torque to ensure a secure mounting and no damage to the hardware.

\section{Electrical Service Connections}

Connect the motor to the power source following good

practices as outlined in the National Electric Codes and any

local codes which may apply. Verify that the available Voltage is the same as the Voltage identified on the label. A suggested example for wiring is illustrated in Figure 5.

The blue lead (positive) extends the unit and green lead (positive) retracts the unit. Refer to Figure 6 for wire colors and corresponding operation.

Once the motor is connected, extend or retract the unit to align the pin connection or specified mounting at the free end of the EHA with the machine mounting. Attach to the machine using appropriate mounting hardware.

The machine in which the EHA is incorporated should be bonded to earth. Each EHA unit must be bolted to the frame of the machinery in which it is incorporated. Therefore, if lightening strikes, this will immediately be returned to ground potential.
Instruction Manual

\section{Compact EHA}

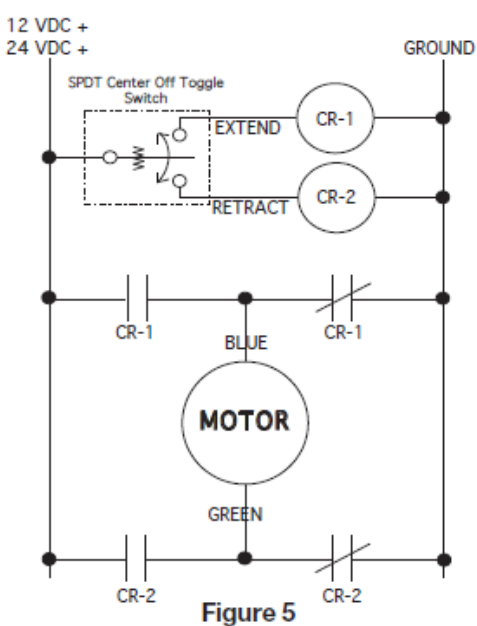

\begin{tabular}{|c|c|c|}
\hline Function & Positive & Ground \\
\hline Extend & Blue & Green \\
\hline Retract & Green & Blue \\
\hline
\end{tabular}

Figure 6

\section{Start-Up Procedures}

Fuse protection can be added to the wiring circuit if desired. Use a slow blow fuse so it will not be tripped from the inrush current. Make sure the fuse is sized above the maximum requirement for the application and below the maximum available from the power supply. See Figure 7 for approximations of maximum amperage based on basic configurations.

The following is the standard operation of the Parker Compact EHA and can be considered as a functional test for unit at the completion of installation or at any time during usage:

1. With the unit fully installed, actuate the extend switch for 2 seconds and release. The rod should stop and lock in position.

2. Press and hold the extend switch until the rod reaches the end of the stroke. When rod stops, release switch. The motor should turn off and the rod should lock in place.

3. Actuate the retract switch for 2 seconds and release. The rod should stop and lock in position.

4. Actuate the retract switch until the rod fully retracts into the cylinder. When rod stops, release switch. The motor should turn off and the rod should lock in place.

If required, any tests for radiated and conducted emissions should be performed in accordance with the Electromagnetic Compatibility (EMC) Generic Emission standards for environments appropriate to the end use product to confirm compliance with the EMC Directive.

If required, any tests for radiated and conducted immunity should be performed in accordance with the Electromagnetic Compatibility (EMC) Generic Immunity standard for environments appropriate to the end use product to confirm compliance with the EMC Directive. 
Bulletin HY22-3200A/US

Safety and Maintenance

Special Tools

No dismantling, service or maintenance is recommended for EHA so no special tools are required.

\section{Safe Operating Procedures}

Should a failure of the electrical power supply occur, power should not be returned to these power units without a conscious action by the operator.

The power switch must be de-activated once the rod reaches either end of stroke. If not, the pressure will build and run over the relief valve which may cause the motor to trip the thermal overload and shut down.

In the unlikely event of sound levels exceeding $70 \mathrm{dBA}$ it is recommended that hearing protection should be worn. If sound levels exceed $80 \mathrm{dBA}$ it is necessary to take measures to reduce sound levels. This is normally achieved by placing machinery in an acoustically lined enclosure.

Motor Voltages for EHA will be 12 VDC or 24 VDC. If these motors are operated at Voltages other than those specified, the life expectancy and safety of these units cannot be guaranteed.

Operating temperature requirements:

$$
-34^{\circ} \mathrm{C} \text { to }+65^{\circ} \mathrm{C}\left(-30^{\circ} \mathrm{F} \text { to }+150^{\circ} \mathrm{F}\right)
$$

The EHA unit must not be operated on a duty cycle or stroke frequency that exceeds those identified in Operation instructions. When necessary, cooling must be provided to ensure that the temperature of the internal fluids used never exceed suitable temperatures for operation.

The Parker Compact EHA can support a load for a finite time determined by the loads and operating conditions of the application. There is no guarantee that an EHA will hold a load indefinitely and some creep should be anticipated.

Removal From Service

If for some reason, the EHA must be removed from service, follow these instructions:

1. Wear protective eye gear.

2. Remove electrical power from the motor.

3. Mechanically hold or block the load held by the actuator should there be any movement once pressure is relieved.

4. Only after the load is mechanically held in place, remove the EHA.

5. When reinstalling the EHA, follow all the procedures and startup instructions given previously.

Operation

Suitable lighting requirements for operation of this unit are the responsibility of the machine manufacturer.

See Figure 7 for performance curves to identify parameters of operation and Figure 8 to identify motor duty cycle characteristics.

Operation of Manual Release Option

Manual release functionality is provided as an option for the Parker Compact EHA. This feature is intended for infrequent emergency use only. It is NOT intended to provide functionality for regular operation.
Instruction Manual

\section{Compact EHA}

To engage the manual release, turn the assembly in a counterclockwise direction using the slot on the end of the assembly. Turn the release until it cannot turn any more. This will release the pressure in the unit so that the actuator rod can be manually moved in and out.

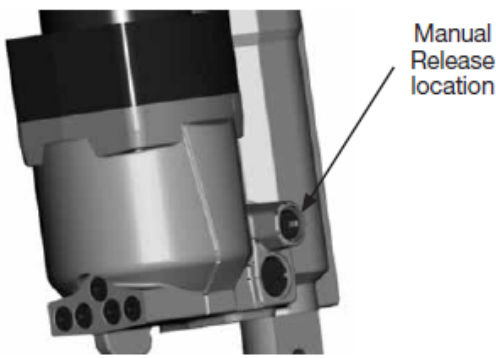

To disengage the manual release and continue regular operation, turn the assembly in a clockwise direction until it won't go any further. Provide power to the motor, pressure will rebuild and the unit will operate as usual.

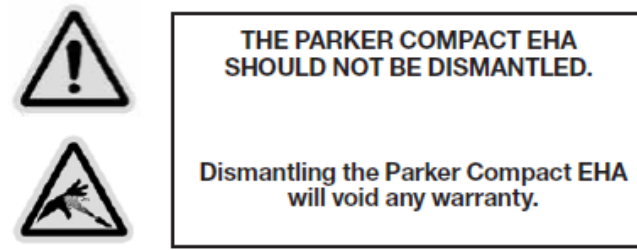

Maintenance

Maintenance should only be conducted when units are disconnected from their power supply.

Maintaining Proper Oil Temperature

Hot oil in your equipment's hydraulic system is one of the primary causes of poor operation, component failure and downtime. Here are some pointers on maintaining proper oil temperature.

1. The oil in your hydraulic system was designed for operation within a specified temperature range. You may be able to run it at hotter temperatures for short periods of time, intermittently, without adverse effects.

2. "Hot oil" is a relative term. In most cases, $49^{\circ} \mathrm{C}\left(120^{\circ} \mathrm{F}\right)$ at the reservoir is considered an ideal operating temperature.

3. Keep your equipment clean. A thick layer of dirt acts as insulation. It will prevent the hydraulic system from getting rid of heat.

\section{Measuring Oil Temperature}

Because your machine does not have a reservoir thermometer, use the "palm test". The reservoir is located adjacent to the motor. First check the reservoir with your fingertip; if it's not too hot to touch, place your palm on the reservoir. You'll be able to hold it there without discomfort if the oil temperature is about

$55^{\circ} \mathrm{C}\left(130^{\circ} \mathrm{F}\right)$ or below. 
The maximum force and speed available and Amperage draw on rod extend for different combinations of motor, pump and cylinder bore can be determined from the tables below:
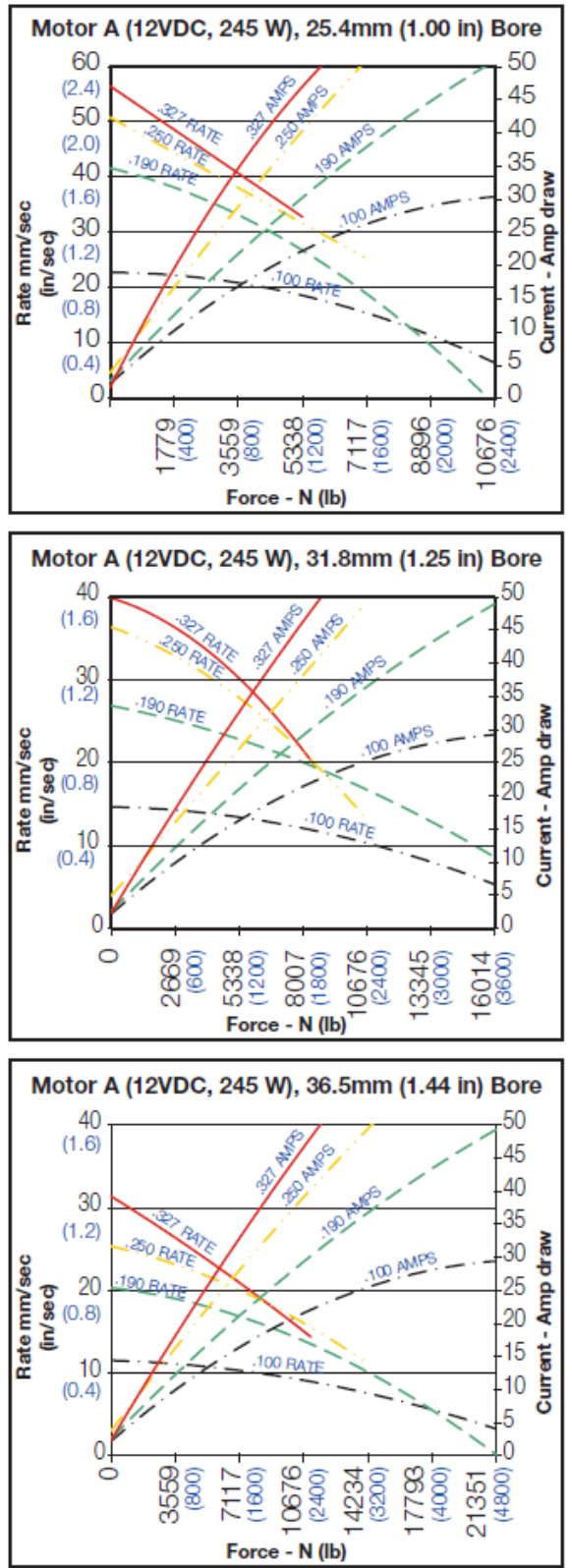

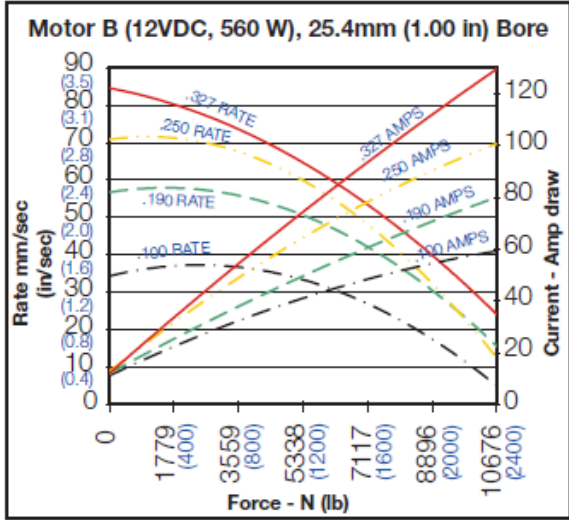

Motor B (12VDC, $560 \mathrm{~W}), 31.8 \mathrm{~mm}$ (1.25 in) Bore

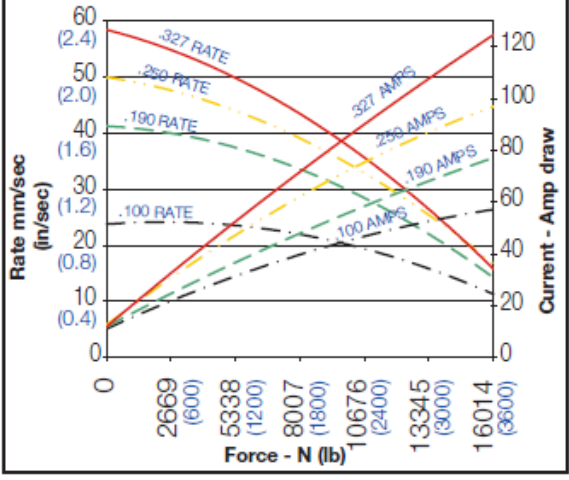

Motor B (12VDC, $560 \mathrm{~W}), 36.5 \mathrm{~mm}$ (1.44 in) Bore

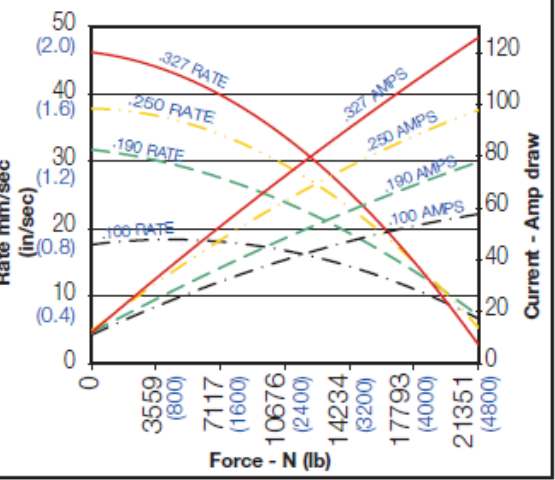

Figure 7

Current draw for Motor C (24VDC, $245 \mathrm{~W}$ ) and Motor D (24VDC, $560 \mathrm{~W}$ ) will be approximately $1 / 2$ of Amp draw shown above.

Retract Forces: The maximum force available on rod retract is lower than on extend due to the presence of the piston rod which reduces the effective surface area of the piston. When the force required to retract the piston rod approaches that required for extend, please contact the factory.

Note: Performance data is based on rod extend, not retract, and is for reference only. 
Standard Motor Duty Cycle Characteristics
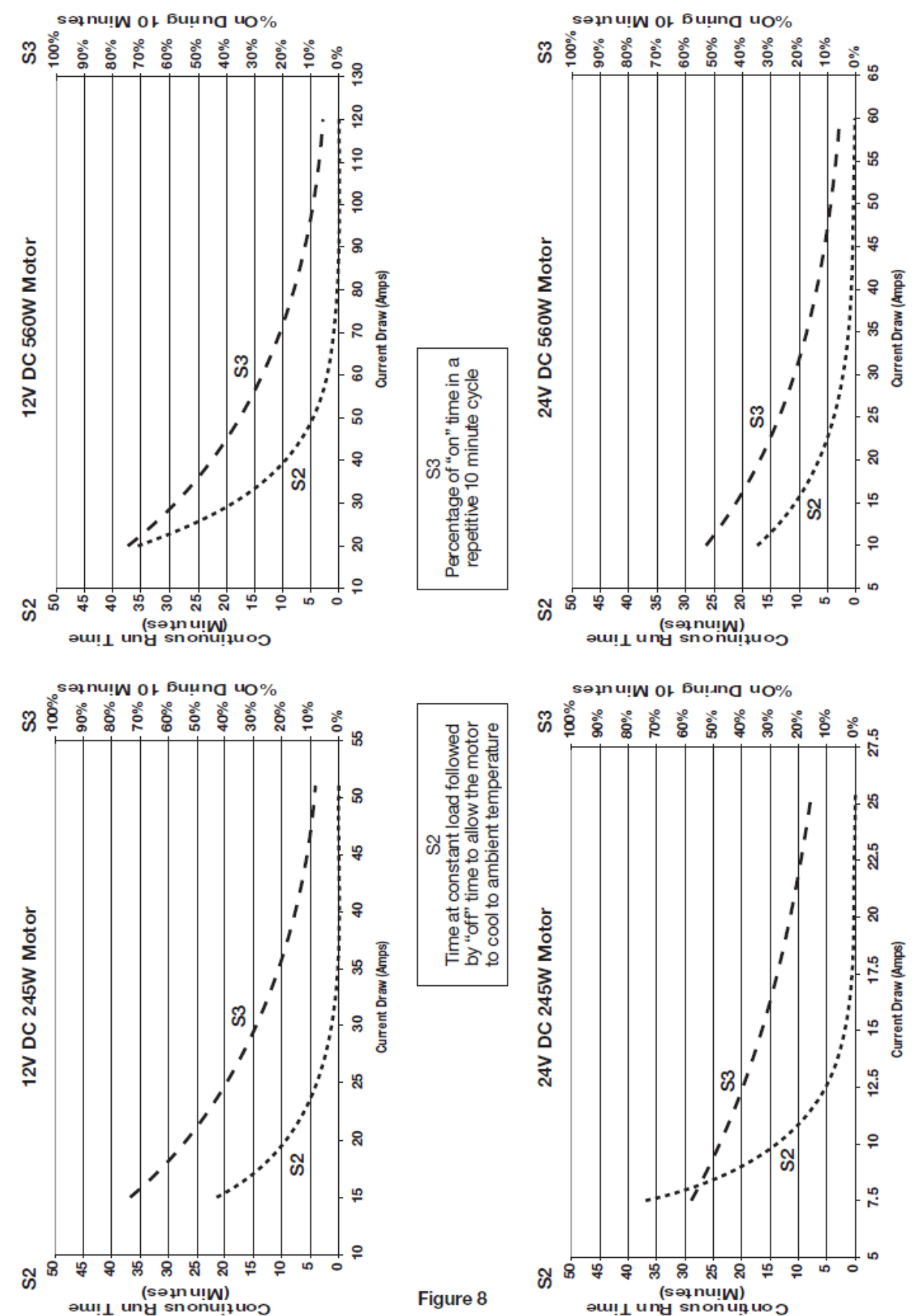

8

Parker Hannifin

HPS Division

New Hope, MN 55428 USA 
Bulletin HY22-3200A/US

Troubleshooting

Recommended Spare Parts

There are no recommended spare parts for the EHA as it is a sealed unit. Any warranty repair would be done at the Oildyne Division.

\section{Troubleshooting}

The information provided in this section will provide some ideas on how to resume normal operation given certain conditions.

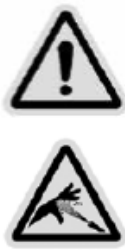

Do not attempt to open the EHA unit to make internal adjustments or repairs; it will void the warranty on the unit.

The Parker Compact EHA is NOT field servicable.

Troubleshooting Areas

Unit fails to operate

1. Power source is not charged - recharge.

2. Amperage from power source is not sufficient to operate unit - use power supply with adequate Amperage to operate EHA.

3. Wiring harness from EHA motor is not securely fastened to power source or wiring - tighten connections to power source.

4. Motor has failed due to higher or more frequent duty cycle than the unit was intended for - replace unit.

5. Motor has run for an extended time and the internal therma breaker tripped.

Unit slows during operation

1. Voltage from power source has changed - examine power supply for source of varying Voltage.

2. Unit is stalling due to high loads-reduce load against unit to the forces prescribed in the specifications.

3. Unit is mis-aligned and is causing side loading - cease operation until alignment is corrected.

4. The load is increased on the unit - this is to be expected.

Unit makes excessive noise

1. Operating temperature too low - operate $\mathrm{EHA}$ above $-34^{\circ} \mathrm{C}$ $\left(-30^{\circ} \mathrm{F}\right)$.

2. Unit is mounted in the wrong orientation - cease operation. Contact the factory.
Instruction Manual

\section{Compact EHA}

Speed of unit varies during operation

Unit is being used with higher or lower Voltage than for which it is designed (12 VDC or 24 VDC) - cease operation. Use unit with power source of appropriate Voltage.

\section{Rod stops moving}

1. Power source has become disconnected - reconnect power source.

2. Motor thermal breaker has been tripped due to high temperature in the motor, causing motor to stop - allow motor to return to ambient temperature and restart operation.

Overheating of unit

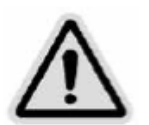

Warning: If motor stops due to thermal overload, de-actuate the power switch. Otherwise, when the motor cools, it will start up again.

1. Continuous operation at relief setting - cease operation Allow the unit to return to ambient temperature before resuming operation.

2. Stalling under load - cease operation. Ensure loads being moved are within the prescribed specifications outlined in this manual.

3. Improper air circulation around reservoir - relocate unit to area in assembly that will provide adequate air circulation to maintain the operating temperature range of $-34^{\circ} \mathrm{C}$ to $+65^{\circ} \mathrm{C}\left(-30^{\circ} \mathrm{F}\right.$ to $\left.150^{\circ} \mathrm{F}\right)$

4. EHA operating in direct sunlight or ambient temperature is too high - move unit to location that will be lower than the specified maximum operating temperature of $+65^{\circ} \mathrm{C}$ $\left(+150^{\circ} \mathrm{F}\right)$

5. EHA operating at a continuous duty cycle - cease operation. Discontinue use until required operation of the unit will fall within the duty cycle characteristics illustrated in Figure 7.

Should the user encounter any other conditions, please contact your local authorized Parker Oildyne distributor or the Oildyne Division directly for further information or to arrange for warranty replacement/repair if within the warranty period.

Conclusive Unit Failure

If the operation of the unit cannot be restored after attempts at the troubleshooting suggestions listed previously, please contact your local authorized Parker Oildyne distributor or the Oildyne Division directly to arrange for warranty replacement/ repair if within the warranty period. 


\section{EC Declaration of Incorporation.}

Manufacturer's Name:

Manufacturer's Address:

\author{
Parker Hannifin Corporation \\ Oildyne Division \\ 5520 Highway 169 North \\ New Hope, MN 55428 USA
}

Declare that the partially complete machinery described below conforms to applicable health and safety requirements of Part 1 of Annex 1 of Machinery Directive 2006/42/EC taking full account of requirements for pressure equipment. This partly completed machinery must not be put into service until the machinery into which it is to be incorporated has been declared in conformity with the provisions of the Machinery Directive. Confidential technical documentation has been compiled as described in Part B of Annex VII of Machinery Directive 2006/42/EC and is available to European national authorities on written request. If a request is received documentation will be transmitted either electronically or by post.

Description:

Model Number:

Sizes:

Serial Number:
Compact Electro-Hydraulic Actuator (EHA)

All

All

All

The following standards have either been referred to or complied with in part or in full as relevant:

ENISO 12100 - 2 Machinery Safety

EN13849 Machinery Safety

EN 982:1996Machinery Safety

Full Name of responsible person

Place of signing:

Parker Hannifin Corporation

Oildyne Division

5520 Highway 169 North

New Hope, MN 55428 USA

Signature

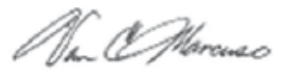

Full Name of Authorized European Representative

Place of signing:

Parker Hannifin Ltd.

Cylinder Division Europe

6 Greycaine Road.

Watford, Hertfordshire. WD24 7QA, UK

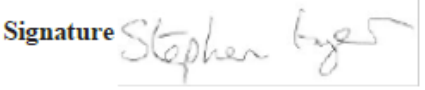

March 17, 2011
Date

March 17, 2011

Basic concepts, general principles for design

- Part 2: Technical principles and specifications.

Safety Related Parts of Control Systems - Part 1: General Principles for Design.

Safety requirements for fluid power systems and their components - Hydraulics.

Van Mancuso

Position

General Manager

Date

Stephen Fryer

Position

General Manager, Cylinder Division Europe

Parker Hannifin

HPS Division

New Hope, MN 55428 USA 


\section{Parker Worldwide}

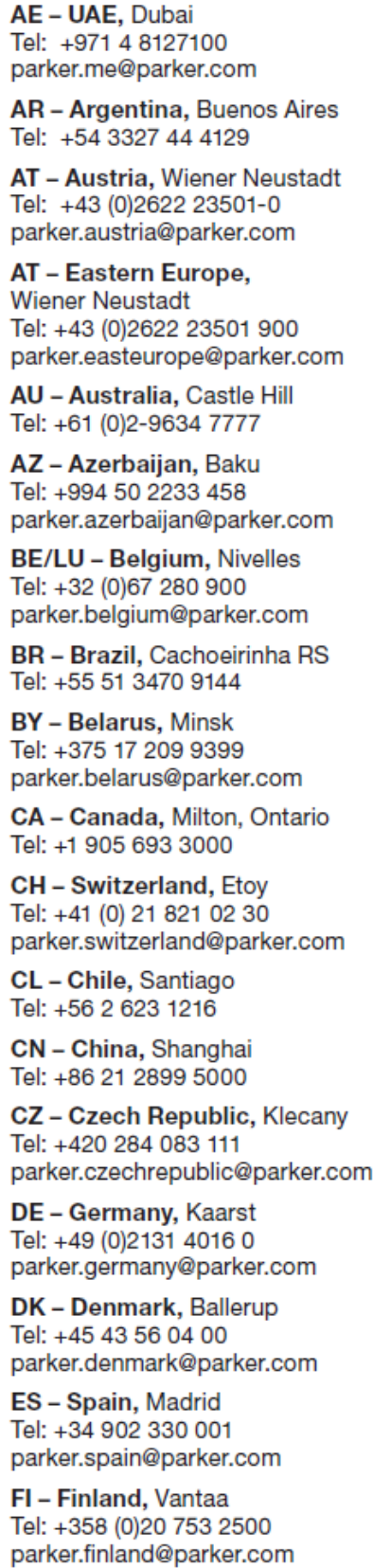

FR - France, Contamine s/Arve Tel: +33 (0)450258025 parker.france@parker.com

GR - Greece, Athens

Tel: +302109336450 parker.greece@parker.com

HK - Hong Kong

Tel: +852 24288008

HU - Hungary, Budapest

Tel: +361220 4155 parker.hungary@parker.com

IE - Ireland, Dublin

Tel: +353 (0)1 4666370

parker.ireland@parker.com

IN - India, Mumbai Tel: +91 226513 7081-85

IT - Italy, Corsico (MI)

Tel: +3902 451921

parker.italy@parker.com

JP - Japan, Fujisawa

Tel: +(81) 466353050

KR - South Korea, Seoul

Tel: +82 25590400

KZ - Kazakhstan, Almaty

Tel: +77272505800

parker.easteurope@parker.com

LV - Latvia, Riga

Tel: +371 67452601 parker.latvia@parker.com

MX - Mexico, Apodaca

Tel: +52 8181566000

MY - Malaysia, Shah Alam Tel: +60 378490800

NL - The Netherlands, Oldenzaal

Tel: +31 (0)541585000 parker.nl@parker.com

NO - Norway, Asker

Tel: +4766753400

parker.norway@parker.com

NZ - New Zealand, Mt Wellington Tel: +6495741744

PL - Poland, Warsaw

Tel: +48 (0)22 5732400

parker.poland@parker.com

PT - Portugal, Leca da Palmeira Tel: +351 229997360 parker.portugal@parker.com
RO - Romania, Bucharest Tel: +4021252 1382 parker.romania@parker.com

RU - Russia, Moscow

Tel: +7 495 645-2156 parker.russia@parker.com

SE - Sweden, Spånga Tel: +46 (0)8 59795000 parker.sweden@parker.com

SG - Singapore

Tel: +65 68876300

SK - Slovakia, Banská Bystrica Tel: +421 484162252 parker.slovakia@parker.com

SL - Slovenia, Novo Mesto Tel: +38673376650 parker.slovenia@parker.com

TH - Thailand, Bangkok

Tel: +662 7178140

TR - Turkey, Istanbul

Tel: +90 2164997081 parker.turkey@parker.com

TW - Taiwan, Taipei

Tel: +88622298 8987

UA - Ukraine, Kiev

Tel +380444942731 parker.ukraine@parker.com

UK - United Kingdom, Warwick

Tel: +44 (0)1926 317878 parker.uk@parker.com

US - USA, Cleveland (industrial)

Tel: +1 2168963000

US - USA, Lincolnshire

(mobile)

Tel: +1 8478211500

VE - Venezuela, Caracas

Tel: +58 2122385422

ZA - South Africa,

Kempton Park

Tel: +27 (0)119610700

parker.southafrica@parker.com

US Product Information Centre Free phone: 1-800-272-7537

European Product Information Centre

Free phone: 0080027275374 www.parker.com

Ph: 937-644-3915

Fax: 937-642-3738

www.parker.com/hps 


\title{
\begin{tabular}{ll}
\hline IIRoboteQ & FDC3260 \\
\hline
\end{tabular}
}

\author{
Advanced Features \\ Triple Channel 60A \\ Brushed DC \\ Motor Controller \\ with USB and CAN
}

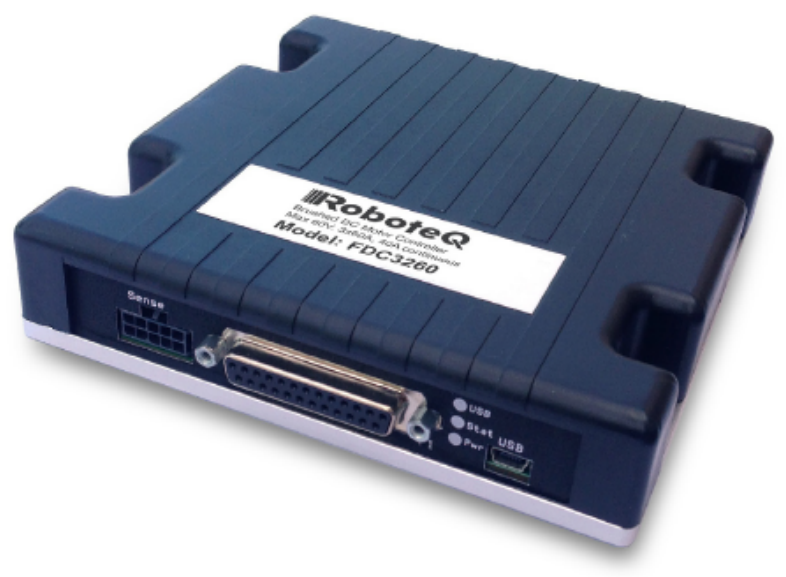

Roboteq's FDC3260 is a feature-packed, high-current, triple channel controller for brushed DC motors. The controller features a high-performance 32-bit microcomputer and quadrature encoder inputs to perform advanced motion control algorithms. The motors may be operated in open or closed loop speed mode, position mode or in torque mode.

The FDC3260 features several Analog, Pulse and Digital I/ Os which can be remapped as command or feedback inputs, limit switches, or many other functions. The FDC3260 accepts commands received from an RC radio, Analog Joystick, wireless modem, PLC, or microcomputer. For mobile robot applications, two of the controller's three motor channels can either be operated independently or mixed to move and steer a vehicle. Using CAN bus, up to 127 controllers can be networked at up to $1 \mathrm{Mbit} / \mathrm{s}$ on a single twisted pair.

Numerous safety features are incorporated into the controller to ensure reliable and safe operation. The controller's operation can be extensively automated and customized using Basic Language scripts. The controller can be configured, monitored and tuned in realtime using a Roboteq's free PC utility. The controller can also be reprogrammed in the field with the latest features by downloading new operating software from Roboteq

\section{Applications}

- Motion simulators

- XYZ platforms

- Underwater Robotic Vehicles

- Stabilization Gimbals

- Machine tools

- Industrial automation

- Telepresence Systems

- Animatronics
Key Features

- USB, RS323, RS485, 0-5V Analog, or Pulse (RC radio) command modes

- CAN bus interface up to $1 \mathrm{Mbit} / \mathrm{s}$ with multiple protocol support

- Auto switch between Serial, USB, CAN, Analog, or Pulse based on user-defined priority

- Built-in dual 3-phase high-power drivers for three brushed DC motor at up to $60 \mathrm{~A}$ each

- Full forward \& reverse motor control. Four quadrant operation. Supports regeneration

- Operates from a single $10 \mathrm{~V}-60 \mathrm{~V}$ power source

- Programmable current limit up to 60A per motor for protecting controller, motor, wiring and battery

- Dedicated connector for three quadrature encoders

- Up to eight Analog Inputs for use as command and/or feedback

- Up to eight Pulse Length, Duty Cycle or Frequency Inputs for use as command and/or feedback

- Up to 10 Digital Inputs for use as Deadman Switch, Limit Switch, Emergency stop or user inputs

- Four general purpose $24 \mathrm{~V}, 1.5 \mathrm{~A}$ output for brake release or accessories

- Selectable min, max, center and deadband in Pulse and Analog modes

- Selectable exponentiation factors for each command inputs

- Trigger action if Analog, Pulse or Encoder counter capture are outside user selectable range (soft limit switches)

- Open loop or closed loop speed control operation

- Closed loop position control with encoder, analog or pulse/frequency feedback

- Torque mode 
- PID control loop

- Built-in Battery Voltage and Temperature sensors

- Optional backup power input for powering safely the controller if the main motor batteries are discharged

- Power Control wire for turning On or Off the controller from external microcomputer or switch

- No consumption by output stage when motors stopped

- Regulated 5V output for powering RC radio, RF Modem, sensors or microcomputer

- Separate Programmable acceleration and deceleration for each motor

- Ultra-efficient $2.0 \mathrm{mOhm}$ ON resistance MOSFETs

- Selectable triggered action if Amps is outside userselected range

- Short circuit protection

- Overvoltage and Undervoltage protection
- Watchdog for automatic motor shutdown in case of command loss

- Overtemperature protection

- Diagnostic LED

- $\quad$ ABS plastic enclosure with heat conducting bottom plate

- Efficient heat sinking. Operates without a fan in most applications.

- Dustproof and weather resistant. IP51 NEMA rating

- Power wiring 0.25 " Faston tabs

- $\quad 5.5^{\prime \prime}(139.7 \mathrm{~mm}) \mathrm{L}, 5.5^{\prime \prime} \mathrm{W}(139.7 \mathrm{~mm}), 1.0^{\prime \prime}(25 \mathrm{~mm}) \mathrm{H}$

- $-40^{\circ}$ to $+85^{\circ} \mathrm{C}$ operating environment

- $0.5 \mathrm{lbs}(250 \mathrm{~g})$

- Easy configuration, tuning and monitor using provided PC utility

- Field upgradeable software for installing latest features via the Internet Orderable Product References

\section{Orderable Product References}

\begin{tabular}{|l|c|c|c|c|c|}
\hline Reference & Number of Channels & Amps/Channel & Volts & Ethernet & Resolver \\
\hline FDC3260 & 3 & 60 & 60 & No & No \\
\hline
\end{tabular}




\section{Important Safety Disclaimer}

Dangerous uncontrolled motor runaway condition can occur for a number of reasons, including, but not limited to: command or feedback wiring failure, configuration error, faulty firmware, errors in user script or user program, or controller hardware failure.

The user must assume that such failures can occur and must make their system safe in all conditions. Roboteq will not be liable in case of damage or injury as a result of product misuse or failure.

\section{Power Wires Identifications and Connection}

Power connections are made by means of faston tabs located at the back of the controller.

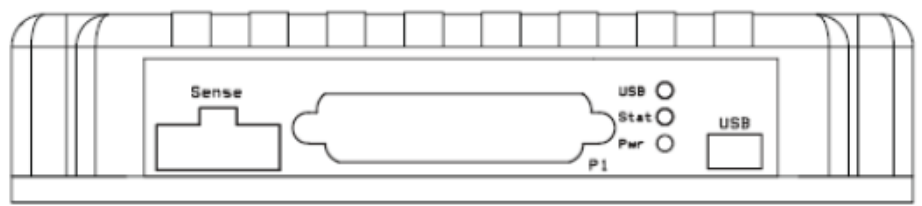
Hall Sensors
I/O Connector
LEDs USB
Connector
Connector

FIGURE 1. FDC3260 Front View

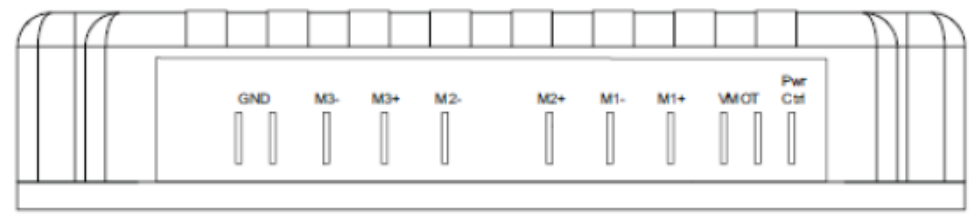




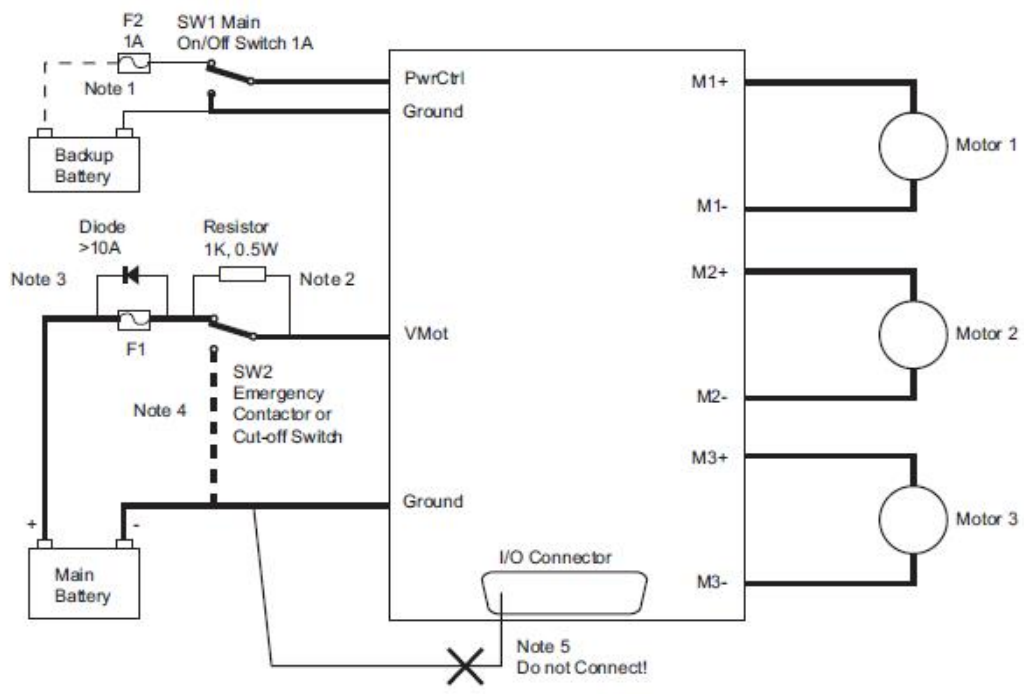

FIGURE 3. Powering the Controller. Thick lines identify MANDATORY connections

\section{Important Warning}

Carefully follow the wiring instructions provided in the Power Connection section of the User Manual. The information on this datasheet is only a summary.

\section{Mandatory Connections}

It is imperative that the controller is connected as shown in Figure 3 in order to ensure a safe and trouble-free operation. All connections shown as thick black lines line are mandatory. The controller must be powered On/Off using switch SW1on the Pwr Ctrl tab. Use a suitable high-current fuse $\mathrm{F} 1$ as a safety measure to prevent damage to the wiring in case of major controller malfunction.

\section{Emergency Switch or Contactor}

The battery must be connected in permanence to the controller's VMot tabs via a high-power emergency switch or contactor SW2 as additional safety measure. The user must be able to deactivate the switch or contactor at any time, independently of the controller state.

\section{Electrostatic Discharge Protection}

In accordance with IEC 61000-6-4, Roboteq Motor Controllers are designed to withstand ESD up to $4 \mathrm{kV}$ touch and $8 \mathrm{kV}$ air gap. This protection is implemented without any additional external connections required.

Some specifications, such as EN12895, require a higher level of protection. To maximize ESD protection, up to $8 \mathrm{kV}$ touch and $15 \mathrm{kV}$ air gap, you may connect the metallic heatsink of the controller to your battery negative terminal. See App Note 062918 for example connections. 


\section{Precautions and Optional Connections}

Note 1: Backup battery to ensure motor operation with weak or discharged batteries, connect a second battery to the Power Control wire/terminal via the SW1 switch.

Note 2: Use precharge 1K, 0.5W Resistor to prevent switch arcing.

Note 3: Insert a high-current diode to ensure a return path to the battery during regeneration in case the fuse is blown.

Note 4: Optionally ground the VMot tabs when the controller is Off if there is any concern that the motors could be made to spin and generate voltage in excess of 60V.

Note 5: Connect the controller's bottom plate to a wire connected to the Earth while the charger is plugged in the AC main, or if the controller is powered by an AC power supply. Note 6: Be sure not to create a path from the ground pins on the $\mathrm{I} / \mathrm{O}$ connector and the battery minus terminal.

\section{Use of Safety Contactor for Critical Applications}

An external safety contactor must be used in any application where damage to property or injury to person can occur because of uncontrolled motor operation resulting from failure in the controller's power output stage.

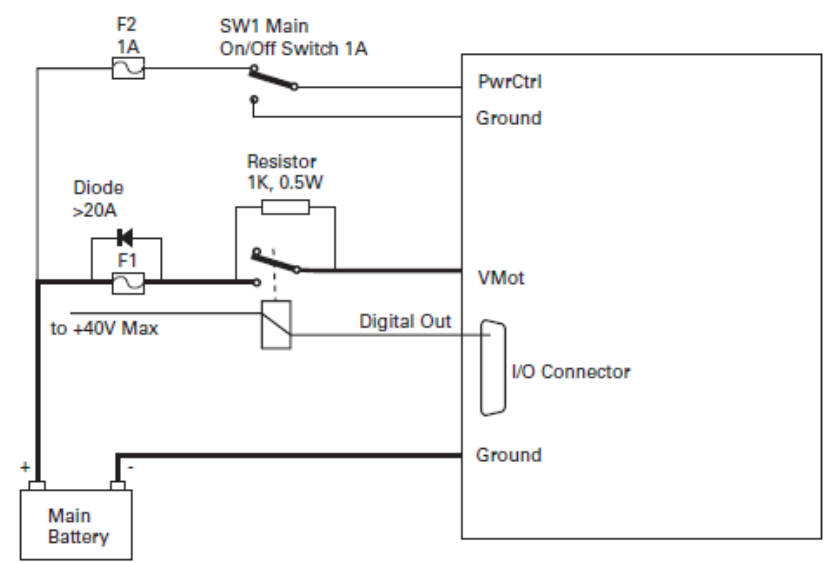

FIGURE 4. Contactor Wiring Diagram

The contactor coil must be connected to a digital output configured to activate when "No MOSFET Failure". The controller will automatically deactivate the coil if the output is expected to be off and battery current of $1 \mathrm{~A}$ or more is measured for more than $0.5 \mathrm{~s}$. This circuit will not protect against other sources of failure such as those described in the "Important Safety Disclaimer" on page 3.

\section{Controller Mounting}

During motor operation, the controller will generate heat that must be dissipated. The published amps rating can only be fully achieved if adequate cooling is provided. Good conduction cooling can be achieved by mounting the controller to a metallic surface, such as the chassis, cabinet, etc. 


\section{Encoder Connection}

Connection to the Encoders is done using a special connector on the front side of the controller. The connector is a 10-pin Molex Microfit 3.0, ref. 43025-1000. Pin assignments are in Table 1, below.

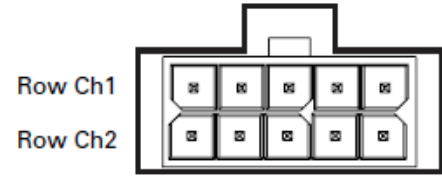

1
5

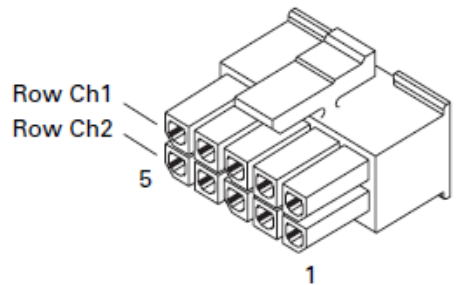

FIGURE 5. Encoder Connector

\section{TABLE 1.}

\begin{tabular}{|l|l|l|l|l|l|}
\hline Pin Number & $\mathbf{1}$ & $\mathbf{2}$ & $\mathbf{3}$ & $\mathbf{4}$ & $\mathbf{5}$ \\
\hline Row Ch1 & $5 \mathrm{~V}$ & Enc3 A & Enc1 B & Enc1 A & Ground \\
\hline Row Ch2 & $5 \mathrm{~V}$ & Enc3 B & Enc2 B & Enc2 A & Ground \\
\hline
\end{tabular}

\section{Commands and I/O Connections}

Connection to RC Radio, Microcomputer, Joystick and other low current sensors and actuators is done via the 25 connector. The functions of many pins vary depending on controller model and user configuration. Pin assignments are found inTable 2, below.

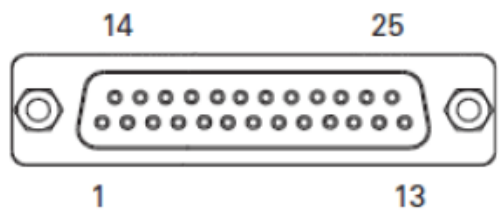

FIGURE 6. Main Connector Pin Locations 
TABLE 2.

\begin{tabular}{|c|c|c|c|c|c|c|c|}
\hline Connector Pin & Power & Dout & Com & Pulse & Ana & Dinput & Default Config \\
\hline 1 & GND & & & & & & \\
\hline 14 & 5VOut & & & & & & \\
\hline 2 & & & RSTxD & & & & $\mathrm{RS} 232 \mathrm{Tx}$ \\
\hline 15 & & & & $\mathrm{RC} 1$ & ANA1 & DIN1 & RCRadio1 \\
\hline 3 & & & RS RxD & & & & $\mathrm{RS} 232 \mathrm{Rx}$ \\
\hline 16 & & & & $\mathrm{RC} 2$ & ANA2 & DIN2 & RCRadio2 \\
\hline 4 & & & & $\mathrm{RC} 3$ & ANA3 & DIN3 & AnaCmd1 (1) \\
\hline 17 & & & & $\mathrm{RC} 4$ & ANA4 & DIN4 & AnaCmd2 (1) \\
\hline 5 & GND & & & & & & \\
\hline 18 & & DOUT1 & & & & & Motor Brake 1 \\
\hline 6 & & DOUT2 & & & & & Motor Brake 2 \\
\hline 19 & & DOUT3 & & & & & Contactor \\
\hline 7 & & DOUT4 & & & & & Unused \\
\hline 20 & & & $\mathrm{CANH}$ & & & & Unused \\
\hline 8 & & & CANL & & & & Unused \\
\hline 21 & & & & $\mathrm{RC} 5$ & ANA5 & DIN5 & Unused \\
\hline 9 & & & & & & DIN9 & Unused \\
\hline 22 & & & & $\mathrm{RC} 6$ & ANA6 & DIN6 & Unused \\
\hline 10 & & & & & & DIN10 & Unused \\
\hline 23 & & & RS485+ & & & & RS485 \\
\hline 11 & & & RS485- & & & & RS485 \\
\hline 24 & & & & $\mathrm{RC} 7$ & ANA7 & DIN7 & Unused \\
\hline 12 & & & & $\mathrm{RC} 8$ & ANA8 & DIN8 & Unused \\
\hline 25 & 5VOut & & & & & & \\
\hline 13 & GND & & & & & & \\
\hline
\end{tabular}

\section{Default I/O Configuration}

While the controller can be configured so that practically any Digital, Analog and RC pin can be used for any purpose, the controller's factory default configuration provides an assignment that is suitable for most applications. Figure 7, below shows how to wire the controller to two analog potentiometers, an RC radio, and the RS232 port. It also shows how to connect two outputs to motor brake solenoids and another output to an external status LED. You may omit any connection that is not required in your application. The controller automatically arbitrates the command priorities depending on the presence of a val- 
id command signal in the following order: 1-RS232, 2-RC Pulse, 3-None. If needed, use the Roborun+ PC Utility to change the pin assignments and the command priority order.

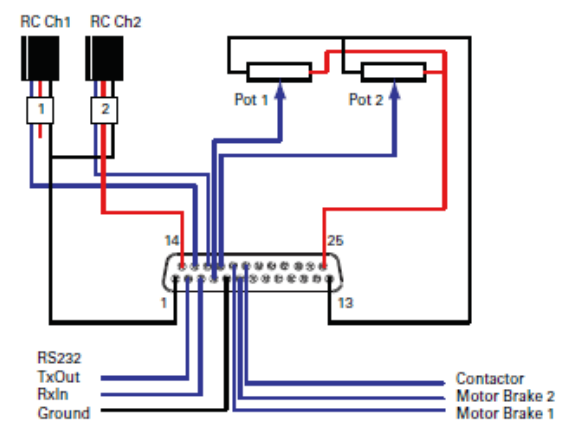

FIGURE 7. Factory Default Pins Assignment

\section{Enabling Analog Commands}

For safety reasons, the Analog command mode is disabled by default. To enable the Analog mode, use the PC utility and set Analog in Command Priority 2 or 3 (leave Serial as priority 1). Note that by default the additional securities are enabled and will prevent the motor from starting unless the potentiometer is centered, or if the voltage is below $0.25 \mathrm{~V}$ or above $4.75 \mathrm{~V}$. The drawing shows suggested assignment of Pot 1 to ANA1 and Pot 2 to ANA4. Use the PC utility to enable and assign analog inputs.

\section{USB communication}

Use USB only for configuration, monitoring and troubleshooting. USB is not a reliable communication method when used in an electrically noisy environment. Communication will not always recover after it is lost without unplugging and replugging the connector, or restarting the controller. RS232 is the preferred method of communication when interfacing to a computer. USB and CAN can operate at the same time on the FDC3260. Plugging USB to a computer will not disable the CAN interface.

\section{Status LED Flashing Patterns}

After the controller is powered on, the Power LED will tun on, indicating that the controller is On. The Status LED will be flashing at a 2 seconds interval. The flashing pattern provides operating or exception status information.

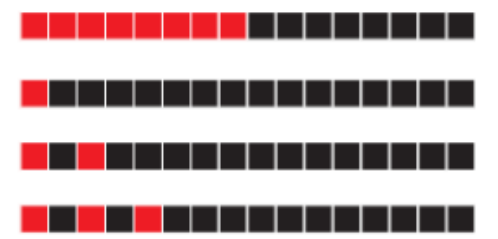

Idle - Waiting for Command

RS232/USB Mode

RC Pulse Mode

Analog Mode

FIGURE 8. Normal Operation Flashing Patterns 


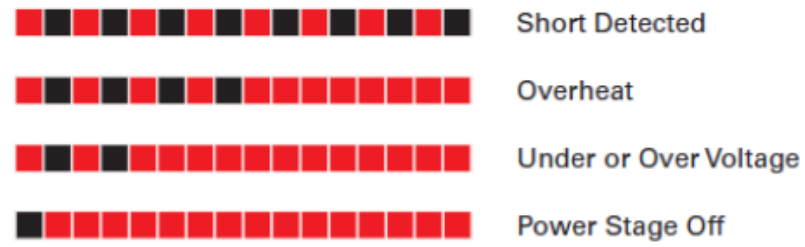

FIGURE 9. Exception or Fault Flashing Patterns

Additional status information may be obtained by monitoring the controller with the PC utility.

\section{Battery Backed Clock and RAM}

The controller includes a real-time clock/calendar and RAM storage for user variables. Both the clock and the RAM storage require a battery to continue running and for the stored data not to be lost while the controller is powered down. The battery is not installed by Roboteq. Users who wish to use the clock and/or battery backed RAM variables must install a battery themselves. The battery socket can be reached by removing the 6 screws that are holding the cover. Lift the cover to reach the board and insert a $3 \mathrm{~V}, 12.5 \mathrm{~mm}$ coin-style battery. Use battery type CR 1225 or equivalent.

\section{Measured and Calculated Amps}

The controller includes Amps sensor in line with the motor terminals. Motor Amps are therefore measured with precision. Battery Amps is estimated using the formula Battery Amps $=$ Motor Amps * PWM. This formula produces accurate results as long as the motor is well tuned, ie Hall Sensors correctly aligned in Trapezoidal mode, and Id $=0$ in Sinusoidal mode.

\section{Secure Connection to AMP FASTON ${ }^{\mathrm{TM}}$ Tabs}

Power Motor and Battery connections are made via standard 250 mils $(6.35 \mathrm{~mm})$ AMP FASTON Tabs. FASTON connectors provide a high current and very secure connection, proven over decades of use in the automotive industry. For maximum current handling, use connectors for AWG10 wires recognizable by their yellow plastic insulator.

FASTON connectors have an extremely tight fit and will not come off on their own. It is recommended, nevertheless, that the wiring is made so that the cables are never pulling the connector outward.

Frequent disconnects and reconnects will eventually loosen the connector's grip on the tab. If frequent disconnection is required, consider using Positive Lock connectors from TE Connectivity or their equivalent. These connectors have a spring loaded tab latch pin that will lock into the hole of the male tab. 


\section{Electrical Specifications}

\section{Absolute Maximum Values}

The values in Table 3, below, should never be exceeded. Permanent damage to the controller may result.

TABLE 3.

\begin{tabular}{|l|l|l|l|l|l|}
\hline Parameter & Measure point & Min & Typical & Max & Units \\
\hline Battery Leads Voltage & Ground to VBat & & & 63 & Volts \\
\hline Reverse Voltage on Battery Leads & Ground to VBat & -1 & & & Volts \\
\hline Power Control Voltage & Ground to Pwr Control wire & & & 63 & Volts \\
\hline Motor Leads Voltage & Ground to M+ and M- wires & & & $63(1)$ & Volts \\
\hline Digital Output Voltage & Ground to Output pins & & & 30 & Volts \\
\hline Analog and Digital Inputs Voltage & $\begin{array}{l}\text { Ground to any signal pin on 15- } \\
\text { pin \& Hall inputs }\end{array}$ & & 15 & Volts \\
\hline RS232 I/O pins Voltage & $\begin{array}{l}\text { External voltage applied to Rx/ } \\
\text { Txpins }\end{array}$ & & & 15 & Volts \\
\hline Case Temperature & Case & -40 & & 85 & ${ }^{\circ} \mathrm{C}$ \\
\hline Humidity & Case & & 100 (2) & $\%$ \\
\hline $\begin{array}{l}\text { Note 1: Maximum regeneration voltage in normal operation. Never inject a DC voltage from a battery or } \\
\text { other fixed source }\end{array}$ & \\
\hline Note 2: Non-condensing & \multicolumn{5}{l|}{} \\
\hline
\end{tabular}

\section{Power Stage Electrical Specifications (at $25^{\circ} \mathrm{C}$ ambient)}

TABLE 4

\begin{tabular}{|l|l|l|l|l|l|}
\hline $\begin{array}{l}\text { Continuous Max Current } \\
\text { per channel }\end{array}$ & Measure point & Min & Typical & Max & Units \\
\hline Battery Leads Voltage & Ground to VMot & $0(1)$ & & 63 & Volts \\
\hline Motor Leads Voltage & Ground to M+ and M- wires & $0(1)$ & & $63(2)$ & Volts \\
\hline Power Control Voltage & Ground to Power Control wire & $0(1)$ & & 65 & Volts \\
\hline Minimum Operating Voltage & VMot or Pwr Ctrl wires & $9(3)$ & & & Volts \\
\hline Over Voltage protection range & Ground to VMot & 5 & $60(4)$ & 63 & Volts \\
\hline Under Voltage protection range & Ground to VMot & 0 & $5(4)$ & 63 & Volts \\
\hline Idle Current Consumption & VMot or Pwr Ctrl wires & 50 & $100(5)$ & 150 & mA \\
\hline $\begin{array}{l}\text { ON Resistance (Excluding wire } \\
\text { resistance) }\end{array}$ & $\begin{array}{l}\text { VMot to M+/-. Ground to } \\
\text { M+/- }\end{array}$ & & 2.5 & & $\mathrm{mOhm}$ \\
\hline Max Current for 30s & Motor current & & & 60 & Amps \\
\hline $\begin{array}{l}\text { Continuous Max Current per } \\
\text { channel }\end{array}$ & Motor current & & & $40(6)$ & Amps \\
\hline Current Limit range & Motor current & 10 & $50(7)$ & 60 & Amps \\
\hline Stall Detection Amps range & Motor current & 10 & $60(7)$ & 60 & Amps \\
\hline
\end{tabular}


TABLE 4.

\begin{tabular}{|c|c|c|c|c|c|}
\hline $\begin{array}{l}\text { Continuous Max Current } \\
\text { per channel }\end{array}$ & Measure point & Min & Typical & Max & Units \\
\hline Stall Detection timeout range & Motor current & 1 & $500(8)$ & 65000 & $\begin{array}{l}\text { milli- } \\
\text { seconds }\end{array}$ \\
\hline $\begin{array}{l}\text { Short Circuit Detection } \\
\text { threshold (9) }\end{array}$ & $\begin{array}{l}\text { Between Motor wires or } \\
\text { Between Motor wires and } \\
\text { Ground }\end{array}$ & & & $\begin{array}{l}500 \\
(10)\end{array}$ & Amps \\
\hline $\begin{array}{l}\text { Short Circuit Detection } \\
\text { threshold }\end{array}$ & $\begin{array}{l}\text { Between Motor wires and } \\
\text { VBat }\end{array}$ & \multicolumn{4}{|c|}{$\begin{array}{l}\text { No Protection. Permanent damage will } \\
\text { result }\end{array}$} \\
\hline $\begin{array}{l}\text { Motor Acceleration/ } \\
\text { Deceleration range }\end{array}$ & Motor Output & 100 & $500(11)$ & 65000 & $\begin{array}{l}\text { milli- } \\
\text { seconds }\end{array}$ \\
\hline \multicolumn{6}{|c|}{$\begin{array}{l}\text { Note 1: Negative voltage will cause a large surge current. Protection fuse needed if battery polarity inver- } \\
\text { sion is possible }\end{array}$} \\
\hline \multicolumn{6}{|c|}{$\begin{array}{l}\text { Note 2: Maximum regeneration voltage in normal operation. Never inject DC voltage from a battery or other } \\
\text { fixed source }\end{array}$} \\
\hline \multicolumn{6}{|c|}{ Note 3: Minimum voltage must be present on VBat or Power Control wire } \\
\hline \multicolumn{6}{|c|}{ Note 4: Factory default value. Adjustable in $0.1 \mathrm{~V}$ increments } \\
\hline \multicolumn{6}{|c|}{ Note 5: Current consumption is lower when higher voltage is applied to the controller's VBat or PwrCtrl wires } \\
\hline \multicolumn{6}{|c|}{ Note 6: Estimate. Limited by case temperature. Current may be higher with better cooling } \\
\hline \multicolumn{6}{|c|}{ Note 7: Factory default value. Adjustable in $0.1 \mathrm{~A}$ increments } \\
\hline \multicolumn{6}{|c|}{ Note 8: Factory default value. Time in ms that Stall current must be exceeded for detection } \\
\hline \multicolumn{6}{|c|}{ Note 9: Controller will stop until restarted in case of short circuit detection } \\
\hline \multicolumn{6}{|c|}{ Note 10: Approximate value } \\
\hline \multicolumn{6}{|c|}{ Note 11: Factory default value. Time in $\mathrm{ms}$ for power to go from 0 to $100 \%$} \\
\hline
\end{tabular}

\section{Command, I/O and Sensor Signals Specifications}

TABLE 5 .

\begin{tabular}{|l|l|l|l|l|l|}
\hline Parameter & Measure point & Min & Typical & Max & Units \\
\hline Main 5V Output Voltage & Ground to 5V pins on & 4.6 & 4.75 & 4.9 & Volts \\
\hline 5V Output Current & 5V pins on RJ45 and DSub15 & & & 200 (1) & $\mathrm{mA}$ \\
\hline Digital Output Voltage & Ground to Output pins & & & 30 & Volts \\
\hline Output On resistance & Output pin to ground & & 0.25 & 0.5 & Ohm \\
\hline Output Short circuit threshold & Output pin & 1.7 & & 3.5 & Amps \\
\hline Digital Output Current & Output pins, sink current & & & 1.5 & Amps \\
\hline Input Impedances & AlN/DIN Input to Ground & & 53 & & kOhm \\
\hline Digital Input 0 Level & Ground to Input pins & -1 & & 1 & Volts \\
\hline Digital Input 1 Level & Ground to Input pins & 3 & & 15 & Volts \\
\hline Analog Input Range & Ground to Input pins & 0 & & 5.1 & Volts \\
\hline Analog Input Precision & Ground to Input pins & & 0.5 & & $\%$ \\
\hline Analog Input Resolution & Ground to Input pins & & 1 & & $\mathrm{mV}$ \\
\hline Encoder Frequency & & & & 500 & $\mathrm{kHz}$ \\
\hline
\end{tabular}


TABLE 5.

\begin{tabular}{|l|l|l|l|l|l|}
\hline Parameter & Measure point & Min & Typical & Max & Units \\
\hline Pulse durations & Pulse inputs & 20000 & & 10 & us \\
\hline Pulse repeat rate & Pulse inputs & 50 & & 250 & $\mathrm{~Hz}$ \\
\hline Pulse Capture Resolution & Pulse inputs & & 1 & & us \\
\hline Frequency Capture & Pulse inputs & 100 & & 1000 & $\mathrm{~Hz}$ \\
\hline Note 1: Sum of all 5VOut outputs & \multicolumn{5}{l}{} \\
\hline
\end{tabular}

Operating \& Timing Specifications

TABLE 6.

\begin{tabular}{|l|l|l|l|l|l|}
\hline Parameter & Measure Point & Min & Typical & Max & Units \\
\hline Command Latency & Command to output change & 1 & 0.5 & 1 & $\mathrm{~ms}$ \\
\hline PWM Frequency & Motor Output & 10 & 18 & 20 & $\mathrm{kHz}$ \\
\hline Closed Loop update rate & Internal & & 1000 & & $\mathrm{~Hz}$ \\
\hline RS232 baud rate & Rx \& Tx pins & & $115200(1)$ & & $\mathrm{Bits} / \mathrm{s}$ \\
\hline RS232 Watchdog timeout & Rx pin & $1(2)$ & & 65000 & $\mathrm{~ms}$ \\
\hline Note 1: 115200, 8-bit, no parity, 1 stop bit, no flow control \\
\hline Note 2: May be disabled with value 0
\end{tabular}

\section{Scripting}

TABLE 7

\begin{tabular}{|l|l|l|l|l|l|}
\hline Parameter & Measure Point & Min & Typical & Max & Units \\
\hline Scripting Flash Memory & Internal & & 32000 & & Bytes \\
\hline Max Basic Language programs & Internal & 1000 & & 3000 & Lines \\
\hline Integer Variables & Internal & & 4096 & & Words (1) \\
\hline Boolean Variables & Internal & & 8192 & & Symbols \\
\hline Execution Speed & Internal & 50000 & 100000 & & Lines/s \\
\hline Note 1: 32-bit words
\end{tabular}

\section{Thermal Specifications}

TABLE 8.

\begin{tabular}{|l|l|l|l|l|l|}
\hline Parameter & Measure Point & Min & Typical & Max & Units \\
\hline Case Temperature & Case & -40 & & $85(1)$ & ${ }^{\circ} \mathrm{C}$ \\
\hline Thermal Protection range & Case & 80 & & $90(2)$ & ${ }^{\circ} \mathrm{C}$ \\
\hline Power Dissipation & Case & & & 70 & Watts \\
\hline Thermal resistance & Power MOSFETs to case & & & 0.6 & ${ }^{\circ} \mathrm{C}$ N \\
\hline Humidity & Case & & & $100(3)$ & $\%$ \\
\hline Note 1: Thermal protection will protect the controller power \\
\hline Note 2: Max allowed power out starts lowering at minimum of range, down to 0 at max of range \\
\hline
\end{tabular}


Mechanical Specifications

\begin{tabular}{|l|l|l|l|l|l|}
\hline & & & & & \\
\hline Weight & Board & & $452(0.99)$ & & $\mathrm{g}$ (lbs) \\
\hline Power Connectors width & Terminal tab & & 0.25 & & Inches \\
\hline
\end{tabular}

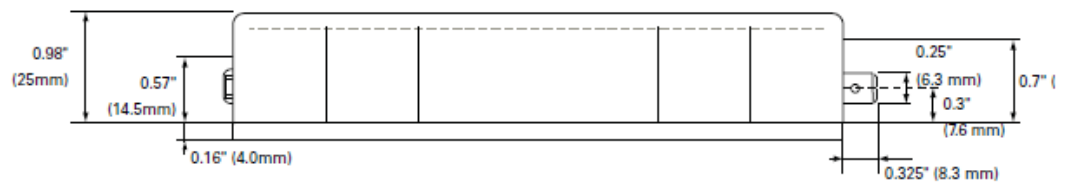

FIGURE 10. FDC32260 Side View and Dimensions

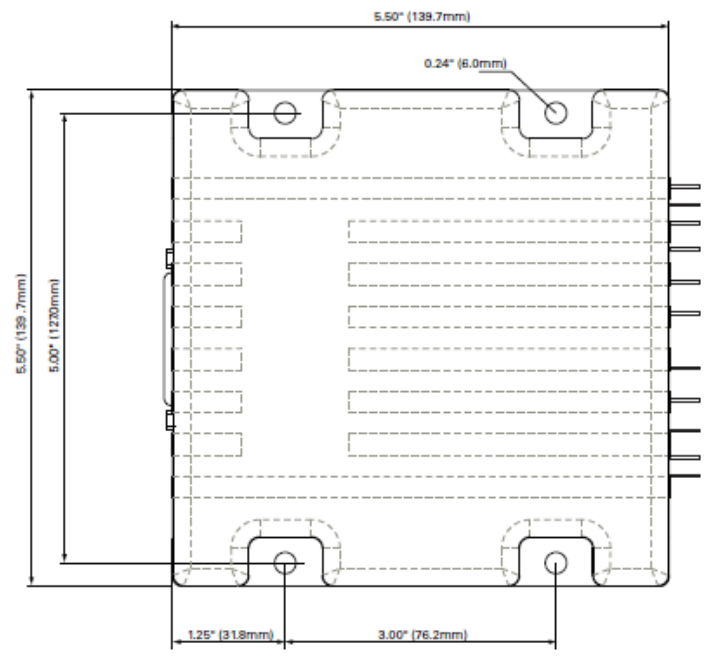

FIGURE 11. Top View and Dimmensions 
Appendix F: Bill of Materials

\begin{tabular}{|c|c|c|c|c|c|c|}
\hline Group & Model Number & Company & $\begin{array}{l}\text { Part } \\
\text { Number }\end{array}$ & Price & Qty & Total \\
\hline $\begin{array}{l}\text { Actuator } \\
\text { Assembly }\end{array}$ & EHA Actuator & MSC & 92667997 & $\$ 616.82$ & 6 & $\$ 3,700.92$ \\
\hline Measurement & 6-Axis Force Sensor & $\begin{array}{l}\text { Sunrise } \\
\text { Intruments }\end{array}$ & M3943 & $\begin{array}{r}\$ \\
5,350.00\end{array}$ & 1 & $\$ 5,350.00$ \\
\hline Hexapod & Ball Joint & $\begin{array}{l}\text { McMaster- } \\
\text { Carr }\end{array}$ & $60745 K 651$ & $\$ 26.22$ & 6 & $\$ 157.32$ \\
\hline Measurement & Cameras & Flir & $\begin{array}{l}\text { CM3-U3- } \\
\text { 13Y3C-CS }\end{array}$ & $\$ 350.00$ & 6 & $\$ 2,100.00$ \\
\hline Camera & Camera Lens & Flir & $\begin{array}{l}\text { LENS- } \\
\text { 15F5-250C }\end{array}$ & $\$ 170.00$ & 6 & $\$ 1,020.00$ \\
\hline Measurement & $\begin{array}{l}\text { Linear Motion Position- } \\
\text { Measuring Transmitters }\end{array}$ & $\begin{array}{l}\text { McMaster- } \\
\text { Carr }\end{array}$ & $6863 K 2$ & $\$ 213.38$ & 6 & $\$ 1,280.28$ \\
\hline Camera & Cables & Flir & $\begin{array}{l}\text { ACC-01- } \\
2301\end{array}$ & $\$ 15.00$ & 6 & $\$ 90.00$ \\
\hline Camera & Host Adapter & FLIR & $\begin{array}{l}\text { ACC-01- } \\
1203\end{array}$ & $\$ 155.00$ & 1 & $\$ 155.00$ \\
\hline $\begin{array}{l}\text { Power \& } \\
\text { Control }\end{array}$ & Arduino Due & Arduino & $\begin{array}{l}\text { 1050-1049- } \\
\text { ND }\end{array}$ & $\$ 38.68$ & 1 & $\$ 38.68$ \\
\hline $\begin{array}{l}\text { Power \& } \\
\text { Control }\end{array}$ & $\begin{array}{l}\text { Brushed DC Motor } \\
\text { Controller }\end{array}$ & Roboteq & FDC3260 & $\$ 595.00$ & 2 & $\$ 1,190.00$ \\
\hline $\begin{array}{l}\text { Power \& } \\
\text { Control }\end{array}$ & Emergency Stop Button & Amazon & & $\$ 6.78$ & 1 & $\$ 6.78$ \\
\hline $\begin{array}{l}\text { Power \& } \\
\text { Control }\end{array}$ & Optima Batteries & Amazon & $\begin{array}{l}8016-103 \\
\text { D34M }\end{array}$ & $\$ 190.36$ & 2 & $\$ 380.72$ \\
\hline $\begin{array}{l}\text { Power \& } \\
\text { Control }\end{array}$ & $\begin{array}{l}\text { Powermax } 40 \mathrm{Amp}, 24 \mathrm{~V} \\
\text { charger }\end{array}$ & PPL & $\begin{array}{l}\text { PM3-40- } \\
24 \mathrm{LK}\end{array}$ & $\$ 170.28$ & 2 & $\$ 340.56$ \\
\hline $\begin{array}{l}\text { Actuator } \\
\text { Assembly }\end{array}$ & Universal Joints & $\begin{array}{l}\text { McMaster- } \\
\text { Carr }\end{array}$ & 2456K17 & $\$ 79.68$ & 6 & $\$ 478.08$ \\
\hline $\begin{array}{l}\text { Actuator } \\
\text { Assembly }\end{array}$ & $\begin{array}{l}\text { Partial-Extension Lock- } \\
\text { Open Drawer Slides }\end{array}$ & $\begin{array}{l}\text { McMaster- } \\
\text { Carr }\end{array}$ & 63835A31 & $\$ 53.03$ & 6 & $\$ 318.18$ \\
\hline $\begin{array}{l}\text { Actuator } \\
\text { Assembly }\end{array}$ & Plastic Corner Bracket & $\begin{array}{l}\text { McMaster- } \\
\text { Carr }\end{array}$ & 13135A59 & $\$ 0.33$ & 12 & $\$ 3.96$ \\
\hline Hexapod & $\begin{array}{l}\text { Ultra-High Capacity } \\
\text { Leveling Mount }\end{array}$ & $\begin{array}{l}\text { McMaster- } \\
\text { Carr }\end{array}$ & 3757K39 & $\$ 49.57$ & 3 & $\$ 148.71$ \\
\hline $\begin{array}{l}\text { Fabrication } \\
\text { Cost }\end{array}$ & 3rd Party Fabrication & $\begin{array}{l}\text { MTS } \\
\text { (Clemson } \\
\text { Campus) }\end{array}$ & & $\begin{array}{r}\$ \\
11,331.16\end{array}$ & 1 & $\begin{array}{r}\$ \\
11,331.16\end{array}$ \\
\hline & & & & & TOTAL: & $\begin{array}{r}\$ \\
28,090.35\end{array}$ \\
\hline
\end{tabular}




\section{Appendix G: Tiger 66.1 Control Code}

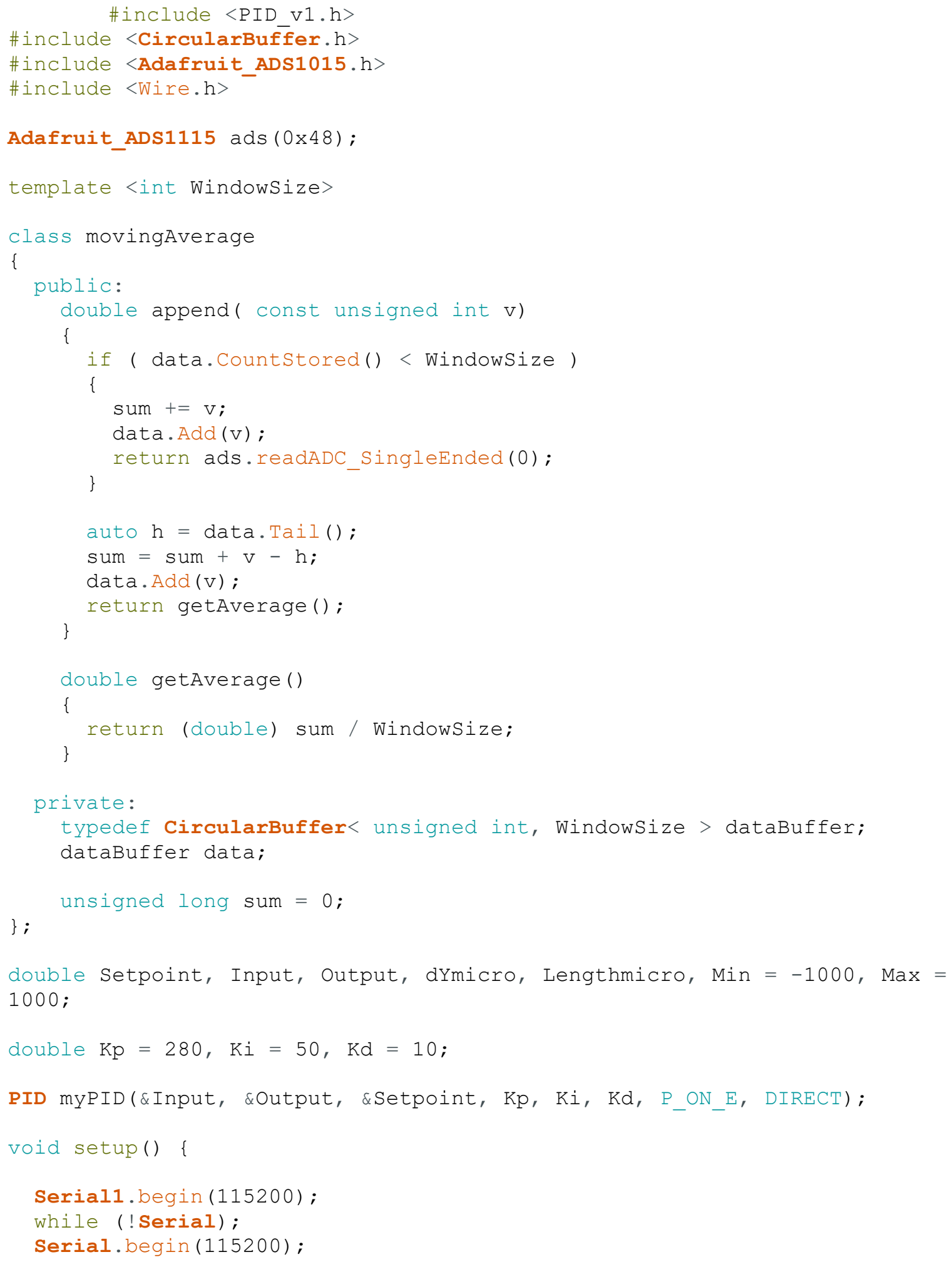




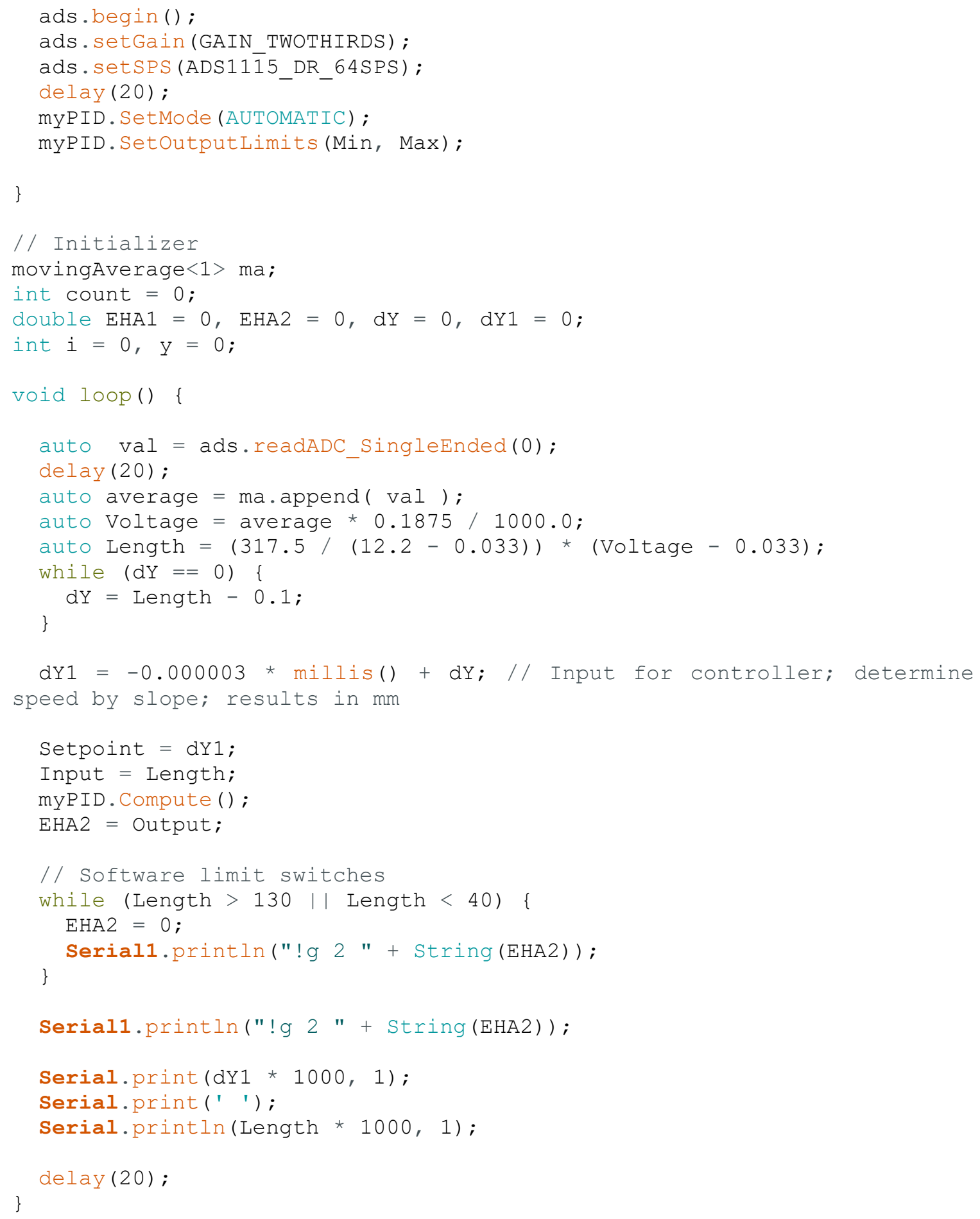


Appendix H: CSM Bill of Materials

\begin{tabular}{|c|c|c|c|c|c|c|}
\hline & ALL ITEMS & & & & & \\
\hline & Item & Company & Model Number & Price & $\begin{array}{l}\text { Qt } \\
y\end{array}$ & Total \\
\hline \multirow{4}{*}{$\begin{array}{l}\text { Hexap } \\
\text { od }\end{array}$} & $\begin{array}{l}\text { Top/Bottom } \\
\text { plate }\end{array}$ & Metals Depot & $\begin{array}{l}\text { 1-1/2in Al plate, } \\
4 \times 8 \mathrm{ft}\end{array}$ & $\begin{array}{l}\$ \\
3,072.00\end{array}$ & 1 & $\begin{array}{l}\$ \\
3,072.00\end{array}$ \\
\hline & $\begin{array}{l}\text { Linear } \\
\text { Actuators }\end{array}$ & Thomson Linear & $\begin{array}{l}\text { PC40PA999B05- } \\
\text { 0060XM1 }\end{array}$ & $\begin{array}{l}\$ \\
1,319.00\end{array}$ & 6 & $\begin{array}{l}\$ \\
7,914.00\end{array}$ \\
\hline & Motors & $\begin{array}{l}\text { Applied Motion } \\
\text { Products }\end{array}$ & НT34-496 & $\begin{array}{l}\$ \\
579.00\end{array}$ & 6 & $\begin{array}{l}\$ \\
3,474.00\end{array}$ \\
\hline & Globe Joint & Myostat & SRJ024C & $\begin{array}{l} \\
380.00\end{array}$ & 12 & $\begin{array}{l}\$ \\
4,560.00\end{array}$ \\
\hline \multirow{2}{*}{ Grips } & $\begin{array}{l}\text { Grips (Set of } \\
\text { 2) }\end{array}$ & ADMET & GV-20T & $\begin{array}{l}\$ \\
2,048.00\end{array}$ & 1 & $\begin{array}{l}\$ \\
2,048.00\end{array}$ \\
\hline & Grip Adapter & Metals Depot & $\begin{array}{l}5 \times 5 \text { in } \text { C1018 steel } \\
\text { square, } 1 \mathrm{ft}\end{array}$ & $\begin{array}{l}\$ \\
421.42\end{array}$ & 1 & $\begin{array}{l}\$ \\
421.42\end{array}$ \\
\hline \multirow{3}{*}{$\begin{array}{l}\text { Sensor } \\
\mathrm{S}\end{array}$} & $\begin{array}{l}\text { 6-Axis Force } \\
\text { Sensor }\end{array}$ & $\begin{array}{l}\text { Sunrise } \\
\text { Instruments }\end{array}$ & M3943 & $\begin{array}{l}\$ \\
5,350.00\end{array}$ & 1 & $\begin{array}{l}\$ \\
5,350.00\end{array}$ \\
\hline & LVDT & Macro Sensors & SE-750-4000-006 & $\begin{array}{l}\$ \\
497.00\end{array}$ & 6 & $\begin{array}{l}\$ \\
2,982.00\end{array}$ \\
\hline & $\begin{array}{l}\text { LVDT Core } \\
\text { Rod Kit }\end{array}$ & Macro Sensors & CCR3M-0650-1 & $\begin{array}{l}\$ \\
67.00\end{array}$ & 6 & $\begin{array}{l}\$ \\
402.00\end{array}$ \\
\hline \multirow{6}{*}{ Optics } & Camera & Point Grey & $\begin{array}{l}\text { FL3-U3-88S2C-C } \\
\text { (Flea 3) }\end{array}$ & $\begin{array}{l}\$ \\
895.00\end{array}$ & 4 & $\begin{array}{l}\$ \\
3,580.00\end{array}$ \\
\hline & Lens & Tamron & 23FM16SP & $\begin{array}{l}\$ \\
245.00\end{array}$ & 4 & $\begin{array}{l}\$ \\
980.00\end{array}$ \\
\hline & $\begin{array}{l}\text { Tripod } \\
\text { Adaptor }\end{array}$ & Point Grey & ACC-01-0003 & included & 4 & $\begin{array}{l}\$ \\
-\end{array}$ \\
\hline & USB Hub & Point Grey & ACC-01-600 & $\begin{array}{l}\$ \\
110.00\end{array}$ & 1 & $\begin{array}{l}\$ \\
110.00\end{array}$ \\
\hline & USB Cable & Point Grey & ACC-01-2301 & $\begin{array}{l}\$ \\
15.00\end{array}$ & 1 & $\begin{array}{l}\$ \\
15.00\end{array}$ \\
\hline & $\begin{array}{l}\text { Camera } \\
\text { Mount }\end{array}$ & Metals Depot & $\begin{array}{l}\text { 1/4in thick 3003- } \\
\text { H14 Al 1x1ft }\end{array}$ & $\begin{array}{l} \\
23.52\end{array}$ & 1 & $\begin{array}{l}\$ \\
23.52\end{array}$ \\
\hline \multirow{3}{*}{ Safety } & Brackets & Sick & C4000 Select & $\begin{array}{l}\$ \\
82.00 \\
\end{array}$ & 4 & $\begin{array}{l}\$ \\
328.00 \\
\end{array}$ \\
\hline & Fence & RapidWire & $\begin{array}{l}4 \times 8 \mathrm{ft} \text { Fence }+2 \\
\text { posts }\end{array}$ & $\begin{array}{l}\$ \\
289.00\end{array}$ & 2 & $\begin{array}{l}\$ \\
578.00\end{array}$ \\
\hline & Light Curtain & Sick & C40E-1203CD010 & $\begin{array}{l}\$ \\
793.00\end{array}$ & 1 & $\begin{array}{l}\$ \\
793.00\end{array}$ \\
\hline $\begin{array}{l}\text { Electro } \\
\text { nics }\end{array}$ & DAQ Card & & & $\begin{array}{l}\$ \\
2,000.00\end{array}$ & 1 & $\begin{array}{l}\$ \\
2,000.00\end{array}$ \\
\hline
\end{tabular}




\begin{tabular}{|l|l|l|l|l|l|l|}
\hline & & & $\$$ & & $\$$ \\
& Hard Drive & Seagate & STCL4000400 & 225.00 & 1 & 225.00 \\
\hline & & & & & & $\mathbf{\$}$ \\
& & & & & & $\mathbf{3 5 , 7 8 3 . 9}$ \\
\hline
\end{tabular}




\section{Appendix I: Initial Singularity Analysis}

\section{I.1 Overview}

While some of the geometry has been explained for a general SG platform in previous sections, this section will discuss the steps taken to analyze the Jacobian and using the results to determine a suitable geometry for an SG platform. The chosen parameters are outlined in Figure 2.2. The variables $\mathbf{a}_{\mathbf{i}}$ and $\mathbf{b} \mathbf{b}$ are found for the SolidWorks model by using a specified coordinate system and using the measure tool in SolidWorks. The leg lengths, $\overline{A_{\imath} B_{l}}$ where $i=1,2, \ldots 6$, are found by using a vector loop equation shown in Equation 2.3. The vectors $\mathbf{a}_{\mathbf{i}}=\left[a_{i x}, a_{i y}, a_{i z}\right]^{\mathrm{T}}$ and ${ }^{\mathrm{B}} \mathbf{b}_{\mathbf{i}}=\left[b_{i u}, b_{i v}, b_{i w}\right]^{\mathrm{T}}$ are with respect to the coordinate systems of the top and bottom plates respectively. For each case, $a_{i z}$ and $b_{i w}$ are equal to zero. The variable ${ }^{A} R_{B}$, shown in Equation 2.4, is the rotation matrix of the top platform [5]. In the case where the top platform is level, the rotation matrix is simply an identity matrix.

With the model of the Stewart Platform established, the Jacobian matrix can be calculated in Equation 6.1 such that,

$$
J=\left[\begin{array}{cc}
\mathbf{s}_{\mathbf{1}}^{T} & \left(\mathbf{b}_{\mathbf{1}} \times \mathbf{s}_{1}\right)^{T} \\
\vdots & \vdots \\
\mathbf{s}_{6}^{T} & \left(\mathbf{b}_{\mathbf{6}} \times \mathbf{s}_{6}\right)^{T}
\end{array}\right]
$$

where $\mathbf{S}_{\mathbf{i}}$ is the unit vector of the leg length calculated in Equation 2.5 [14]. With the Jacobian formulated, there is now a way to find the condition number and determinant of the Jacobian. 
Next, pathways are designated so that the singularities can be detected along it. For simplicity, pure tensile, bending, and torsion tests were used to analyze possible singularities. In order to determine the amount of movement needed for each test, a deflection prediction was completed on a specified material, ABS-ESD7 [29]. The tensile test is the simplest case. The goal is to use an iteration to calculate the Jacobian matrix with input of $\mathbf{p}$ and the rotation matrix. Since it is a pure tensile test, only the $z$ value of the $\mathbf{p}$ vector needs to be used, $x$ and $y$ are equal to zero. The rotation matrix is simply an identity matrix considering there is no rotation about the $\mathrm{x}, \mathrm{y}$, or $\mathrm{z}$ axis. For the pure bending test, only the $x$ (or $y$ depending on orientation) values are changed or the $\mathbf{p}$ position, along with the specified result of the rotation matrix. In the case of revolution about the y-axis for the bending test, the rotation matrix is given in Equation 6.2,

$$
{ }^{A} R_{B}=\left[\begin{array}{ccc}
\cos (\theta) & 0 & \sin (\theta) \\
0 & 1 & 0 \\
-\sin (\theta) & 0 & \cos (\theta)
\end{array}\right]
$$

where $\theta$ is the angle at which the coordinate system rotates about the y-axis. For the deflection value of the bending test, it was assumed that the material specimen is loaded as a cantilever beam with a concentrated loading scenario in which the maximum deflection occurs at the maximum bending moment needed to cause failure. Lastly, for the torsion test, the top plate is rotated about the z-axis such that the rotation matrix, given in Equation 6.4 , is,

$$
{ }^{A} R_{B}=\left[\begin{array}{ccc}
\cos (\gamma) & -\sin (\gamma) & 0 \\
\sin (\gamma) & \cos (\gamma) & 0 \\
0 & 0 & 1
\end{array}\right]
$$


where $\gamma$ is the angle at which the top plate coordinate system revolves about its $\mathrm{z}$-axis. Maximum deflection was calculated with the torsion equation with a solid rectangular cross-section (maximum defection was calculated assuming the specimen was completely solid). In this case, $x$ and $y$ are equal to zero and $z$ is equal to the "home" height of the Stewart-Gough platform in the $\mathbf{p}$ vector. The only variable that changes in the torsion case is the angle, $\gamma$.

Applying the equations for the motion of SG platform, we calculate the deflection of ABS-ESD7 for each of the tests using the material properties outlined in the table below.

Table I.1: Material properties of ABS-ESD7 [6].

$\begin{array}{lcc}\text { Tensile Elongation } & 3.000 & \% \\ \text { Elastic Modulus } & 2400 & \mathrm{MPa} \\ \text { Tensile Strength } & 36.00 & \mathrm{MPa} \\ \text { Flexural Strength } & 61.00 & \mathrm{MPa} \\ \text { Flexural Modulus } & 2400 & \mathrm{MPa}\end{array}$

Using the properties in Table I.1, one can calculate the resulting deflections in which the material fails. First, the tensile deflection is calculated by simply multiplying the tensile elongation in Table 1 with the height of the specimen, $50 \mathrm{~mm}$. The deflection of the bending test is calculated Equation 6.6,

$$
\theta=\frac{T_{\max } l}{J G}
$$

where $T_{\max }$ is the maximum torque needed to cause failure, $l$ is the length of the material, in this case the height of the specimen, $J$ is the polar moment of inertia of a solid rectangular 
bar, and $\mathrm{G}$ is the shear modulus, which is calculated using the equation $G=E / 2(1+v)$. For the deflection of the pure bending test, it was assumed that the scenario is like a cantilever beam with a concentrated loading such that,

$$
y_{\max }=\frac{F_{\max } l^{3}}{3 E I}
$$

where $F_{\max }$ is the maximum force needed to deflect the specimen till failure, and $I$ is the second moment of area of a rectangle in which,

$$
I=\frac{l t^{3}}{12}
$$

where $t$ is the thickness of the specimen. To determine the angle at which the top platform should be at, we simply find the maximum slope of the bar with Equation 6.10. Where Slope is the angle at which the top plate will orientate when maximum deflection has occurred [30]. Specifically, for the $\mathbf{p}$ vector, the change in $x$ position is the value $y_{\max }$, and the change in the angle of the coordinate system of the top plate is the value Slope.

$$
\text { Slope }=\frac{F_{\text {max }} l^{2}}{2 E I}
$$

With the equations above, graphs can be made in which singularities can be identified at certain points along the path. An iteration loop can be used in MATLAB to produce values of the determinant and condition number over the movement of the manipulator. To go further, the data from several geometries can be analyzed to see which design is more suitable for additively manufactured material characterization.

Even with analyzing the condition number with various material testing scenarios, certain singularities cannot be determined using the methods above. Tsai, as well as Bonev 
and Zlatanov, mention singularities that occur based on architecture that cannot be determined using kinematic methods [14], [31]. The design shown in Figure 2.3 is not suitable, and a different geometry was used for further testing. The first issue at hand is that the top platform geometry is very similar to the bottom platform geometry. Section 2.6 explains in more detail, but in sum, having the top platform smaller than the bottom platform results in lower condition numbers which results in better controllability and performance.

Upon initial testing, the condition number and determinant values varied by the units used, which corresponds with the fact that the Jacobian matrix is inhomogeneous when considering the units of the elements. To better organize the results, the Jacobian is normalized along the $x, y$, and $z$ axes by using Equation 6.11 below,

$$
J_{N}=\frac{J-J_{M i n}}{J_{M a x}-J_{M i n}}
$$

where $J_{N}$ is the normalized Jacobian, and $J$ is the Jacobian of the current position. The center or zero of the normalization is the "home" position of the platform. The variable $J_{\text {Min }}$ is the Jacobian at the min radius in the direct opposite direction of the max radius of $J_{M a x}$. $J_{\text {Max }}$ is the Jacobian at the max value, or where one of the legs of the platform reaches max length, causing a singularity. The results of this method are in the next section. Ma and Angeles, as well as Fattah and Ghasemi, took a similar approach in which they defined a homogenous Jacobian matrix by dividing the orientation side (left side) of the matrix in equation 6.1 by a characteristic length [32,33]. The left side is shown in Equation 6.12. 


$$
J_{S}=\left[\begin{array}{c}
\boldsymbol{s}_{1}^{T} \\
\vdots \\
\boldsymbol{s}_{6}^{T}
\end{array}\right]
$$

To produce the desired "map" in which singularities within the workspace are visible, MATLAB was used to create a boundary space in which the Jacobian could be normalized to. For feasibility, spherical coordinates were used. The radius, $r$, was increased to the max value for each $\mathrm{x}-\mathrm{y}$ plane angle, $\theta$, at each angle from the $\mathrm{z}$-axis, $\gamma$, ranging from -90 to 90 degrees. An architecture similar to Ma's and Angeles' was used in which they determined triangular top and bottom platforms to be suitably conditioned [32]. A "slice" was taken from the workspace at the "home" position height and analyzed based on the condition number. Consequently, a "map" was developed by color coding the data points based on the condition number values. This process was repeated at different heights to see the change in condition number values over a vertical distance.

\section{I.2 Results with Translation}

Calculations of deflections for pure tensile, bending, and torsion were conducted of a 50 x $50 \mathrm{~mm}$ and $5 \mathrm{~mm}$ thick specimen. The material ABS-ESD7 was chosen to establish the pathways the manipulator needed to follow till failure of the material. Using the equations in the previous section, the results are depicted in Table I.2. For simplicity and for maximum estimation, it was assumed the specimen was a solid rectangular bar. 
Table I.2: Results of deflection calculations of ABS-ESD7

$\begin{array}{lrl}\text { Tensile Test } & 1.500 \mathrm{~mm} \\ \text { Bending Test } & 25.00 \mathrm{~mm} \\ \text { Torsion Test } & 11.68 \mathrm{deg}\end{array}$

After applying the methodology outlined, simulations were completed with a pure tensile test. It is also noted that all graphs are shown with the deflection of the specimen till failure. Figure I.1 shows the results, note that the results of $500 \mathrm{~mm}, 550 \mathrm{~mm}$, and 600 $\mathrm{mm}$ are close in value.

It was found that increasing the radius of the bottom plate reduces the condition number of the Jacobian, which follows the conclusion of Tsai that similar geometries of the top and bottom plate results in a singularity or that the manipulator is in closer proximity of a singularity [14]. It is also noted that while the condition number is reduced, the StewartGough platform becomes more controllable in such that the accuracy and dexterity increases as the condition number gets closer to $1[34,35]$. To further analyze the manipulator, the determinant of the Jacobian was calculated throughout the path. While the results did not indicate that there are any singularities in the path, the determinant of the top and bottom plates of $250 \mathrm{~mm}$ diameter indicated that this geometry is closer to a singularity throughout the path than the other geometries. Note that the graphs in Figure I.1-Figure I.6 were used as a way to visualize how the condition number and determinant 
changed with certain changes in geometry. The desire is to have lower condition numbers and high determinants.

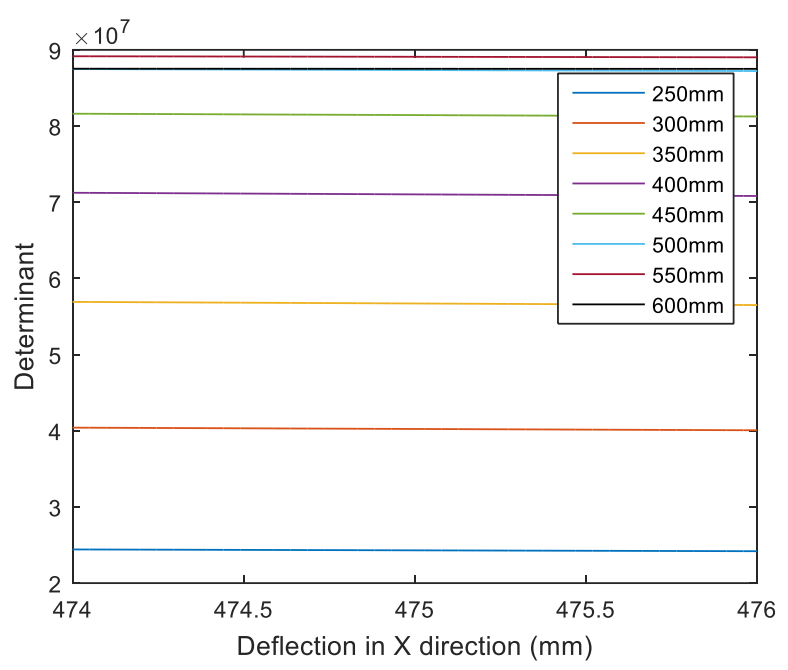

Figure I.1: Results of increasing the bottom plate radius while keeping the top radius of $250 \mathrm{~mm}$.

Next, the condition number and the determinant were calculated while keeping the bottom radius the default of $250 \mathrm{~mm}$ and increasing the radius of the top plate. Looking at Figure I.2, the top plate radius to be bigger than the bottom plate radius causes the condition number to rise further away from the value 1, indicating that this style of design becomes significantly less accurate as the ratio of the top and bottom plate grows. It follows that increasing the top plate radius also adds more weight that the linear actuators must control, putting more stress on the system. As for the determinant of this scenario, the results are the same as in Figure I.3. 


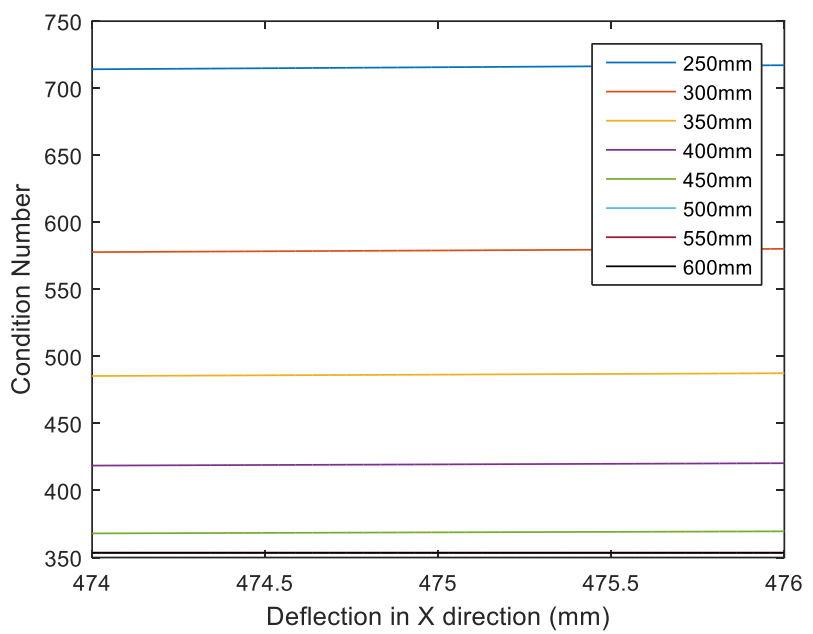

Figure I.2: Results of increasing the radius of the bottom plate. The top plate was kept at the initial 250 $\mathrm{mm}$ of the design.

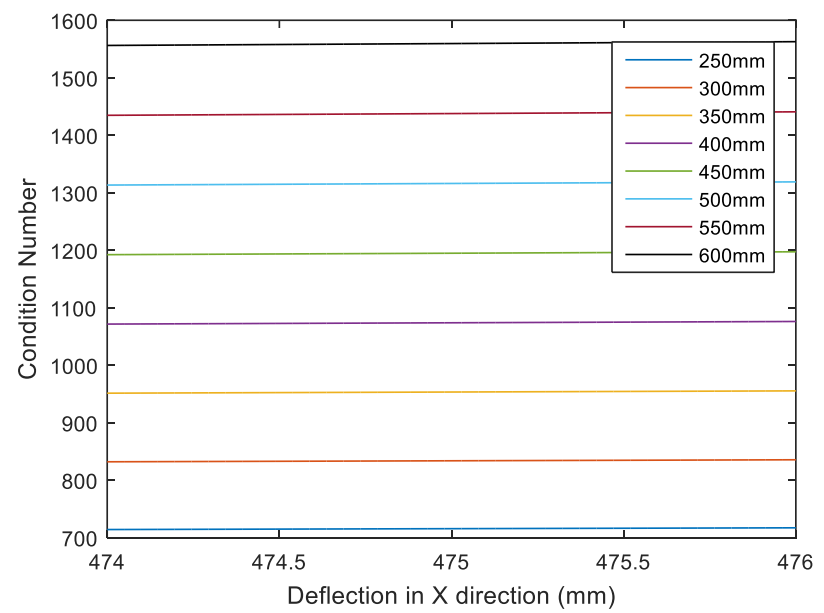

Figure I.3: Results of increasing the top plate radius while keeping the bottom radius at a default of 250

$\mathrm{mm}$.

After the tensile test, a scenario of a pure bending test was looked at. The path of the Stewart-Gough platform was calculated by using simple geometry to find the distance of $x$ traveled of point $\mathbf{p}$ and the equivalent angle at which the top plate finalizes at, which in this 
case is the angle of deflection of the specimen. Figure I.4 depicts the results of the determinant and condition number over the path. Like the tensile test results, increasing the bottom plate radius reduces the condition number and increases the determinant. It can be noted that at a certain ratio of the size of the top and bottom plates, the condition number and determinant only have minimal changes compared to the changes of plate sizes with lower ratios. This suggests that at a certain point, there is no need to make the bottom plate larger. It is also noted that the slope of the curves for the larger radii starts decreasing at a faster rate than smaller radii. The decrease in slope for the determinant suggests that the manipulator is approaching a singularity. 

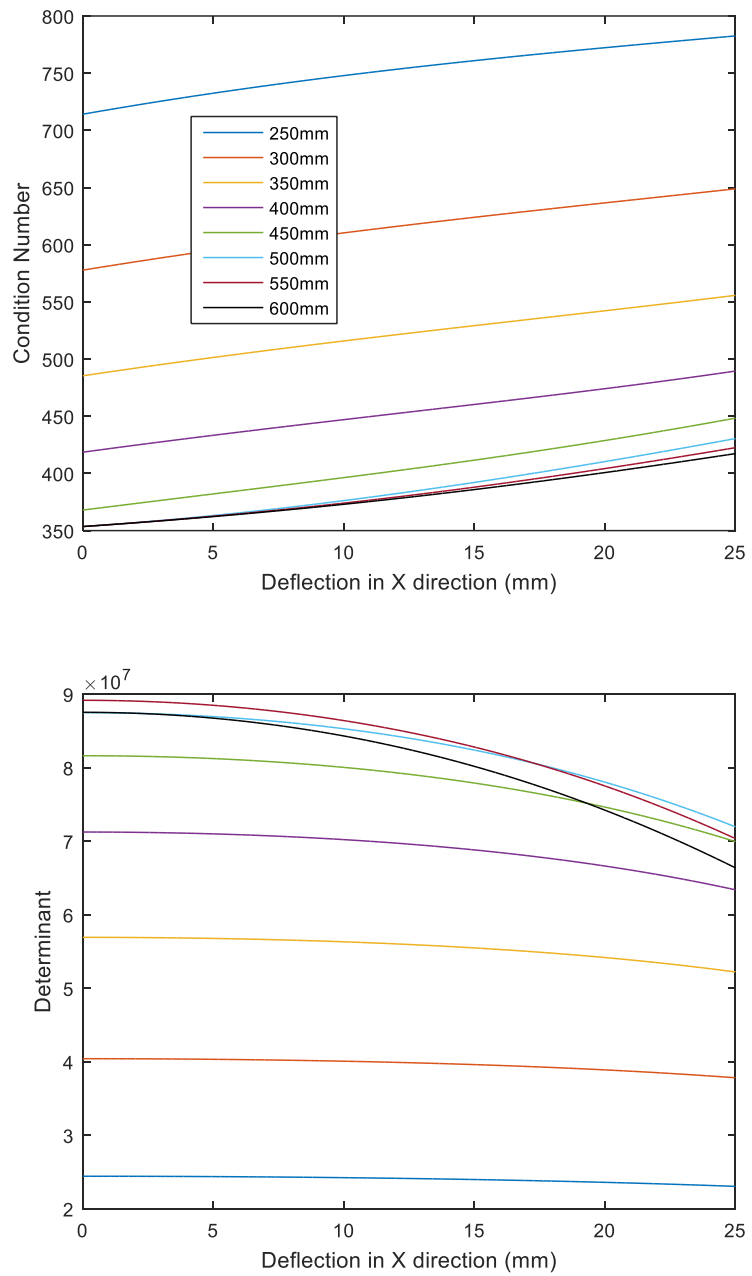

Figure I.4: Results of the condition number and determinant for a pure bending test. The top plate radius is kept at default while the bottom plate radius is increased.

The condition number and determinant where calculated while increasing the top plate radius and following the path of the manipulator such that the material specimen would fail in a pure bending test. Considering the results of the tensile test, it was concluded that for the positions between the singularities, increasing the top radius would cause larger condition numbers than keeping the geometry at default as shown in Figure I.5. The slopes 
of the graphs also suggest that the manipulator is approaching a singularity, and it approaches the singularity at a faster rate than that of only increasing the bottom plate radius.
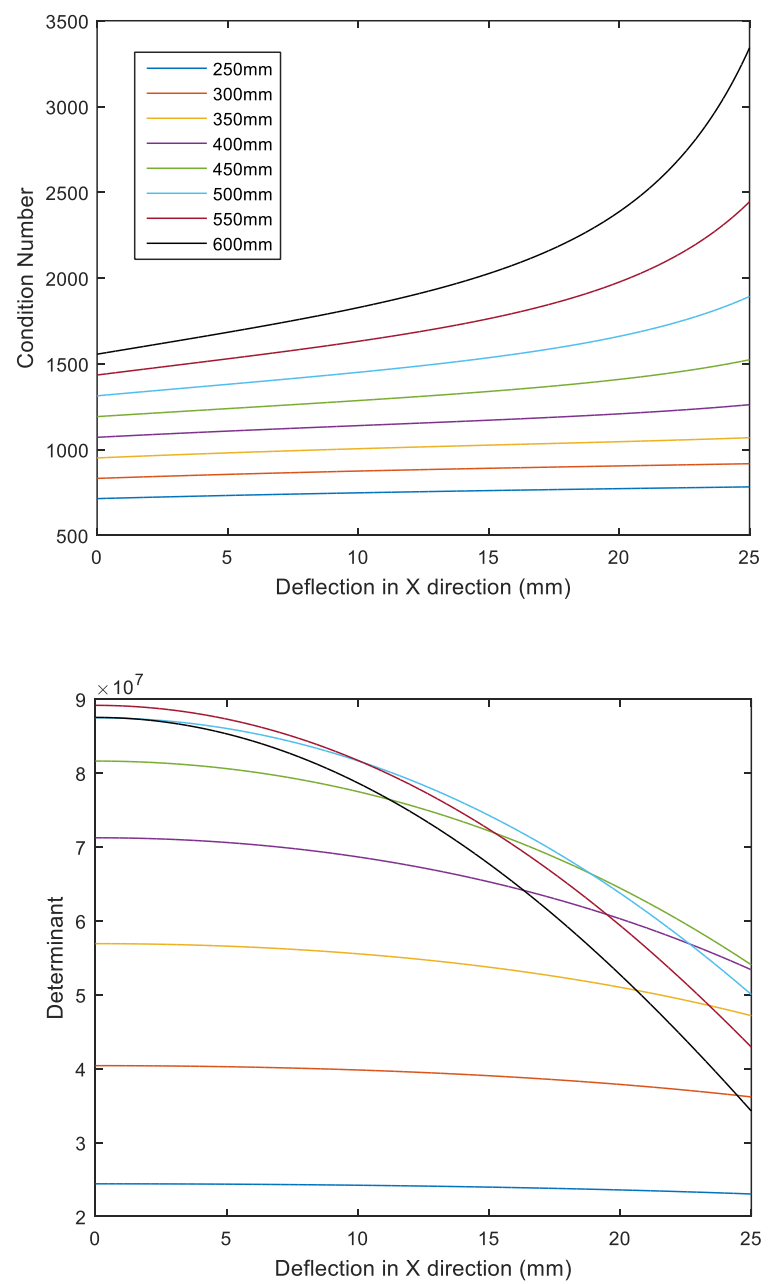

Figure I.5: Results of the condition number and determinant for pure bending with increasing top plate radius and a constant default bottom plate radius.

Finally, the condition number and determinant were calculated over the pathway for a pure torsion test. In this case, the graphs are presented for the change in angle starting from 
the negative $\mathrm{x}$-axis going counterclockwise towards the $\mathrm{z}$-axis. Looking at the results of the pure torsion test, one can see that the condition number for each case does not change significantly over the change in position. Increasing the radius of the top plate, though, decreases the condition number and increases the determinant, following previous observations that once past a certain ratio, the change in the condition number and determinant decreases significantly. 

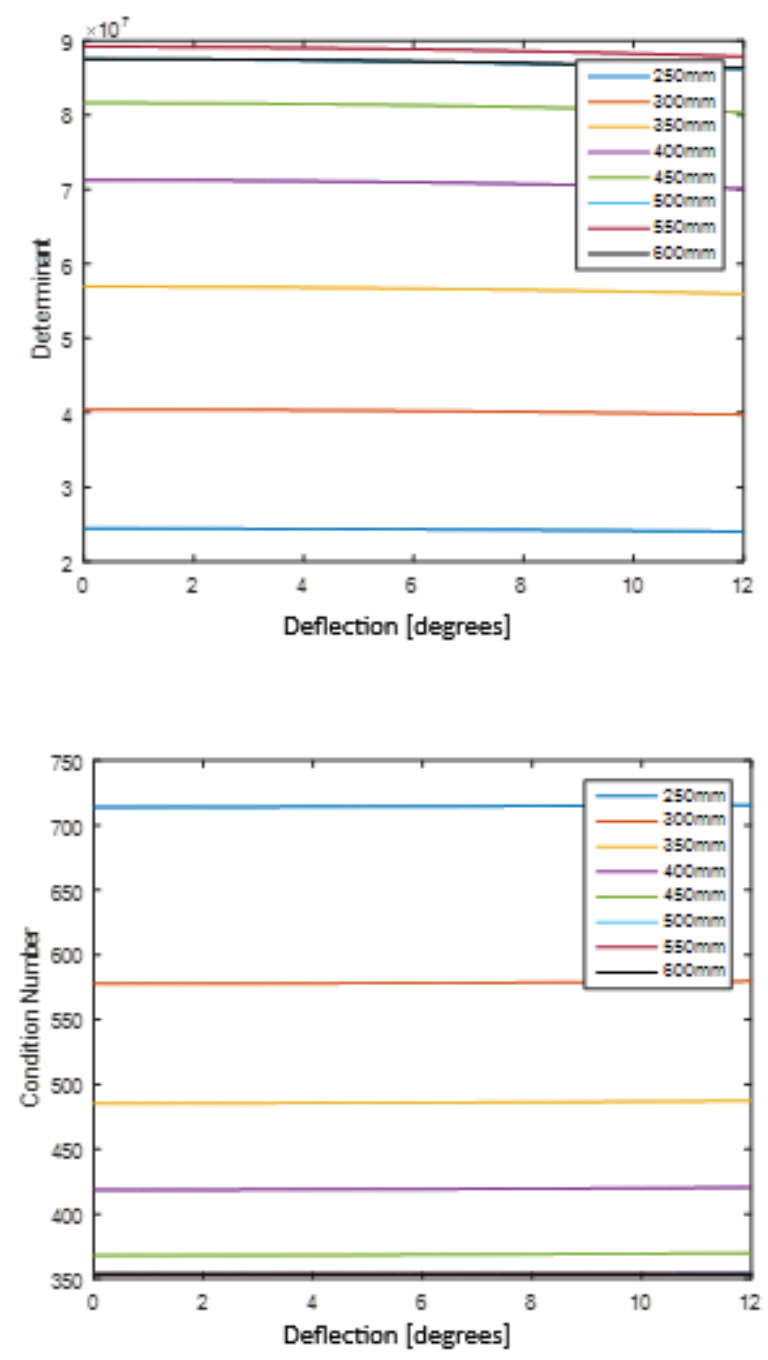

Figure I.6: Results of the condition number and determinant over the pathway of a pure torsion test with increasing bottom plate radius with a constant default top plate radius. Note that the last three legend values are close together on both charts.

Concluding the results for the initial performance analysis, the last test was completed by only increasing the top radius again. For the pure torsion application, there is a clear increase in overall condition numbers while the determinant values remain the same. This 
correlates with the results of the pure tensile test in that similar geometries brings the manipulator closer to a singularity. It should be noted that the results of the condition number and determinant are similar for the pure tensile and pure torsion tests.

For the normalized condition number analysis, a MATLAB program determined the data points within a "slice" of the workspace of the platform. The max Jacobian is located at the farthest point from the $p$ origin (see Figure 2.2) located on the plane of the $\mathrm{z}$ value of the "home" position. The minimum Jacobian was taken at the origin $p$. The results depict a platform with a top radius of $62.5 \mathrm{~mm}$, a bottom radius of $250 \mathrm{~mm}$, and a "home" position height of $300 \mathrm{~mm}$. Figure I.7 shows the result.

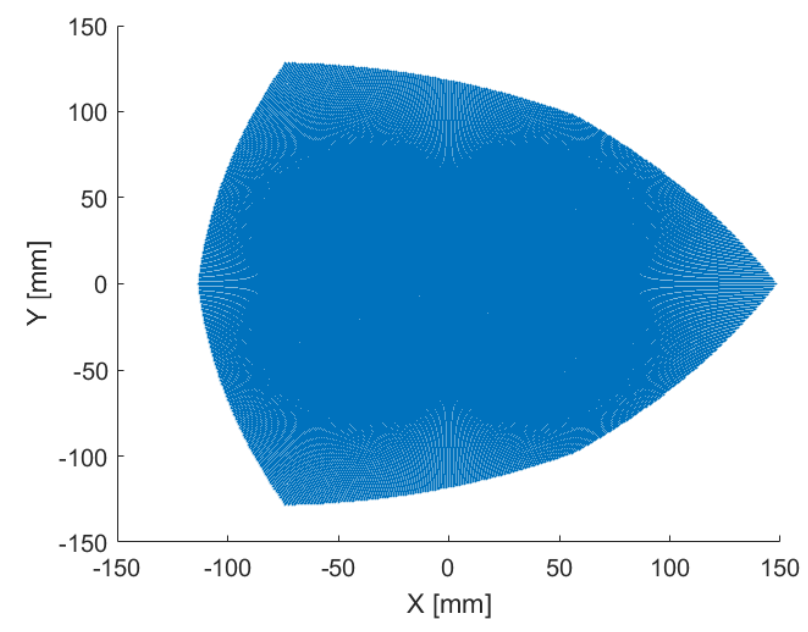

Figure I.7: Data for "slice" of workspace at the "home" location.

It can be seen from the graph that the "slice" of the workspace resembles a shield. The max Jacobian was if the next iteration of increasing the radius, $r$, caused the stroke of one of the actuators to exceed its limit, and it must be noted that the orientation of the top 
platform is kept horizontal throughout the process. Once the "slice" was created, the points were color coded based on the condition number values to show a specific "map" of where possible singularities can be located, which is shown in the figure below. Table I.3: Color coding scheme. shows the color-coding scheme.

Table I.3: Color coding scheme.

\section{Color}

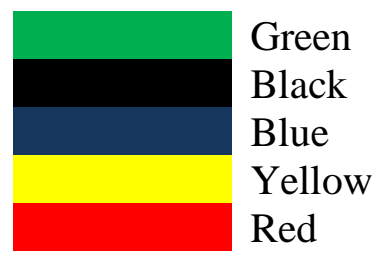

\section{Condition Number Range}

$$
\begin{gathered}
<=50 \\
>50 \&<=100 \\
>100 \&<=250 \\
>250 \&<=500 \\
>500
\end{gathered}
$$

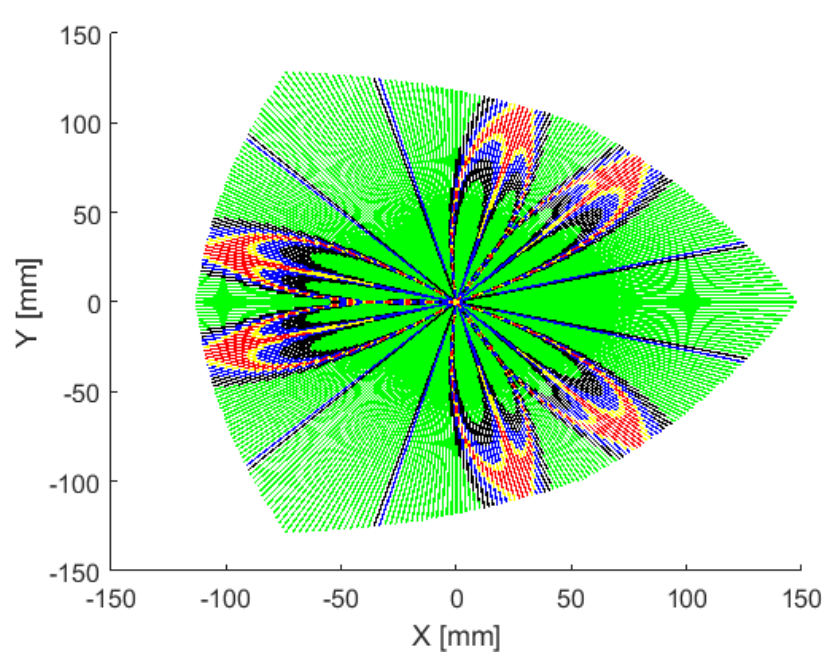

Figure I.8: Color coding of position points based on condition number.

Looking Figure I.8, a "map" can be seen of the condition number ranges. General areas can be located that would be suitable for low condition numbers as well as areas to avoid due to higher condition numbers. The green area is the most suitable. It can also be seen 
that using the right side of the platform is desirable as it can reach farther than the left side. It can also be seen that the condition number fluctuates at certain areas. For example, near the $x$ value of 0 and the $y$ value of -50 the condition number fluctuates due to the multiple colors present in a small area.

Depending on the ranges desired, some areas can be seen in which they should be avoided. In this case, condition numbers of greater than 500, or the red area in Figure I.8, should be avoided. If that number increases to a higher value, for example 50,000, and the platform can be controlled with values less than that, then the result is Figure I.9: Color coding scheme by changing yellow to range between 250 and 50,000 and red to range above 50,000.. This shows that the range of condition numbers can be chosen based on the user's choice. Specific areas can be isolated to plan a path, decide if a certain geometry is sufficient, or identify the specific points where singularities are. 


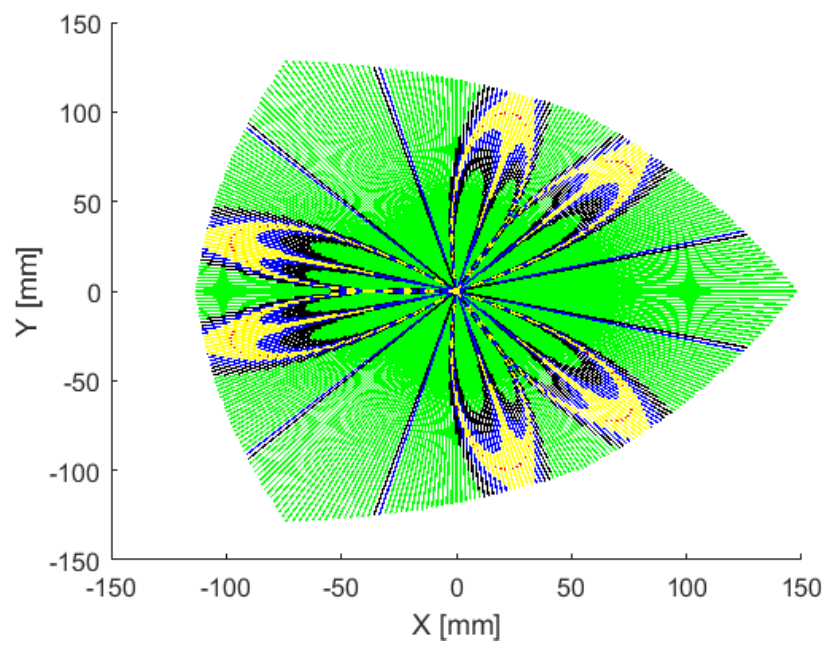

Figure I.9: Color coding scheme by changing yellow to range between 250 and 50,000 and red to range above 50,000 .

An ideal method would be to analyze the condition numbers in the $3 \mathrm{D}$ workspace. While it is important to analyze the horizontal movement for shear and bending tests, tensile tests and compression tests rely on movements on the z-axis and therefore the change in condition numbers along the $\mathrm{z}$-axis is important. 


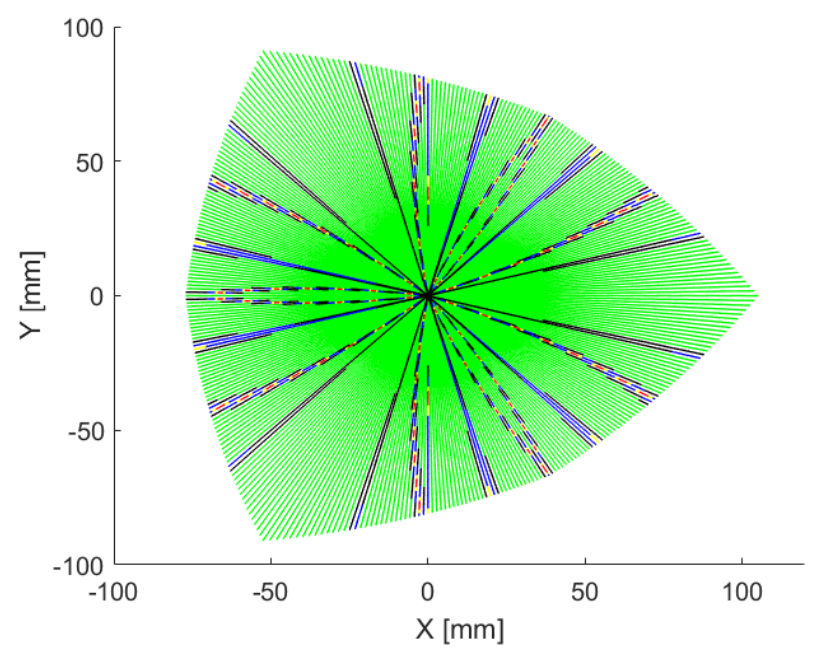

Figure I.10 Condition number analysis at a height of $37.5 \mathrm{~mm}$ above the "home" position using the color scheme in table 2.

The graph above indicates that most of the workspace in the "slice" contains sufficient condition numbers while thin portions of it containing other colors shows less sufficient condition numbers. Considering the amount of red depicted in Figure I.10, this area of the workspace is sufficient. It can also be noted that there is a red zone in the center suggesting that the controllability becomes difficult in the $-\mathrm{z}$ direction. 


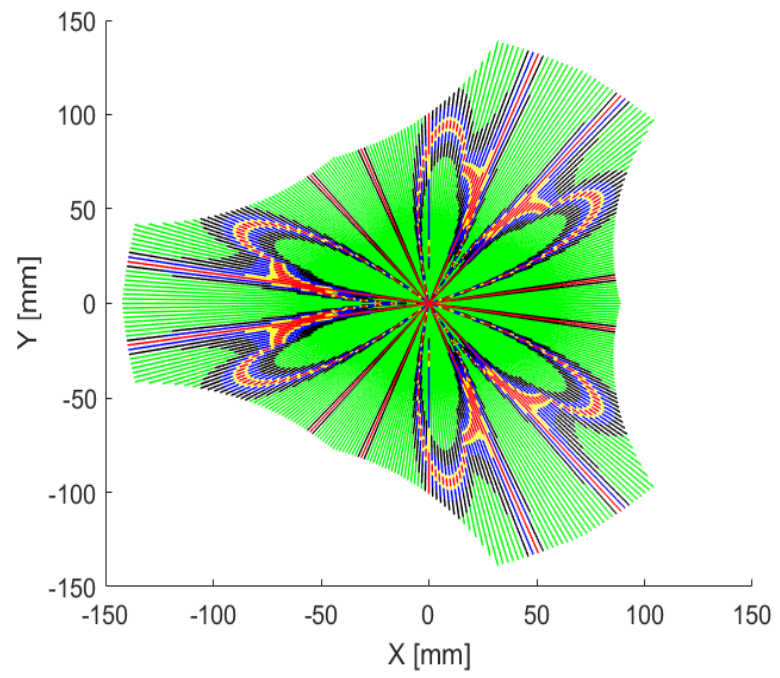

Figure I.11: Condition number analysis at $37.5 \mathrm{~mm}$ below the "home" position. Same color scheme as table 2 . 

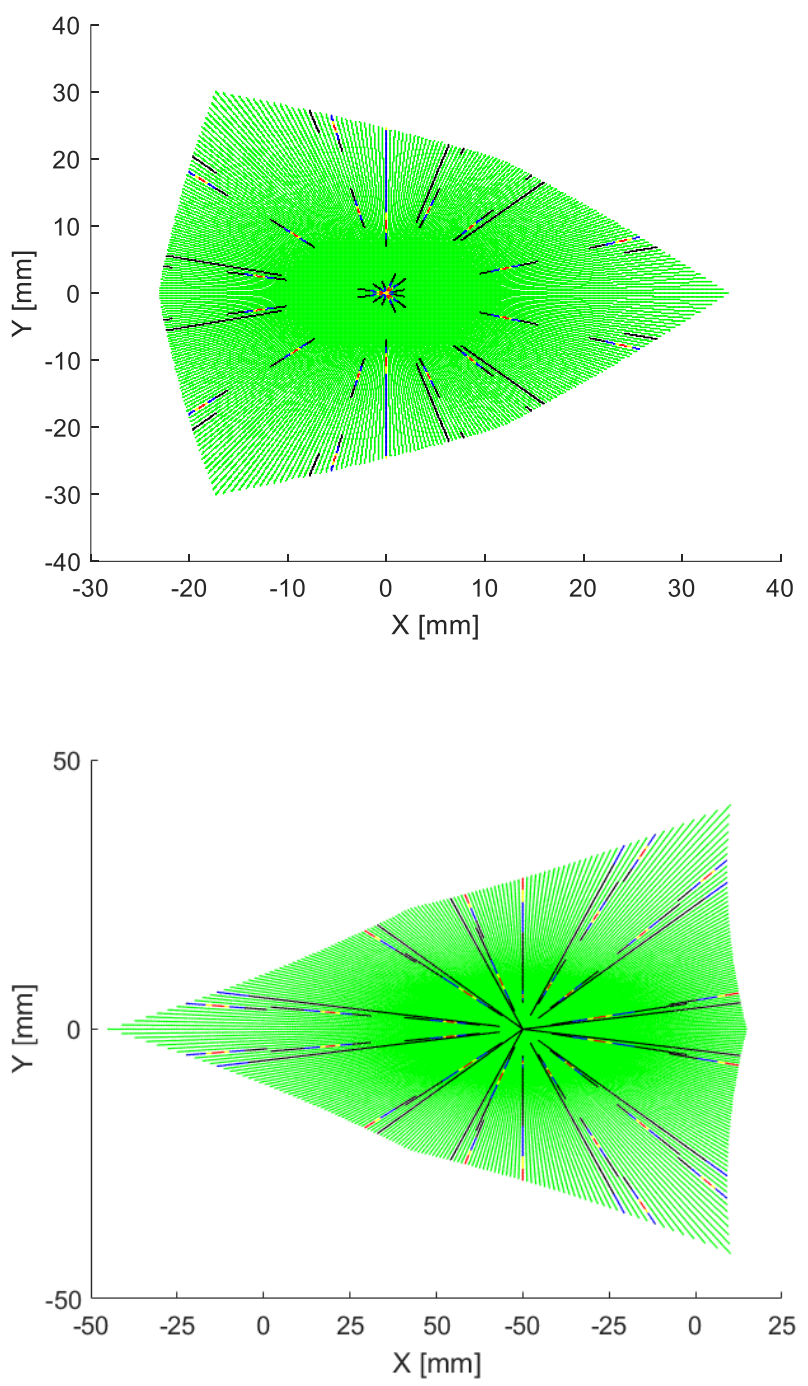

Figure I.12: Condition number analysis at $75 \mathrm{~mm}$ above (top) and below (bottom) the "home" position.

As the platform reaches the outermost limits of the z-axis, according to Figure I.12, there is less space for the platform to move horizontally on the $x-y$ plane. It also can be noted that areas of higher condition numbers are "thinned out" with a few significantly small red areas. There are also red areas around the origin $p$ located $75 \mathrm{~mm}$ above the "home" position. 
Since the results at $75 \mathrm{~mm}$ above and below suggests the areas of higher condition numbers reduce in size as the platform moves away from the "home" position, an analysis was conducted at $19 \mathrm{~mm}$ above and below the starting position. Figure I.12 correlates with the observation that the higher condition number areas reduce in size moving away from the starting position. The figure also shows the reduction in the size of the horizontal workspace. The graph at the top slightly reduces in size while still resembling a shield and the bottom graph starts to take the form of Figure I.10 and the bottom graph of Figure I.11. 

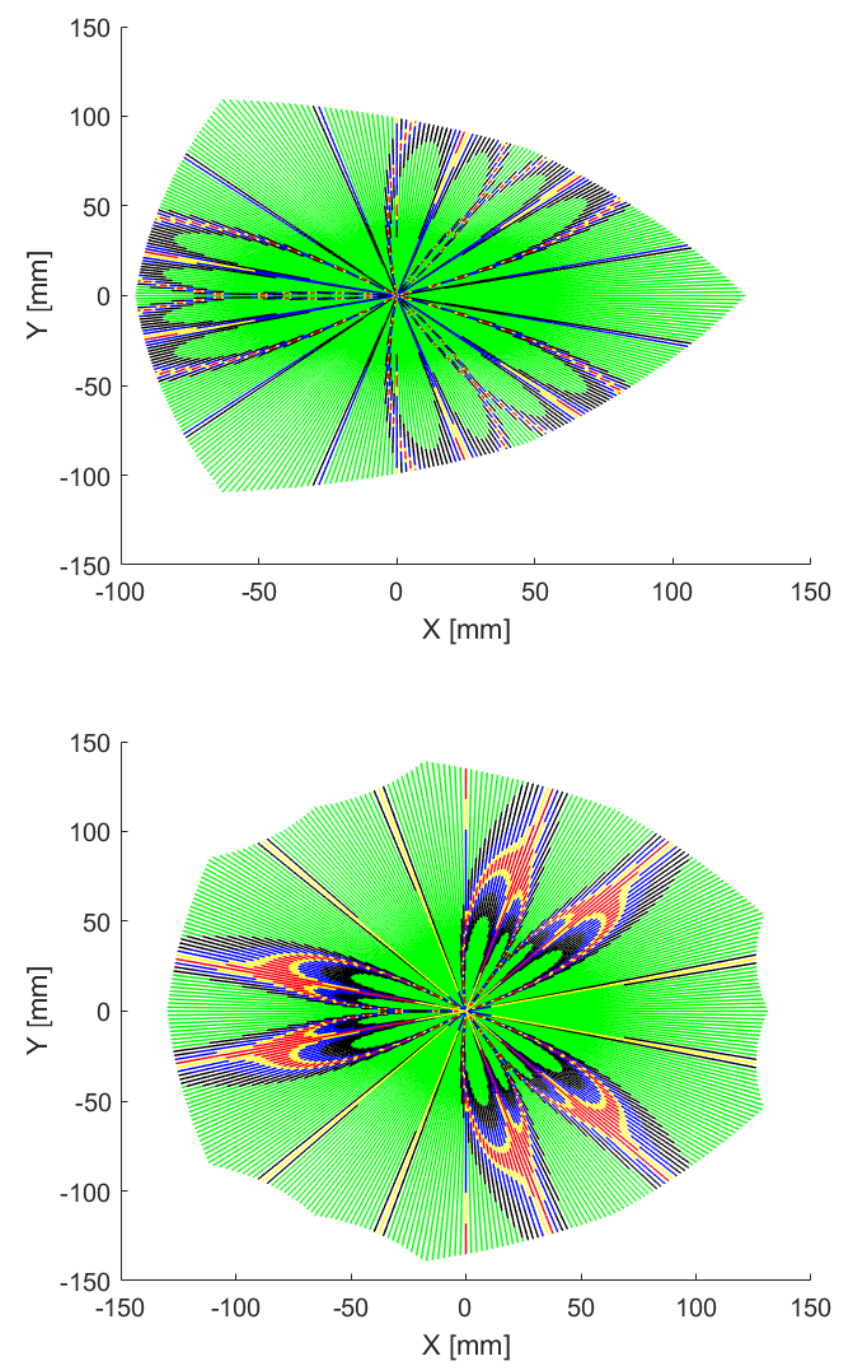

Figure I.13: Condition number results using the color scheme in table 2, $19 \mathrm{~mm}$ above (top) and below (bottom).

While there is a clear pattern above and below the "home" position of the platform, there is significant difference between the condition analysis at the starting height and the analyses above and below. A 3D depiction of "slices" that are close to the starting position was created to see if there is a quick change that is not noticed at the $\mathrm{z}$ positions chosen in 
the above results. Figure I.14 shows that there is no gradual change between the similar

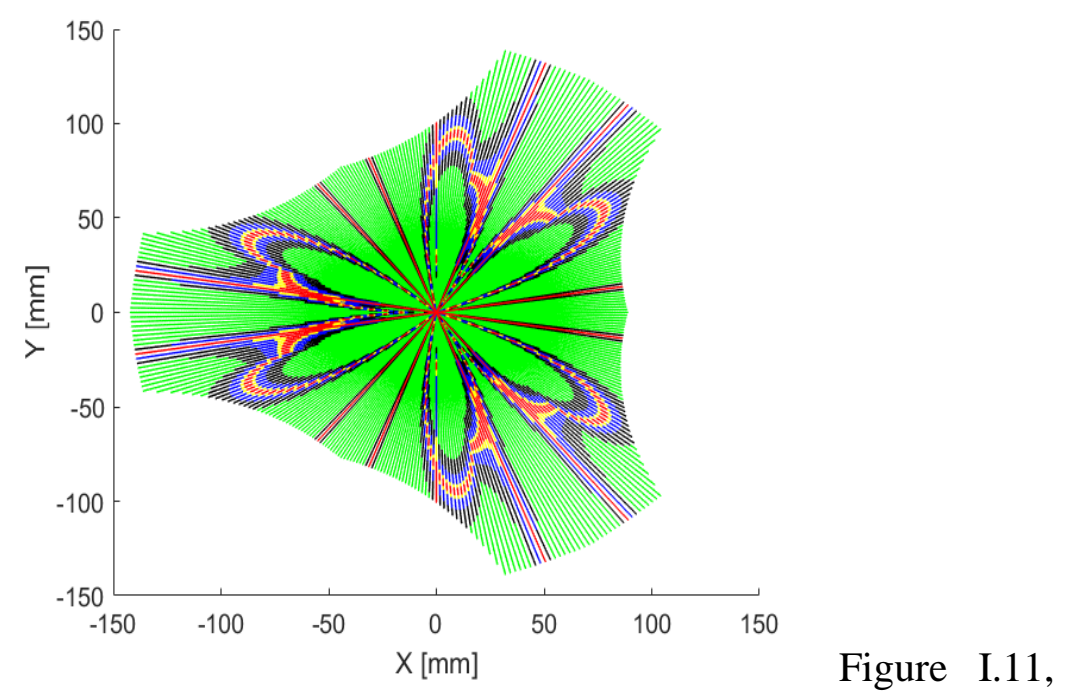

Figure I.12, Figure I.13 and the result of Figure I.8. It is unclear for the reason of this. The large amount of higher condition numbers at the "home" position suggests that the current design should not be used at that height.

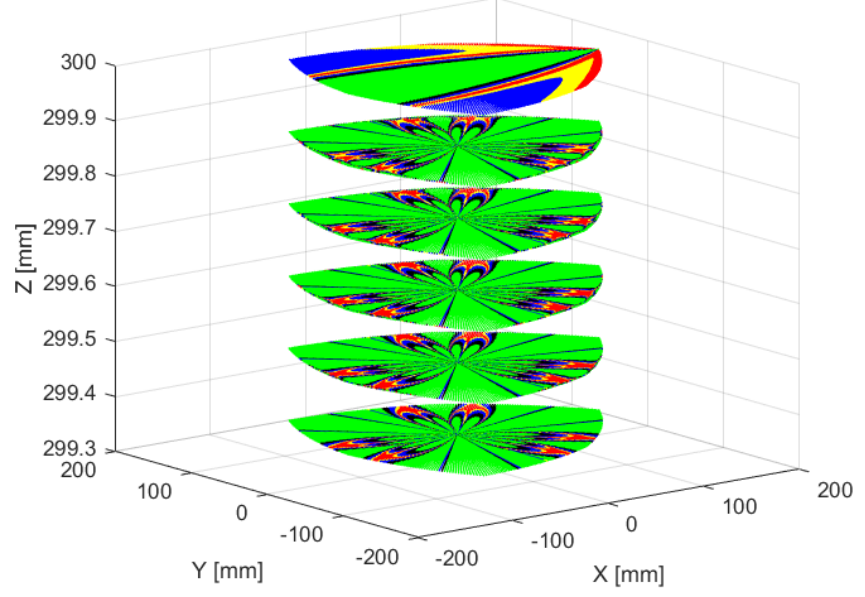

Figure I.14: Condition analysis with increasing z value up to the "home" position from below.

\section{I.3 Results with Orientation}


Additional work was completed following the work of [36] on "mapping" singularities within the workspace involving translation at a given height of the top platform. This additional work included singularities with respect to the orientation of the SG platform. Two scenarios were tested using a normalization of the Jacobian matrix. These scenarios included moments about the origin point of the top plate reference frame, and the second included moments about the center point or the intersection point of axes 3 and 4 on Figure I.15. Note that these are just used as reference and as test specimens to test that the 66.1 Tiger can apply the loading conditions set by requirements 18-18.4. The moments about the axes of the specimen were done to simulate a pure bending scenario.

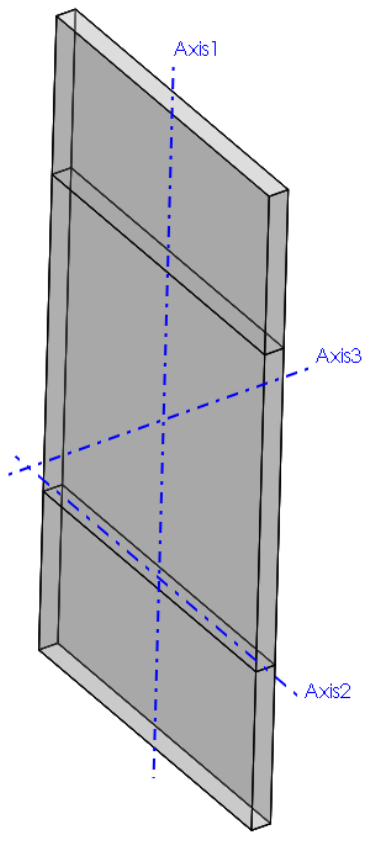

Type 1

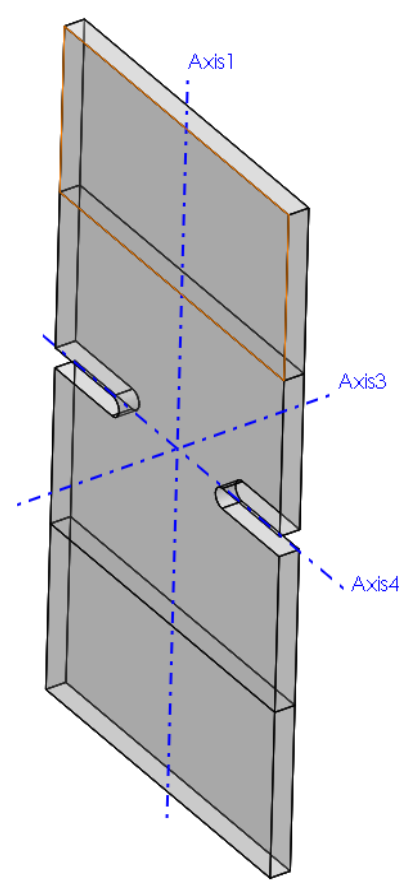

Type 2 


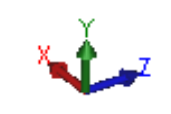

Figure I.15: Specimen designs used for analysis and testing.

Figure I.16 shows the results of the second scenario and the top of Figure I.17 shows the results of the pure bending scenario. The axes represent the angle of the platform relative to the $\mathrm{x}$-axis for $\theta$ and the $\mathrm{y}$-axis for $\phi$ using a common rotation matrix.

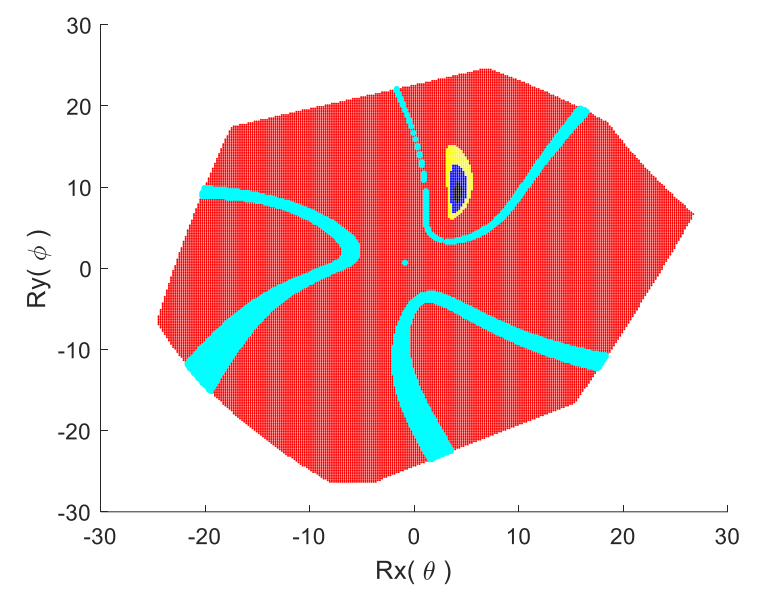

Figure I.16: Results from moments about the specimen. 

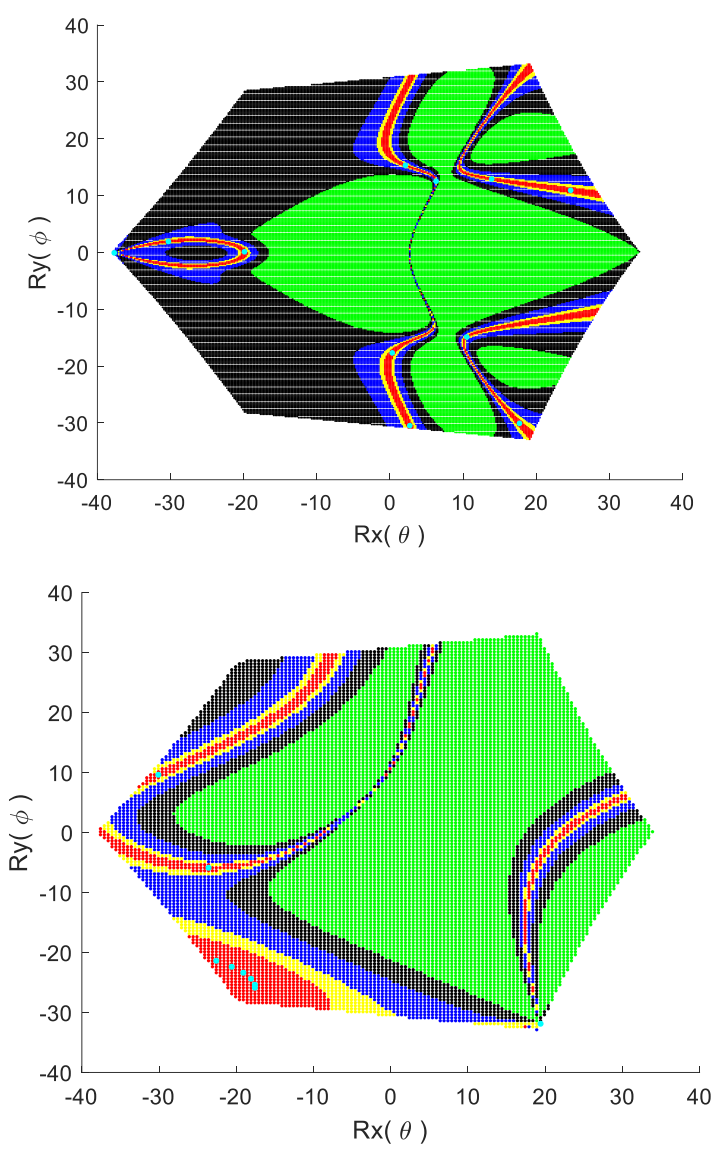

Figure I.17: Results for orientation of rotation about "home" position (top) and the results with greater distance between data points (bottom).

A different process was used to normalize the Jacobian than that of the previous work. The condition number was found for each Jacobian at each point within the "slice" of the workspace. The largest and smallest condition number were found, and their respective Jacobians were set as the maximum and minimum Jacobians. From there the Jacobian was normalized and new Jacobians were found for each point following a calculation of the 
condition number. To be consistent the color code scheme consists of the values in Table I.3, which is the same as the work in [36].

It must be noted that while there are significant points that are cyan, not all cyan values indicate singularities, it may just indicate an elevated level of uncontrollability within the area. Also, one data point in the plot in Figure I.17 does result in a condition number of infinity. This point is at values of $\theta=-37.6$ and $\varphi=-0.2$ at a specific $S G$ platform geometry. There may be more singularities within these "slices" as the distance between data points affects the results.

These maps of the controllability of a specific geometry of a SG platform were used as a basis for choosing an ideal geometry. Iterations of geometry were compared until results showed all green, but only for the translation portion of [36] as the work for Figure I.16 and Figure I.17 was done after the final design. Figure I.16 shows higher values of condition numbers but rotations about the center of the top plate at the "home" position does not represent any loading scenarios that would be used for testing. It must also be noted while the "maps" were used to find an ideal geometry, it is not known how much the values of the condition number affect the controllability of the SG platform. In other words, the scale of affect is not known except for the cases in which the condition number is infinity. While the new work on singularities and controllability with respect to the orientation was completed after the final design of the test frame, this method of obtaining an optimized geometry can be used for future designs of multiaxial test frames to provide optimal designs where singularities can be avoided. 